\title{
REGGAENOMICS: THE RELATIONSHIP BETWEEN COPYRIGHT LAW AND DEVELOPMENT IN THE JAMAICAN MUSIC INDUSTRY
}

BY

\section{SHARMA LATOYA TAYLOR}

\author{
A thesis \\ submitted to the Victoria University of Wellington \\ in fulfilment of the requirements for the degree of \\ Doctor of Philosophy
}

Victoria University of Wellington 


\begin{abstract}
One argument posits that copyright is necessary for incentivising creative expressions. To what extent does this hold true for individual copyright-based sectors in a developing nation's economy? Although Jamaica's Copyright Act 1993 complies with the major copyright treaties, little is known about whether (and how) the copyright regime allows the Jamaican music industry to foster national development.

Accordingly, the focus of this thesis is to examine the developmental impact of the copyright system on the Jamaican music industry. This thesis traces the evolution of the local music industry and its complex interaction with copyright law. This research assesses the various approaches to economic development and highlights the limitations of a collective management-based approach and weaknesses in the individual rights management model. It also analyses the compatibility between a human development approach to copyright and the theoretical justifications for copyright. It points out substantive areas of the domestic copyright legislation that could be reformed in order to improve the statute's applicability to the music industry insofar as development is concerned.

This thesis adopts a qualitative methodological approach and uses interviews from 57 music industry participants. The findings suggest that societal context is as important as the legal rights, in giving copyright owners incentives to create. Historical, political, socio-cultural, economic and institutional factors play a key role in shaping stakeholders' treatment of copyright. Music industry players' experiences can help inform policymaking by fostering a better understanding of the implications of copyright protection for this vital sector of the economy.
\end{abstract}




\section{ACKNOWLEDGEMENTS}

In Jamaican patois, there is a proverb which says "one one coco full basket." Literally: you can fill a basket with coco (a potato-like edible root) by simply dropping them in one by one. This means that success is not achieved overnight. Instead, consistent contributions complete the job over time. So it is with the $\mathrm{PhD}$ process.

Completing this thesis would have been impossible without the expert guidance of my supervisors: Professor Susy Frankel and Associate Professor Susan Corbett. I received valuable feedback from Professor Tony Angelo and my previous supervisor, Professor Geoff McLay. I am grateful to the New Zealand Government for funding this research through the award of a Commonwealth Scholarship. I appreciate the assistance from the academic and administrative staff at the Faculty of Law, the Faculty of Graduate Research, Student Learning Support Services and in particular, Dr. Deborah Laurs (my "thesis therapist"). I am also thankful to the dedicated team at the Victoria International office, especially, the hardworking NZAID officers.

My interviewees generously shared their time and expertise. Without their input, I would have had very little data to analyse. I salute their passion for the development of the music industry and hope that my research was able to do justice to that passion. Long live the sounds of Jamaica!

My $\mathrm{PhD}$ journey was made enjoyable because of the support from friends in Jamaica and New Zealand. Kia ora!

I dedicate this thesis to my heroes: my mother, Yvonne Christie, my brother Sean, and to the memory of my lion-hearted grandmother Josephine Walton (Rita) and my late father, Winston Taylor, who have always believed, against all odds, that I could succeed at anything I embarked on. I live to do you proud! I praise the Creator for the health and strength to do the work. When all else fades, your love endures. 



\section{CONTENTS}

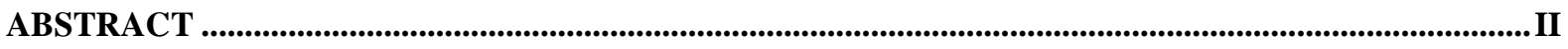

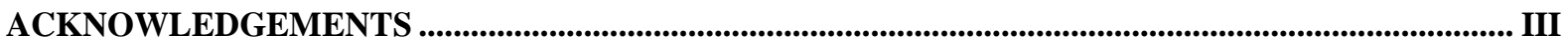

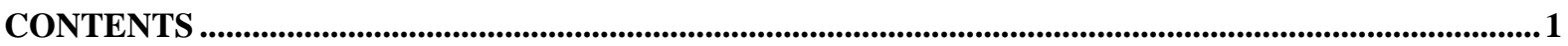

LIST OF ABBREVIATIONS ......................................................................................................................................

\section{CHAPTER ONE}

\section{INTRODUCTION, BACKGROUND TO THE RESEARCH QUESTION, THESIS STRUCTURE AND}

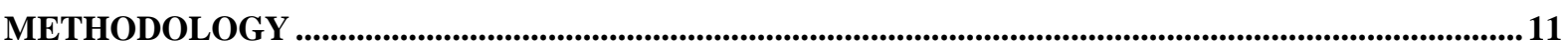

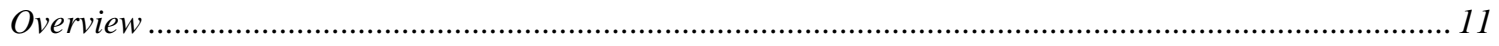

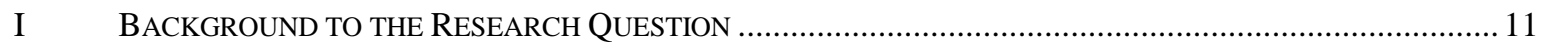

A The Economic Potential of Jamaica's Music Industry ...................................................................... 13

$B \quad$ Trends in the International Copyright Regime Strengthening Copyright Protection ......................... 14

1 Domestic copyright lawmaking in response to TRIPS and other international agreements.............................14

2 The economic benefits of TRIPS for developing countries ......................................................................... 16

C Limited Research on Copyright's Impact on Development in Jamaica........................................... 18

D Jamaica's Development Needs ........................................................................................ 19

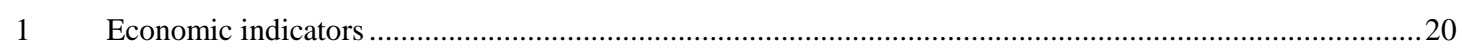

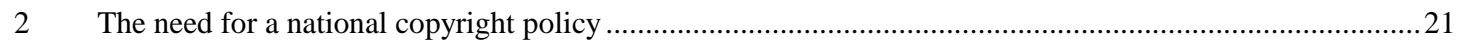

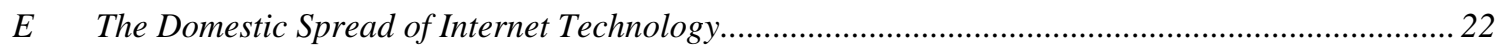

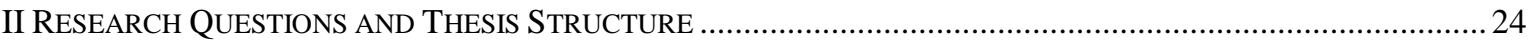

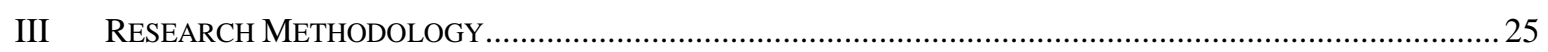

A Research Design ............................................................................................................... 25

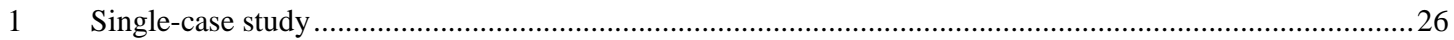

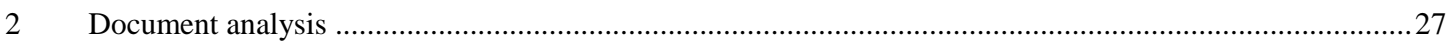

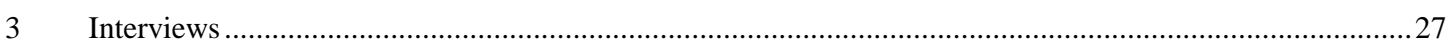

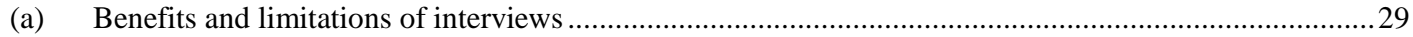

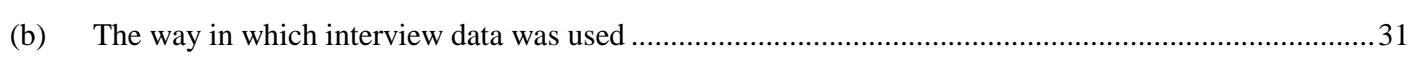

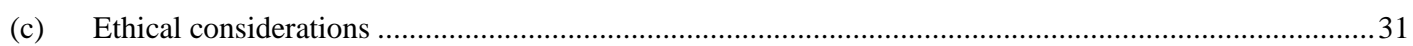

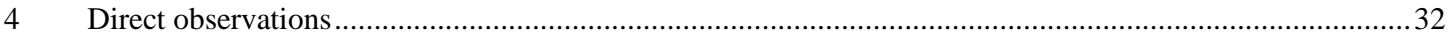

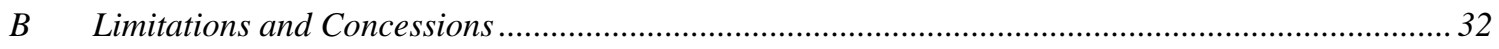

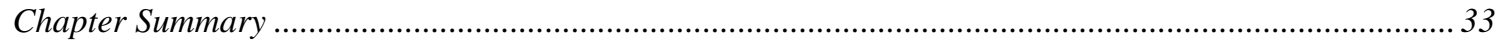

CHAPTER TWO

THE EVOLUTION OF THE JAMAICAN MUSIC INDUSTRY AND ITS RELATIONSHIP WITH

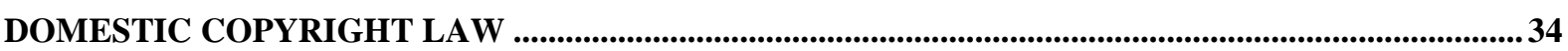

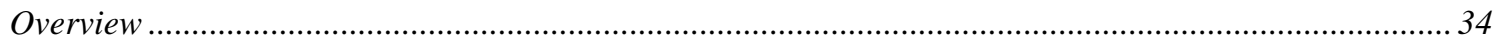

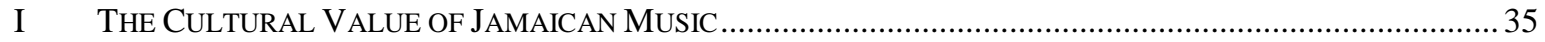




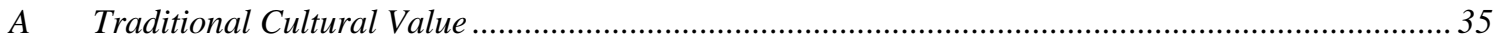

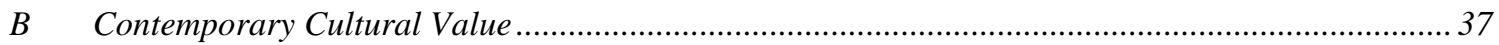

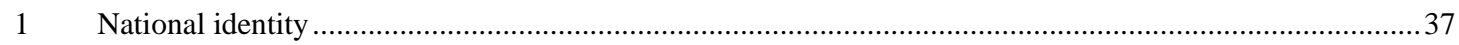

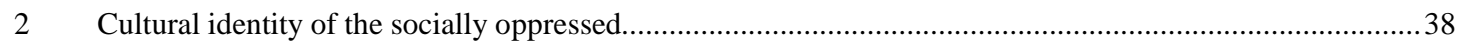

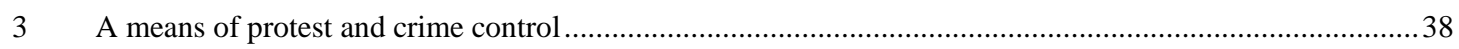

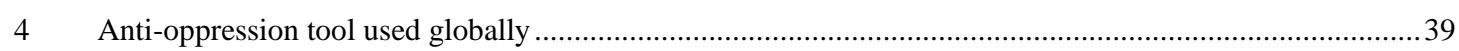

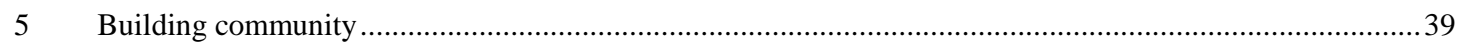

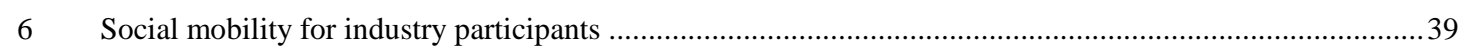

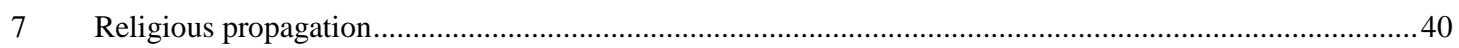

C How Cultural Value is Reflected in the Copyright Act 1993 ........................................................... 41

II THE COMmerCIAL VALUE OF THE MUSIC INDUSTRY ................................................................................. 42

A Background to the Jamaican Music Industry and Its Interaction with Copyright Law ...................... 43

1 Pre-industry evolution: the Copyright Act 1911 ............................................................................................4

2 Stage one: adoption of American Rhythm \& Blues (1940s - 1956) ..........................................................4 45

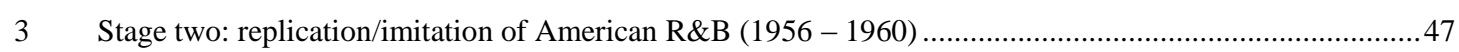

$4 \quad$ Stage three: innovation/copyright infringement: $(1960$ - 1970s) ………………………………………….....49

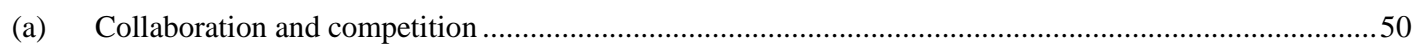

(b) Record producers' and publishers' practices in violation of copyright .................................................51

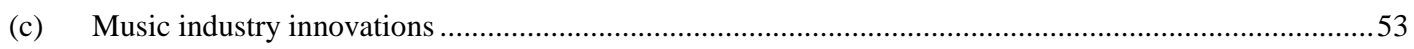

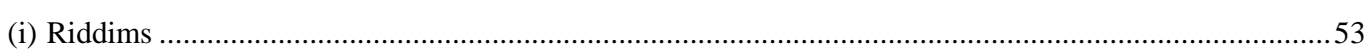

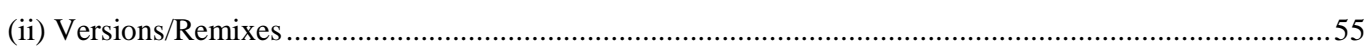

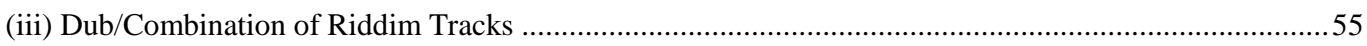

$5 \quad$ Stage four: internationalisation/demand for greater copyright protection (late 1970s - 1990s) ...................56

B How the Copyright Act 1993 Safeguards the Music Industry's Commercial Value .......................... 59

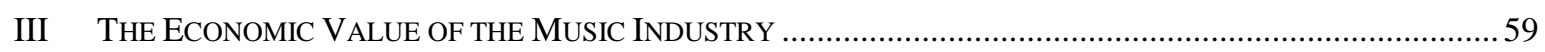

A The Music Industry's Potential to Contribute to the Jamaican Economy ......................................60

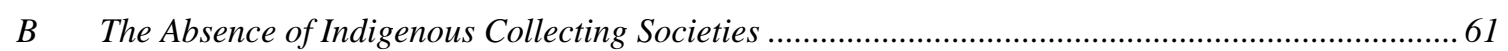

C How the Copyright Act 1993 emphasises the Economic Value of the Music Industry ...................... 63

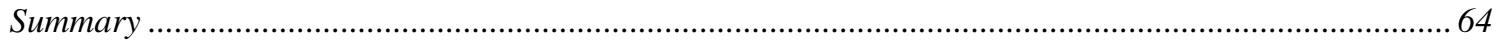

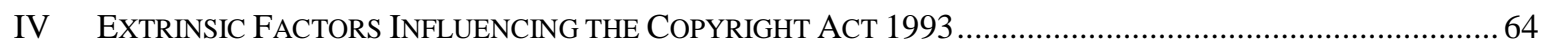

A Local and International Pressure to Accede to Major Copyright Treaties ................................... 64

$1 \quad$ Local pressure from music industry interest groups ............................................................................6 65

2 International pressure from the World Intellectual Property Organization ..................................................6 66

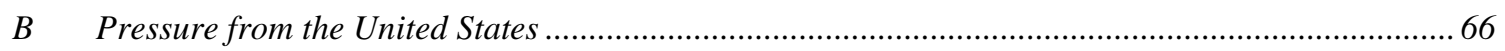

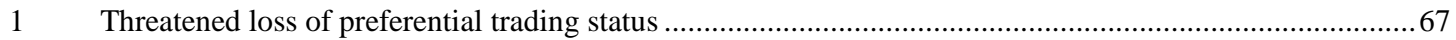

2 Use of international trade as a force to drive copyright lawmaking ..............................................................6 68

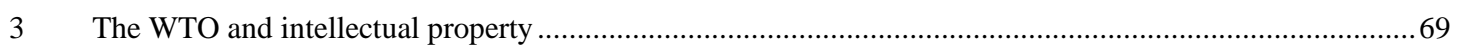

C Regional Harmonisation of Copyright Laws ......................................................................... 70

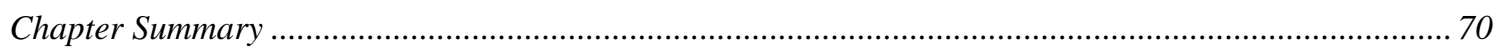




\section{CHAPTER THREE}

THE EFFECTIVENESS OF THE JAMAICAN COPYRIGHT INFRASTRUCTURE AS A MEANS OF ECONOMIC DEVELOPMENT

Overview

I ECONOMIC DEVELOPMENT THROUGH INDIGENOUS COLLECTIVE MANAGEMENT ORGANISATIONS (CMOS)

A Problems with Royalty Payments to and from foreign CMOs ..................................................... 75

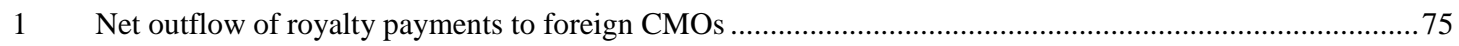

2 Outstanding royalties due to Jamaican CMOs from overseas use of Jamaican works ...................................78

3 Unfavourable reciprocal arrangements with foreign CMOs …............................................................ 80

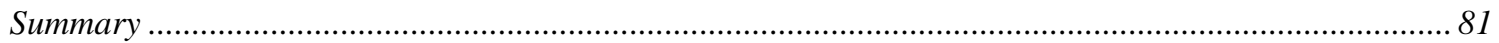

B Challenges with Collecting Royalties for Domestic use of Jamaican copyright works ....................81

$1 \quad$ Low levels of collections from local commercial users of music ............................................................. 81

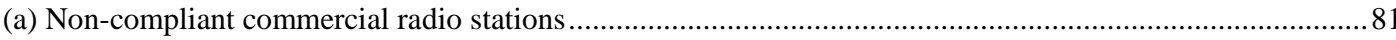

(b) Non-payment of royalties by other commercial users of music ..................................................................8 83

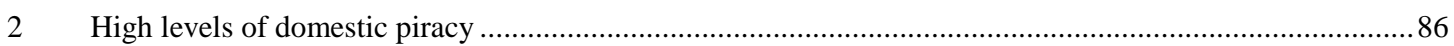

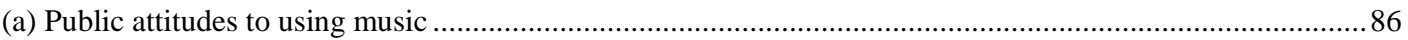

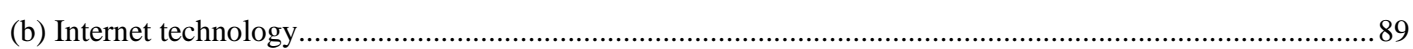

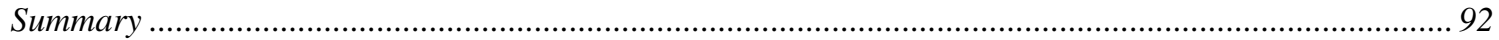

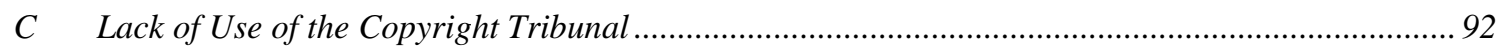

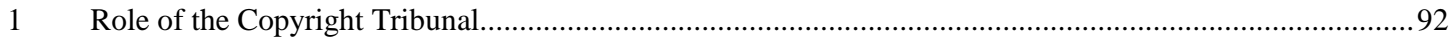

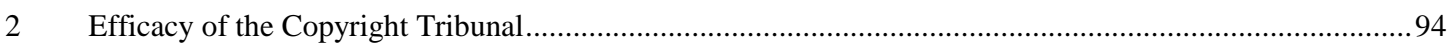

D Membership of foreign CMOs favoured by Jamaican rights holders.........................................99

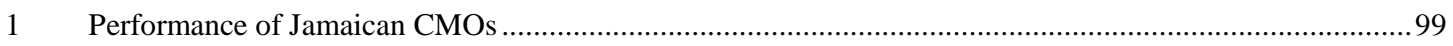

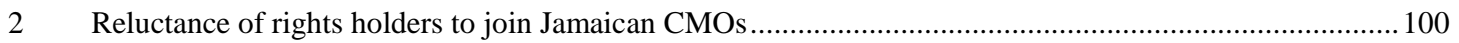

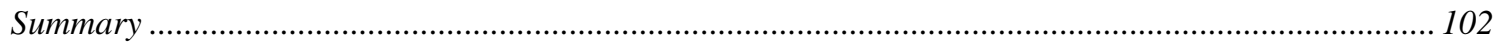

E The Absence of a Socio-Cultural Role for Local CMOs................................................................ 102

F CMOs'Administrative and Capacity Challenges and Limited Powers to Initiate Criminal Action on

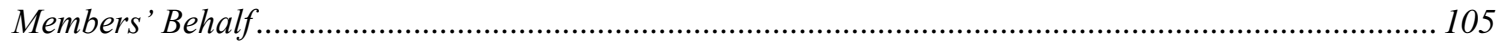

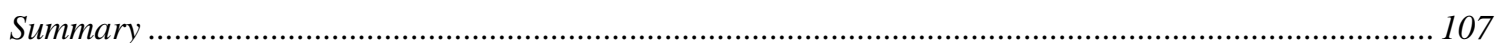

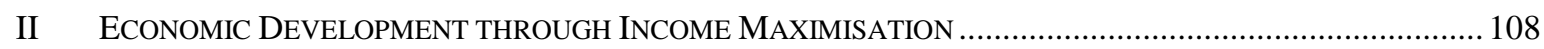

A Rights Holders' Ignorance about the Commercialisation of Copyright ..................................... 111

B The Lack of Government Assistance to Rights Holders in the Commercialisation of Copyright .... 114

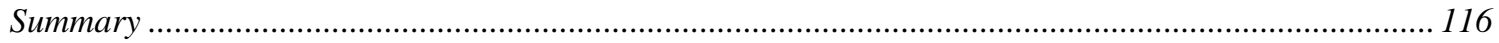

III ECONOMIC DEVELOPMENT THROUGH EQUITABLE RESOURCE DISTRIBUTION................................... 116

A Educational Inequalities among Music Industry Stakeholders................................................. 117

B Uneven Distribution of Copyright Income at the Domestic and International Levels................... 119

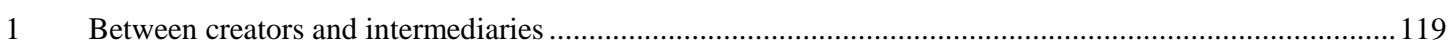

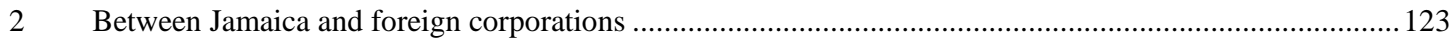

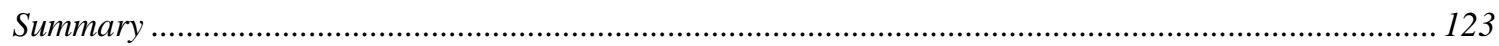


A Direct Government Investment in the Value Chain and Channelling of Resources from Traditional Export Sectors into the Music Industry.

B Exploring and Leveraging Linkages between the Music Industry and other Sectors .................... 126

C Greater Government Involvement in Collective Administration ................................................. 128

Chapter Summary

\section{CHAPTER FOUR}

\section{COPYRIGHT FOR DEVELOPMENT: THE INTERSECTION OF DEVELOPMENT AND} COPYRIGHT LAW

Overview

I HUMAN DEVELOPMENT (OR THE CAPABILITIES APPROACH TO DEVELOPMENT).............................. 133

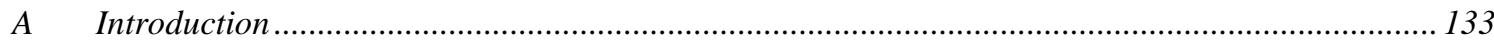

B The Emergence of Human Development within Development Theory ........................................ 135

$1 \quad$ The Neoliberal approach to development .......................................................................................... 135

2 The growth of the Human Development model.................................................................................. 137

II MAJOR TheORETICAL JUSTIFICATIONS FOR COPYRIGHT PROTECTION AND COPYRIGHT TREATIES ...... 139

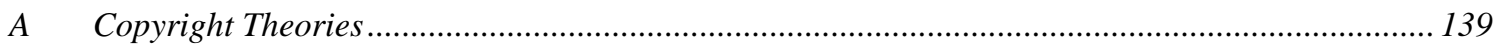

$1 \quad$ Natural Rights and Personality perspectives....................................................................................... 139

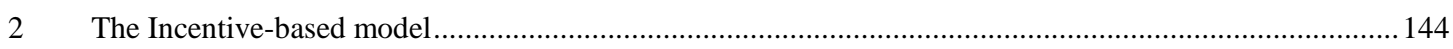

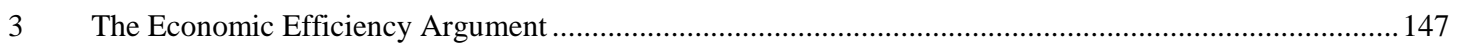

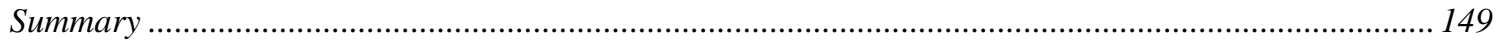

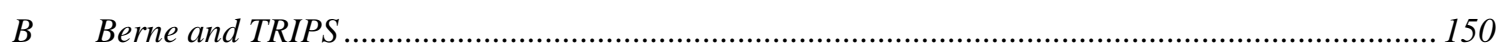

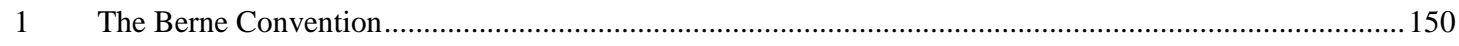

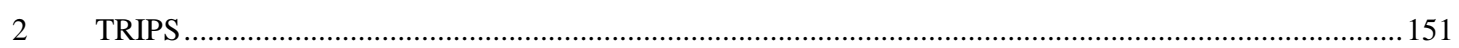

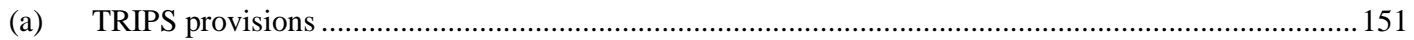

(b) Post-TRIPS arguments about the developmental impact of heightened copyright protection ................. 153

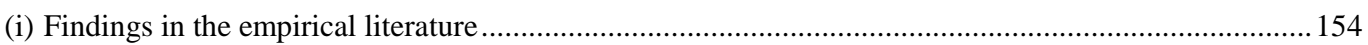

(ii) Developing Countries' Recommended Response to the Pressure to Increase Copyright Protection ..... 157 Summary

III THE INTERFACE BETWEEN DEVELOPMENT AND COPYRIGHT THEORY: A HuMAN DEVELOPMENT APPROACH TO COPYRIGHT

A General Implications of Applying a Human Development Approach to Copyright in Domestic Copyright Lawmaking

B Support for a Human Development Approach to Copyright within the International Copyright Regime.

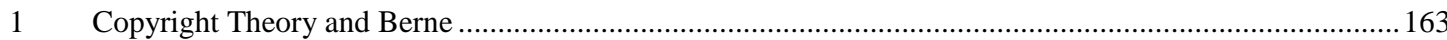

2 A Vienna Convention on the Law of Treaties (VCLT) analysis of articles 7 and 8 of TRIPS ...................165

(a) Good faith interpretation of the ordinary meaning of the terms ....................................................... 168

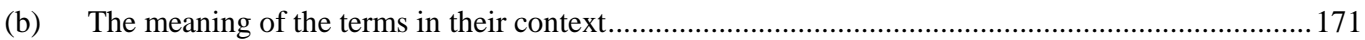


(i) Context as evident from the surrounding text and related agreements ................................. 171

(ii) Subsequent events to be considered with Context ....................................................... 173

(iii)Relevant rules of international law to be considered with Context ...................................... 176

(c) Meaning of the terms in light of the treaty's object and purpose …................................................ 178

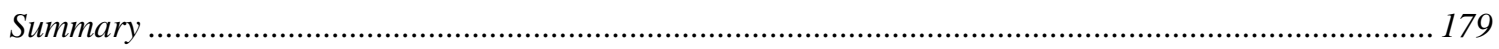

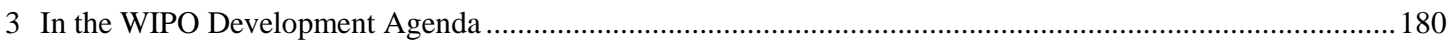

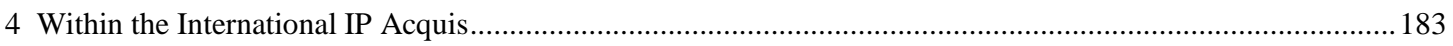

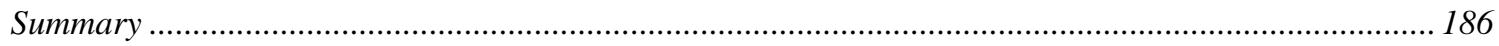

IV ILLUSTRATIONS OF THE HUMAN DEVELOPMENT APPROACH IN JAMAICAN COPYRIGHT LAW............... 186

A Evidence in Domestic Copyright Policy and Law ........................................................... 187

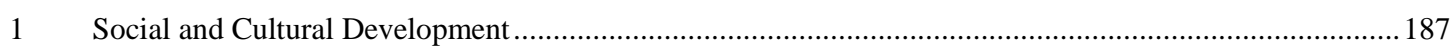

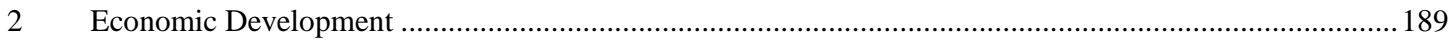

B Evidence in the Economic Partnership Agreement with the European Community...................... 191

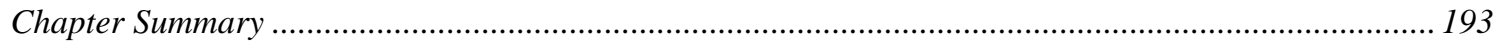

\section{CHAPTER FIVE}

\section{COPYRIGHT LEGISLATION APPLIED TO THE JAMAICAN MUSIC INDUSTRY: REFORM IN}

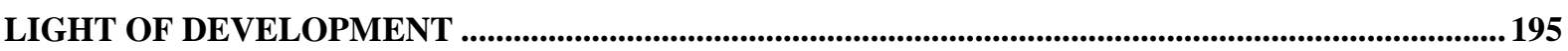

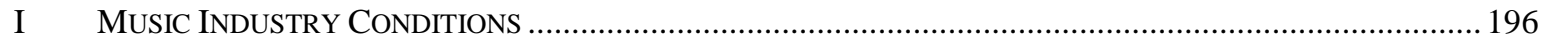

A Business Orthodoxies and Industry Structure ...................................................................... 197

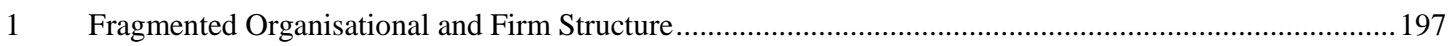

(a) Music Production Companies without exclusive deals with artistes ...................................................198

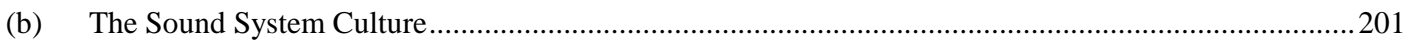

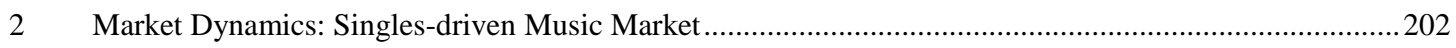

B Artistes' Practices: Collaborative Creative Process .................................................................... 203

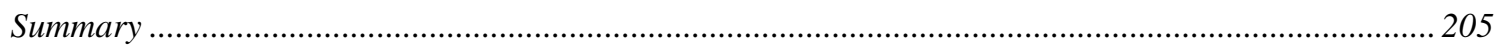

II SPECIFIC AREAS REQUIRING LEGISLATIVE REFORM ............................................................205

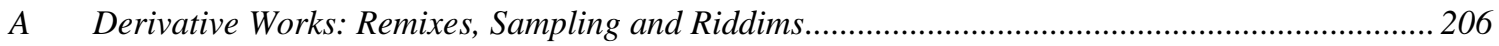

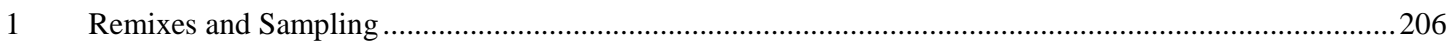

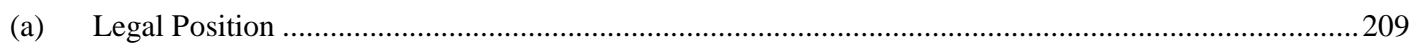

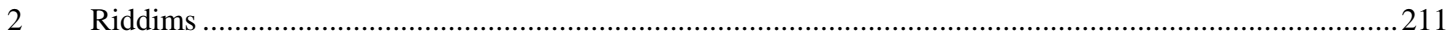

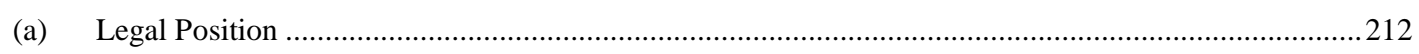

3 Recommended Amendments to the Copyright Act to Accommodate Derivative Works ...........................215

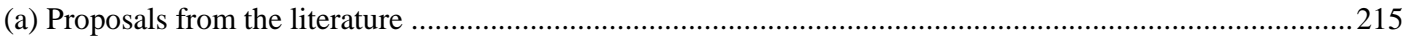

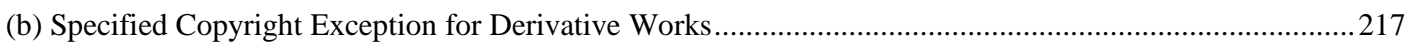

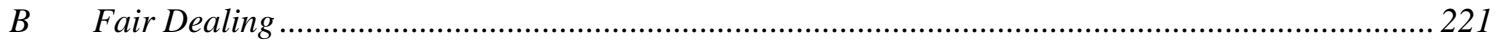

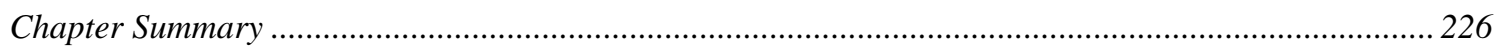




\section{CHAPTER SIX}

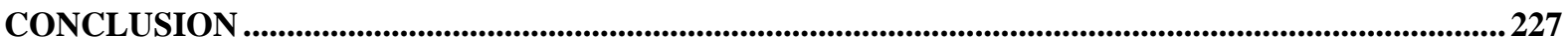

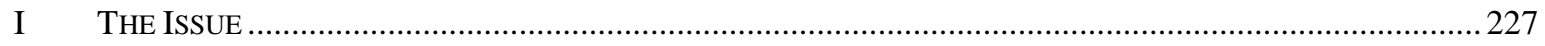

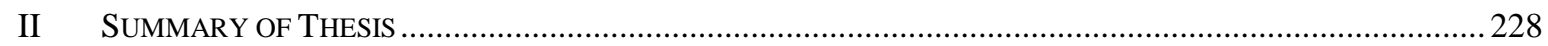

III CONTRIBUTION TO SCHOLARSHIP AND AREAS FOR FURTHER RESEARCH ........................................... 230

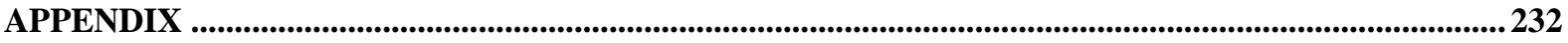

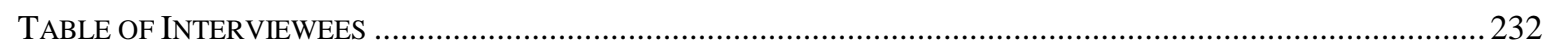

BIBLIOGRAPHY ...................................................................................................................................................2 239

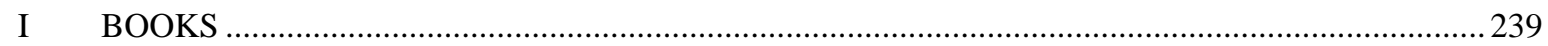

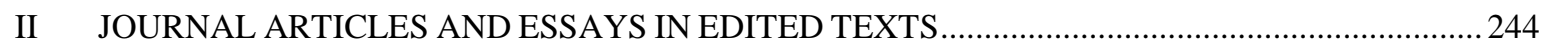

III UNPUBLISHED REPORTS, RESEARCH PAPERS, SEMINAR PAPERS, PRESENTATIONS AND

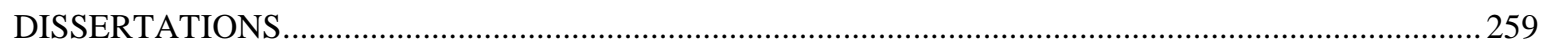

IV JAMAICAN LEGISLATION, PARLIAMENTARY MATERIAL, REGULATIONS AND POLICY

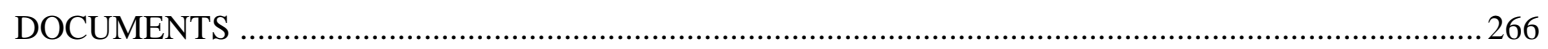

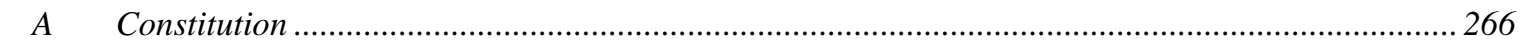

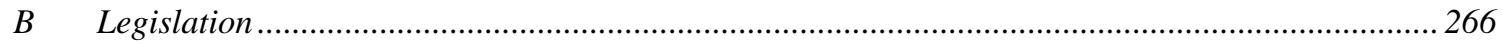

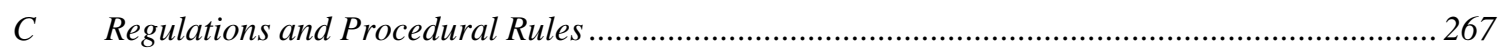

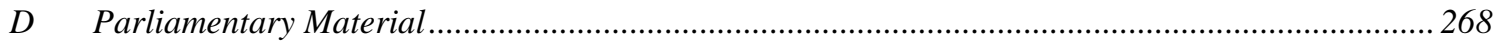

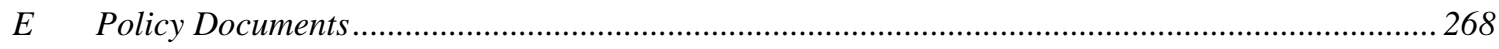

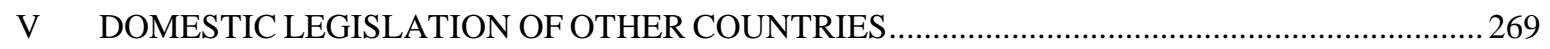

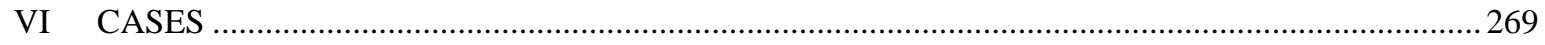

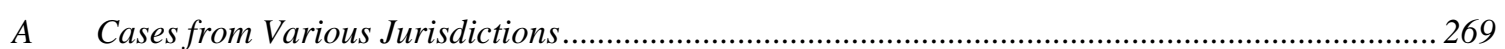

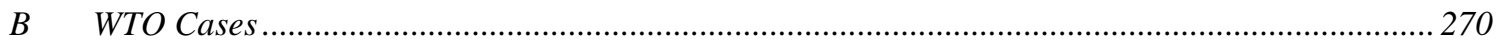

VII INTERNATIONAL INSTRUMENTS, AGREEMENTS, TREATIES AND DECLARATIONS ........272

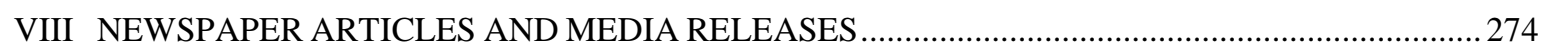

IX ONLINE MATERIAL, WEBSITES AND MISCELLANEOUS MATERIALS..................................2275 


\section{LIST OF ABBREVIATIONS}

\begin{tabular}{|c|c|}
\hline $\mathrm{ACP}$ & African, Caribbean and Pacific Group of States \\
\hline ASCAP & American Society of Composers, Authors and Publishers \\
\hline $\mathrm{BC}$ & Broadcasting Commission of Jamaica \\
\hline Berne & Berne Convention for the Protection of Literary and Artistic Works \\
\hline BMI & Broadcast Music Inc \\
\hline CARICOM & Caribbean Community \\
\hline $\mathrm{CD}$ & Compact Disc \\
\hline CDPA & Copyright, Designs and Patent Act (United Kingdom) \\
\hline CISAC & International Confederation of Societies of Authors and Composers \\
\hline $\mathrm{CMO}$ & Collective Management Organisation \\
\hline DRM & Digital Rights Management \\
\hline DSB & Dispute Settlement Body \\
\hline DVD & Digital Video Disc \\
\hline $\mathrm{EC}$ & European Commission \\
\hline EPA & Economic Partnership Agreement \\
\hline EU & European Union \\
\hline FDI & Foreign Direct Investment \\
\hline FTA & Free Trade Agreement \\
\hline GATS & General Agreement on Trade in Services \\
\hline GATT & General Agreement on Tariffs and Trade \\
\hline
\end{tabular}




\begin{tabular}{|c|c|}
\hline GDP & Gross Domestic Product \\
\hline ICT & Information and Communication Technology \\
\hline IFPI & International Federation of the Phonographic Industry \\
\hline IFRRO & International Federation of Reproduction Rights Organization \\
\hline IP & Intellectual Property \\
\hline IPRS & Intellectual Property Rights \\
\hline ISP & Internet Service Provider \\
\hline $\mathrm{J} \$$ & Jamaican Dollar \\
\hline JACAP & Jamaica Association of Composers, Authors and Publishers \\
\hline JAMCOPY & Jamaican Copyright Licensing Agency \\
\hline JAMMS & Jamaica Music Society \\
\hline JAMPRO & Jamaica Promotions Corporation \\
\hline JAMRAS & Jamaica Musical Rights Administration Society \\
\hline JAPA & Jamaica Anti-Piracy Alliance \\
\hline JARIA & Jamaica Reggae Industry Association \\
\hline JAVA & Jamaica Association of Vintage Artistes \\
\hline JFM & Jamaica Federation of Musicians \\
\hline JIPO & Jamaica Intellectual Property Office \\
\hline JPAS & Jamaica Performers' Administration Society \\
\hline OAS & Organization of American States \\
\hline OCID & Organised Crime Investigation Division \\
\hline OECD & Organisation for Economic Co-operation and Development \\
\hline
\end{tabular}


MYSC Ministry of Youth, Sports and Culture

PRS Performing Right Society

Revised Treaty Treaty of Chaguaramas Establishing the Caribbean Community, Including the CARICOM Single Market and Economy

RIAJAM Recording Industry Association of Jamaica

RRO Reprographic Rights Organisation

SOCAN Society of Composers, Authors and Music Publishers of Canada

SME Small and Medium Enterprise

STV Subscriber Television

TRIPS Trade-Related Aspects of Intellectual Property Rights

UK United Kingdom

UN United Nations

UNCTAD United Nations Committee for Trade and Development

UNDP United Nations Development Programme

UNESCO United Nations Educational, Scientific and Cultural Organization

US United States of America

UTECH University of Technology

UWI University of the West Indies

WCT WIPO Copyright Treaty

WIPO World Intellectual Property Organization

WPPT WIPO Performances and Phonograms Treaty

WTO World Trade Organization 
"If the fire of the law dies here and burns there, it is not operating properly."

Proverb from Ghana 


\section{CHAPTER ONE}

\section{INTRODUCTION, BACKGROUND TO THE RESEARCH QUESTION, THESIS STRUCTURE AND METHODOLOGY}

\section{Overview}

A conventional justification for copyright is that it incentivises creation and protects the financial interests of individual creators. International agreements codify certain minimum standards for copyright protection and mandate their members to enact legislation to protect these private rights, while giving members the option to carve out copyright exceptions in the public interest. What are the implications of copyright protection for a developing nation?

This thesis investigates the relationship between copyright law and development in Jamaica in regard to the local Reggae music industry. The background to the research question, the subsidiary questions to be addressed in each chapter and the research methodology are the subject of this chapter.

\section{Background to the Research Question}

A story came to me that when Bob Marley was seeking to register his tax escape companies and needed tax identity, he went to the Jamaican Tax Office, and he advised them that his earnings, at that time, was Three Hundred Thousand US Dollars (US\$300,000). Quite funnily enough, the Tax Officer jumped up off his desk and asked [Marley] which of the larger weeds [marijuana] was he smoking that morning; because it was beyond his realm of understanding that this kind of occupation could earn that kind of money. ${ }^{1}$

\footnotetext{
${ }^{1}$ Hansard (26 January 1993) House of Representatives (per Mike Henry, Member of Parliament and former Minister of State in the Ministry of Culture).
} 
In 1993, during the debate on the Copyright Bill, a Jamaican politician gave the abovementioned account of a civil servant scoffing at Bob Marley's income to warn his fellow Members of Parliament. His message was that if the Jamaican Government were to underestimate the earning power of the Reggae music industry, it would do so at its peril. Later, during that same Parliamentary sitting, the Copyright $\mathrm{Act}^{2}$ was passed with the overwhelming support of both sides of the House of Representatives.

This thesis asks: does the copyright legislation allow the Reggae music industry to make a useful contribution to Jamaica's development? And, if not, how could reforming Jamaica's copyright law address this problem?

First, it is important to clarify what is meant by "music industry." "Music industry", in its broadest sense, includes the people, processes and products involved in the composition, production, marketing, distribution, sale and consumption of music. The phrase thus captures activities such as music publishing, musical training, the sale of musical equipment, broadcasting, the recording business, live performances, audio-visual production, retailing of musical products, information and communication technologies utilised in making and distributing music, the provision of professional services (such as legal services), technical support and the operations of industry organisations and collecting societies. ${ }^{3}$

The question of the impact of music-related copyright ${ }^{4}$ on Jamaica's development has arisen for five reasons: (a) the economic potential of Jamaica's music industry; (b) trends in the international copyright regime strengthening copyright protection; (c) the limited research on

\footnotetext{
${ }^{2}$ Copyright Act No. 4 of 1993 (in force 1 September 1993) as amended in 1999 by Copyright (Amendment) Act No. 29 of 1999 [Copyright Act].

${ }^{3}$ See: Vanus James “The Caribbean Music Industry Database (CMID), 2000” (UNCTAD/WIPO Report, 2001) at 3.

${ }^{4}$ The different types of copyright involved in music are: copyright in the literary work, musical work and sound recording. According to the Copyright Act, s 2: a literary work is "any work, other than a dramatic or musical work, which is written, spoken or sung." This would include the words or lyrics of a song. A musical work is "a work consisting of music, exclusive of any words or action intended to be sung, spoken or performed with the music": Copyright Act, s 2. Thus, this term refers to a composition's sonic elements. Throughout this thesis I use the term "music" to refer to the embodiment of both the musical and literary elements of a song. Copyright Act, s 2 states that a sound recording is "(a) a recording of sounds from which sounds may be reproduced; or (b) a recording of the whole or any part of a literary, dramatic or musical work from which sounds reproducing the work or part may be produced, regardless of the medium on which the recording is made or the method by which the sounds are reproduced or produced." References to "copyright" in this thesis, unless stated otherwise, include the related or neighbouring rights of performers and producers of sound recordings.
} 
copyright's impact on development in Jamaica; (d) Jamaica's development needs; and (e) the domestic spread of internet technology. Each is discussed below.

\section{A The Economic Potential of Jamaica's Music Industry}

Reggae music is an indigenous form of creative expression that is a recognisable export of Jamaica. It has been estimated that Jamaican music generates over US\$1 billion globally. ${ }^{5}$ In spite of the commercial success enjoyed internationally by Jamaican Reggae artistes, such as Bob Marley and the Wailers, Jimmy Cliff, Shaggy and Sean Paul, the financial gains from the music industry have not translated into long term returns for the domestic economy. Commentators have described the local economic impact of the music industry as negligible. ${ }^{6}$ The latest study on the economic contribution of Jamaica's copyright-based industries found that in 2005 those sectors contributed 4.8 per cent of Jamaica's Gross Domestic Product or US $\$ 464.7$ million. $^{7}$ The core copyright sector contributed 1.7 per cent of the 4.8 per cent figure. ${ }^{8}$

The Jamaican music industry faces several challenges, which may explain why its contribution to Jamaica's economy has not been significant. These challenges include: deficiencies in the institutional, legal and financial infrastructure to support integrated planning and policy development, financing, marketing and other business support services for the industry; unsuitable industry business practices, piracy and lack of political will. ${ }^{9}$ Many of these problems result from the limited investment in the music industry by the

\footnotetext{
${ }^{5}$ Zeljka Kozul-Wright and Lloyd Stanbury "Becoming a Globally Competitive Player: The Case of the Music Industry in Jamaica" (UNCTAD Discussion Paper No 138, 1998) at 19. But see: Michael Witter "Music and the Jamaican Economy" (UNCTAD/WIPO Report, 2004) at 32 (estimating that, in terms of record sales, the size of the international market for reggae is US\$60-75 million, with an upper limit of US\$100 million).

${ }^{6}$ See Beverley Pereira "A Regional Approach to the Management of Copyright in the Caribbean Community" (PhD thesis, Queen Mary, University of London, 2009) at 79 and Dianne Daley Jamaica (Roger Blanpain and Michele Colucci (eds) Kluwer Law International: International Encyclopaedia of Laws (Intellectual PropertySupplement 47, Wolters Kluwer, Eastbourne, 2008) at [22].

${ }^{7}$ Vanus James "The Economic Contribution of Copyright-based Industries to the Jamaican Economy" (WIPO Report, 2007) at 8 . No current figures were available as this study has not been updated.

${ }^{8}$ Ibid, at 76.

9 See: Hilary Brown "National Strategy \& Action Plan to further develop the Jamaican Music Industry" (UNESCO Report, 2004) at 3-4.
} 
private and public sector. For example, entertainment sector loans accounted for only 0.2 per cent of the total loans and advances issued by domestic commercial banks in early $2009 .{ }^{10}$

Despite these problems, studies have consistently highlighted the music industry's potential for contributing to the wider Jamaican economy, as well as to non-economic aspects of social welfare. For example, Kozul-Wright and Stanbury observed: ${ }^{11}$

Jamaica's music industry has important externalities and indirect effects for the rest of the economy, such as the preservation and promotion of national culture, support of local talent, the stimulation of the creativity of the Jamaican population (especially the youth), poverty reduction, job creation, the provision of an increased tax base and consequently improved welfare of the local population.

In order to help the Jamaican music industry realise its potential for contributing to national economic development, several studies have proposed that the enforcement of copyright legislation be improved. ${ }^{12}$ While these studies fail to elaborate on what this improvement should look like, their recommendation does raise questions as the role copyright law can play in advancing the development of the music industry and Jamaica, as well as the nature and means of this development.

\section{B Trends in the International Copyright Regime Strengthening Copyright Protection}

$1 \quad$ Domestic copyright lawmaking in response to TRIPS and other international agreements

\footnotetext{
${ }^{10}$ Steven Jackson, "Entertainment Loans Jump \$1B but Industry Sceptical” The Daily Observer (Jamaica, 14 August 2009).

${ }^{11}$ Kozul-Wright and Lloyd Stanbury "Becoming a Globally Competitive Player: The Case of the Music Industry in Jamaica" (UNCTAD Discussion Paper No 138, 1998) at 19.

${ }^{12}$ For example, Vanus James "The Economic Contribution of Copyright-based Industries to the Jamaican Economy" (WIPO Report, 2007) at [7.2]; Michael Witter "Music and the Jamaican Economy" (UNCTAD/WIPO Report, 2004) at 49; Zeljka Kozul-Wright and Lloyd Stanbury "Becoming a Globally Competitive Player: The Case of the Music Industry in Jamaica" (UNCTAD Discussion Paper No 138, 1998) at 33 and Keith Nurse "The Cultural Industries in CARICOM: Trade and Development Challenges" (Caribbean Regional Negotiating Machinery Report, 2006 (revised 2007)) at 30.
} 
Another rationale for the research question concerns Jamaica's membership of various international copyright law agreements. ${ }^{13}$ In 1995, Jamaica became a member of the World Trade Organization's (WTO) Agreement on Trade-Related Aspects of Intellectual Property Rights (TRIPS), ${ }^{14}$ the first multilateral trade agreement on intellectual property rights (IPRS) protection. A key goal of TRIPS is to reduce barriers to trade by protecting IPRS. ${ }^{15}$ While TRIPS' provisions do not guarantee increased foreign investment and technology transfer ${ }^{16}$, developed country proponents of TRIPS argued during its negotiation that strengthening and expanding copyright protection was a prerequisite for increased flows of foreign investment and technology transfer to developing countries $^{17}$ and for achieving their national socioeconomic interests through trade. ${ }^{18}$

In response to TRIPS, Jamaica, like other developing countries, ${ }^{19}$ has had to strengthen its domestic intellectual property (IP) regime. Accordingly, in 1999 the Jamaican Copyright Act

13 Jamaica is a party to the following Agreements: Convention Establishing the World Intellectual Property Organization 1967 (since 1978); Berne Convention for the Protection of Literary and Artistic Works (1886) (as revised at Paris 1971) [Berne] (since 1994); International Convention for the Protection of Performers, Producers of Phonograms and Broadcasting Organizations 1961 [Rome Convention] (since 1994); Convention for the Protection of Producers of Phonograms Against Unauthorized Duplication of Their Phonograms 1971 [Phonograms Convention] (since 1994); Agreement Concerning the Protection and Enforcement of Intellectual Property Rights between United States and Jamaica 1994 (since 1994); Convention Relating to the Distribution of Programme-Carrying Signals Transmitted by Satellite 1974 [Brussels Convention] (since 2000); WIPO Copyright Treaty 1996 (since 2002) and WIPO Performances and Phonograms Treaty 1996 (since 2002). Amendments to the Jamaican Copyright Act to comply with the provisions of the 1996 WIPO treaties are being currently being finalised. On 26 June 2012 Jamaica signed the Beijing Treaty on Audiovisual Performances 2012.

${ }^{14}$ The Agreement on Trade-Related Aspects of Intellectual Property Rights, Annex 1C to the Marrakesh Agreement Establishing the World Trade Organization (15 April 1994) [TRIPS].

${ }^{15}$ See TRIPS, Preamble.

${ }^{16}$ This refers to the transmission of technology bilaterally, for example, through a licensing agreement; unlike "dissemination" of technology which is the diffusion of technology: UNCTAD/ICTSD Resource Book on TRIPS and Development (Cambridge University Press, New York, 2005) at 126. Technology Transfer can take various forms, such as: capital goods, turn-key plants, licences and technical assistance: Carlos Correa "Can the TRIPS Agreement foster Technology Transfers to Developing Countries?" in Keith Maskus and Jerome Reichman (eds) International Public Goods and Transfer of Technology Under a Globalised Intellectual Property Regime (Cambridge University Press, Cambridge, 2005) 227 at 229.

${ }_{17}$ Carlos Correa "Can the TRIPS Agreement foster Technology Transfers to Developing Countries?" in Keith Maskus and Jerome Reichman (eds) International Public Goods and Transfer of Technology Under a Globalised Intellectual Property Regime (Cambridge University Press, Cambridge, 2005) 227 at 227.

${ }^{18}$ See Chapter 3 for further discussion.

${ }^{19}$ See Andy Crump The A to Z of World Development (Wayne Ellwood ed, New Internationalist, Oxford, 1998) at 78-79: where developing countries are defined as nations with "low levels of technology, basic living standards and little in the way of an industrial base. Their economies are mainly agricultural and are characterised by cheap, unskilled labour and a scarcity of investment capital. Per capita incomes are below US\$5,000 and often less than [US] $\$ 1,500$. Around $70 \%$ of the world's population live in the developing countries, almost all of which are in Africa, Asia, Oceania and Latin America": Within the WTO framework, 
was amended. ${ }^{20}$ Although TRIPS provides minimum standards of protection, Jamaica has entered into TRIPS-Plus bilateral and regional agreements, which require higher levels of IP protection. $^{21}$

\section{The economic benefits of TRIPS for developing countries}

The trade advantages for developed countries from TRIPS are clear. TRIPS protects the exports of their domestic economies in countries with previously low levels of copyright protection. ${ }^{22}$ However, researchers have argued that developing countries, like Jamaica, acceded to TRIPS for various reasons, including ignorance. ${ }^{23}$ It is significant that Jamaica did not have expert representation on IPRS during the TRIPS negotiations. ${ }^{24}$ Another reason advanced for developing countries' agreeing to TRIPS was the uneven bargaining power between developed and developing countries. ${ }^{25}$ Therefore, TRIPS represented a compromise whereby developing countries strategically agreed to higher protection for developed countries' IP in exchange for greater market access for their agricultural and textile exports in developed country economies. ${ }^{26}$

developing countries are countries which define themselves as such, although other countries may challenge this identification: <www.wto.org/english/tratop_e/devel_e/d1who_e.htm>

${ }^{20}$ By the Copyright (Amendment) Act No. 29 of 1999 which incorporated obligations under TRIPS (such as database protection).

${ }^{21}$ For example, the Agreement Concerning the Protection and Enforcement of Intellectual Property Rights between the Government of the United States and the Government of Jamaica (signed on 17 March 1994) and the Economic Partnership Agreement between the European Community (EC), its Members States and CARIFORUM initialled 16 December 2007. See generally: David Vivas-Eugui "Regional and Bilateral Agreements in A TRIPS-plus World: The Free Trade Area of the Americas (FTAA)" (Quaker United Nations Office Report, 2003) <www.geneva.quno.info>; and Rosemary Coombe, "Fear, Hope, and Longing for the Future of Authorship and a Revitalized Public Domain in Global Regimes of Intellectual Property" (2003) 52 DePaul L Rev 1171.

${ }^{22}$ Ruth Okediji "Back to Bilateralism? Pendulum Swings in International Intellectual Property Protection" (2003-2004) 1 UOLTJ 125 at 128.

${ }^{23}$ Peter Yu "TRIPS and Its Discontents" (2006) 10 Marquette IP L Rev 369 at 371-379.

${ }^{24}$ Dianne Daley "Commission on Intellectual Property Rights Country Case Study for Study 9: Institutional Issues for Developing Countries in IP Policy-Making, Administration and Enforcement Jamaica, Trinidad \& Tobago, St. Lucia" (Commission on Intellectual Property Rights Report, 2002) at 12.

${ }^{25}$ Peter Yu, "TRIPS and Its Discontents" (2006) 10 (2) Marquette Intellectual Property Law Review 369 at 371. 26 See Graeme Dinwoodie and Rochelle Dreyfuss "Designing a Global Intellectual Property System Responsive to Change: The WTO, WIPO and Beyond" (University of Oxford Legal Research Paper Series Paper No. 50, $2009)$ at 1 . However, although they agreed to stronger copyright and other IP protections some developing countries, including Jamaica, are unable to afford adequate domestic enforcement regimes for intellectual property infringements. 
Regardless of their reasons for agreeing to TRIPS, the question is whether copyright protection influences economic development in developing countries through foreign direct investment $(\mathrm{FDI})^{27}$ and technology transfer, as some negotiators suggested during TRIPS negotiations. ${ }^{28}$ One commentator noted: ${ }^{29}$

The means by which IPRS influence FDI are complex and subtle. Furthermore, strong IPRs alone are not sufficient incentives for firms to invest in a country. If they were, recent FDI flows to developing countries would have gone mainly to sub-Saharan Africa and Eastern Europe. In contrast, China, Brazil, and other high-growth, large market developing economies with weak protection would not have attracted nearly as much FDI.

Because of this lack of clarity about IP's impact on economic development, some have criticised TRIPS for being "skewed in favour of the interests of [IP] right-holders and the countries where they reside at the expense of right-users and developing countries." 30 Another researcher concluded: ${ }^{31}$

It now seems clear that because TRIPS was informed more by the belief that introducing "Western" IP norms would induce development than by actual supporting analyses and data, TRIPS put the policy cart before the empirical horse.

This uncertainty has contributed to developing countries' growing dissatisfaction with TRIPS for what their governments consider to be TRIPS' limitation of access to knowledge and information and its failure to address their interests and local conditions. ${ }^{32}$ This frustration

\footnotetext{
${ }^{27}$ Foreign Direct Investment [FDI] has been defined as "the act of establishing or acquiring a foreign subsidiary over which the investing firm has substantial management control": Keith Maskus "The Role of Intellectual Property Rights in Encouraging Foreign Direct Investment and Technology Transfer" (1998) 9 Duke J Comp \& Intl L 109 at 119. It has been argued that FDI is the best way for developing countries to increase their knowledge capacity, technical innovation and eventually their economic growth: Daniel Gervais "Intellectual Property, Trade \& Development: The State of Play" (2005) 74 Fordham L Rev 505 at 515-516. FDI is usually measured by a country's net capital inflow investment from overseas and studied as a portion of a country's Gross Domestic Product [GDP].

${ }^{28}$ See: UNCTAD/ICTSD Resource Book on TRIPS and Development (Cambridge University Press, New York, 2005) at ch 1 and ch 6. This issue is discussed later at Chapter 4.II.B.2(b).

${ }^{29}$ Keith Maskus "Intellectual Property Rights and Foreign Direct Investment" (Centre for International Economic Studies Policy Discussion Paper No 0022, 2000) at v.

${ }^{30}$ See Xu Yi-chong "Last chance? Multilateralism, TRIPS and Developing countries" in Justin Malbon and Charles Lawson (eds) Interpreting and Implementing the TRIPS Agreement- Is it Fair? (Edward Elgar, Cheltenham, 2008) at 46.

${ }^{31}$ Daniel Gervais "(Re)implementing the Agreement on Trade-Related Aspects of Intellectual Property Rights to Foster Innovation" (2009) 12 The Journal of World IP 348 at 352.

32 Peter Yu “TRIPS and Its Discontents" (2006) 10 Marquette IP L Rev 369 at 370.
} 
underscores the need for research shedding light on copyright's impact on economic development.

\section{Limited Research on Copyright's Impact on Development in Jamaica}

Literature exists on the strengths and weaknesses of creative industries across the Caribbean region. ${ }^{33}$ There have also been studies looking specifically at the features, challenges and economic contribution of the Jamaican music industry, but none of these discusses copyright law in any detail. ${ }^{34}$ In 2009, the first textbook on Jamaican IP law was published, outlining the content of substantive copyright law. ${ }^{35}$ However, that treatise did not give attention to the application of these copyright rules to the music industry.

Interestingly, while researchers have assumed that the economic returns from creative expressions are dependent on enacting and enforcing copyright law, ${ }^{36}$ research into the connection between copyright law in music and development in Jamaica has been lacking. Specifically, there has been no comprehensive analysis of what kind of copyright framework is needed for the effective operation of the Jamaican music industry.

This gap in the empirical research requires attention for several reasons. As mentioned earlier, researchers have argued that TRIPS was finalised on the assumption that positive economic returns for developing countries like Jamaica would follow from increased IP

\footnotetext{
${ }^{33}$ For example: Vanus James "The Caribbean Music Industry Database (CMID), 2000" (UNCTAD/WIPO Report, 2001), Keith Nurse "The Caribbean Music Industry: Building Competitiveness and Enhancing Export Capabilities in an Emerging Sector" (Caribbean Export Development Agency Report, 2003), Allison Demas and Ralph Henry "Entertainment Services with Special Reference to Music, Mas and the Film and Video Segments" (CARICOM Trade Project/Caribbean Regional Negotiating Machinery Report, December 2001) and Compton Bourne and SM Allgrove "Prospects for Exports of Entertainment Services From the Caribbean: The Case of Music" (World Bank Report, 1995, (revised 1996)).

${ }^{34}$ Such as: Andrea Davis "Strategic Plan for Jamaican Music in the $21^{\text {st }}$ Century, 1999-2004" (JAMPRO Report, December 1998) and Lloyd Stanbury "Mapping the Creative Industries - The Experience of Jamaica" (paper presented to WIPO-CARICOM Meeting of Experts on the Creative Industries and Intellectual Property, Georgetown, Guyana, 8-9 February 2006) and Vanus James "The Economic Contribution of Copyright-based Industries to the Jamaican Economy" (WIPO Report, 2007).

${ }^{35}$ Dianne Daley Jamaica (Roger Blanpain and Michele Colucci (eds) Kluwer Law International: International Encyclopaedia of Laws (Intellectual Property-Supplement 47, Wolters Kluwer, Eastbourne, 2008).

${ }^{36}$ See, for example, Hilary Brown "National Strategy \& Action Plan to further develop the Jamaican Music Industry" (UNESCO Report, 2004) at 12.
} 
protection domestically. ${ }^{37}$ Developing countries likely contemplated that these economic benefits would take the form of trade gains in other non-IP export sectors or foreign investment in other local sectors. However, the issue of whether a strengthened copyright system can, on its own, generate domestic socio-economic benefits for a developing country is unresolved. Copyright is often overlooked by researchers dealing with IP's impact on socio-economic development. ${ }^{38}$ As a result, scholars have noted that a pressing question is: ${ }^{39}$

...how copyright (a right primarily held today by Western corporations and, much less so, by individuals in developed countries) can serve the varied goals of poor nations and poor communities within them.

Addressing this question is particularly appealing from a developing country perspective because such countries generally lack the technical skills and financial resources required for investment in patent innovation and large-scale indigenous private corporations with highvalue trademarks. For those nations, copyright products represent a more accessible form of IP than patents or trademarks, given the relatively lower cost of creation. In light of this, there is value in assessing the advantages and limitations associated with increasing copyright protection as a result of international copyright agreements. Furthermore, the significant development challenges that exist in developing countries ${ }^{40}$ heighten the need for clarity about whether copyright law can lead to development by impacting key industries.

\section{Jamaica's Development Needs}

The development needs of Jamaica also influenced the formulation of the research question.

37 See Daniel Gervais "TRIPS and Development" in Daniel Gervais (ed) Intellectual Property, Trade and Development: Strategies to Optimize Economic Development in a TRIPS-Plus Era (Oxford University Press, New York, 2007) 3 at 59.

${ }^{38}$ See Zorina Khan "Intellectual Property and Economic Development: Lessons from American and European History” (British Commission on Intellectual Property Rights Report, Study Paper 1a, 2002) at 9.

39 Alan Story "Study on Intellectual Property Rights, the Internet, and Copyright" (Commission on Intellectual Property Rights Report, 2001) at 8.

40 Challenges in terms of poverty levels, unemployment, human capital development, international competitiveness, Gross Domestic Product (GDP) growth and inflation: see World Bank <www.worldbank.org> 
Despite signing the major copyright treaties ${ }^{41}$ and adopting increasing levels of copyright protection as a result of TRIPs and other agreements, Jamaica's socio-economic indicators remain sluggish. ${ }^{42}$ Although it has a multi-sector economy, its primary productive sectors are linked to its natural resources and include: manufacturing, mining and quarrying, agriculture and tourism. Since its political independence from England in 1962, Jamaica underwent successive decades of negative economic growth until the end of the 1990s. ${ }^{43}$

Jamaica's unimpressive economic performance has been manifested in a decline in Gross Domestic Product (GDP) and increased debt, inflation, trade deficit, unemployment and poverty. Based on the available figures, Jamaica's debt is an estimated 150 per cent ${ }^{44}$ of its US $\$ 8.8$ billion GDP with interest payments averaging 16 per cent of GDP. In 2008, inflation stood at 16.8 per cent. ${ }^{45}$ In that same year, real GDP grew by -0.6 per cent. A trade deficit of US $\$ 4,216.4$ million was recorded in 2008 as imports rose by 45.6 per cent while exports increased by only 19.7 per cent. In 2004, 26 per cent of persons between age 15 and 24 were unemployed. ${ }^{46}$ A recent estimate put unemployment at 10.1 per cent. ${ }^{47}$ There is no state welfare system. ${ }^{48}$

Jamaica's small domestic economy is particularly vulnerable to activities of the global markets. For instance, the 2008 global recession impacted on the overall performance of the Jamaican economy. In the last quarter of 2008, real GDP decreased by 0.7 per cent relative to the same period a year before. ${ }^{49}$ Goods-producing industries fell by 2.6 per cent. The dollar depreciated by 6 per cent and there was a fiscal deficit of $\mathrm{J} \$ 32.8$ billion.

Jamaica's economic frailty is easily understood given that it is a small player in terms of its geo-political influence and lack of access to international capital. Although its nationals are

\footnotetext{
${ }^{41}$ See above $\mathrm{n} 13$.

${ }^{42}$ For general data on Jamaica see: Statistical Institute of Jamaica (STATIN) <www.statinja.com/stats.html>

${ }^{43}$ In 1999, GDP growth was -2\%: Planning Institute of Jamaica <www.pioj.gov.jm>.

${ }^{44}$ World Bank data: < http://web.worldbank.org >.

45 Planning Institute of Jamaica (PIOJ) Report dated 17 November 2008 <www.pioj.gov.jm>.

${ }^{46}$ World Bank data: <http://web.worldbank.org>.

${ }^{47}$ Central Intelligence Agency Fact book on Jamaica <www.cia.gov>.

${ }^{48}$ See "Jamaica Poverty Rate Jumps" Jamaica Gleaner (Jamaica, 13 October 2010).

49 Planning Institute of Jamaica "Review of Economic Performance October-December, 2008" (16 February 2009) <www.pioj.gov.jm>.
} 
prolific creators of copyright content, Jamaica is a net importer of copyright products. ${ }^{50}$ The World Bank stated that Jamaica's poor economic growth results from a loss of competitiveness: $:^{51}$

[T]o restore self-sustaining and job-creating growth, Jamaica will have to improve its international competitiveness and productivity, while also tackling urgent short-term economic and social needs.

However, the decline in traditional exports has caused Government and private stakeholders to pay greater attention to protecting IP-based products, particularly copyright in music. ${ }^{52}$

\section{The need for a national copyright policy}

Given the uncertainty about the developmental impacts of copyright law, scholars have advocated that countries place greater focus on domestic copyright policymaking (which suits local circumstances), and that flexibilities be maintained within the international law regime to allow for this. ${ }^{53}$ One main argument for developing countries managing their copyright systems in light of their particular developmental needs is that the costs and benefits of copyright vary based on countries' levels of technological and economic development. ${ }^{54}$ Although a degree of flexibility in the design of copyright systems ensures that the domestic

\footnotetext{
${ }^{50}$ See Joan Webley "First World Copyright Law in Third World Jamaica: Is there a Need for a New Approach?" (Article prepared for the International Association of Entertainment Lawyers, 27 November 2009) at 3.

51 World Bank "Jamaica- The Road To Sustained Growth - Country Economic Memorandum" (Report Number 26088) <www-wds.worldbank.org>.

${ }^{52}$ Stephen Jackson "JACAP looks to protecting works on Internet" The Daily Observer (Jamaica, 10 April 2009) at 13 and 15; "Maximizing Profits through Intellectual Property Protection" (Ministry of Industry, Investment and Commerce Media Release, 23 March 2009); "UTECH opens Office of Intellectual Property" (University of Technology Press Release, 12 May 2009) and "Music Could Expand Economy" (Jamaica Intellectual Property Office Press Release, 2009).

53 See: Graeme Dinwoodie and Rochelle Dreyfuss "TRIPS and the Dynamics of International Property Lawmaking” (2004) 36 Case W Res J Int'1 L 95 at 95; Peter Drahos “An Alternative Framework for the Global Regulation of Intellectual Property Rights" (Centre for Governance of Knowledge and Development Working Paper No. 1, Australian National University, October 2005) at 28 and Margaret Chon "A Rough Guide to Global Intellectual Property Pluralism" (Seattle University School of Law, Legal Studies Paper 09:01, 2009) at 10 .

${ }^{54}$ Mohan Kumar, 'Intellectual Property in the World Trade Organization: Turning it into Developing Countries' Real Property" (United Nations Conference on Trade and Development Report, 2010) at 1-2.
} 
copyright law would be appropriate to each country's specific circumstances, the problem is that copyright policy formulation has often not been based on adequate empirical evidence. ${ }^{55}$

Jamaica does not currently have a national copyright policy. Examining Jamaica's copyright legal system from the music industry context allows a clearer picture to emerge of the way in copyright intersects with development from the perspective of a critical economic sector. In this thesis, domestic stakeholders describe the complexities and characteristics of the relationship between copyright and development. Their viewpoints can be useful in creating a national copyright policy.

\section{E The Domestic Spread of Internet Technology}

Emerging technology in Jamaica has resulted in an increasingly digitally literate population. Jamaica's investment in modern Information and Communication Technology (ICT) infrastructure has brought improved connectivity and better access to the internet. Since 1999, the liberalised telecommunications sector has led to greater investment in infrastructure. ${ }^{56}$ This has attracted telemarketing and other ICT businesses. By 2003, 69 per cent of Jamaican householders used the internet, with 31.2 per cent having internet at home. ${ }^{57}$ A 2006 survey found internet penetration was 39 per cent. ${ }^{58}$ Efficient broadband deployment has become a Government priority and this goal has been met by local internet companies. In the World Economic Forum's Global Information Technology Report (Networked Readiness Index 2008-2009) ${ }^{59}$ Jamaica's network infrastructure was ranked $53^{\text {rd }}$, behind China but ahead of other developing countries such as India, Brazil, Columbia, Argentina and Venezuela.

\footnotetext{
55 Intellectual Property Office "The Government Response to the Hargreaves Review of Intellectual Property and Growth" (London, 2011) at 3.

56 Nicole Foga and Delreo Newman, "Liberalization of the Telecommunications Industry in CARICOM: Case Study Jamaica and Dominica" unpublished paper <www.fogadaley.com>.

57 See Cordel Green "The Regulators' Dilemma: Payback Trade-offs - a Developing Countries Perspective" (paper presented at the $34^{\text {th }}$ International Institute of Communication Conference, 30 September 2003).

${ }^{58}$ Elaine Wallace "Telecommunications Convergence: The Implications for the Role of Traditional Media to Serve the Public Interest in the Caribbean" (paper delivered at World Press Freedom Day-Caribbean Observance, St. Lucia, 1-3 May 2007).

${ }^{59}$ The Networked Readiness Index is a comparative and benchmarking framework developed in order to capture the state of the technology readiness in the 134 countries worldwide: 〈www.weforum.org>.
} 
Jamaican policymakers have noted the implications of internet technology. The head of the Broadcasting Commission has commented that "broadband development is central to economic growth in a digitized world" and "efficient broadband deployment and access must be planks on which to build developing countries. ${ }^{, 60}$ Policymakers have also acknowledged the ability of the internet to be a vehicle for the dissemination of culturally distinct material. ${ }^{61}$ The importance of producing local works for a global audience has also been highlighted by the Asian Development Bank Institute, ${ }^{62}$ which noted that investment in content as opposed to research and development in technology will yield greater returns.

The internet represents an opportunity for the creation and dissemination of locally produced copyright works ${ }^{63}$ in the music industry, particularly derivative works. ${ }^{64}$ Jamaicans have access to a pool of musical and film works from the United States (US), Jamaica's closest and largest English-speaking neighbour. Since the early 1990s, with the birth of the cable industry, Jamaica has been a heavy and steady consumer of American cable products, films, music and movies. The internet has increased access to these audiovisual materials, which as well as the presence of a domestic "copying culture", raises the opportunity for the generation and dissemination of remixed works, which have copyright implications. ${ }^{65}$

In summary, this thesis was motivated by the following factors: the economic potential of the Jamaican Reggae music industry, developments in international copyright law emphasising increased copyright protection, the limited research on copyright's impact on development in Jamaica, national socio-economic needs and the spread of internet technology locally.

The next section outlines the research questions that stemmed from these observations and how this thesis intends to answer those questions.

\footnotetext{
${ }^{60}$ See Cordel Green "The Regulators' Dilemma: Payback Trade-offs - a Developing Countries Perspective" (paper presented at the $34^{\text {th }}$ International Institute of Communication Conference, 30 September 2003).

${ }^{61}$ Hopeton Dunn "Link ICTS, Telecoms and Culture for Regional Growth" (paper presented at the Caribbean Regional Negotiating Machinery (CRNM) consultative forum, Trinidad and Tobago, 7 October 2007).

62 Asian Development Bank Institute "Information and Communication Technology (ICT) Strategies for Developing Countries" (Report, 28 February 2001) < www.adbi.org>.

${ }^{63}$ See Robert Ostergard Jr "Economic Growth and Intellectual Property Rights Protection: A Reassessment of the Conventional Wisdom" in Daniel Gervais (ed) Intellectual Property, Trade and Development: Strategies to Optimize Economic Development in a TRIPS-Plus Era (Oxford University Press, New York, 2007) 115 at 155.

${ }^{64}$ Defined at Chapter 5.II.A.

${ }^{65}$ These implications, such as copyright infringement, are discussed in Chapter 5.
} 


\section{Research Questions and Thesis Structure}

The primary research question explores copyright law's relationship to development in Jamaica, from the perspective of the local music industry.

This thesis hypothesises that whether copyright law stimulates or hinders development might depend on a range of historical, political, socio-cultural, economic and institutional factors which are not exclusively within the realm of copyright law. Nonetheless, these factors could be important for the successful operation of the copyright regime, and, as such, copyright policymakers may need to have regard to them in designing copyright legislation.

The primary research question gives rise to several related questions, namely:

1. How has domestic copyright law traditionally affected the Jamaican music industry; and how did the industry's evolution influence the passage of the current copyright statute?

2. What approaches exist among music industry stakeholders in regard to how economic development can be achieved through copyright protection? Are there limitations with these approaches?

3. What is meant by "development"? Is there a definition of development which is consistent with both the theoretical justifications for copyright and the international copyright treaties? Is there support for the argument that copyright law can serve a developmental function?

4. How applicable is the substantive content of the copyright legislation to the peculiarities of the local music industry? What areas are in need of reform?

The next Chapter (Chapter Two) addresses the question at point 1 (above) by looking at the factors that led Jamaican legislators to pass updated copyright legislation in 1993, including the local music industry's role in this process. It discusses how the non-observance of copyright law influenced the birth and growth of the Reggae music industry as well as how the commercial success of that industry became the impetus for the Copyright Act 1993. 
Chapter Three considers the questions at point 2. It assesses the various means of economic development contemplated by Jamaican policymakers and other stakeholders: namely, reliance on collective administration, income maximisation and resource redistribution.

Chapter Four examines the questions at point 3.This chapter argues that human development is relevant to interpreting TRIPS and is compatible with the major theoretical justifications for copyright as well as the Berne Convention for the Protection of Literary \& Artistic Works, 1886 (Berne Convention). ${ }^{66}$ Finally, this Chapter further demonstrates that in passing the Copyright Act 1993, Jamaican lawmakers conceived of an idea of development consistent with the human development approach.

Chapter Five presents a discussion of the questions at point 4 regarding the suitability of the Copyright Act's provisions to the Jamaican music industry. That chapter proposes altering the legislation to make it more appropriate to the dynamics of music industry.

Chapter Six concludes the thesis by commenting on the significance and implications of the findings.

\section{Research Methodology}

\section{A Research Design}

This research examines the way in which domestic music industry actors encounter and evaluate copyright law's role in development. It is an empirical legal study. Empirical legal scholarship views law as a social phenomenon ${ }^{67}$ and scrutinises its origins, operation and enforcement as well as the impact of legal changes. ${ }^{68}$

\footnotetext{
${ }^{66}$ Berne Convention for the Protection of Literary and Artistic Works (9 September 1886), as revised at Paris 24 July 1971, and amended 28 September 1979. The Act of Paris entered into force 15 December 1972 [Berne].

67 This is essentially a socio-legal approach, see: A Bradshaw "Sense and Sensibility: Debates and Developments in Socio-legal Research Methods" in Philip Thomas (ed) Socio-legal Studies (Dartmouth Publishing, Aldershot, 1997) 99.

${ }^{68}$ See John Baldwin and Gwynn Davis "Empirical Research in Law" in Peter Cane and Mark Tushnet (eds) The Oxford Handbook of Legal Studies (Oxford University Press, New York, 2003) 880.
} 
I have adopted a constructivist research paradigm, ${ }^{69}$ the thrust of which is that "reality is socially constructed." ${ }^{70}$ Constructivists generally use qualitative methods of data collection to determine the "participants' views of the situation being studied."71 Qualitative research is "a situated activity that locates the observer in the world" using interpretative approaches which make the world visible. ${ }^{72}$ Constructivist researchers tend to generate theory or "patterns of meaning" inductively during the research process. ${ }^{73}$

In terms of research methods, this research uses a case study, literature review, interviews and researcher observations:

\section{$1 \quad$ Single-case study}

This thesis intends to uncover whether the relationship between copyright law and development is discernible from how copyright law has (or has not) protected the Jamaican music industry. Case studies: ${ }^{74}$

...are the preferred strategy when "how" or "why" [research] questions are being posed, when the investigator has little control over events, and when the focus is on a contemporary phenomenon within some real-life context.

A single-case study is ideal when the subject matter has experienced only limited empirical study, and as such the case is revelatory. ${ }^{75}$ While it may be difficult to draw universally applicable conclusions, theoretical generalisations can be made. ${ }^{76}$ In order to strengthen the case study, multiples sources of evidence were used.

\footnotetext{
${ }^{69}$ A research paradigm is the interpretative framework or set of knowledge claims which shapes the researcher's approach to the research question and the collection, analysis and interpretation of data. Research paradigms also inform the overall intent, motivation and expectations for the research: Noella Mackenzie and Sally Knipe "Research Dilemmas: Paradigms, Methods and Methodology" (2006) 16 Issues in Educational Research 193.

${ }^{70}$ Donna Mertens Research Methods in Education and Psychology: Integrating diversity with Quantitative and Qualitative Approaches (2nd ed Sage, Thousand Oaks, 2005) at 12 and Michael Crotty The Foundations of Social Research (Allen \& Unwin, Australia, 1998) at 9 and 64.

${ }^{71}$ John Creswell Research Design: Qualitative, Quantitative and Mixed Methods Approaches (2nd ed, Sage, Thousand Oaks, 2003) at 8 [Creswell "Research Design"].

72 Norman Denzin and Yvonna Lincoln "The Discipline and Practice of Qualitative Research" in Norman Denzin and Yvonna Lincoln (eds) Handbook of Qualitative Research (3rd ed, Sage, Thousand Oaks, 2005 ) at 3.

${ }^{73}$ Creswell "Research Design", above n 68, at 9.

${ }^{74}$ Robert Yin Case Study Research: Design and Methods (3rd ed, Sage, Thousand Oaks, 2003) at 1.

75 Ibid, at 42 .

${ }^{76}$ Ibid, at 10 .
} 


\section{Document analysis}

I gathered documentary material from various sources. The Parliament library had a record of the Copyright Act's passage and public libraries ${ }^{77}$ kept folders of newspaper articles from the 1980s that catalogued the various debates and perspectives on the upgrading of the copyright legislation. Other institutions ${ }^{78}$ stored copies of economic studies and policy documents about the creative industries. Libraries ${ }^{79}$ possessed useful historical information about the cultural history of music and characteristics of the industry.

I was mindful that documentary materials are in many cases no less subjective or opinionated than non-documentary sources. ${ }^{80}$ For example, historical documents may not be literal record of events, reports were written to persuade its original readers and documents are subject to author bias in the selection and reporting of data.

\section{Interviews}

I conducted fieldwork in Jamaica during the period February - May 2011. The 57 stakeholders interviewed included:

- $\quad$ the drafter of the Copyright Act 1993;

- academics and researchers who specialise in local music, including a musicologist and an economist whose research specialisation is the economic impact of the music industry;

- policymakers and implementers (such as officials with the Ministry of Foreign Affairs and Foreign Trade, the Ministry of Youth, Sports and Culture, the Jamaica

\footnotetext{
77 The National Library of Jamaica and the St. Andrew Parish Library (Tom Redcam).

78 Planning Institute of Jamaica, Broadcasting Commission of Jamaica, Jamaica Promotions Corporation and Jamaica Intellectual Property Office libraries.

${ }^{79}$ Edna Manley College for the Visual and Performing Arts, Jamaica Information Service, Jamaica Tourist Board, African Caribbean Institute and Jamaica Cultural Development Commission libraries.

${ }^{80}$ See Lindsay Prior "Doing Things with Documents" in David Silverman (ed) Qualitative Research: Theory, Method and Practice (2nd ed, Sage, Thousand Oaks, 2004) 76.
} 
Promotions Corporation, the Jamaica Intellectual Property Office (JIPO) and the Broadcasting Commission of Jamaica);

- industry interest groups, collecting societies, rights holders (songwriters, singers, musicians, record producers), the media, industry entrepreneurs/insiders and other members of the entertainment industry;

- members of the judiciary and the legal profession (including a Supreme Court judge, an arbitrator, a criminal prosecutor of breaches of the Copyright Act, a lawyer with the Attorney-General Chambers and entertainment lawyers), the Organised Crime Investigation Division of the Jamaica Constabulary Force (who investigate breaches of the Copyright Act), the Jamaica Customs Department (which seizes bootleg music CDs and DVDs entering Jamaica); and

- $\quad$ private users of music, commercial users (such as radio stations), copyright infringers and librarians.

The Appendix lists the categories and characteristics of interviewees. I selected interviewees on the basis of their knowledge of and involvement with the copyright legal system and music. I located industry associations, collecting societies, and Government agencies through a variety of internet and telephone directory searches. Other respondents (for example, lawyers, judge and prosecutor) were found through my existing professional network. I sourced some interviewees through references from persons in my social network (for example, the drafter, trade negotiator, customs, rights holders, private users). I used the snowball technique in which I asked each respondent for three potential interviewees. My goal was to ensure a representation of multiple stakeholders. Care was taken to have interviewees with diverse positions, to lessen individual bias and provide more balanced views.

Most interviewees' names are omitted from the research findings. Experts in their fields all waived confidentiality in order to be cited as authorities in their areas of specialisation and research. Throughout the thesis, interviewees are either referred to by name or by the prefix 
" $\mathrm{R}$ " (for respondent) and then the number or letter ${ }^{81}$ assigned to them in the Appendix. Although a majority of interviewees opted for personal confidentiality, they consented to their organisation being named in the research. The caveat is that their views do not necessarily represent those of the entire organisation.

(a) Benefits and limitations of interviews

I asked open-ended questions in the semi-structured interviews I conducted. This allowed greater focus on stakeholders' experiences with the existing system as well as their perceptions about its effectiveness and thoughts about policy change. Non-leading, probing questions helped minimise researcher bias. One benefit of using semi-structured interviews is that I could ask follow-up questions to clarify and uncover implicit meanings within given answers to standardised questions. ${ }^{82}$

The privacy of interviews created a non-threatening, non-judgmental environment in which interviewees were free to express their views. My tone was kept deliberately conversational (instead of interrogatory) in order to encourage respondents to provide their opinions. Since misunderstandings can result from equivocal or evasive responses, my questions were sometimes rephrased and re-asked.

The veracity of interview findings can be affected by bias, which can occur in two ways. First, an interviewer's demeanour, tone, or phrasing of questions may suggest the interviewer is biased towards a certain response, which can then influence interviewee's answers. A biased interviewer can also presume interviewee's assumptions or misinterpret responses as supporting the researcher's biased view. Second, many respondents are not aware of the personal bias behind their responses.

I took care to mitigate these risks by being balanced in the tone and wording of questions and many respondents seemed acutely aware of their personal bias. For example, some clearly stated that their view was shaped by their role and the interests of the organisation they

\footnotetext{
${ }^{81}$ At participants' request, five interviews were conducted with two interviewees at the same time and in these cases, the interviewees share the same number but are assigned designations of "A" and " $B$ ".

${ }^{82}$ See Michael Salter and Julie Mason Writing Law Dissertations: An Introduction and Guide to the Conduct of Legal Research (Pearson Education, England, 2007) at 167.
} 
represented. ${ }^{83}$ Others, in presenting their opinions, also stated the dissenting view. ${ }^{84}$ Some interviewees openly acknowledged gaps in their knowledge ${ }^{85}$ and uncertainty about certain facts. ${ }^{86}$ I also asked interviewees to reflect on their reasons for holding certain views.

Interviewees can suffer from impaired memory, faulty recollections, poor articulation and partiality which can result in important omissions or inaccurate statements. Interviews are also particularly susceptible to interviewees and the interviewer privileging certain responses over others because of power differentials among interviewees. The view of those with greater social and political power can overshadow and exclude those with less power.

To address these issues, I ensured that stakeholders represented a cross-section of interests to lessen the likelihood of one perspective becoming dominant. Dominance of a single opinion did not become a problem because I discovered that even within a single category of stakeholder there were striking differences of opinion. ${ }^{87}$

Additionally, I utilised the process of triangulation ${ }^{88}$ in which multiple sources of information are used to clarify meaning. First, any distortion in findings from interviews was reduced by using primary documents found through archival research as well as a review of secondary materials. Second, I used the secondary data collected from interviewees (such as reports, studies, statistics, policy documents) to both establish chains of evidence which supported respondents' comments and to contextualise their claims. Third, I discovered that the findings from one interview were usually corroborated by other interviewees, and so, interviews could be used as a means of triangulating the data.

However, I am cognisant that recounting and recording past events: ${ }^{89}$

...[is] inevitably presentist and perspectival [in] nature. Total recall is neither possible nor desirable. The world (and the past)...always exceeds the facts, always requires choices to be

\footnotetext{
${ }^{83}$ Respondent [R] 29 (see the Appendix).

${ }^{84}$ For example, R-4.

${ }^{85}$ For example, R-49B.

${ }^{86}$ For example, R-49A.

${ }^{87}$ For example, rights holders R-3 and R-36 disagreed on whether piracy was harmful or helpful to the music business.

${ }^{88}$ See Robert Stake "Qualitative Case Studies" in Norman Denzin and Yvonna Lincoln (eds) Handbook of Qualitative Research (3rd ed, Sage, Thousand Oaks, 2005) at 443.

89 Ian Duncanson "Writing and Praxis: Law, History and the Postcolonial" (2003) 7 Law Text Culture 9 at 17.
} 
made by a positioned observer, who therefore has a responsibility to reflect on what that position is and why it is being occupied.

Without the interviews, I would have had very limited sources specific to Jamaica. Interviews allowed me to combine theoretical positions (evident from documentary review) with the practical workings of the copyright system. Interviewees provided first-hand accounts and observations, which, in many instances, were not documented elsewhere. In areas where documentary information did exist, interviews were used to complement, corroborate or challenge information in the primary documentary sources.

(b) The way in which interview data was used

Once the interviewing process was complete, the participants' feedback was comparatively analysed into groupings around broad and specific issues related to the research questions. Recurring themes were manually coded and grouped according to respondent.

In terms of probative value, the literature has argued that "information about social worlds is achievable through in-depth interviewing." 90 I have treated the data from interviews not as conclusive evidential statements or irrefutable facts but as evidence of the reality "on the ground"; a reality which has been shaped by the experiences of the various legal actors. This approach was consistent with the purpose of qualitative interviewing. The goal of qualitative interviewing is to use the data gathered to form explanations or offer theories to account for the observed phenomena from the interviewees' perspective. ${ }^{91}$

(c) Ethical considerations

Ethical approval was obtained from the Victoria University of Wellington Human Ethics Committee prior to conducting interviews. In discussions with legal professionals, care was taken to respect lawyer/client privilege. Copyright-infringing users were advised that self-

\footnotetext{
90 Jody Miller and Barry Glassner “The 'Inside' and the 'Outside': Finding Realities in Interviews" in David Silverman (ed) Qualitative Research: Theory, Method and Practice (2nd ed, Sage, Thousand Oaks, 2004) 125 at 126.

91 Herbert Rubin and Irene Rubin Qualitative Interviewing: The Art of Hearing Data (Sage, Thousand Oaks, 1995) at 4.
} 
incriminating information could be withheld and no information supplied would be shared with the authorities. Some sections of quotations used in the thesis have been redacted to protect the identity of confidential interviewees and third parties named therein. Interviews were digitally recorded and each interviewee was emailed a transcript of the interview and given an opportunity to correct errors or clarify statements.

\section{Direct observations}

My visit to Jamaica also meant I could observe relevant behaviours and environmental conditions. In several instances, for example, I was offered bootleg music CDs by street vendors in both rural and urban centres. I spent time in recording studios and saw how various rights holders interacted and collaborated in producing music and the way in which business dealings were conducted. I spent time at the criminal court and reviewed court records involving copyright infringement. Despite the disadvantage that behaviour can change due to persons' awareness of being observed, ${ }^{92}$ observational evidence provides an additional source of information and allows for a greater sense of context and reality.

\section{B Limitations and Concessions}

Since I am concentrating on copyright (and not on other aspects of IP), in one industry (the music industry) within a single country (Jamaica), my research findings does not represent the experience of developing countries generally or even of other copyright-based sectors in Jamaica. While the breadth of analysis is necessarily limited, this country and industryspecific approach does allow for a greater depth of analysis.

I also acknowledge that there are likely to be other non-copyright factors that affect Jamaica's socio-economic condition, including: macroeconomic policies, fiscal responsibility of decision makers, tax and investment climate, social and physical infrastructure, inflation, cost of living, health and education of population and availability of resources. It is outside the

\footnotetext{
${ }^{92}$ Robert Yin Case Study Research: Design and Methods (3rd ed, Sage, Thousand Oaks, 2003) at 86 and 92.
} 
scope of this study to address these in detail or ascribe weight to them in relation to the extent to which they hinder or promote development.

While this thesis has used the most recent statistical data available, the Jamaican music industry is largely an underground and informal sector. ${ }^{93}$ As such, the quantitative data accessible is limited.

\section{Chapter Summary}

This chapter gave the background to the research question, listed key questions and described how the thesis is structured to address those issues. It also explained the methodological approach used in this thesis.

This research examines Jamaican copyright law's influence on the development of local music industry, from the perspective of key stakeholders. This thesis will look at factors that shaped the creation of the domestic copyright law as well as the factors affecting its content and implementation, and determine whether there is scope for legal reform which would allow the copyright legislation to better facilitate development.

Utilising a case study allows first-hand accounts from multiple stakeholders to be combined with documentary material and direct observation. The thesis' use of historical and social narrative adds temporality and physicality to the body of literature on copyright and development.

The next chapter gives a detailed account of the historical and political influences behind the Jamaican Copyright Act 1993 as well as its intended consequences.

\footnotetext{
${ }^{93}$ Vanus James "The Economic Contribution of Copyright-based Industries to the Jamaican Economy" (WIPO Report, 2007) at 7.
} 


\section{CHAPTER TWO}

\section{THE EVOLUTION OF THE JAMAICAN MUSIC INDUSTRY AND ITS RELATIONSHIP WITH DOMESTIC COPYRIGHT LAW}

Those of us who view the law essentially as an instrument for the development of our own people, and related to the circumstances of our locality and our times, and a fundamental part of our problemsolving mechanisms, may well wonder how it is that in 1993, thirty-one years after our achievement of national status in Jamaica, our copyright legislation is still the United Kingdom Act of 1911. ${ }^{94}$

\section{Overview}

A major objective of the Copyright Act 1993 was to protect the local music industry in ways the pre-existing legislation, the Copyright Act $1911,{ }^{95}$ could no longer do. The cultural importance, commercial value and economic significance of this industry acted as a catalyst for the 1993 Act. Additional reasons extrinsic to the music industry also led to the Government adopting new copyright legislation. Considering both sets of factors (musicrelated and external influences) is critical for understanding the origins of the Copyright Act 1993.

This Chapter answers four main questions. First: what was the cultural, commercial and economic value of the music industry legislators considered worth protecting in 1993? By "cultural value" I am referring to the value attached to music's role in Jamaican culture. ${ }^{96}$ "Commercial value" centres on the financial returns for individual music industry rights holders. "Economic value" relates to the music industry's ability to benefit the national economy.

\footnotetext{
${ }^{94}$ Hansard, 27 January 1993 (Carl Rattray, Attorney-General).

95 The Copyright Act No. 46, December 1911 (UK, Imp).

${ }^{96}$ I am using the word "culture" to refer to both the "process of artistic creation" and "the sum total of the material and spiritual activities and products of a given social group which distinguishes it from similar groups": Rodolfo Stavenhagen "Cultural Rights: A Social Science Perspective” in Halina Niec (ed) Cultural Rights and Wrongs (UNESCO Publishing, Paris, 1998) 1 at 4-5.
} 
Second: why was the pre-existing copyright legislation considered inadequate? Third: how is recognition of the music industry's value reflected in the Copyright Act 1993? And fourth: what other factors prompted the enactment of the Copyright Act 1993?

\section{The Cultural Value of Jamaican Music}

The cultural value attached to music is evident in Parliamentarians' statements that recognised copyright's role in securing cultural value, for example:

This [Copyright] Bill is being presented at a time of heightened cultural activity; particularly in...popular music we are feeling a new dynamism. ${ }^{97}$

Jamaican music as a major creative force in this country is here to stay, and therefore must be looked at as...enduring phenomena for which proper provision should be made. ${ }^{98}$

The two aspects of music's cultural value are the traditional and the contemporary:

\section{A Traditional Cultural Value}

During the centuries of slavery, enslaved Africans in Jamaica used music as a salve against the adversities they experienced. African slaves from different linguistic and cultural backgrounds utilised music to create identity in various ritual, ceremonial, social and work contexts. ${ }^{99}$ Similarly, Respondent 50, a senior official with the Ministry of Youth, Sports and Culture (MYSC) made the following observation about the historical role of music in identity formation:

...Jamaican music has played [a role] historically in Jamaica's efforts at restoration of dignity and at the promotion of the integrity of our heritage...Music was of monumental value in developing...not only a culture of resistance but, even more so, cultural identification...There's a song that has biblical connotations: "By the Rivers of Babylon" and it...says: "They required of us a song, but how can we sing the Lord's song in a strange land?"...when the land became no longer strange and started becoming our own, we had to create the music to take control of the land. And so, the music played a very important role in

\footnotetext{
${ }^{97}$ Hansard 26 January 1993 (PJ Patterson, Prime Minister).

${ }^{98}$ Hansard, 27 January 1993 (Edward Seaga, Leader of the Opposition).

99 Olive Lewin "Traditional Music in Jamaica" (1983) 29 Caribbean Quarterly 32.
} 
that transitioning from the original identification with Africa to beginning, perhaps, to see ourselves as Jamaicans.

Music was not banned because slave plantation owners believed they could use music as a tool of social control and indoctrination. One academic interviewed noted: ${ }^{100}$

At Christmas time, the planter class... as a kind of safety valve to relieve tension...would allow parties. There was some religious influence, so that these parties, they wanted to curtail [the slaves' celebrations] in a particular kind of way. And in the whole history of building a people with "manners and civility", sometimes these parties were called "soirees".

While these two uses of music (identity formation and social conditioning) were at odds with each other during slavery, music took on increased importance when the slave trade was abolished. Respondent 50 elaborated:

We used [music] to survive. We sang while we worked, and even more so we made up songs in the barracks at nights...some of them were songs of resistance, some were songs of freedom. Some were songs of comfort and consolation. Some were just trivial, frivolous songs in which we played with each other...

Then the music provided a kind of...communal bonding within that arc of resistance that...started even from the moment we left Africa...that continuous acclimation and aggression and affirmation was embodied a lot in the music.

The music also provided some kind of escape. It provided a means for lament. So we had our sad songs, songs that came through like negro spirituals, songs of wailing...Then we had songs that we used to engage our children and teach values...

...you're seeing a people using musical culture to define themselves, to express their spirituality, to express their worldview, their cosmology, to express their sense of who they were and to construct a determination, to create that platform where their children in the midst of all that was going on could still have hope that one day they would survive.

For these early Afro-Jamaicans, music was not simply a form of entertainment but a way of life. One commentator emphasised the significance of the musical art form: ${ }^{101}$

For over 350 years Africans and their descendants were owned as property and worked by pain of force, without pay and hence without the means of passing on to their offspring the

\footnotetext{
${ }^{100}$ Interview with Sonjah Stanley-Niaah, University of the West Indies [UWI] Lecturer in Cultural Studies (11 May 2011) [Stanley-Niaah interview].

${ }^{101}$ Clinton Hutton "The Creative Ethos of the African Diaspora: Performance Aesthetics and the Fight for Freedom and Identity" (2007) 53 Caribbean Quarterly 127 at 127-128. See also: Rex Nettleford "The Arts and Post Colonial Certitude" (2007) 53 Caribbean Quarterly 1 at 1 noting that the arts "provided a route to redemption and certitude in coping with the obscenities of slavery, indentureship and the humiliation and dehumanization which those socio-economic systems imposed."
} 
material fruits of their labour...To a great extent, the enslaved coped with and resisted slavery and fashioned their being, their agency by embracing/becoming one personality and agency above any other, the artist.

This "artist" identity fuelled the earliest forms of Jamaican music which blended African and European forms. ${ }^{102}$

\section{B Contemporary Cultural Value}

Copyright policymakers also recognised music's contemporary socio-cultural role. Respondent 51, another high-ranking MYSC official, pointed out that:

At the Ministry we recognise that the creative industries holds extreme economic potential for Jamaica's development, as well as the significance of culture in social transformation and, therefore, we treat music and the creative industries in general along those two strands.

My research revealed different types of cultural values assigned to music in present-day Jamaica, including: constructing national identity, cultural identity, crime control, an antioppression tool, community-building, social mobility and dissemination of religious beliefs: ${ }^{103}$

\section{$1 \quad$ National identity}

Some stakeholders were of the view that Jamaican music "speaks to our national identity in the international market [and] our national identity at home." ${ }^{104}$ Witter $^{105}$ described music as part of our "Jamaican-ness." Stanley-Niaah ${ }^{106}$ noted that music is a feature of the way in which Jamaica has "become identified for the rest of the world." Respondent 40, a singer,

\footnotetext{
${ }^{102}$ For example, Mento was African in its performance mode, rhythmic impulse, its call and response singing pattern but European in its scale patterns, harmonic concept and verse and chorus structure: Rhythms: Jamaica's Heritage in Music and Dance (Jamaica Information Service, Kingston) at 1. Other traditional folk music included Dinki Mini/Gerreh, Pocomania and Kumina.

${ }^{103}$ See also: Michael Witter "Music and the Jamaican Economy" (UNCTAD/WIPO Report, 2004) at 3 and Vanus James "The Economic Contribution of Copyright-based Industries to the Jamaican Economy" (WIPO Report, 2007) at 11 (on the non-economic benefits of music).

${ }^{104}$ Interview with Andrea Davis, Creative Industries Brand Consultant and drafter of the Entertainment Sector Policy document (21 April 2011) [Davis interview].

${ }^{105}$ Interview with Dr. Michael Witter, UWI Lecturer and Economist (24 May 2011) [Witter interview].

${ }^{106}$ Stanley-Niaah interview.
} 
summed up the cultural role of music in these words: "Reggae really put Jamaica on the map." Therefore, creativity in music is one way to define what being Jamaican means. ${ }^{107}$

\section{Cultural identity of the socially oppressed}

Jamaican music is largely a product of the inner-cities and rural Jamaica. ${ }^{108}$ Respondent 40, a performer said:

The music is the cry of the poor. And it sings about their aspirations, their dreams, their hopes and their trials that they are going through. So it uplifts them spiritually.

One academic stated that music was integral to: 109

...the lives of ordinary working class Jamaicans who...used the music to express a lot of the challenges they have with their life, celebrate a lot of the things that are important, plan for and project fantasies of what they would like to achieve and how they plan to achieve it and really identify themes that are critical to their lives at that point in their history.

Music is thus an enduring component of affirming the cultural identity of the socially oppressed, in that "music becomes a way of finding a space and claiming power in the society." $" 110$

\section{A means of protest and crime control}

Music is also a safety value for relieving social pressure. Respondent 31 , a policymaker, remarked that:

We're very good at social commentary and I think one thing that the whole creative industry has done is to keep us sane, so it gives us an outlet so we don't have to have to go literally and pick up [fire]arms because we express ourselves through...music.

Respondent 50 also noted the link between music and crime reduction, calling music the:

\footnotetext{
107 See R-7.

108 Interview with Professor Carolyn Cooper, Reggae Studies Unit, UWI (13 April 2011) [Cooper interview].Cooper interview. See generally: Carolyn Cooper Sound Clash: Jamaican Dancehall Culture at Large (Palgrave Macmillan, New York, 2004).

109 R-16. See generally: Donna Hope Inna di Dancehall: Popular Culture and the Politics of Identity in Jamaica (University of the West Indies Press, Kingston, 2006).

${ }^{110}$ Cooper interview.
} 
...one product area where the greater percentage of those who are employed in it, whether self-employed or otherwise, are young people, vulnerable young men...who with a little nudge could become a criminal.

Through their involvement with earning from music people can "send their children to school but also, not pick up a gun in order to be a nuisance to that society and the nation." ${ }^{111}$ In this way, music is an instrument of social cohesion.

\section{Anti-oppression tool used globally}

The lyrical content of early Reggae music which became popular overseas had political overtones: ${ }^{112}$

[Reggae] was anti-imperialist. It was anti-colonial....there was so much counter-hegemonic nuance to Jamaican music...It was a tool for resistance. It was a tool of liberation.

Respondent 30 commented that "Reggae spoke to the downtrodden" in places like Eastern Europe and Africa. Respondent 22 identified the importance of Reggae in the anti-apartheid movement in South Africa and noted its value for "dislocated people."

\section{Building community}

In Jamaica, the community shares in making and consuming music. As an academic noted: ${ }^{113}$

[Music's value] is therefore tied up with...the need for community...the need for strengthening bonds of solidarity.

In particular, lower-income communities gain social profile through their participation in hosting music events. For these communities, music is "a way of affirming visibility." 114

\section{Social mobility for industry participants}

\footnotetext{
${ }^{111}$ Stanley-Niaah interview.

112 Interview with Dr. Dennis Howard, Musicologist, UWI Lecturer and Journalist (8 and 12 April, 2011) [Howard interview].

${ }_{113}^{113}$ Stanley-Niaah interview.

${ }^{114}$ Cooper interview.
} 
Some interviewees recognised music as a mechanism for upward mobility for songwriters, performers and musicians who gain a sense of status. ${ }^{115}$ For instance, Respondent 40, a singer, acknowledged:

$[\mathrm{M}]$ any Jamaicans...from poorer backgrounds, because of the music, have been able to elevate themselves and put themselves on a higher rung in the society.

Recording a song, hearing one's music on the radio or performing in shows is a kind of selfaffirmation: ${ }^{116}$

You're talking about some youth [who] don't have nothing...for them now to be counted that was more important to them than the economic benefits. The importance of being a "somebody", somebody who in your community everybody look up to you [was] a mindblowing experience for them.

Within the music industry itself, music can also be a tool for social equality among members: ${ }^{117}$

It is a tool for youth empowerment... gender empowerment. It is across the board, one of the most equalising tools we have in our arsenal.

\section{Religious propagation}

Reggae music was influenced by the African drumming patterns ${ }^{118}$ which are part of religious practice in Rastafarianism. ${ }^{119}$ Reggae was used to spread the Rastafarian ideology overseas: ${ }^{120}$

We see...Rastafari religion, developed in Jamaica, being strongly marketed globally through Reggae.

Respondent 50 strongly emphasised the significance of spiritual overtones that both drove the emergence of Jamaican music and permeated its content:

115 Cooper interview.

${ }^{116}$ Howard interview. See: R-22.

${ }^{117}$ Davis interview.

118 See Marcus Goffe "Exploring Ras Tafari Culture" (WIPO Magazine, April 2011) <www.wipo.int/wipo_magazine/en/2011/02/article_0008.html>

${ }^{119}$ Rastafarianism is a religious movement that began in Jamaica in the 1930s. See generally: Dennis Forsythe "West Indian Culture through the Prism of Rastafarianism" (1980) 26 Caribbean Quarterly 62 and Leahcim Semaj "Rastafari: From Religion to Social Theory" (1980) 26 Caribbean Quarterly 22.

120 Cooper interview. 
Rastafari played a central role in modern Jamaican culture...and therefore it's not accidental Bob Marley is out of that tradition and that through him that movement took off and Reggae music...and then when you look at the songs, it was all songs of, again, resistance, acclimation, affirmation:

"Buffalo soldier, dreadlocks Rasta, stolen from Africa,

fighting on arrival,

fighting for survival."

An academic observed: ${ }^{121}$

[T]here's a lot of that dialogue infused with, of course, the Rastafarian chants and the Rastafarian symbols that come out very strongly in Reggae music of the kind that is popularised by Bob Marley.

Having outlined the traditional and contemporary cultural value of music, it is worth investigating how the Copyright Act 1993 reflects this value.

\section{How Cultural Value is Reflected in the Copyright Act 1993}

Section 86 of the Copyright Act is the provision which recognises Jamaican music's cultural value by allowing for exceptions to copyright protection where works are used for national cultural events. Legislators did not wish to unduly limit the use of cultural works which are frequently recited, adapted and performed during annual festivals celebrating the end of slavery and political independence from England. ${ }^{122}$ A Member of Parliament stated: ${ }^{123}$

[I]n our culture, there are certain attributes which are uniquely ours and we should attempt to use them as such...consider for example...at Festival time, Independence time...there are people....who have to do certain things and take certain excerpts perhaps, from works that really are not theirs.

\footnotetext{
$121 \mathrm{R}-16$.

122 R-15.

${ }^{123}$ Hansard, 26 January 1993 (AJ Nicholson, Parliamentary Secretary in the Ministry of Education and Culture). See also: Ministry Paper No 5 of 1993 at 61.
} 
Section 86(1) enables the Minister to make an order that the copyright in a work is not infringed where, in relation to such work, permitted acts stipulated in the order are done in the circumstances so specified. ${ }^{124}$ Sub-section 2 says:

(2) The Minister shall not make an order under subsection (1) unless he is satisfied that the acts specified in the order in relation to the work-

(a) are necessary in the public interest in connection with an event of national importance;

(b) would not conflict with the normal exploitation of the work; and

(c) would not unreasonably prejudice the legitimate interest of the owner of the copyright in the work.

Section 86(3) safeguards rights holders' interests by providing that an order made under subsection (1) must make provision for the payment of equitable remuneration to the copyright owner to be determined, in default of agreement, by the Copyright Tribunal. ${ }^{125}$

\section{The Commercial Value of the Music Industry}

Music's importance is not restricted to its cultural value. Parliamentarians also recognised the commercial value of the monetary returns generated by the music industry. For instance, during the Parliamentary debates, the then Prime Minister commented that: ${ }^{126}$

Reggae has penetrated the four corners of the world, and Reggae festivals are the order of the day on every Continent...we must put in place a law that facilitates the establishment in Jamaica of a copyright system in the interest of present and future creative people and those who through their entrepreneurial and managerial skills assist them to disseminate their creative work.

Respondent 31, a Government lawyer, gave an insight into why Parliamentarians were focussed on the commercial aspect of the music industry:

[T] here is a recognition basically at the level of the Parliament, which is where the legislation would have passed, of the importance of copyright because...[Parliamentarians] Edward

\footnotetext{
${ }^{124} \mathrm{I}$ could not find a record of an order made under s 86.

125 The compatibility between s 86 of the Copyright Act and art 13 of TRIPS is discussed in Chapter 5.II.A.3(b).

${ }^{126}$ Hansard 26 January 1993 (PJ Patterson).
} 
Seaga who was Prime Minister of Jamaica at one period, ${ }^{127}$ Olivia 'Babsy' Grange, ${ }^{128}$ P.J Patterson, ${ }^{129}$ all of these persons have been involved in intellectual property in different aspects of it and in the music industry to a large extent.

Lawmakers' assessment of Jamaica's copyright legislation actually began three decades before the Copyright Act 1993, and was strongly connected to the commercial success of the music industry. ${ }^{130}$ The financial returns of the 1970s, combined with the lobbying efforts of members of the music industry, directly influenced the passage of the 1993 Act. The next section divides the music industry into chronological stages and looks at how the historical evolution of the music industry affected the operation of copyright legislation in the 20th century and eventually shaped the Copyright Act 1993.

\section{A Background to the Jamaican Music Industry and Its Interaction with Copyright Law}

\section{$1 \quad$ Pre-industry evolution: the Copyright Act 1911}

The Copyright Act of 1911 of the United Kingdom (UK) ${ }^{131}$ (1911 Act) abolished common law rights in copyright that existed in Jamaica. ${ }^{132}$ The law was the first copyright statute in Jamaica and came into operation in 1912 by virtue of a proclamation. In 1913, the Jamaican Parliament enacted supplementary legislation ${ }^{133}$ to specifically incorporate the provisions of the 1911 Act which dealt with copyright offences. ${ }^{134}$

\footnotetext{
${ }^{127}$ Founder of the West Indies Recording Limited, which issued songs by local performers.

${ }^{128}$ Former manager of Reggae acts, Leroy Sibbles and Carlene Davis.

${ }^{129}$ Former manager of the Ska band, The Skatalites.

${ }^{130}$ Hansard, 27 January 1993 (Edward Seaga) and R-14.

131 The Copyright Act No. 46, December 1911 (Imp) consolidated and upgraded England's law in adherence to the standards of international copyright protection found in the Berlin Revision of the Berne Convention in 1908, by granting rights holders control over the mechanical reproduction of their literary and musical works. After Jamaica's political independence, this Act continued to be applicable in Jamaica by virtue of the Jamaica Constitution Order in Council, 1962 which preserved all laws which were in force immediately prior to Independence.

132 Copyright Act 1911, s 31.

133 The Copyright Act No. 12, 1913 which dealt mainly with penalties. The statutory fines for criminal offences remained fixed over the years, despite inflation.

${ }^{134}$ Without such supplementary legislation, the offences would only have been applicable to the UK.
} 
The level of enforcement of the 1911 Act was low. This was partly because the 1911 Act was "directly imposed upon Jamaica and ... thus not shaped or influenced by cultural traditions or lobbying interests." 135 Although not discriminatory in terms of the kinds of creators who merited protection, a common perception among industry members and lawmakers was that the 1911 Act was primarily advantageous to foreign copyright owners: ${ }^{136}$

[The 1911 Act] was not set up for indigenous people, because at that point, nobody was doing any significant amount of composition, which was even being recognised, so it was an extension of protection for British composers and songwriters and people who had copyrighted material.

Given the relatively few copyright owners in Jamaica during the early 20th century, copyright protection, arguably, could be viewed as historically benefitting only the minority elite within the social strata. In support of this view, one industry stakeholder noted that: ${ }^{137}$

Because we came from a plantocracy, where the laws were basically designed to protect the planter class, there were always laws in place that would ensure the protection of rights because the rights...your ability to say that this is yours and you are the owner of this, is what differentiated you from the persons who had no rights.

There was a general lack of knowledge among rights holders about the existence and content of the 1911 Act. Certain groups in particular, such as songwriters, musicians and vocalists, were not very knowledgeable about their rights:

Jamaicans in general, and musicians in particular, were not broadly aware of the meaning, much less the legal intricacies, of their copyrights. Even when producers did follow the law, they were able to take advantage of artists' ignorance and coerce them into assigning away their rights for minimal compensation. ${ }^{138}$

We [Jamaica] had this weird system of a Copyright Act which was never enforced, because while it was there nobody knew about it, especially in the music industry, apart from some of the producers. ${ }^{139}$

\footnotetext{
135 Johnson Okpaluba “"Free-riding on the Riddim?' Open source, Copyright law and Reggae music in Jamaica" in Lionel Bently, Jennifer Davis and Jane Ginsburg (eds) Copyright and Piracy: An Interdisciplinary Critique (Cambridge University Press, New York, 2010) 374 at 376.

${ }^{136}$ Howard interview. See also: Hansard, 27 January 1993 (per Carl Rattray).

${ }^{137} \mathrm{R}-31$

${ }^{138}$ Carter Van Pelt "Toward a Conventional Copyright System: The Jamaican Experience with Rights Management and a New Law" (Master of Arts dissertation, Columbia University, 2006) at 7.

${ }^{139}$ Howard interview.
} 
Although the 1911 Act offered a reasonable measure of protection, ${ }^{140}$ rights holders' ignorance about their rights caused them to conclude that the Act was inimical to their interests. $^{141}$

It was in this legal environment that the local music industry began to grow:

\section{Stage one: adoption of American Rhythm \& Blues (1940s - 1956)}

By the 1930s, Mento and other forms of traditional folk music had declined in popularity among Jamaicans living in cities. ${ }^{142}$ With the increased migration to urban centres, the masses wanted to disassociate themselves from traditional music considered too reminiscent of their rural origin. ${ }^{143}$ Initially, the popular music market in Jamaica was dominated by African-American Rhythm and Blues (R\&B). ${ }^{144}$ R\&B was first introduced in the 1940 s by Jamaican migrant labourers who returned from cutting sugar cane in the south of the US. These workers brought back R\&B music from the Mississippi Delta region. ${ }^{145}$ Commercial radio broadcasting did not begin in Jamaica until $1950^{146}$ but at the time R\&B was considered inappropriate for public airplay. ${ }^{147}$

\footnotetext{
${ }^{140}$ Hansard 27 January 1993 (Edward Seaga) and Beverley Pereira "A Regional Approach to the Management of Copyright in the Caribbean Community" (PhD thesis, Queen Mary, University of London, 2009) at 72.

${ }^{141} \mathrm{R}-15$. See also: R-49.

${ }^{142}$ Folk music was still played by local live bands on the hotel circuit for tourists or in exclusive night clubs frequented by the upper-middle class: Daniel Neely "Calling All Singers, Musicians and Speechmakers: Mento Aesthetics and Jamaica's Early Recording Industry" (2007) 53 Caribbean Quarterly 1 at 5-8.

${ }^{143}$ Kevin O'Brien Chang and Wayne Chen Reggae Routes: The Story of Jamaican Music (Temple University Press, Philadelphia, 1998) at 24. R-16, a cultural studies researcher, said Mento was "very agrarian, very rural, using a lot of instrumentation that was... mainly homemade." This musical form is characterised by the accented fourth (final) beat of each bar and was used by gangs of field labourers to ensure a strong downward movement of their pickaxes on the first beat of each bar. A strong upward movement on the previous beat (final beat of the previous bar) was required to do so.

${ }_{144}^{144}$ Hansard, 27 January 1993 (Edward Seaga).

${ }^{145}$ Kevin O'Brien Chang Jamaica Fi Real: Beauty, Vibes and Culture (Ian Randle Publishers, Kingston, 2010) at 98. Reasons for the Jamaican audience's preference for Rhythm and Blues [R\&B] include: the common slavery heritage, similar social changes caused by urbanisation and relaxed style of the R\&B rhythm.

${ }^{146}$ Alma Mock Yen Rewind: My Recollections of Radio and Broadcasting in Jamaica (Arawak Publications, Kingston, 2002) at 40.

${ }^{147}$ The local radio station, Radio Jamaica and Rediffusion (RJR) had a strong bias for Classical and Country and Western music: Michael Witter "Music and the Jamaican Economy" (UNCTAD/WIPO Report, 2004) at 4-5.
} 
Sound systems were developed to meet the need for local audiences to hear R\&B music. A sound system is essentially a large, portable discotheque or: ${ }^{148}$

...an electronic mode of playing for mass entertainment, units of pre-recorded music analogically stored on gramophone or phonograph records spun on a turntable connected to an amplifier, from which an assemblage of speakers...are attached.

Because the cost of hiring a live band for events or owning a radio or personal playback devices was prohibitive for many lower income Jamaicans, ${ }^{149}$ sound systems acted as record players for entire communities and were used by business owners to attract customers to their stores. ${ }^{150}$ Having their own source of power (batteries or portable generators) ${ }^{151}$ meant that sound systems could be played across the island in places that did not have regular electricity supply.

In vying for popularity among their live audiences, sound system operators engaged in practices that "would make all persons interested in copyrighting shudder." 152 To ensure exclusivity and increase competitiveness, a common tactic of sound system operators was to remove or obscure the labels of $\mathrm{R} \& \mathrm{~B}$ records obtained from the US (to make the names of the song and the artiste unidentifiable $)^{153}$ and giving them Jamaican titles. Some sound system owners also had record distribution businesses and would sell these popular records (with their acquired Jamaican names) to the local market. ${ }^{154}$

Jukeboxes, introduced in the early 1950s, also played a developmental role in the early years of the Jamaican popular music industry. Jukeboxes, ubiquitous in rum bars, shops and restaurants, allowed recorded music to be accessible and cheaply available to the masses. Citing the significance of the jukebox, Howard considers it "a major tool in the promotion,

\footnotetext{
148 Clinton Hutton "Forging Identity and Community Through Aestheticism and Entertainment: The Sound System and the Rise of the DJ" (2007) 53 Caribbean Quarterly 16 at 17.

${ }^{149}$ See Lloyd Bradley Reggae: The Story of Jamaican Music (BBC, London, 2002) at 25-26.

${ }^{150}$ Garth White "The Evolution of Jamaican Music Part I: Proto-Ska to Ska" (1998) 47 Social and Economic Studies 5 at 13.

${ }^{151}$ Clinton Hutton "Forging Identity and Community through Aestheticism and Entertainment: The Sound System and the Rise of the DJ" (2007) 53 Caribbean Quarterly 16 at 19.

${ }^{152}$ Hansard, 27 January 1993 (Edward Seaga).

${ }^{153}$ See Norman Stolzoff Wake the Town and Tell the People: Dancehall Culture in Jamaica (Duke University Press, Durham, 2000) at 51.

${ }^{154}$ Hansard, 27 January 1993 (Edward Seaga).
} 
socialization, camaraderie and cultural hybridity in the formative years of the Jamaican music industry."155

\section{Stage two: replication/imitation of American $R \& B(1956-1960)$}

The next stage of the Jamaican music industry was imitation, ${ }^{156}$ precipitated by a decline in the production of R\&B music in America as Rock N' Roll gained popularity. Rock N' Roll did not find favour with Jamaican audiences, ${ }^{157}$ but sound system operators no longer had a large pool of R\&B music at their disposal. Gooden summarised how this dilemma was solved: ${ }^{158}$

The first person to act was Edward Seaga, who would go on to become Prime Minister of Jamaica. In 1958 he found[ed] WIRL - West Indian Records Limited - and began releasing records by local artists. They were blatant copies of American music, but that barely mattered; they were new and playable on the sound systems...within twelve months both Reid and Dodd [sound system owners], seeing the possibility of having records available exclusively on their systems, had jumped on the bandwagon with the Treasure Isle and Studio One labels, respectively. And once a pressing plant, Caribbean Records, had been established on the island (meaning the masters159 no longer had to be shipped to America for pressing), the Jamaican recording industry was well and truly born.

Record producers recorded songs on soft acetate on dub plate machines ${ }^{160}$ with the intention of playing them on their sound systems. However, by the close of the 1950s record producers were pressing vinyl discs for public consumption. ${ }^{161}$ Eventually, the systems for distributing

\footnotetext{
155 Dennis Howard "Punching for Recognition: The Juke Box as a Key Instrument in the Development of Popular Jamaican Music" (2007) 53 Caribbean Quarterly 32 at 37.

${ }^{156}$ See Jason Toynbee "Reggae Open Source: How the Absence of Copyright Enabled the Emergence of Popular Music in Jamaica" in Lionel Bently, Jennifer Davis and Jane Ginsburg (eds) Copyright and Piracy: An Interdisciplinary Critique (Cambridge University Press, New York, 2010) 357 at 364 calling this process "translation" of musical style through adopting similar vocal registers, voice quality, accompaniment and production values. Toynbee considered it not simply a passive process of copying but a "development of musical codes into new areas of semiotic possibility" (page 364).

157 Kevin O'Brien Chang and Wayne Chen Reggae Routes: The Story of Jamaican Music (Temple University Press, Philadelphia, 1998) at 25.

${ }^{158}$ Lou Gooden Dancehall Sound Systems: The Good, The Bad and The Ugliest (manuscript, 2011, book forthcoming) at 349.

${ }^{159}$ A master recording is the recording that embodies the musical performance of a recording artiste from which phonograph records can be manufactured.

${ }^{160}$ Howard interview.

161 John McMillan “Trench Town Rock: The Creation of Jamaica's Music Industry” (unpublished paper, Graduate School of Business, Stanford University, June 2005) at 7.
} 
records became more organised ${ }^{162}$ as entrepreneurs saw the potential to earn from sales to the local Jamaican market and export to markets such as America and England. ${ }^{163}$

The songs recorded in Jamaica at that time, even though they had an indigenous element, ${ }^{164}$ largely mimicked British pop, Blues, Jazz and R\&B. ${ }^{165}$ For example, local groups not only copied the vocal styles of American groups ${ }^{166}$ (which is permissible in copyright law) but also the melody and lyrics, which were protected under copyright law:

The [Jamaican music] industry developed by mirroring another industry...the American records that were coming down to Jamaica and...the first recordings that were done in Jamaica was sing-overs...We developed a system of piggybacking and copying and making our own versions. ${ }^{167}$

There are those who would argue that the Jamaican music industry was built on piracy. In the pre-Ska period a lot of the local hits were Jamaican versions or...what we call "lick overs" of popular American Blues, R\&B hits. ${ }^{168}$

British and American publishers were either unaware of the copyright infringement or unconcerned about cover versions given the small size of the domestic music market. ${ }^{169}$ Their lack of enforcement of the copyright regime allowed the practice of imitation to thrive and helped the local music industry to grow: ${ }^{170}$

Because a lot of the people were not trained in performance and recording... what they did was to learn from the American songs, from the British songs and that's how they developed their writing skills...they used the records and imitated them, learned harmonies, two-part, threepart, four-part harmonies.

\footnotetext{
162 Ibid.

${ }^{163}$ See Howard Campbell "Chris Blackwell and the Internationalisation of Reggae" (2010) 33 Jamaica Journal 36.

${ }^{164}$ See Garth White "The Evolution of Jamaican Music Part I: Proto-Ska to Ska" (1998) 47 Social and Economic Studies 5 at 14 and 17.

${ }^{165}$ See Stephen Foehr Waking up in Jamaica (Sanctuary, London, 2002) 217-218.

${ }^{166}$ Howard interview: "a lot of people don't even realise that part of "One Love" was taken from a song called "People Get Ready" by Curtis Mayfield, because the Wailers fashioned themselves in terms of their harmonies and their presentation, off The Impressions. So groups like The Temptations, the Impressions, The Drifters, The Platters, all of these guys were imitated by our Jamaican artistes, because that was their reference point."

${ }^{167}$ Interview with Joan Webley, Entertainment lawyer and Board Member of the Jamaica Reggae Industry Association (Kingston, 4 April 2011) [Webley interview].

${ }^{168}$ Interview with Natalie Corthésy, University of the West Indies (UWI) Lecturer in Law, founder of Jamaica Anti-Piracy Alliance and former policymaker (Kingston, 14 April 2011) [Corthésy interview].

169 See Dennis Howard “Copyright and the Music Business in Jamaica- Protection for Whom?” (2009) IX Revista Brasileira do Caribe 503 at 506-507.

${ }^{170}$ Howard interview.
} 
The result is that during this period, as the music industry evolved, Jamaican artistes benefitted from (and became accustomed to) essentially uninhibited use of the work of foreign authors. ${ }^{171}$

\section{Stage three: innovation/copyright infringement: $(1960-1970$ s)}

Eventually, the Jamaican audience tastes changed. They considered the locally recorded imitations to be unauthentic, watered-down copies of the original R\&B sound. ${ }^{172}$ Gooden observes: ${ }^{173}$

Jamaicans were ready for something new. The home-grown copies of R\&B just didn't have the punch of the originals. "We were trying to imitate" noted singer Derrick Morgan, "but when we did it, it wasn't real."

To satisfy their consumers, record producers sought to make the sound more Jamaican and experimented with various sounds as they covered foreign songs without permission or crediting the authors. ${ }^{174}$ The blending of influences such as indigenous religious musical expressions $^{175}$, Mento ${ }^{176}$ and Rastafarian Drumming ${ }^{177}$ created Ska ${ }^{178}$, a distinctively

171 Carter Van Pelt "Toward a Conventional Copyright System: The Jamaican Experience with Rights Management and a New Law" (Master of Arts dissertation, Columbia University, 2006) at 7. See Dick Hebdige Cut N'Mix: Culture, Identity and Caribbean Music (Routledge, London, 1987) noting that there was a relaxed attitude to musical ownership in Jamaica.

172 See Kevin O'Brien Chang and Wayne Chen Reggae Routes: The Story of Jamaican Music (Temple University Press, Philadelphia, 1998) at 25: "most early Jamaican records sound like second-rate imitations...Because of limited resources and outdated equipment, Jamaican producers were never able to precisely duplicate the foreign sound."

${ }^{173}$ Lou Gooden Dancehall Sound Systems: The Good, The Bad and The Ugliest (Manuscript, 2011, book forthcoming) at 351.

${ }^{174}$ Dennis Howard “Copyright and the Music Business in Jamaica- Protection for Whom?” (2009) IX Revista Brasileira do Caribe 503 at 512.

${ }^{175}$ Such as Kumina, Revival and Pocomania.

${ }^{176}$ See Robert Witmer “Kingston’s Popular Music Culture: Neo-colonialism to Nationalism” (1989) 22 Jamaica Journal 11.

${ }^{177}$ A technique using buru drums known as Nyabinghi drumming: see R-16, R-50 and Howard interview. The misappropriation of traditional cultural expressions (TCEs) by domestic non-members of the Rastafarian and Maroon traditional communities aided the evolution of the local music industry. Excessive protection of these traditional expressions would have restricted creativity in the Jamaican music industry, see: R-15. See generally: Marcus Goffe "Protecting the Traditions of the Maroons and Rastafari: An Analysis of the Adequacy of the Intellectual Property Laws of Jamaica and Proposals for Reform" (2009) 6 SCRIPTed 575.

${ }^{178} \mathrm{Ska}$ is a musical form in which the drums come on the second and fourth beats with the guitar emphasizing the second, third and fourth beat. See generally: Clinton Hutton "The Social and Aesthetic Roots and Identity of Ska: Interview with Garth White" (2007) 53 Caribbean Quarterly 81. 
Jamaican vocal aesthetic. Ska gave way to Rocksteady ${ }^{179}$ in 1966 and eventually to Reggae ${ }^{180}$ in 1968 and Dancehall music ${ }^{181}$ in the late 1970s. Local artistes, voices of the new sound, such as Millie Small ${ }^{182}$, The Skatalites, Bob Marley and the Wailers, Bunny Wailer, Peter Tosh and Jimmy Cliff grew in prominence.

During this period of heightened creativity, members of the music industry carried out various activities that had implications for copyright protection: collaboration and competition; record producers' and publishers' practices in breach of copyright; and rights holders' innovations:

(a) Collaboration and competition

During this period, non-enforcement of the Copyright Act 1911 was widely accepted. Toynbee's research found that: ${ }^{183}$

Since 1960 a highly innovative form of music making has developed in Jamaica in the effective absence of copyright...Reggae music would never have emerged had copyright been implemented...local forms of creativity and the nature of the musical labour process were inimical to intellectual property.

This process of producing a new genre or an indigenous sound has been called "intensification" 184 , in which creation was a communal process, in an "open domain environment." 185 The musicologist described the music industry as "an organic movement

\footnotetext{
${ }^{179}$ Rocksteady introduced the electric base, a slower pace and complex chord progressions: Howard interview.

${ }^{180}$ A sound marked by an emphasis on the third beat, " Reggae it is almost a minimalist kind of music, because there was the emphasis on strictly drum and base and piano... embellishment with horns and organs and... stuff came after": Howard interview.

${ }^{181}$ Dancehall music is essentially a musical genre characterised by deejays "toasting over a rhythm": see Donna Hope "Dancehall: Origins, History, Future" in Groundings (St. Michael's Theological College, Kingston, July 2011) at 7.

${ }^{182}$ Jamaica's first Ska song to become a hit in the international market was Millie Small's "My Boy Lollipop" which was a cover of a song by American Barbie Gaye: R-16. The song was produced in England, sold 6 million copies worldwide and made the US and UK top 10 charts.

${ }^{183}$ Jason Toynbee "Reggae Open Source: How the Absence of Copyright Enabled the Emergence of Popular Music in Jamaica" in Lionel Bently, Jennifer Davis and Jane Ginsburg (eds) Copyright and Piracy: An Interdisciplinary Critique (Cambridge University Press, New York, 2010) 357 at 357.

184 Jason Toynbee Bob Marley: Herald of a Postcolonial World? (Polity, Cambridge, 2007) 87- 94.

185 Dennis Howard “Copyright and the Music Business in Jamaica- Protection for Whom?” (2009) IX Revista Brasileira do Caribe 503 at 512.
} 
with like-minded people working together in the same space and coming up with a sound." 186 Music was played by one person, adopted by another, so that "after a while nobody remembers who did initiate it or anything." 187

Notwithstanding the collaboration among musicians, performers and songwriters in the creative process, this period was also marked by intense competition among record producers. Producers' primary objective was to have a hit when their sound systems played for the crowds and to be first to the market ${ }^{188}$ with the most well-liked songs. Songs were debuted and tested for crowd appeal in the dancehall and only the popular ones were released for sale in the retail record market. ${ }^{189}$ The issue of copyright protection was tangential as producers were less concerned about preventing others from using their product over the long term. ${ }^{190}$ A respondent recounted an incident which illustrates record producers' rivalry as well as their lack of concern about copyright:

Derrick Harriott [a singer] recorded "Lollypop Girl" for Coxsone['s record label and sound system]. Coxsone used it for a very long time to beat Duke Reid['s sound system in the dancehalls] and then Duke Reid got a copy of it. There's a story that Duke Reid saw Derrick Harriott, accosted him, drape him up [collared him], and he had to give him the song. So after that when Duke Reid played the song to conquer Coxsone, Coxsone abandoned the song. And then a year or two later, Duke Reid...recorded the song "Lollypop Girl" and it came out on the Technique Label.

(b) Record producers' and publishers' practices in violation of copyright

Local record producers, stage show promoters and publishers also engaged in exploitative practices in violation of creators' copyright:

186 Howard interview.

187 Ibid.

188 See Michele Boldrin and David Levine "The Economics of Ideas and Intellectual Property" (2005) 102 Proceedings of the National Academy of Sciences 1252 on the first-mover advantage.

189 The Dancehall session is a feedback loop between producers and consumers: Lloyd Bradley Reggae: The Story of Jamaican Music (BBC Publications, London, 2002) at 26-28.

190 Jason Toynbee "Reggae Open Source: How the Absence of Copyright Enabled the Emergence of Popular Music in Jamaica" in Lionel Bently, Jennifer Davis and Jane Ginsburg (eds) Copyright and Piracy: An Interdisciplinary Critique (Cambridge University Press, New York, 2010) 357 at 362. 
- Producers exploited songwriters', singers' and musicians' general misunderstanding about copyright by having these creators assign their rights to them without adequate compensation. ${ }^{191}$ Respondent 22 recalled:

Back in the 60s and 70s...records used to sell and record companies used to make a lot of money pressing $45 \mathrm{~s}$ and albums, and so, they would make millions...[Producers] were able to get lawyers and they learnt, they knew the [copyright] system and they kept [knowledge] back from us...And they let a lot of the musicians and performers who were semi-literate sign some bogus contracts.

- Because of the oversupply ${ }^{192}$ of new artistes trying to break into the music market, singers and songwriters had diminished bargaining power and received one-off payments instead of royalties: ${ }^{193}$

Big music houses...would have artistes come into the studio [who] would be paid a day's wages or a week's wages...and that was it. And the question was never asked: "well, what are my copyrights? Am I going to be attributed with any credits? Is it just my $\$ 50$ at the end of the week?"... "whose rights? Who to sue? Is this criminal activity?" No one is asking about infringement and these things.

According to a cultural studies academic: ${ }^{194}$

[T] he creators of most of the Jamaican music...were not really accessing... the kind of information that did exist [that] could have given them an opportunity to understand the value of what they were producing and how to protect it... they had no idea that the value that they were creating was something that could go beyond the one-shot payment of a couple shillings that the promoter or the producer would hand to them and then take their cultural creation and replicate it in multiple times...in multiplicities for benefit.

- Producers often claimed song writing credits for an artiste's work, which affected royalties the artiste received when their work was used overseas: ${ }^{195}$

${ }^{191}$ See Johnson Okpaluba "'Free-riding on the Riddim?' Open source, Copyright law and Reggae music in Jamaica" in Lionel Bently, Jennifer Davis and Jane Ginsburg (eds) Copyright and Piracy: An Interdisciplinary Critique (Cambridge University Press, New York, 2010) 374 at 376-377.

192 Jason Toynbee "Reggae Open Source: How the Absence of Copyright Enabled the Emergence of Popular Music in Jamaica" in Lionel Bently, Jennifer Davis and Jane Ginsburg (eds) Copyright and Piracy: An Interdisciplinary Critique (Cambridge University Press, New York, 2010) 357 at 362.

${ }^{193}$ Corthésy interview.

${ }^{194} \mathrm{R}-16$. See also: R-27.

195 R-22. 
So when you wrote a song what the old time producers used to do, because they knew the system... they would put their names on the record as co-writer with you or sometimes they just stole it outright.

- Publishing companies took a bigger share of ownership of rights than authors: ${ }^{196}$

[Creators] used to sign away a lot of their rights also by giving...publishing companies, the right to use their music and that was also bad. Publishing companies would...take $90 \%$ and give them $10 \%$ of the royalties.

Producers justified these practices on the basis that they undertook the financial costs of recording the songs without a guarantee that the record would be successful or allow them to recoup their investment. ${ }^{197}$ Performers, songwriters and musicians largely accepted these practices because of non-economic motivations, such as attaining fame, status in the community and being recognised as "somebody": 198

People started to write original songs not because they wanted money from copyright but because they wanted to get a hit or become popular in the dancehalls. The economic motivation was very limited. Motivation included getting recognised, becoming a star.

Furthermore, the prospect of future royalties was less attractive to authors than receiving immediate payments from promoters, publishers and producers, which met pressing financial needs. ${ }^{199}$

(c) Music industry innovations

During this period, Jamaican music rights holders created innovations, which were instrumental in developing Jamaica music but inconsistent with copyright law, the riddim, the version and dub:

(i) Riddims

The technical definition of a riddim is: ${ }^{200}$

\footnotetext{
${ }^{196}$ R-22.

${ }^{197}$ Howard interview.

${ }^{198}$ Howard interview.

${ }^{199}$ Howard interview.
} 
[A]n autonomous accompanimental track, typically based on an ostinato (which often includes melodic instrumentation as well as percussion)...the riddim is not exclusive to [one] song but is typically used in many other songs.

Respondent 20 explained:

A riddim is basically the music bed on which a particular...vocal work is done...the music bed is created, somebody comes and sings a song on it, somebody else comes and sings a song on that same music bed...

The musicians who created the musical bed or riddim were not paid royalties for the subsequent use and adaptation of their work. Riddims were developed by producers as a costsaving measure ${ }^{201}$, given the high cost of hiring and paying musicians for every session: ${ }^{202}$

The [producer] realise that enough returns weren't coming from the recordings anymore... let's say the [studio] musician is earning [J]\$5,000 for each song that he plays on. Ten musicians is ten $5[000$ dollars]...The [producer] work out that after him spend that ten $5[000$ dollars], him record everybody on the same rhythm, so him don't have to go back to make it again.

Producers not only repeatedly used riddims to accompany the lyrics written by various songwriters and the vocals of numerous performers, but utilised other producers' riddims without remuneration: ${ }^{203}$

It was not a problem for me to give another guy [producer] my riddim to put some songs on it, although we know the copyright implications but it is more a social, creative kind of dynamics more than just the mere economic situation.

One reason producers shared their riddims was for heightened profile within the musical community. ${ }^{204}$ Other instruments could be added to riddims and the work renamed by other producers.

\footnotetext{
${ }^{200}$ Peter Manuel and Wayne Marshall "The Riddim Method: Aesthetics, Practice, and Ownership in Jamaican Dancehall" (2006) 25 Popular Music 447.

${ }^{201}$ See Johnson Okpaluba “'Free-riding on the Riddim?' Open source, Copyright law and Reggae music in Jamaica" in Lionel Bently, Jennifer Davis and Jane Ginsburg (eds) Copyright and Piracy: An Interdisciplinary Critique (Cambridge University Press, New York, 2010) 374 at 380.

${ }^{202} \mathrm{R}-30$ and R-49B.

${ }^{203}$ See Joshua Chamberlain "So Special, So Special, So Special: The Evolution of the Jamaican 'Dubplate"” (2010) 33 Jamaica Journal 20 at 22.

204 'Producers who owned hit 'riddims' saw the 'licking over' (cover) of his/her riddim as a sign of respect of the quality of the work, which afforded bragging rights among his/her peers": Dennis Howard "Copyright and the Music Business in Jamaica- Protection for Whom?” (2009) IX Revista Brasileira do Caribe 503 at 514.
} 
In the 1960s, versions (or remixes) ${ }^{205}$ became standard industry practice. Versioning is a process in which a new song is created by combining the major melodic and rhythmic features of an original song with new lyrics, without necessarily compensating or crediting the original creator. ${ }^{206}$ The musicologist explained versioning's origin: ${ }^{207}$

If we never had a weak copyright structure versions couldn't be a phenomenon...[versions] developed quite by accident in the studio....an engineer left out the vocals of a particular song and a sound system man called Ruddy Redwood...took it to his dance and played the version and it became a big hit...producers could now put the version, which is the instrumental side of the song, on the flip side of the 45[RPM vinyl record]... what version afforded you was to just lick one rhythm, get a vocal or several vocals on it and then every 45 you do you put the vocals on the A side and then you put the instrumental track on the B side.

(iii) Dub/Combination of Riddim Tracks

Another innovation was dub, a musical genre built by combining riddim tracks with different vocals and instruments. From the late 1950s onwards, during party sessions, Jamaican deejays $^{208}$ would create improvised vocals by talking or extemporising over the versions being played by sound systems. Record producers later recorded and remixed these songs (which would later become known as Dancehall music) for distribution and sale to the public: ${ }^{209}$

King Tubbys and Lee "Scratch" Perry [recording studio engineers] started to experiment with the versions, taking out instruments, putting out instruments and remixing. That was where the remix culture started: in Kingston. Because what you used to have is like 5 different versions of a same song remixed several different ways. So you might have the dub version, you might have the deejay [version] which is the combination of the singer and the deejay... and you might have several other interpretations by other engineers.

\footnotetext{
205 The issue of remixes is revisited in Chapter 5.

206 Carter Van Pelt "Toward a Conventional Copyright System: The Jamaican Experience with Rights Management and a New Law" (Master of Arts dissertation, Columbia University, 2006) at 9.

${ }^{207}$ Howard interview.

208 Deejays/DJs are the "individuals who do the toasting, mike chatting and articulates the lyrics across particular rhythms. The Selector, on the other hand, chooses and spins records and dictates the pace of the music on a sound system, or at a dance or party or club scene.": Donna Hope "Dancehall: Origins, History, Future" in Groundings (St. Michael's Theological College, Kingston, July 2011) at 6.

${ }^{209}$ Howard interview.
} 
...in fact, without [dub], you wouldn't even have some music genres. You wouldn't have Techno. You wouldn't have Dub Step. You wouldn't have Grime. You wouldn't have Hip Hop. You wouldn't have Kwaito which is coming from South Africa. You wouldn't have Reggaeton. $^{210}$

In summary, the disregard for copyright during this period of heightened creativity led to these innovations. As Toynbee concluded: ${ }^{211}$

...brutal and exploitative though the [music] system could be, it worked extremely efficiently to generate a high rate of musical innovation in the absence of IP.

5 Stage four: internationalisation/demand for greater copyright protection (late 1970s $-1990 s)$

By the 1970s, performers and musicians in the Reggae music industry experienced an unprecedented level of international success. Various overseas independent and major labels sought out and signed Jamaican artistes. ${ }^{212}$ Not only were these labels aware of Jamaican music's earning potential but local artistes also began to appreciate that significant returns could be generated beyond what had been earned in the earlier stages of the music industry. ${ }^{213}$ Music-making, rather than predominantly being a means of contributing to the cultural life of the community, thus became more commercially motivated. ${ }^{214}$ Respondent 16 , a cultural studies academic, placed creators' growing concern about financial return within the broader context of increased capitalism:

The economic component of the music [became] critical after Bob Marley's rise to international stardom and iconic status, and more so, with the type of changes that Jamaica has had in its economic structures, its political structures and the rise of market capitalism. So Dancehall [an offspring of Reggae] is a type of music that is...insisting on "money, money, money"... the ideals of what kind of money can be made and how it can be made and also

\footnotetext{
${ }^{210}$ See Sonjah Stanley-Niaah Dancehall: From Slave Ship to Ghetto (University of Ottawa Press, Ottawa, 2010) at 179-188 and Siva Vaidhyanathan Copyrights and Copywrongs (New York University Press, New York and London, 2003) at 136 (on Jamaican music's influence in creating other musical genres).

${ }^{211}$ Jason Toynbee "Reggae Open Source: How the Absence of Copyright Enabled the Emergence of Popular Music in Jamaica" in Lionel Bently, Jennifer Davis and Jane Ginsburg (eds) Copyright and Piracy: An Interdisciplinary Critique (Cambridge University Press, New York, 2010) 357 at 363.

${ }^{212}$ Dennis Howard "Copyright and the Music Business in Jamaica- Protection for Whom?" (2009) IX Revista Brasileira do Caribe 503 at 516.

${ }^{213}$ See R-22, R-49B and R-50.

${ }^{214}$ Stanely-Niaah interview.
} 
what kind of values reside in that particular cultural product has become more central in this era...

The growing foreign exploitation of Jamaican music triggered an industry thrust for new copyright law. As a JIPO official noted: ${ }^{215}$

The '70s and the '80s were significant periods when Jamaican music now has exploded on the international scene and is coming into its own and it has its own recognition...Therefore, the local artiste or local entertainment industry [said] "why don't we have a law that properly addresses our needs, if we're not only just big at home, we're big abroad?"

This increased use by non-Jamaicans had brought more opportunities for unauthorised treatment of Jamaican copyright works, ${ }^{216}$ as the following story shows: ${ }^{217}$

The first man to make Bob Andy [veteran Reggae artiste] know about copyright was an American artiste who make him [Andy] write two songs and then claim the copyright...And [Andy said] that is when him realise that there is something name "copyright." And then [Andy] started to publish [his songs] and copyright [his] songs.

Music industry members were also concerned that, without an updated copyright law, they would be unable to secure royalties from their work used overseas: ${ }^{218}$

[Music rights holders] felt that if you had a copyright law that was modern...the royalties, the opportunities would be increased.

Since the existing 1911 Act predated technologies which were prevalent in Jamaica by the 1970s (such as, commercial radio, films, television broadcasting and private recording devices) rights holders believed the statute had become out of touch with the music industry: ${ }^{219}$

The backward colonial law...didn't serve the new technologies and the new ways of distribution... The need for radio stations and show promoters to pay for the use of intellectual property: all of those things were not outlined in the old law...

\footnotetext{
${ }^{215}$ R-32. See also: R-15, R-17 and Hansard 27 January 1993 (Carl Rattray).

${ }^{216}$ Dominic Power and Daniel Hallencreutz "Profiting from Creativity? The Music Industry in Stockholm, Sweden and Kingston, Jamaica" (2002) 34 Environment and Planning A 1833 at 1844.

${ }^{217}$ Howard interview.

${ }^{218} \mathrm{R}-15$

${ }^{219} \mathrm{R}-27$.
} 
The music industry formed a powerful lobby group ${ }^{220}$ in the 1970s with the purpose of urging the Government to pass legislation giving greater copyright protection.

As a result of their efforts, a new Copyright Act was enacted in $1977^{221}$ (1977 Act), modelled on the 1956 copyright legislation in the UK. ${ }^{222}$ However, this 1977 Act never came into force $^{223}$ because by the time it was passed further technological changes had rendered it obsolete: ${ }^{224}$

...so many changes had occurred in the copyright landscape that there was a cry [from rights holders] not to bring that law into effect...by then the UK had reformed its own [1956] law and included some more up-to-date provisions. So the issue was, here we were in 1977, bringing in a law which was supposed to be a reform and the very so-called "reformed law" was already outdated.

Not only did the 1977 Act fail to deal with moral rights, it also did not address the rights of performers, producers of phonograms and broadcasting organisations, which by then had become internationally recognised by the International Convention for the Protection of Performers, Producers of Phonograms and Broadcasting Organizations, 1961 (Rome Convention). ${ }^{225}$ The more recent changes in technology that allowed recordings of live performances necessitated greater protection of those performances to prevent unauthorised recordings. $^{226}$

By the 1990s, legislators felt that technology allowed users an ease of access to works which could tip the copyright balance between authors and users in favour of users: ${ }^{227}$

[T] hese new technologies because of their widespread dissemination are now threatening to overwhelm that delicate balance of entitlements without which no sustained creation of works can take place.

\footnotetext{
${ }^{220}$ See: R-15, R-30, Corthésy interview and Hansard 26 January 1993 (PJ Patterson).

${ }^{221}$ Copyright Act No. 17, July 1977.

${ }^{222}$ Copyright Act (UK) 1956, in force 1 June 1957. This statute did not automatically extend to the colonies.

${ }^{223}$ Although the Act was passed in the House and assented to, the Minister did not fix a date for the legislation to become operative and thus, no notice to this effect (Appointed Day Notice) was published in the Gazette.

${ }^{224}$ R-15. See also: R-30.

${ }^{225}$ International Convention for the Protection of Performers, Producers of Phonograms and Broadcasting Organizations, 1961 (signed on 26 October 1961) [Rome Convention].

${ }^{226}$ See Hansard 26 January 1993 (PJ Patterson).

${ }^{227}$ Hansard 27 January 1993 (Edward Seaga).
} 
Designed to remedy the flaws of the 1977 Act, ${ }^{228}$ the Copyright Act 1993 was intended to enable rights holders to maximise financial returns from their music. Respondent 32, a JIPO representative, said:

At the core [of the Copyright Act 1993] is the recognition of the depth and richness of Jamaican creativity and the need, therefore, to provide an appropriate legal framework to... provide a vehicle to commercialise, to manage, to rightly exploit that creativity.

\section{B How the Copyright Act 1993 Safeguards the Music Industry's Commercial Value}

The extensive economic rights found in copyright legislation protect the commercial value of copyright-based industries such as music. Economic rights allow rights holders to have greater control over the exploitation of their work, including the exclusive right: ${ }^{229}$

(a) to copy the work;

(b) to issue copies of the work to the public;

(c) to perform the work in public or, in the case of a sound recording, film, broadcast or cable programme, to play or show the work in public;

(d) to broadcast the work or include it in a cable programme service; or

(e) to make an adaptation of the work and, in relation to such adaptation, to do any or all of the foregoing acts.

Rights holders can exploit these rights so as to generate financial returns.

\section{The Economic Value of the Music Industry}

The Jamaican Government also hoped financial returns accruing to individual rights holders for use of their work overseas would cause an inflow of monies into the domestic economy. ${ }^{230}$ As outlined by the then Prime Minister during the Parliamentary debates on the Copyright Bill: ${ }^{231}$

\footnotetext{
${ }^{228}$ Hansard 26 January 1993 (PJ Patterson).

${ }^{229}$ Copyright Act, s 9(1).

${ }^{230}$ It is worth noting that Gross Domestic Product does not include royalty streams in its measurement.

${ }^{231}$ Hansard 26 January 1993 (PJ Patterson).
} 
The economic sectors which are involved in publishing, the film industry, broadcasting, to name but three, accounts for a significant addition to our Gross National Product. Considering this key economical importance of copyright we therefore believe that the use of every copyrighted work has an economic impact. This is why we feel there is a clear need for dynamic process of resource management, which in international copyright terms is referred to as 'collective administration'.

The next sections examine the potential economic impact of the music industry and the use of collective administration as a means of realising that impact.

\section{A The Music Industry's Potential to Contribute to the Jamaican Economy}

In the 1950s, the Jamaican Government noticed growing interest in Caribbean music in the US popular music market. ${ }^{232}$ These hits songs were mostly performed by American and African-American entertainers: ${ }^{233}$

[These songs] generated from the base of our traditional music as sung by Harry Belafonte [African-American singer]...were, to a certain extent, external to us, especially when the lyrics didn't quite fit what we knew the original lyrics to be...this helped to spark the feeling that emerged at the time for our own creations.

However, by the 1960s, Jamaican-created music became popular in England and the Government attempted to capitalise on the local music's global appeal by active marketing in the US. The then Minister of Culture, Edward Seaga, with the help of the Social Development Commission, brought Jamaican performers and dancers to the 1964 New York World Fair. Seaga recollected: ${ }^{234}$

And it was at this point, that the question of copy-righting first entered the picture. None of these artists, who were extremely productive had ever thought of copy-righting any material. Once we spoke of American publication and performance and recording, copy-rights became essential.

Although lawmaking efforts continued in the 1970s and 1980s, it took the Government until the 1990s to finalise copyright legislation. This legislation was passed on the basis that it would protect the entertainment industry as a critical segment of the economy:

\footnotetext{
${ }^{232}$ This so-called "Calypso invasion" in the US was due to the success of Trinidadians performers such as Attila the Hun: Howard interview.

${ }^{233}$ Hansard 27 January 1993 (Edward Seaga).

${ }^{234}$ Hansard 27 January 1993 (Edward Seaga).
} 
If we are serious about encouraging an indigenous entertainment industry...we must ensure that they are offered adequate protection at home. ${ }^{235}$

[T] he entertainment industry is one of the most significant earners of foreign exchange, and is one of the fastest growing sectors...in Jamaica when we speak of an industry we think primarily of the manufacturing sector, the mineral sector...agriculture and...tourism, but we do not pay sufficient attention to...the artistic sector; and I think as we seek to develop our economy...these are areas which must be deserving of our attention. ${ }^{236}$

Underpinning this strategy was a sense among Parliamentarians that copyright protection of music could help to transform Jamaica's socio-economic status. Three years after the Copyright Act 1993 was enacted, the National Industrial Policy of Jamaica (1996) identified the entertainment sector as one of the key clusters for development as a non-traditional export. It signalled Government's: ${ }^{237}$

formal recognition of the entertainment industry, its importance as an expression of the richness of our national culture, and its incorporation as an integral element of the national effort to promote growth and development of the Jamaican economy and society.

\section{B The Absence of Indigenous Collecting Societies}

The Jamaican Government believed that the absence of indigenous collecting societies or collective management organisations (CMOs) inhibited the growth of the local music industry and its ability to contribute to the economy.

Although its role varies by jurisdiction, ${ }^{238}$ a CMO administers some or all of the rights on behalf of numerous rights holders who have either assigned these rights to the organisation or designated the CMO to act as their agent. ${ }^{239}$ CMOs typically handle the licensing or contractual authorisation to use a protected work. ${ }^{240}$ Except in the case of compulsory

\footnotetext{
${ }^{235}$ Hansard 26 January 1993 (PJ Patterson).

${ }^{236}$ Hansard 27 January 1993 (PJ Patterson). See also: R-9.

${ }^{237}$ Government of Jamaica National Industrial Policy (1996) at 128. See also: Planning Institute of Jamaica, Vision 2030 Jamaica: National Development Plan (2009) at 216.

${ }^{238}$ Daniel Gervais "The Landscape of Collective Management Schemes" (2011) 34 Columbia Journal of Law \& the Arts 423.

${ }^{239}$ Copyright Act 1993, s 87(1) refers to a "licensing body" which is "a society or other organization which has as its main object or one of its main objects, the negotiation or granting, either as owner or prospective owner of copyright or as agent for him, of licences, and whose objects include the granting of licences covering works of more than one author."

${ }^{240}$ Daniel Gervais "Introduction" in Daniel Gervais (ed) Collective Management of Copyrights and Related Rights (Kluwer, Netherlands, 2006) at xix. See also: Copyright Act, s 87(1): a licence means "any licence that is
} 
licences, a licence is granted in exchange for a royalty payment prior to use. CMOs benefit rights holders by reducing transactional costs and increasing efficiency in the management of the exploitation of their copyright works worldwide. ${ }^{241}$ CMOs also remove the need for users seeking rights clearance to engage in lengthy and costly searches for copyright owners. ${ }^{242}$

A branch of the UK-based CMO Performing Right Society (PRS) had been in existence in Jamaica since the 1930s. Its primary function was collecting public performance fees locally and sending those fees to London for distribution. ${ }^{243}$ In the 1960 s, with the international success of Jamaican music, the Government initially encouraged Jamaican rights holders to join PRS. ${ }^{244}$ Even though PRS represented a way to exploit their musical rights, local rights holders felt that "they [PRS] were there to collect money on behalf of British composers."245 Eventually, the Government also thought PRS was not fully representing local interests: ${ }^{246}$

Jamaica had inherited a colonial system which is PRS as the collecting society. Many of our composers and publishers were really not earning...In most instances, the use of colloquial language with music and the names of artistes and so on were just unknown so these works were not even identified in many instances by the English.

As Jamaican rights holders increasingly registered with foreign rights agencies (such as, the American Society of Composers, Authors and Publishers (ASCAP) and Broadcast Music Incorporated (BMI)), ${ }^{247}$ the Government became worried about the economic fall-out if this trend were to continue: ${ }^{248}$

[Rights holders joining overseas CMOs] had implications because it meant their money stayed outside and so on. So if we were thinking of developing indigenous copyright industries or advancing the music internally, the absence of that [domestic] protection was important.

issued or offered by a licensing body authorizing, in relation to works in which copyright subsists, the doing of any of the acts restricted by copyright."

${ }^{241}$ See Uma Suthersanen "Collectivism of Copyright: The Future of Rights Management in the European Union" in Eric Barendt and Alison Firth (eds) The Yearbook of Copyright and Media Law (Oxford University Press, Oxford, 2000) 15 at 15-17.

${ }^{242}$ See Stanley Besen, Sheila Kirby and Steven Salop “An Economic Analysis of Copyright Collectives” (1992) 78 Virginia L Rev 383 at 383-384.

243 Johnson Okpaluba “'Free-riding on the Riddim?' Open source, Copyright law and Reggae music in Jamaica” in Lionel Bently, Jennifer Davis and Jane Ginsburg (eds) Copyright and Piracy: An Interdisciplinary Critique (Cambridge University Press, New York, 2010) 374 at 375.

${ }^{244}$ Hansard 27 January 1993 (Edward Seaga).

${ }^{245}$ Howard interview.

${ }^{246}$ R-7.

${ }^{247} \mathrm{R}-7$.

${ }^{248} \mathrm{R}-15$. 
The Government therefore sought to establish a sturdy domestic rights management system in order to "capture as much revenue as possible, inside its borders, from the value chain associated with written and recorded music." 249 The goal was for these indigenous CMOs to serve all rights holders (through licensing, collecting and distributing royalties and monitoring and defending against unauthorised uses of copyright works) and network with their foreign equivalent societies. ${ }^{250}$ Rights holders were strongly urged to join the local CMOs, whose formation the Copyright Act 1993 was intended to facilitate. According to the then Prime Minister: ${ }^{251}$

In [collective administration] the creator or rights holder, backed up by the law, holds the destiny of the work in his or her hands...and, of course, the creator is advised to protect his or her interest, not only by the existence of an Act on the Statute Book, but by becoming a member of a licensing body or collecting society.

\section{How the Copyright Act 1993 emphasises the Economic Value of the Music Industry}

The economic value of the music industry is recognised in the Copyright Act 1993 through provisions for collective administration. There are exhaustive sections in the Copyright Act addressing licensing arrangements. ${ }^{252}$

The Copyright Act mirrors the Anglo-Saxon approach in the US and UK in that it highlights CMOs' economic functions. In contrast, CMOs in continental Europe generally provide for the welfare of members and advance the development of the local creative industries. ${ }^{253}$ European CMOs' socio-cultural roles can either be mandated by statute ${ }^{254}$ or undertaken by voluntarily. ${ }^{255}$ However, in Jamaica there is neither a statutorily imposed duty nor comprehensive voluntary arms of CMOs. Because CMOs were a prominent part of the

\footnotetext{
249 Carter Van Pelt "Toward a Conventional Copyright System: The Jamaican Experience with Rights Management and a New Law" (Master of Arts dissertation, Columbia University, 2006) at 30.

${ }^{250} \mathrm{R}-14$ and R-7.

${ }^{251}$ Hansard 26 January 1993 (PJ Patterson).

${ }^{252}$ Copyright Act, s 87- 102.

${ }^{253}$ See Chapter 3.I.E.

${ }^{254}$ For example, Law on the Administration of Copyright and Neighboring Rights of 9 September 1965 (Germany), arts 7 and 8.

${ }^{255}$ As is the case in France where in 2004 CMOs spent $€ 95$ million on cultural activities: KEA European Affairs "Collective Management of Rights in Europe: the Quest for Efficiency" (European Parliament Report, 2006) at $40<w w w . e u r o p a r l . e u r o p a . e u / c o m p a r l / j u r i / s t u d y / r i g h t s \_e n . p d f>$.
} 
Government's development strategy, the next Chapter will discuss their limitations in greater detail. $^{256}$

\section{Summary}

The previous sections, in discussing the historical relationship between the music industry and the copyright regime, concentrated on the cultural, commercial and economic value that legislators placed on Jamaican music. This value was greatly influenced by the growth of the music industry, primarily its commercial success. The legislature's recognition of the different kinds of value of the music industry eventually culminated in the Copyright Act 1993, which had a policy focus on developing the industry's economic value through collective administration.

The remainder of the Chapter will consider the extrinsic influences on the Copyright Act 1993.

\section{Extrinsic Factors Influencing the Copyright Act 1993}

In the early 1990s, Jamaican legislators were under pressure from local rights holders and the World Intellectual Property Organization (WIPO) to accede to the major copyright treaties, ${ }^{257}$ as well as from the US and the regional grouping of Caribbean states, Caribbean Community (CARICOM):

\section{A Local and International Pressure to Accede to Major Copyright Treaties}

The Government enacted the Copyright Act 1993 partly in response to growing pressure on Jamaica to sign the major copyright treaties finalised over the previous decades: ${ }^{258}$

\footnotetext{
${ }^{256}$ See Chapter 3.

${ }^{257}$ Such as the Berne, Rome and Phonograms Conventions.

${ }^{258}$ Hansard 26 January 1993 (PJ Patterson). See also: Ministry Paper No 49 of 1988 (tabled in Parliament 19 December 1988 by Edward Seaga, Prime Minister) at 9 identifying these conventions.
} 
[T] he passage of this law is extremely important and timely, for us to be able to accede to three Conventions [Berne, Universal Copyright Convention and Rome Convention], which will afford reciprocal protection to Jamaican authors, performers, broadcasters and producers...but we would have to put our national legislation in place before we could assume the obligations that will be expected of us.

Demands upon Jamaica to accede to copyright treaties and join the international copyright community came from both internal and external sources:

\section{Local pressure from music industry interest groups}

Jamaican music rights holders encouraged the Government to strengthen domestic copyright protection because they believed that such legislation would enable Jamaica to become a member of major international copyright agreements. They felt that Jamaica's membership of these copyright treaties would guarantee greater protection in the overseas markets in which Jamaica music was sold. ${ }^{259}$ If Jamaica became a party to the various treaties, they anticipated that Jamaican music would have increased foreign copyright protection, based on the national treatment ${ }^{260}$ principle. As a policymaker explained: ${ }^{261}$

...unless you are linked in to the international landscape you didn't have the possibility, or the possibility was reduced, for you to benefit. And this is where membership of the Berne Convention comes in, because, as you know, if you are not a member of the relevant international convention, other countries who are members of that convention have no responsibility in relation to you. So if Jamaica is outside of Berne, then Berne members have no responsibility to protect Jamaican music or other creative expression in their country.

Notwithstanding industry lobbying, lawmakers were aware that, given the heavy usage of foreign music by radio and television broadcasters ${ }^{262}$, enacting copyright legislation could create a net outflow of royalties. ${ }^{263}$ During the public consultations on the Copyright Bill a group of stakeholders asked policymakers why copyright legislation was being enacted,

\footnotetext{
${ }^{259}$ See: R-7, R-9 and R-15.

${ }^{260}$ Which requires individual member countries to provide the same level of copyright protection to works created by or in other member countries as they would provide to works created by their nationals, for example, Article 5(1) of the Berne Convention, art. See generally: Graeme Dinwoodie "The Development and Incorporation of International Norms in the Formation of Copyright Law" (2001) 62 Ohio State LJ 733.

${ }^{261} \mathrm{R}-15$. See also: R-14.

${ }^{262}$ On Jamaica's status as a net user of copyright works, see: Webley interview, R-9 and R-44. See also: Joan Webley "First World Copyright Law in Third World Jamaica: Is there a Need for a New Approach?" (Article prepared for the International Association of Entertainment Lawyers, 27 November 2009) at 3.

${ }^{263}$ Hansard 27 January 1993 (Edward Seaga).
} 
"bearing in mind that we are engaged in the whole-scale business of pirating the material of artists abroad who have copyrighted material that is foreign owned." 264 The drafter of the Copyright Act summarised the dilemma faced by the Government in passing the law: ${ }^{265}$

[I]t was recognised that the music and other industries that benefit from copyright probably would not develop without a modern copyright system...On the other hand, it was recognised that we were more users of copyright [and] if we upgraded the system we would then become more indebted to people outside of Jamaica...there was this feeling that in the end...we were going to be disadvantaged.

The Government's concern about a likely royalty imbalance was not, however, powerful enough to counteract the escalating pressure from rights holders.

\section{International pressure from the World Intellectual Property Organization}

Additionally, WIPO was urging the Jamaican Government to update its domestic laws in light of existing international obligations. Jamaica had been a member of WIPO since 1978 by virtue of the World Intellectual Property Organization Convention, 1968. WIPO advocated that Jamaica join the Berne Convention:

By then we had become a member of [WIPO] mainly so that we would qualify for some technical assistance and training and so on...the next step is to become a member of the Berne. But to become a member you really have to have your laws that are in line with what the Berne says. And we weren't...although we were being encouraged to do so... ${ }^{266}$

WIPO at this stage was hosting seminars and training for the legislative drafters of the Copyright Bill as well as offering assistance in establishing JIPO. ${ }^{267}$ WIPO's involvement was important in developing Jamaica's IP infrastructure and legislation. ${ }^{268}$

\section{B Pressure from the United States}

\footnotetext{
${ }^{264}$ Hansard 26 January 1993 (PJ Patterson). The Senate was also cognisant of these concerns, see: "Heather Robinson lashes critics of Copyright Act" The Gleaner (Jamaica, 22 February 1993) and "Senate passes Copyright Act" The Daily Gleaner (Jamaica, 21 February 1993).

265 R-15.

${ }^{266} \mathrm{R}-15$. See also: R-32.

${ }^{267} \mathrm{R}-7$ and R-31.

${ }^{268}$ R-38.
} 
The US also exerted political power on the Jamaican Government to pass the Copyright Act 1993 in three ways:

\section{$1 \quad$ Threatened loss of preferential trading status}

In Jamaica during the 1980s, there was large-scale capturing of satellite signals originating from American television stations. Even the Jamaica Broadcasting Corporation, the stateowned television station, engaged in the unauthorised broadcast of these programmes to the Jamaican public. In response to this copyright infringement, the US threatened to remove Jamaica's preferential status under the Caribbean Basin Economic Recovery Act (CBERA). ${ }^{269}$ The Caribbean Basin Initiative (CBI) had been launched by the CBERA in 1983. The CBI is the US trade programme in the Caribbean and Central America to "facilitate the economic development and export diversification of the Caribbean Basin economies." 270 The CBI was also the first U.S. trade programme to contain IP-related provisions. ${ }^{271}$ Essentially, the CBI provided beneficiary countries with duty-free access to the US market for a number of goods, conditional upon the domestic protection of copyright. ${ }^{272}$ As a policymaker commented: ${ }^{273}$

[T] he US Government said, in effect, that we would lose our preferential status if we infringed the copyright of their nationals...and that was very important to us, because [Jamaican negotiators] had negotiated a quite beneficial entry of Jamaican apparel [into the US market].And if we jeopardised that we would be in serious trouble.

Given its dependence on exports to the US, Jamaica could not afford to lose the duty free trading privileges enjoyed in that market.

\footnotetext{
${ }^{269}$ See Howard interview and R-15.

270 Office of the United States Trade Representative "Caribbean Basin Initiative" <www.ustr.gov/tradetopics/trade-development/preference-programs/caribbean-basin-initiative-cbi>

${ }^{271}$ International Intellectual Property Alliance "US Trade Tools" < www.iipa.com/cbera_cbtpa.html>.

${ }^{272}$ See Peter Drahos' Presentation to Commission on Intellectual Property Rights' Conference: "How Intellectual Property Rights Could Work Better for Developing Countries and Poor People - Session 4: Copyright and Developing Countries" Transcript (The Royal Society, London, 21-22 February 2002) on the American Motion Picture Association's exercise of its influence over the US Congress to ensure the passage of the Caribbean Basin Initiative in 1983.

${ }^{273}$ R-15. See also: Howard interview.
} 
During the early 1990s the Jamaican Government desired to enter into a bilateral investment treaty with the US. As part of the negotiations, the US insisted on greater copyright protection in Jamaica, as the drafter of the Copyright Bill recalled: ${ }^{274}$

[T] he Government of Jamaica was very interested in having a bilateral investment treaty with the US...And during the currency of that negotiation they said: "oh, by the way, we also have a bilateral on intellectual property"; which was a bit of a surprise.

During the debate on the Copyright Bill, the then Prime Minister alluded to the fact that the Government had to take onboard the copyright issues being articulated by the US: ${ }^{275}$

And even as we engaged in discussions, in things like reciprocal investment treaties, there is an insistence that the whole question of protection of intellectual property rights must be observed.

Six months after the Copyright Act 1993 came into force, the US-Jamaica Bilateral Investment Treaty was signed, ${ }^{276}$ which required each party to "provide effective means of asserting claims and enforcing rights with respect to investments." 277 For the purposes of the bilateral investment treaty, IP was defined as an "investment" to which its provisions applied. ${ }^{278}$ One month later, Jamaica entered into a bilateral agreement with the US which made it an offence to manufacture or trade in decoders of encrypted satellite signals. ${ }^{279}$ As required under this agreement, ${ }^{280}$ Jamaica also became a member of the Brussels Convention Relating to the Distribution of Programme-Carrying Signals Transmitted by Satellite 1974 and the Geneva Convention for the Protection of Producers of Phonograms Against Unauthorized Duplication of Their Phonograms 1971.

\footnotetext{
${ }^{274}$ R-15.

${ }^{275}$ Hansard 26 January 1993 (PJ Patterson).

${ }^{276}$ Treaty between the United States of America and Jamaica concerning the Reciprocal Encouragement and Protection of Investment (signed at Washington on 4 February 1994; in force 7 March 1997) [US/Jamaica Bilateral Investment Treaty 1994].

${ }^{277}$ US/Jamaica Bilateral Investment Treaty 1994, art II (6).

${ }^{278}$ US/Jamaica Bilateral Investment Treaty 1994, art I.1(a)(iv).

279 Agreement Concerning the Protection and Enforcement of Intellectual Property Rights between the Government of the United States and the Government of Jamaica (signed on 17 March 1994) [US/Jamaica Bilateral Agreement on Satellite Signals].

${ }^{280}$ US/Jamaica Bilateral Agreement on Satellite Signals, art 1. The Copyright Act was amended to incorporate the provisions this Agreement, see: sections 136A, 136B and 136C of the Copyright Act 1993 (as amended) by Copyright (Amendment) Act No. 29 of 1999 (in force 3 September 1999).
} 


\section{The WTO and intellectual property}

The US, along with the European Union and Japan, was also instrumental in having the issue of IP brought into the Uruguay round of multilateral trade negotiations and eventually into the WTO Agreements. ${ }^{281}$ TRIPS originally had no impact on the Copyright Act 1993, as that treaty was finalised after the Act had been passed. As the drafter of the Bill explained, "TRIPS was not in our consciousness at the time.,"282

However, lawmakers were cognisant that the General Agreement on Tariffs and Trade (GATT) discussions taking place at that time signalled that increasing compliance with IP law had become an international priority. As one Parliamentarian observed: ${ }^{283}$

We are not the only country, of course, that has failed to be participants of or signatories to these [major IP] conventions...This is one of the reasons why the protection of [IP] rights...became a very important part of the GATT discussions which have taken place in Uruguay.

Because the Jamaican Copyright Act 1993 had been modelled on the UK Copyright, Designs and Patents Act 1988 (CDPA), ${ }^{284}$ it was already largely TRIPS-compliant. ${ }^{285}$ In 1993, copyright protection in Jamaica was already substantially consistent ${ }^{286}$ with the standards that would later be laid down in TRIPS. Jamaica became a member of TRIPS in 1995 and in 1999 amended its Copyright Act 1993 to bring enforcement measures fully in line with TRIPS. Jamaican policymakers felt they had no alternative, as a JIPO official commented: "even if you don't sign TRIPS, especially as a developing country, how long can you keep outside of this international network?",287

However, the dramatic progress in copyright lawmaking in Jamaica in the 1990s was not solely attributable to the influence of the US.

\footnotetext{
${ }^{281}$ See generally, Daniel Gervais The TRIPS Agreement: Drafting History and Analysis (Sweet \& Maxwell, London, 1998).

282 R-15.

${ }^{283}$ Hansard 27 January 1993 (Edward Seaga).

${ }^{284}$ Copyright, Designs and Patents Act (UK) 1988 [CDPA] in force 1 August 1989. R-15 noted that the CDPA was then "hot off the press" and used as "a point of departure" for Jamaican drafters. This is supported by R-7, R-14, R-31 and R-32 acknowledging the reliance on English legislation based on shared jurisprudence.

${ }^{285} \mathrm{R}-15$.

${ }^{286}$ The Copyright (Amendment) Act 1999 brought the 1993 Copyright Act into compliance with TRIPS in terms of explicitly providing for the protection of compilations of data or original databases. See: ss 2 and $6(3 \mathrm{~A})$ of the Copyright Act 1993 (as amended).

${ }^{287}$ R-7. See also: R-38.
} 


\section{Regional Harmonisation of Copyright Laws}

Aside from local and international pressure, regional influences also affected Jamaica's copyright legislation. Jamaica is a member of the Caribbean Community and Common

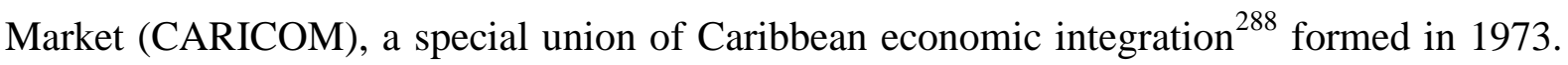
During the Parliamentary debates on the Copyright Bill, the then Attorney-General identified the impact of the formation of CARICOM on the 1977 Copyright Act: ${ }^{289}$

It was clearly indicated in [CARICOM's] establishment that it was desirable to harmonize such laws, and administrative practices has affected the operation of the Common market in certain specified areas, including Copyright. A Unit for Harmonisation of Laws was established in 1976...in 1977 the Unit established a Copyright Project.

Independent of the Harmonisation Unit, the Jamaican Government finalised the Copyright Act 1977 but opted not to bring that legislation into force until a CARICOM model copyright law was finalised: ${ }^{290}$

[Jamaica was] aware of and in touch with the initiatives of the CARICOM Harmonization Unit, and we wished to benefit from their work in respect of any improvements which could be made to the legislation.

However, by the time the model CARICOM legislation became available in the 1980s, the advances of technology made updating of the legislation necessary. ${ }^{291}$ Jamaica decided to undertake an assessment of the copyright law and established a Copyright Committee and a Task Force, whose efforts eventually resulted in the 1993 Act.

\section{Chapter Summary}

\footnotetext{
${ }^{288}$ Created by the Treaty of Chaguaramas Establishing the Caribbean Community (which came into effect 1 August 1973) <www.caricom.org/jsp/community/original_treaty>. CARICOM's objectives include free trade and economic unity, free movement of labour and capital, and increased coordination of foreign policies among its Caribbean members. The Treaty was revised in 2001 to allow for a CARICOM Single Market and Economy: Revised Treaty of Chaguaramas Establishing the Caribbean Community Including the CARICOM Single Market and Economy (signed on 5 July 2001) [Revised Treaty of Chaguaramas] <www.caricom.org/jsp/community/revised_treaty-text.pdf>

${ }^{289}$ Hansard 27 January 1993 (Carl Rattray, Attorney-General).

${ }^{290}$ Ibid.

${ }^{291}$ Hansard 27 January 1993 (Carl Rattray, Attorney-General).
} 
This Chapter demonstrated how non-enforcement of copyright law fuelled the birth of the local music industry and sparked innovative practices. However, the industry's growth eventually led to demands for upgraded copyright law.

It argued that while some of the reasons behind the Jamaican Government's decision to pass the Copyright Act 1993 concerned the music industry's cultural, commercial and economic value (along with the pre-existing copyright legislation's inability to protect that value), other important factors were the growing internal and external pressure to strengthen the domestic copyright regime to bring it in line with international copyright standards. 


\section{CHAPTER THREE}

\section{THE EFFECTIVENESS OF THE JAMAICAN COPYRIGHT INFRASTRUCTURE AS A MEANS OF ECONOMIC DEVELOPMENT}

\section{Overview}

This research is concerned with how Jamaican music industry stakeholders assess the effectiveness of the Jamaican copyright system as a development tool. Interview questions that were directed at music industry stakeholders thus focussed on what has hindered or helped the copyright system in achieving developmental objectives.

This Chapter will discuss the economic aspects of development. Concentrating my research on the Jamaican music industry is appropriate given that commentators increasingly recognise the role played by IP rights in economic development is not only country-specific but also industry-sensitive. ${ }^{292}$ However, as the next chapter will explain, development also has social and cultural components, ${ }^{293}$ which my focus on economic development in this Chapter is not intended to downplay.

In analysing the interviews, three distinct approaches emerged. Music industry stakeholders felt that copyright protection for the music industry could lead to economic development through: (1) collective administration; (2) income maximisation, or (3) equitable resource distribution, each of which will be discussed in this Chapter.

As Chapter Two explained, building an effective domestic collective management framework was the main mechanism through which the Government felt copyright protection of Jamaican music could facilitate economic development. ${ }^{294}$ The first part of the chapter discusses the challenges with adhering to a Collective Management Organisation (CMO)-

\footnotetext{
292 See: ICTSD/UNCTAD Resource Book on TRIPS and Development: An Authoritative and Practical Guide to the TRIPS Agreement (ICTSD/UNCTAD, Geneva, 2005) at 15 and Sanjaya Lall "Indicators of the Relative Importance of Intellectual Property Rights to Developing Countries" (UNCTAD-ICTSD Project on IPRs and Sustainable Development, Issue Paper No. 3, 2003) at 10.

${ }^{293}$ Chapter 4.I.B.2.

${ }^{294}$ See Chapter 2.III.B-C.
} 
dependent economic development model in Jamaica. Unlike the public international law minimum standards concerning copyright protection which are contained in treaties such as TRIPS, ${ }^{295}$ the collective administration of rights is largely contractual in nature and varies from country to country.

\section{Economic Development through Indigenous Collective Management Organisations (CMOs)}

The Jamaican Government envisioned that active indigenous CMOs would safeguard the economic interests of their Jamaican members through the domestic collection of royalty payments, and that international payments received from these CMOs' foreign counterparts would be a source of foreign exchange. The Government hoped that a significant portion of the economic activities involved in the creation of music would be conducted within Jamaica. As Van Pelt explained: ${ }^{296}$

Every stage in the process of creating a marketable music product (writing, recording, manufacturing, and distributing) adds value toward the final marketable product. Much of the value chain associated with Jamaican music has taken place off the island, mitigating its economic development potential.

Since the Copyright Act's passage in 1993, three active CMOs have been established in Jamaica: the Jamaica Association of Composers, Authors and Publishers (JACAP), the Jamaican Copyright Licensing Agency (JAMCOPY) and the Jamaica Music Society (JAMMS). These CMOs are not-for-profit, private companies, which administer different types of rights under the Copyright Act.

JACAP is responsible for administering the public performing rights of composers, authors and publishers in respect of their musical works (including music broadcast and/or diffused by cable) as well as film synchronisation rights and mechanical/recording rights ${ }^{297}$ granted under the Copyright Act. JACAP monitors the use of its members' works and licenses its members' rights to users in exchange for licence fees, which are then distributed to members

\footnotetext{
${ }^{295}$ See Chapter 4.II.B.2(a).

${ }^{296}$ Carter Van Pelt "Toward a Conventional Copyright System: The Jamaican Experience with Rights Management and a New Law" (Master of Arts dissertation, Columbia University, 2006) at 30.

${ }^{297}$ Monies paid to composers and publishers when works are duplicated on physical carriers such as CDs.
} 
and affiliates. JACAP was incorporated in 1998 to succeed the local agency of PRS which had set up branches in former British colonies like Jamaica. JACAP has reciprocal representation agreements with several foreign CMOs, such as ASCAP and BMI, and is a member of the International Confederation of Societies of Authors and Composers (CISAC). ${ }^{298}$ JACAP occupies a central role in terms of the Government's plans for realising the economic potential of the music industry: ${ }^{299}$

From the perspective of national policy, JACAP is viewed as having the potential to keep more performing rights related revenue in the Jamaican economy.

JAMCOPY was the first reprographic rights organisation (RRO) in the Anglophone Caribbean. Incorporated in 1998, it administers the reprographic rights of authors and publishers of printed works. This role involves licensing the right to make multiple copies of these works. JAMCOPY's licensees include government agencies, tertiary educational institutions and copy shops. Although copyright in literary works is not infringed by copying for instructional purposes such copying cannot be done by a reprographic process, ${ }^{300} \mathrm{such}$ as photocopying and digital scanning. JAMCOPY is a member of the International Federation of Reproduction Rights Organization (IFRRO) and has foreign reciprocal agreements with equivalent RROs in 31 countries. JAMCOPY represents composers, songwriters, lyrists and music publishers in respect of scores, sheet music and the words of songs appearing in printed form, for example, in songbooks that accompany CDs.

Formed in 2006, JAMMS administers broadcasting and public performance rights in respect of protected sound recordings. It licenses radio and television broadcasters, cable operators, hotels, retail shops, nightclubs, restaurants, bars, gyms and other commercial users. It represents local and international sound recording copyright holders (record companies and record producers) and is affiliated with the International Federation of the Phonographic Industry (IFPI).

\footnotetext{
298 See Dianne Daley Jamaica (Roger Blanpain and Michele Colucci (eds), Kluwer Law International: International Encyclopaedia of Laws (Intellectual Property-Supplement 47, Wolters Kluwer, Eastbourne, 2008) at [274].

${ }^{299}$ Carter Van Pelt "Toward a Conventional Copyright System: The Jamaican Experience with Rights Management and a New Law" (Master of Arts dissertation, Columbia University, 2006) at 30.

${ }^{300}$ According to section 2 of the Copyright Act, "reprographic process" means a process for making facsimile copies or involving the use of an appliance for making multiple copies and where works are in held in electronic form, copying by electronic means but this does not include making a film or sound recording.
} 
Respondents viewed the establishment of these three CMOs as a sign of accomplishment for the new copyright regime, as a JIPO official commented: ${ }^{301}$

[JACAP] did bring about a kind of revolution in the music industry because here it is for the first time there is a national society that could represent the interests of our composers, who could just go to the office, ask questions, get guidance, get information...even information from PRS or ASCAP or BMI in America, they could assist with. So that was a big success story and continues to be a success.

Another stakeholder, a member of the judiciary, also asserted that an efficient collective management system underpinned an effective copyright system: ${ }^{302}$

[In] an effective system...the producers of work, for example, songs, can collect their royalties so that it can be properly identified, whoever produces the work they can have it registered and...the register is reliable and trustworthy and whoever administers the register has the ability to track the use of the material.

The next sections describe my research findings on the challenges experienced by CMOs (which arguably undermine the CMO-driven model of economic development) as well as offer suggestions for improving the CMO system.

\section{A Problems with Royalty Payments to and from foreign CMOs}

\section{Net outflow of royalty payments to foreign CMOs}

Theoretically, establishing indigenous CMOs should have ensured that Jamaican members earn greater royalties from their copyright works. However, in practical terms, "collecting societies and rights organisations even in such more developed countries as South Africa act principally as revenue collectors for foreign rights holders. ${ }^{\text {303 }}$ In fact, Jamaica has seen a net outflow of royalty payments from indigenous CMOs to overseas CMOs (and their foreign rights holder members). The CMO representatives interviewed were reluctant to provide the

\footnotetext{
${ }^{301}$ R-7. In support, see: R-3, R-14, R-27, R-31, R-40 and R-49A.

${ }^{302} \mathrm{R}-34$.

${ }^{303}$ Alan Story "Study on Intellectual Property Rights, the Internet, and Copyright" (Commission on Intellectual Property Rights, 2001) at 12.
} 
current royalty collection figures. ${ }^{304}$ However, between 2006 and 2008, JACAP's annual licensing income averaged in the region of US\$300,000; the bulk of which was paid to foreign CMOs in respect of their members' works used locally. ${ }^{305}$

This trend of Jamaica being a net exporter of royalty income is not new. In 1999 PRS (JACAP's predecessor) which had been the only collecting society in Jamaica for 64 years, "reported collections of approximately US\$2.5 million, most of which accrued to foreigners. $" 306$ This outbound pattern in Jamaica is replicated in the wider Caribbean region. A large proportion of royalties collected by Caribbean CMOs for broadcasting and public performances are remitted overseas for distribution to foreign right owners. ${ }^{307}$

One main reason for the net payout of royalties in the Jamaican context is that commercial users of copyright (such as radio stations) consume more foreign copyright material than local works. A Jamaica Reggae Industry Association (JARIA) representative revealed: ${ }^{308}$

[E]ven though Jamaica is perhaps one of the luckier Caribbean islands in that our music still has a very strong presence on our airwaves, we're still open to the foreign influences like anything else. And so, you're finding that we listen to a lot of their music...

Additionally, local radio stations are more likely to record and report the use of foreign music than local music for the purposes of royalty collection. ${ }^{309}$ Furthermore a substantial portion of the local music played on air is not registered from a CMO and thus no collection is possible. $^{310}$

The creation of indigenous CMOs in Jamaica has thus been insufficient to reverse the direction of royalty income streams. This runs counter to the Government's objective that royalty revenue remain in the Jamaican economy. One possible measure copyright policymakers could consider is to encourage commercial users to make greater use of local

\footnotetext{
${ }^{304}$ Information that is not publicly disclosed or easily accessible.

${ }^{305}$ Beverley Pereira "A Regional Approach to the Management of Copyright in the Caribbean Community" ( $\mathrm{PhD}$ thesis, Queen Mary, University of London, 2009) at 92-93. See also: Dianne Daley and Nicole Foga "Jamaica: Progress Despite Challenges" in Managing IP magazine (IP Focus, Americas, 4th ed, 2008) 43 in which one local CMO's chairman confirmed that 75 per cent of collections are outbound.

${ }^{306}$ Michael Witter "Music and the Jamaican Economy" (UNCTAD/WIPO Report, 2004) at 48.

${ }^{307}$ Allison Demas and Ralph Henry "Entertainment Services with Special Reference to Music, Mas and the Film and Video Segments" (CARICOM Trade Project/Caribbean Regional Negotiating Machinery Report, 2001) at 94.

308 Webley interview.

${ }^{309}$ Webley interview.

${ }^{310}$ Webley interview.
} 
content and to record and report this usage to local CMOs. The Government could copy the Canadian Government's approach of imposing local content quotas which require broadcasters to air not less than a stipulated percentage of local music. ${ }^{311}$ Another measure would be to offer assistance and encouragement to rights holders to register their works with CMOs.

While Jamaican CMOs have been keeping track of the use of foreign works, foreign CMOs are relatively less thorough in monitoring the use of Jamaican work overseas. This factor contributes to the comparatively smaller inflow of royalty payments to local CMOs. Although Caribbean music is popular on radio, in clubs and at music festivals in the North America and Europe, foreign CMOs generally fail to remit royalties for their use of Caribbean music because their sampling mechanisms focus mainly on mainstream media and events (as opposed to music festivals and broadcast media geared towards the diaspora). ${ }^{312}$ Adding to the problem is the high incidence of piracy of Caribbean music works overseas. ${ }^{313}$

A further contributor to the net royalty payout trend is the territorial nature of copyright. The rights for which royalties can be collected are not the same in every country. For instance, US copyright legislation withholds public performance right from sound recordings (except for rights in specified digital performances). ${ }^{314}$ This contrasts with the position in countries like Jamaica, the United Kingdom, the European Union, Australia, New Zealand and Canada where the rights in sound recordings are less limited. ${ }^{315}$ Since 1994, Jamaica has been a member of Rome Convention which gives producers of phonograms (sound recordings) the right to be compensated for any broadcast and public communication of their phonograms. ${ }^{316}$ The Jamaican CMO JAMMS collects royalties for broadcasting and public performance

\footnotetext{
311 Keith Nurse "The Cultural Industries in CARICOM: Trade and Development Challenges" (Caribbean Regional Negotiating Machinery Report, 2006 (revised 2007)) at 44.

312 Ibid, at 53 .

313 Allison Demas and Ralph Henry "Entertainment Services with Special Reference to Music, Mas and the Film and Video Segments" (CARICOM Trade Project/ Caribbean Regional Negotiating Machinery Report, 2001) at 103.

${ }^{314}$ US Copyright Act $1976 \S 106(4)$ and (6). For more on the US position on sound recordings see: Paul Goldstein Copyright: Principles, Law and Practice- Volume 1 (Little Brown, Boston, 1989) 610-611 and Lydia Loren "Understanding the Complexity of Music Copyrights in the United States" in Peter Yu (ed) Intellectual Property and Information Wealth: Issues and Practices in the Digital Age - Volume One (Praeger, Connecticut, 2007) 161.

315 See generally: Paul Goldstein International Copyright: Principles, Law and Practice (Oxford University Press, New York, 2001) at 274.

${ }^{316}$ Rome Convention, arts 10 and 12.
} 
rights in respect of sound recordings. Variations within countries' domestic laws on the extent of the public performance right in sound recordings would impact the level of royalties Jamaican sound recording owners receive when their recordings are publicly performed in countries which limit the right, such as the US. When those royalties are compared with the royalties in respect of sound recording rights collected locally by Jamaican CMOs on behalf of foreign rights holders, it is evident that differentials in copyright regimes can result in uneven royalty flows.

\section{Outstanding royalties due to Jamaican CMOs from overseas use of Jamaican works}

Royalties due to Jamaican rights holders from overseas CMOs often go unpaid. A major reason for this is the absence of a performing rights CMO in Jamaica. ${ }^{317}$ The royalties owed to Jamaican performers in France is an estimated US\$ 60 million. ${ }^{318}$ A copyright lawyer noted: ${ }^{319}$

We don't have a performers' rights association, so there's a lot of royalty that is due to performers that sits in escrow in Europe because there is no facility. There is no system by which it can be collected and what we have in Jamaica is an abundance of performers and we have a lot of creators who also perform who will collect from the creation but they will not collect from the performance.

Rights holders observed that the unclaimed overseas money owed to Jamaican rights holders is used to promote the cultural arts in countries in which the funds are held. ${ }^{320}$

Legal, CMO and rights holder stakeholders underscored the need for Government intervention in recouping the sums owed, given the costs and time involved in private recovery actions, as well as the funds' value to the Jamaican economy. As an entertainment lawyer and the JAMMS official argued:

\footnotetext{
317 The currently defunct Jamaica Performers' Administration Society (JPAS) was formed in 2000 to administer performers' rights in live and fixed performances. JPAS is currently inactive pending the implementation of the WPPT (to which Jamaica acceded in 2002). Domestic implementation of the WPPT will give Jamaican performers greater proprietary rights.

${ }_{318}$ Michael Witter "Music and the Jamaican Economy" (UNCTAD/WIPO Report, 2004) at 51-52.

319 R-20. See also: R-29 and Basil Walters "French Lawyer Wins Royalty Payments Case for 180 J'can Artistes" The Observer (Jamaica, 29 July 2005) at 21, in which two French collecting agencies agreed to pay more than $€ 1$ million for outstanding royalties to Jamaican artistes.

${ }^{320}$ See, for example, R-27.
} 
[W]e need...a fund that can help local artistes, local producers audit international record labels and even collecting societies to ensure that there is no unaccounted for money, and if there is a discrepancy they can get it...the more that the Government can help, even in small ways, in bringing money back to the artistes in Jamaica is the better off Jamaicans will be... ${ }^{321}$

[T] he Government...could look at...assisting maybe at a Government to Government level, bilateral level; and intervene and have JIPO and their IP office help to facilitate the claims process, along with the collecting societies and the rights holders at large, and bring home these monies that are there for Jamaican rights owners. ${ }^{322}$

The seemingly non-interventionist attitude of the Jamaican Government can be contrasted with that of the Swedish Government. Sweden is a relatively small, but highly creative, player in the international music market. ${ }^{323}$ Sweden has been ranked highly in terms of enforcement of IP rights ${ }^{324}$ and has maximised its earnings from the domestic music industry: ${ }^{325}$

The domestic presence and international surveillance and enforcement mechanisms of many of these organisations [industry groups and collecting societies], combined with the Swedish state's active international protection of Swedish intellectual property, are important in minimising as much as possible the loss of export revenue within the chaotic maze of international music licensing and consumption, and to a lesser extent to piracy.

On the other hand, in Jamaica's case: ${ }^{326}$

...it is obvious, when compared with the likes of Stockholm that Kingston is reaping extremely meagre benefits from its globally competitive position in music...The Jamaican government has only recently begun to recognise officially the industry's economic significance and potential and attempt to develop a more effective copyright environment.

In summary, greater Government support is required in order for local CMOs to collect the royalties owed to Jamaican rights holders from overseas. The current absence of that assistance could continue to stymie the CMO-centric model of economic development.

\footnotetext{
321 R-46.

${ }^{322} \mathrm{R}-29$

${ }^{323}$ Linda Portnoff and Tobias Nielsén "The Music industry in Numbers - Statistics for 2010 - Executive Report" (Report prepared for the Swedish Agency for Economic and Regional Growth and Musiksverige, 2012) at 2 showing Sweden's export revenue to be nearly 800 million kronor in 2010.

324 See: Property Rights Alliance “International Property Rights Index (IPRI) Report 2012” (2012) <www.internationalpropertyrightsindex.org>. This Report ranks the effectiveness of the intellectual property regimes of 130 countries and gives Sweden a rating of 8.6 out of 10 (or $4^{\text {th }}$ highest in the world) in its protection of intellectual property rights.

325 Dominic Power and Daniel Hallencreutz "Profiting from Creativity? The Music Industry in Stockholm, Sweden and Kingston, Jamaica" (2002) 34 Environment and Planning A 1833 at 1842.

${ }^{326}$ Ibid, at 1848 .
} 


\section{Unfavourable reciprocal arrangements with foreign CMOs}

Another apparent weakness in Jamaica's CMO-dependent economic development strategy is that the terms of reciprocal agreements between local and overseas CMOs may not always be favourable to Jamaican rights holders. In some cases, overseas CMOs, such as PRS, deduct high administration costs from the royalties collected on behalf of Jamaican rights holders before sending these monies to local CMOs for distribution. ${ }^{327}$ Given the confidential nature of those contracts, CMO respondents were not forthcoming as to the exact terms of those arrangements. However, a former policymaker assessed their overall effect on the net distribution to local rights holders: $:^{328}$

[T] he mechanisms [between local and foreign CMOs] have not run as smoothly as one would have hoped; because there were some transitional arrangements between PRS and JACAP in relation to the repertoire and exchange of royalties. And so, to a certain extent the objectives [behind the formation of local CMOs] have not been fully met.

A copyright lawyer/rights holder commented on why Jamaican CMOs might enter into reciprocal agreements with foreign CMOs that cause the royalties to Jamaican rights holders to be minimised: ${ }^{329}$

We believe that we are too poor and we don't develop sufficient revenues to be able to pay out [for use of foreign works]...We then say [to foreign CMOs]: "Okay. Whatever we collect here [in Jamaica] we will keep, and whatever you collect there [abroad], you will keep." What it does is that it does not allow for us to actually benefit from the vast revenues that are available internationally. I mean, the market for Reggae music outside of Jamaica is probably 20 times the size of the market it is in Jamaica...the balance of outflow would have been so much in our favour if we were paying them something and collecting all that was there [overseas].

But we also have a perception of the international system in that it is not sufficiently balanced and that people will not put systems in place there to reflect the true potential and earnings of our music and so we will not recover.

Having had no opportunity to peruse the reciprocal agreements signed by indigenous CMOs, it is difficult to discuss this interviewee's comment in further detail. However, his statement suggests that the challenge for local CMOs is to negotiate reciprocal agreements that are

\footnotetext{
327 See: Keith Nurse "The Caribbean Music Industry: Building Competitiveness and Enhancing Export Capabilities in an Emerging Sector" (Caribbean Export Development Agency Report, 2003) at 53.

328 R-14.

${ }^{329}$ R-20.
} 
favourable to Jamaican rights holders and ensure accountability for both foreign works used in Jamaica and Jamaican works used internationally.

\section{Summary}

Three main factors have led to a steady haemorrhage of royalty fees from Jamaican CMOs to their foreign counterparts: the high level of local consumption of foreign musical works, lax collection mechanisms for monitoring the overseas use of Jamaican music and unfavourable reciprocal arrangements. These conditions could explain why local CMOs have not led to the increased inflow of royalties policymakers anticipated.

Further, there are also problems with the indigenous CMOs' collection of royalties for the local use of Jamaican copyright works, as analysed in the next section.

\section{B Challenges with Collecting Royalties for Domestic use of Jamaican copyright works}

\section{Low levels of collections from local commercial users of music}

The total distributable income collected by Jamaican CMOs is relatively low $^{330}$ due in large part to the failure of a number of commercial users to pay royalties: ${ }^{331}$

(a) Non-compliant commercial radio stations

CMOs use sample playlists or track sheets from radio stations for calculation of royalty fees and distribution of these monies to their members based on respective portions of airplay (after deducting administrative costs). ${ }^{332}$ Playlists perform an important role: ${ }^{333}$

\footnotetext{
${ }^{330}$ Beverley Pereira "A Regional Approach to the Management of Copyright in the Caribbean Community" (PhD thesis, Queen Mary, University of London, 2009) at 92.

${ }^{331}$ See Michael Witter "Music and the Jamaican Economy" (UNCTAD/WIPO Report, 2004) at 53.

332 R-28.

${ }^{333}$ Webley interview.
} 
[T] he playlist is one of the best mechanisms for you to validate or for you to authenticate your claim to payment from royalties. So a playlist is generated or should be generated from a radio station anytime music is played by that radio station and what they generate is a list of all songs that they have broadcast...they then submit these songs to the different collection agencies who are then able to pay the different rights holders.

Despite their importance, several respondents mentioned the habitual delinquency of radio stations to record or submit playlists to the CMOs. ${ }^{334}$ A radio disc jockey respondent is responsible for submitting playlists on behalf of his radio station employer confessed: ${ }^{335}$

...to some degree even as a [radio programme] producer, I have been guilty of not submitting music sheets, but less than some of my peers. Usually, they have to be threatened with suspensions and all kinds [of things] to get them to adhere to submitting music sheets.

The practice of failing to prepare and submit playlists to local CMOs is commonplace for various reasons, including, the generally inadequate formal training received by radio disc jockeys. ${ }^{336}$ Another explanation is the increased demands created by the centralisation of functions performed by individual radio announcers: ${ }^{337}$

...back in the day you had a technical operator, you had the [radio programme host] personality and you had the DJ [disc jockey]. Those functions are now done by one person... The majority of people who play music play from their computer so they can generate lists from that, so it becomes easier with technology, but up to a point.

Another important factor is that the Television and Sound Broadcasting (TSB) Regulations of the Broadcasting and Radio Re-diffusion Act (under which radio and television stations are licensed to operate in Jamaica) do not explicitly require the preparation of playlists. Respondent 10, a senior official with the Broadcasting Commission and veteran broadcaster, advised that the Commission relies on the continuation of good practice, which started in the early decades after the establishment of commercial radio in Jamaica in 1950.

Despite the absence of an explicit requirement in the TSB Regulations, the Broadcasting Commission has since 2011 been increasingly insistent on the filing of playlists. ${ }^{338}$ JARIA has been campaigning for the lodging of playlists and JAMMS is considering investing in technology that would automatically monitor the use of members' works on all local radio

\footnotetext{
${ }^{334}$ For example, Webley and Cooper interviews and R-22, R-27 and R-40.

335 R-3.

${ }^{336}$ Webley interview.

${ }^{337} \mathrm{R}-3$.

${ }^{338}$ See R-40. See also: R-51.
} 
stations. ${ }^{339}$ The extent to which these efforts will result in greater compliance on the part of radio stations remains to be seen. However, the issue of capturing greater royalties from radio stations requires the urgent attention of copyright policymakers. There is significant potential for revenue generation due to the popularity of radio among Jamaican consumers and the fact that CMOs rely heavily on royalties from radio airplay for their income. ${ }^{340}$

(b) Non-payment of royalties by other commercial users of music

Domestic copyright non-compliance is not limited to radio stations. Stage show promoters, hotels, cable operators and other commercial users have also been failing to pay royalties. ${ }^{341}$

Royalties and licensing fees charged by CMOs represent cost pressures to these businesses, both in terms of the quantum of royalty fees and the number of CMOs requesting payment. One legal practitioner observed that collecting societies "put forward inflated tariffs...that are not realistic based on the market." 342 Since different CMOs administer different rights, ${ }^{343}$ users must make payments to different agencies in respect of their use of a single musical work. This causes collection challenges because of users' resistance to compensating multiple payees: ${ }^{344}$

I get the impression that people can feel ripped off when...you have one set of people who come and say "oh, we represent composers and authors." Then you have somebody else turning up saying "I represent producers." And each person comes saying "I am entitled to $5 \%$ of your revenue." It does impact people's bottom line and there is a need, I believe, for more information and for rights agencies to look at how they can collaborate to make copyright enforcement a more efficient exercise for businesses.

Similarly, a copyright attorney who has acted on behalf of CMOs commented: ${ }^{345}$

I know that when I used to do work for collecting societies, it's like you go there [to users] and you try [to collect fees] and they are like: "Oh God, another one?! But we just signed with

\footnotetext{
${ }^{339}$ See R-22 and Steven Jackson "Jamaica Music Society to invest in costly software” The Observer (Jamaica, 3 January 2010).

${ }^{340}$ See Webley interview.

${ }^{341}$ See R-3, R-10, R-28 and R-29.

${ }^{342} \mathrm{R}-14$. It is the Copyright Tribunal's role to moderate these tariffs. See the discussion at Chapter 3.I.C, below.

${ }^{343}$ Rights in the musical work, rights in the sound recording and rights in the literary work.

${ }^{344} \mathrm{R}-10$.

345 R-1.
} 
them."... I know from a user perspective...it's easier from a practical standpoint if you could just deal with one umbrella organisation.

Another reason for commercial users' tendency not to pay for their use of copyright works involves the CMO's role as intermediary between user and rights holder. Commercial users do not directly interact with rights holders and may be sceptical as to whether the funds paid to CMOs are ultimately disbursed to the rightful rights owners. As an economist reflected: ${ }^{346}$

If I buy yam from a farmer, he gets the money but if I operate a [business that uses copyright works] and I pay over to the collecting society for the use of music, how do I know that that money goes back to the singers who were there?

In response to users' concerns, at the time of this research the Government was seeking to draft regulations ${ }^{347}$ under the Copyright Act to address the need for transparency in CMOs. The regulatory goal is to create a situation whereby: ${ }^{348}$

...when these copyright societies go to users, radio station, television station, restaurants and [users] say: "well, who are you?" and "how can you come and say you represent so many other persons and you're going to ask me to pay a licence fee?" They'd be able to say: "Well, we have followed a registration procedure with this Government entity, you can go and see our Articles of Association with the Companies office, we have our audited accounts," that persons can be confident that "we can do business with these persons."

Although the drafting of regulations reflects Government's acceptance of the need for greater control over the affairs of CMOs, unresolved issues remain, such as: the appropriate level of state control over CMO operations and the best way for this Government supervision to take place. Thus far, the extent to which the Government will have the power to audit and supervise CMOs' activities is unclear.

Further, these regulations do not deal with the underlying issue of whether there should be a cap on the number of CMOs allowed to operate in Jamaica. Having more than one organisation for any one category of rights causes a duplication of administrative functions as well as prevents members from benefiting from the economies of scale associated with a

\footnotetext{
${ }^{346}$ Witter interview.

347 At the time of the research these Regulations were being drafted by the Chief Parliamentary Counsel, for subsequent approval by the responsible Minister. To date, these Regulations have not been finalised. ${ }^{348} \mathrm{R}-32$.
} 
single organisation. ${ }^{349}$ Although CMOs in Jamaica currently do not directly compete, a JIPO official said: $:^{350}$

We are concerned that for a small market like Jamaica we really would not wish to have more than one society for each repertoire of work; so, one society for music, one for literary and so on. The experience of other countries which have had three societies, for example for music, as I know in the case of Trinidad and Tobago currently, [is] chaos in the marketplace and we certainly would not want that to happen. Currently, there's no Regulation that would prevent another body from appearing tomorrow [to] say that they will represent composers, authors and publishers of musical works...

Policymakers may therefore wish to consider amending the Copyright Act to make provision for a single $\mathrm{CMO}$ to administer rights in the music industry. To ensure its power is not abused, this CMO's actions would be subject to review by a regulator.

Another option for Jamaican copyright policymakers to consider, which could assist in the rights clearance process (thereby increasing CMOs' domestic royalty revenue), would be the introduction of an extended repertoire system (ERS), also referred to as extended collective licensing (ECL). A common regime in Nordic countries, ERS involves a voluntary assignment or transfer of rights from rights holders to a collective organisation whose repertoire can legally be extended to include both domestic and foreign non-member rights holders. In order to offer users an extended collective licence, a collective organisation must have a substantial number of rights holders in a given category in its membership. ${ }^{351}$ The collective organisation can grant blanket licences to freely use the work without the possibility of a legal or financial claim from the non-represented rights holder. The nonrepresented rights holder is entitled to individual remuneration from the collective organisation and will be legally bound by the agreement between the user and the collective organisation. The law would make provisions for rights holders to expressly withdraw or opt out of an ERS (so that they can exercise their rights individually by negotiating directly with users). This scheme is ideal in countries where a relatively large portion of the copyright

\footnotetext{
${ }^{349}$ See Allison Demas and Ralph Henry "Entertainment Services with Special Reference to Music, Mas and the Film and Video Segments" (CARICOM Trade Project/Caribbean Regional Negotiating Machinery Report, 2001) at 94

350 R-7.

351 See generally: Daniel Gervais "Application of an Extended Collective Licensing Regime in Canada: Principles and Issues Related to Implementation" (Study prepared for the Department of Canadian Heritage, June 2003) and Tarja Koskinen-Olsson "Collective Management in the Nordic Countries" in Daniel Gervais (ed) Collective Management of Copyrights and Related Rights (Kluwer, Netherlands, 2006) 257 at 264-267.
} 
material is foreign owned. In such circumstances, obtaining authorisation can be a complicated and protracted process. Because it accelerates the acquisition of rights, an ERS increases the efficiency and promptness of royalty collection, ${ }^{352}$ particularly since individual rights holders may be unable to negotiate a better licensing deal with commercial users.

\section{High levels of domestic piracy}

Jamaican CMOs' commercial sustainability has also been threatened by excessive levels of domestic piracy among non-commercial users of copyright works. Many of the rights holders, industry group representatives and $\mathrm{CMO}$ respondents interviewed bemoaned the widespread nature of piracy, ${ }^{353}$ which has been worsened by (a) Jamaican cultural attitudes and (b) the internet:

(a) Public attitudes to using music

The public's general attitude to musical works is that these works can be freely copied and shared, without compensating the rights holders. The absence of a culture of copyright compliance in Jamaica accounts for the general reluctance to pay CMOs for the use of copyright works: ${ }^{354}$

People can recognise real estate, a piece of land. They can recognise financial assets. But they find it difficult to recognise intellectual work as something that they must pay to use...there's a sense in Jamaica that: "it's our music and therefore we must be able to listen to it." And even owners of the music themselves will tell you that "...I don't see why I must collect any royalties for it."

352 Daniel Gervais "The Changing Role of Copyright Collectives" in Daniel Gervais (ed) Collective Management of Copyrights and Related Rights (Kluwer, Netherlands, 2006) 3 at 29.

${ }^{353}$ The prevalence of piracy has been documented in previous literature. See, for example: Beverley Pereira "A Regional Approach to the Management of Copyright in the Caribbean Community" (PhD thesis, Queen Mary, University of London, 2009) at 100; Hilary Brown "National Strategy \& Action Plan to further develop the Jamaican Music Industry" (UNESCO Report, 2004) at 4 and Keith Nurse "The Caribbean Music Industry: Building Competitiveness and Enhancing Export Capabilities in an Emerging Sector" (Caribbean Export Development Agency Report, 2003) at 56.

${ }^{354}$ Witter interview. 
This finding is supported by literature in this area, which reveals inadequate understanding among users about copyright and among rights holders about their rights and the management of those rights. ${ }^{355}$

The belief in Jamaican society that "music is free" is deeply rooted in African traditions. ${ }^{356}$ As one entertainment lawyer explained: ${ }^{357}$

Our culture is one steeped in communal participation of cultural forms...It's about the village mentality, transposed from Africa, displaced and placed here in the Caribbean...The music [is] something that is free...[and] should be shared. That's the goal of music...to communicate, at least from the African perspective...We're a society where people come out and hang out together in centres and share music and make music...everybody is a deejay. You talk to people their gardener is a deejay, their barber is a deejay, their hairdresser's son is a deejay. The waiter right now I'm sure that she sings.

Other research has examined the intercultural tensions between Afro-Jamaican and European worldviews on copyright ownership, attributable to the inherently social nature of knowledge in West African society. In West African tradition, because truth and knowledge originate in the spiritual world rather than from individuals, expressions can be detached from their human mouthpieces. ${ }^{358}$ This tradition is reflected in the collectivist tendencies in Jamaicans' attitude to using music. ${ }^{359}$ Copyright law, on the other hand, is underpinned by a more individualist approach to ownership of creative expression. ${ }^{360}$

Because users' and owners' stances on free access to copyright works are so entrenched, the CMOs' collection task is harder to perform, as shown by the following statements from a former policymaker and a CMO respondent:

[JACAP is] fighting a battle to let people understand that there is such a law and what the [copyright] law stands for. ${ }^{361}$

\footnotetext{
${ }^{355}$ See Michael Witter "Music and the Jamaican Economy" (UNCTAD/WIPO Report, 2004) at 51.

${ }^{356}$ See earlier discussion on the traditional cultural value of music at Chapter 2.I.A.

${ }^{357}$ Webley interview. This was supported by the Cooper interview.

358 Carter Van Pelt "Toward a Conventional Copyright System: The Jamaican Experience with Rights Management and a New Law" (Master of Arts dissertation, Columbia University, 2006) at 49-50.

359 See Clinton Hutton "The Creative Ethos of the African Diaspora: Performance Aesthetics and the Fight for Freedom and Identity” (2007) 53 Caribbean Quarterly 127 at 131 calling the nocturnal musical gatherings of African slaves "rituals of repossession engendering a profoundly important psycho-epistemic/psychoontological weaving of personhood, of community, and of agency antithetical to enslavement."

360 Carter Van Pelt "Toward a Conventional Copyright System: The Jamaican Experience with Rights Management and a New Law" (Master of Arts dissertation, Columbia University, 2006) at 51.

${ }^{361}$ R-28. See also: R-14 and R-29.
} 
We [JAMCOPY] do know that there's quite a bit of [unauthorised] copying taking place of sheet music...amongst choirs generally...in churches that project the words upon the screen...less than $1 \%$ of the churches that do [projection]...have a licence. ${ }^{362}$

Policymakers see overcoming the challenge of changing the public's attitude as a fundamental prerequisite for an effective copyright system in Jamaica:

What we ideally want is a copyright culture where people think first and foremost about respecting people's creative works before they pirate it or abuse it. ${ }^{363}$

[An effective copyright system will] ultimately to get to the point where members of the public, they want to use a song they think immediately in terms of "do I need to get permission to use this song?"364

Public education is thus critical. ${ }^{365}$ However, public education requires significant investment in time and resources. Although CMO respondents indicated that they run their own public awareness campaigns, one CMO felt that the Governmental agency, JIPO, ${ }^{366}$ was not fully shouldering its public education responsibility: ${ }^{367}$

I think there needs to be more sustained effort so that...music users are more aware that in fact "I run a business and it is very likely that during the course of my business I'm infringing copyright unwittingly." I think the role of JIPO is to let more persons and businesses be aware that "look, this is something that is with you every day. It's in front of you every day and there's a great chance that you are not being compliant, albeit unwittingly, and you should be."

On the other hand, JIPO respondents pointed out difficulties faced in educating the public, such as a small staff complement and a limited operational budget: ${ }^{368}$

We need an arm that is dealing with publicity and public awareness exclusively...because just like any business that has the communication side, that's what we need here. I think if we had that with, of course, a budget that reflected that, then we'd go a long way.

Given these obstacles, it is perhaps unsurprising that public education has not succeeded in creating a cultural norm of copyright compliance. While altering the public's perception is

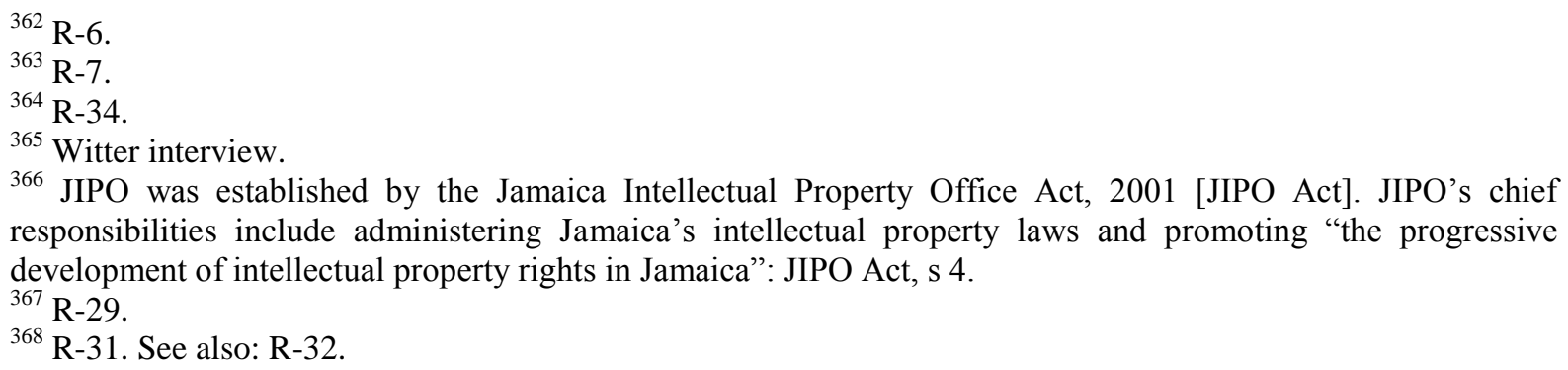
responsibilities include administering Jamaica's intellectual property laws and promoting "the progressive development of intellectual property rights in Jamaica": JIPO Act, s 4. 
likely to be a slow and difficult process, the creation of a dominant copyright compliance culture is crucial for local CMOs to be able to collect royalties more easily.

\section{(b) Internet technology}

In addition to cultural practices, a further threat to the commercial viability of indigenous CMOs is Jamaicans' increased usage of the internet. ${ }^{369}$ Greater connectivity has given the public more access to musical works and made it more difficult for CMOs and rights holders to monitor this access. While these challenges are not unique to Jamaica, there is a strong sense that technology has outpaced Jamaican rights holders' efforts to recover income from the use of their work on the internet, as a copyright lawyer observed: ${ }^{370}$

Whereas [Caribbean countries] are just now getting into these modules of collective administration to get royalties, the Internet is making some of these modules redundant so we are catching up but not fast enough.

Two CMO respondents remarked:

Years gone by, what was done with the PRS, was that you had organisations, businesses that would supply bars with music through a jukebox. ${ }^{371}$ Those jukeboxes had to be licensed and as such, [PRS] would get a list of the songs, the records that were in the jukeboxes and with that licence again, assign...the royalties...Today, with the advent of the internet and satellite, it's almost impossible; because now a guy sets up a satellite receiver and he...can collect music from anywhere in the world and play it...not only are they downloading music but it also comes into piracy because they now are suppliers of music. They are not licensed suppliers... How does an organisation like JACAP capture that? We can't. ${ }^{372}$

I think seeing the internet as free...just makes it far more of a challenge for content creators to be able to protect their work and to be rewarded for it or even be acknowledged for it. ${ }^{373}$

Licensing opportunities in the digital environment should expand once the Copyright Act 1993 has been amended ${ }^{374}$ to comply with the WIPO Copyright Treaty 1996 and WIPO

\footnotetext{
${ }^{369}$ See Chapter 1.I.E on the increased technological opportunities in Jamaica to access copyright works.

370 Dianne Daley's presentation at the Commission on Intellectual Property Rights' Conference: "How Intellectual Property Rights Could Work Better for Developing Countries and Poor People" (The Royal Society, London, 21-22 February 2002) Session 4: Copyright and Developing Countries Transcript.

${ }^{371}$ On jukeboxes, see Chapter 2.II.A.2.

372 R-28.

${ }^{373}$ R-6.

${ }^{374}$ The Amendment Bill has been drafted and is in the final stages of approval. As the Bill is still in the drafting stage, no proposed amendments are disclosed to the public. Passage is anticipated in 2013.
} 
Performances and Phonograms Treaty 1996 (WIPO internet treaties). ${ }^{375}$ There would be more opportunities for licensing online music services, which include any music service provided on the Internet such as webcasting, downloading, simulcasting (the simultaneous transmission of radio or TV programmes over the Internet), streaming, online "on-demand" service and music services provided to mobile telephones, such as ringtones. However, music industry stakeholders' unfamiliarity with online royalty collection means they are likely to continue to grapple with recovering royalties lost due to unauthorised online activities. ${ }^{376} \mathrm{~A}$ JACAP respondent described the problems with online licensing: "the whole matter of protection online is still a very grey area...[it] is still in its infancy [and] understanding online licensing and how royalties are paid out, I think could go a long way."377

Similarly, an economist explained music rights holders' predicament in levying royalty fees for works disseminated online: ${ }^{378}$

We are used to shipping out banana. So we agree with the people how much for a bunch of banana. We count the amount of banana and we get an amount of money. How do you do that with a riddim track $?^{379}$ Somebody has a riddim and they put it in a flash drive and they email it out and how do you collect payment on those kinds of things? And if those of us who are in the business of recognising it as property [are] having difficulty pricing it, then the ordinary person, it is hard for them to comprehend at this point in time.

From the users' perspective, internet use among the current generation of Jamaicans supports an attitude of non-payment: ${ }^{380}$

...you now have a generation of people who have never paid and never intend to pay; so even if it wasn't because of drumming back in Africa that they didn't want to pay [for copyrighted musical works], now they don't want to pay because they grew up with Limewire...Napster... Myspace, with their friends posting their music for free...with online radio where it's streaming all day for free; why are they going to buy a CD?

\footnotetext{
375 The WIPO Copyright Treaty 1996 [WCT] and WIPO Performances and Phonograms Treaty, 1996 [WPPT] (adopted in Geneva 20 December 1996) deal primarily with obligations concerning technological protection measures and rights management information in the digital environment. These treaties: grant rights owners protection when their works are disseminated on the Internet and contain provisions requiring States to legislate efficient protection for technological measures (by prohibiting the import, manufacture and distribution of illicit circumvention devices and also criminalising acts detrimental to rights management information systems, such as the circumvention of technical protection measures and the removal or alteration of any elements of the digital information systems).

${ }^{376}$ This is of course, an international problem.

${ }^{377}$ R-49A.

${ }^{378}$ Witter interview.

${ }^{379}$ Riddims were defined in Chapter 2.II.A.4(c).

${ }^{380}$ Webley interview.
} 
However, CMOS are attempting to gain ground by adopting rights management practices responsive to the digital environment. For instance, the $\mathrm{CMO}$ respondents interviewed mentioned that their organisations were interested in venturing into licensing online distributions of copyright works:

[JAMCOPY] manage[s] reproduction rights in books, magazines, newspapers, journals, things in print media, for the most part. We are looking at managing materials also in digital format, although our licences do include some digital uses. ${ }^{381}$

In terms of [JAMMS licensee] categories, we're talking radio and television broadcasters, cable operators, webcasters in terms of simulcasters [simultaneous broadcasters] and all of that. ${ }^{382}$

The JACAP representative indicated that his organisation was interested in licensing ringtones to cellular companies. ${ }^{383}$ However, licences would also be required for a range of online activities, such as: interactive services, internet radio and digital broadcasts.

The literature has attempted to propose various solutions to the problem created by technology, ${ }^{384}$ including the use of anti-piracy technological tools. ${ }^{385}$ Interviewees suggested three main remedies for the problem. First, numerous respondents advanced public education as an answer. For example, the JAMCOPY representative noted: ${ }^{386}$

[Persons] think public education [is] not going to help because people know and still do wrong but there has to be a place for education that things on the internet is not free and not because it is there you can reach out for it...that just like how you can't walk into a bookshop or you can't walk into a record shop and take up a CD and walk out with it, it's the same principle that applies on the internet.

The second recommendation, from the JACAP representative, was that internet service providers (ISPs) should be licensed by CMOs in their country of operation: ${ }^{387}$

\footnotetext{
381 R-6.

${ }^{382} \mathrm{R}-29$

383 R-28.

${ }^{384}$ See: Marco Ricolfi "Individual and Collective Management of Copyright in a Digital Environment" in Paul Torremans (ed) Copyright Law: A Handbook of Contemporary Research (Edward Elgar, Cheltenham, 2007) 283 and Meghan Dougherty “Voluntary Collective Licensing: The Solution to the Music Industry's File Sharing Crisis?" (2006) 13 J Intell Prop L 405.

${ }^{385}$ See Allison Demas and Ralph Henry "Entertainment Services with Special Reference to Music, Mas and the Film and Video Segments" (CARICOM Trade Project/Caribbean Regional Negotiating Machinery Report, 2001) at 100-102 on banderole/hologram anti-piracy devices.

386 R-6.

${ }^{387} \mathrm{R}-28$.
} 
That's the only way we can capture [royalties lost through the internet]. If you go on the internet, you can go to anyone and download a song for 99 cents. Now, how is that 99 cents divvied up? Where's the royalties on that?

Third, a solution suggested by the Broadcasting Commission official ${ }^{388}$ was that a special regulator should be created for licensing providers of content on the internet and other media who offer their work for sale. He justified this approach on the basis of changes in the media landscape which enable ordinary individuals to become commercial content creators (who could then be licensed and answerable to a regulator). All three options merit further consideration by policymakers.

\section{Summary}

This section analysed the challenges Jamaican CMOs encounter in the domestic collection of royalties for the use of music. Not only has there been a low level of compliance among commercial users but the public's cultural attitudes, along with internet technology, have made the collection exercise more difficult.

\section{Lack of Use of the Copyright Tribunal}

The monopoly enjoyed by CMOs in relation to users may generate incentives for these organisations to behave in a manner which limits users' rights or abuse its dominant position. ${ }^{389}$ CMOs may charge excessive rates for royalties which users are unable to pay. The Copyright Tribunal acts as a forum for licensees and potential licensees to bring disputes. By ensuring that reasonable licensing fees are agreed on, the Copyright Tribunal aids CMOs in royalty collection.

\section{Role of the Copyright Tribunal}

\footnotetext{
${ }^{388} \mathrm{R}-10$.

${ }^{389}$ See Whitney Broussard "The Promise and Peril of Collective Licensing" (2009) 17 J Intell Prop L 21 at 27 28.
} 
The Jamaican Copyright Tribunal is a quasi-judicial institution whose primary function is to hear and settle disagreements between users and collecting societies regarding royalty rates and terms of licences. This adjudicatory body, established under the Copyright Act, ${ }^{390}$ is charged with the following duties: ${ }^{391}$

(a) to hear and determine-

(i) any matter referred to it... pursuant to any provision of Part VII relating to a licensing scheme or licence [CMOs];

(ii) an application under section 101 to settle the royalty or other sum payable for rental of a sound recording, film or computer program;

(b) to keep under review the prescribed rate of royalty payable to a performer in connection with an adaptation of an original recording of his performance; and

(c) to make recommendations to the Minister on the rate of royalties or other payments payable in respect of the use or presentation in such national cultural event as he may by order designate, of any works or performance in which copyright or other rights subsist.

The Minister may make regulations governing the Tribunal's operations, including: stipulating the factors the Tribunal must consider before entertaining applications from organisations claiming to act on behalf of licensees or prospective licensees; imposing rules prohibiting references from user organisations; specifying parties to proceedings and governing how proceedings before the Tribunal be conducted. ${ }^{392}$ The statute gives parties the right of appeal to the Supreme Court on a point of law arising from the Tribunal's decision. ${ }^{393}$

The idea for a Copyright Tribunal in the Jamaican Copyright Act came from the UK Copyright, Designs and Patents Act 1988. UK lawmakers had seen a need for a Copyright Tribunal because of CMOs' dominance in the licensing market. ${ }^{394}$ As the drafter of the Jamaican Copyright Act explained: ${ }^{395}$

If you have performing rights, for example, you're going to have one strong organisation. Your broadcasting companies couldn't work if that organisation says 'I'm not giving you any

\footnotetext{
${ }^{390}$ Copyright Act, s 103.

391 Copyright Act, s 104(1). See the Schedule to the Act for the composition and procedural rules of the Copyright Tribunal.

392 Copyright Act, ss 100 and 105. To date, no regulations to this effect have been promulgated.

393 Copyright Act, s 106.

394 The Copyright Tribunal's predecessor was the Performing Rights Tribunal, initially introduced in the UK Copyright Act 1956.

${ }^{395} \mathrm{R}-15$.
} 
licence"... or "I'm not giving you a licence unless you pay this amount", which could be excessive, because it's a monopolistic position. To whom would the user, in this case, let's say a broadcasting organisation, turn? Instead of running to the court, the Tribunal was put now to say: "that is who you must go to and they will determine." So the Tribunal will make a business decision....and also [consider] public policy.

The Copyright Tribunal was intended to hear matters in relation to licensing schemes, or licences granted by a licensing body in regard to the copyright in: literary, dramatic, musical or artistic works or films (or soundtracks that accompany films) provided such licences or licensing schemes cover works of more than one author. ${ }^{396}$ Such licenses or schemes must relate to the protected work's reproduction, public performance, broadcasting or cablecasting. The Tribunal can also deal with licensing schemes and licences in relation to copyright in sound recordings, broadcasts and cable programmes. ${ }^{397}$ In regard to the scope of disputes, the legislation is very clear that the local Copyright Tribunal, like its UK counterpart, would essentially deal with applications involving the amount of licensing fees levied, the terms of licences and CMOs' refusal to grant a licence. Part of its job is to set and review tariff rates and structures. ${ }^{398}$

Essentially, the Copyright Tribunal is interposed between the dominant rights holder and user to guard against exorbitant licence fees and unconscionable licence terms. Because the Copyright Tribunal is a kind of competition regulator, resolving cases of alleged copyright infringement is outside its purview. ${ }^{399}$

\section{Efficacy of the Copyright Tribunal}

Although designed to play a key role in the copyright management system, in its 19-year existence the Jamaican Copyright Tribunal's dispute mechanism remains untested.

\footnotetext{
${ }^{396}$ Copyright Act, ss 88(a) and 95(a).

${ }^{397}$ Copyright Act, ss 88(b) and 95(b).

${ }^{398}$ Copyright Act, ss 89-99.

399 See Uma Suthersanen "The Role and Structure of the United Kingdom Copyright Tribunal" in Ysolde Gendreau (ed) Institutions administratives du droit d'auteur/Copyright Administrative Institutions (Yvon Blais, Montreal, 2002) 481 and UK Intellectual Property Office "Review of the Copyright Tribunal" (May 2007) at 10-12 <www.ipo.gov.uk/ctribunalreview.pdf>. See also: R-15.
} 
There is disagreement between policymakers and rights holders as to the Tribunal's proper role. After the Copyright Act was passed, policymakers realised that rights holders had an erroneous opinion about the tasks the Copyright Tribunal would be undertaking: 400

There was an expectation that the Copyright Tribunal would perform the role of the court... that if a man is taking your work you must be able to run cheaply and quickly to somebody who will say: "this person is wrong"...that the Government would champion or provide a system that would facilitate the championing of the rights of people. So there was disappointment that you had to go to the courts for infringement.

Given the costs and delays associated with suing for copyright infringement in the mainstream court system, ${ }^{401}$ rights holders felt that if making pronouncements about copyright infringement was off-limits, then the Tribunal's utility was diminished.

Not only were rights holders dissatisfied that the Tribunal could not determine copyright liability, CMOs were also unhappy with the Tribunal's narrow terms of reference. The Copyright Act gives persons (or organisations that require licences) the right to bring licensing matters (such as proposed terms of a licensing scheme, refusal to grant a licence, rates and licensing terms) before the Tribunal. ${ }^{402}$ But the Copyright Act does not allow operators of licensing schemes to initiate claims or refer licensing disputes to the Tribunal. Unable to approach the Tribunal with disputes against licensees, CMOs regard access to the Tribunal as skewed in favour of users. The JAMCOPY representative said: ${ }^{403}$

We have been negotiating with a particular user...for 7 years and we're just left at the mercy of the particular user because the rights holder or the rights holder organisation in this case cannot take a matter to the Tribunal. The only recourse left to us is to go to the Supreme Court, which is time-consuming. The cost to do that is tremendous.

From CMOs' perspective, the statute has barred access to the Copyright Tribunal. While these complaints explain rights holders' and CMOs' failure to utilise that body, they do not account for why users, who are statutorily guaranteed access to the Tribunal, have not made

\footnotetext{
${ }^{400}$ R-15.

${ }^{401}$ See R-1, R-6, R-34, R-44, R-47B and R-51.

402 See for example, Copyright Act, s 89(1), 90(1)(b), 92(1) and (2), 96(1) and 97(1). The CMO can apply for a review of an order that has been made: see s 93(1) and 98(1). By virtue of s 101, copyright owners can apply to the Tribunal to settle the royalty under s 78 of the Act (in regard to rental of sound recordings, films or computer programmes).

${ }^{403}$ R-6.
} 
use of it. To understand the reason for this, one must revisit the assumptions underlying the rationale for the Tribunal.

The Tribunal's purpose is to balance the interests of users and licensing organisations by acting as a referee or gatekeeper. Its operation is implicitly premised on having an active group of user organisations who are aware of the Tribunal's function; and whose predisposition to paying for licences causes them to approach the Tribunal with unresolved licensing issues. However, in Jamaica, each premise can be challenged. For example, licensees are largely ignorant about the Copyright Tribunal's existence and role, as an entertainment lawyer observed: ${ }^{404}$

I don't think [commercial users] are aware of [the Copyright Tribunal]... And also, when and if it is publicised more, I think care needs to be taken as to what it actually does.

Moreover, the Tribunal is seemingly a poor fit in the Jamaican music industry because its market conditions differ from the UK, primarily in terms of consumer practice. A copyright academic described the behavioural difference between users in the more sophisticated UK market and the embryonic Jamaican music industry environment: ${ }^{405}$

...the Tribunal is good in a context where you have a society that wants to become compliant and you have a group of users who are proactive enough to ensure that [licensing] terms are fair. Whereas in Jamaica, you have a group of users who never want the issue to be aired and so they will never initiate an action...And so, there's no functionality there.

Similarly, a JACAP representative affirmed: ${ }^{406}$

The average [commercial] user is not aware of the [copyright] law and the average user is saying: "why should I pay to play? If I don't play this in my place of business you [the rights holders] get no exposure."

Therefore, user attitudes in the Jamaican music industry undermine the presumptions on which the Tribunal is based, effectively preventing the execution of its mandate.

Rights holders' and CMOs' dissatisfaction with the Tribunal, coupled with users' general ignorance of its existence and reluctance to obtain licences, has transformed the Copyright

\footnotetext{
${ }^{404} \mathrm{R}-1$.

${ }^{405} \mathrm{R}-14$

${ }^{406}$ R-28.
} 
Tribunal into what stakeholders referred to as the proverbial "white elephant"407 or a nonoperationalised "paper provision." 408 The fact that the Tribunal has never heard a case was cited as a "very telling" example of the low level of implementation of the copyright legislation. ${ }^{409}$ On the other hand, a former policymaker noted: ${ }^{410}$

[We brought] down the retired Chairman of the UK Tribunal [to Jamaica] and his view was that just the existence of the Tribunal sometimes helps people to sort [licensing] out, because they don't want an arbitrator to meddle in their business.

Possibly, awareness that users can resort to the Tribunal encourages CMOs and users to engage in private negotiation instead.

However, stakeholders agreed that amending the Copyright Act to extend its jurisdiction could improve the Tribunal's usefulness. Specifically, respondents felt the Copyright Act ought to empower the Tribunal to:

- enquire into the commercial negotiations of rights holders and users to ascertain whether rates are reasonable, particularly: "whether somebody is putting forward a rate which is in fact frustrating another party from complying with the Copyright provisions or whether somebody is being intransigent...disrespectful and undervaluing people's rights."

- offer general assistance in the low-cost resolution of copyright infringement disputes and advice to rights holders (as to what agreements they should enter into or should be wary of) so that the specific purpose of commercial exploitation of copyright can be achieved; ${ }^{412}$

- hear licensing disputes from CMOs and other rights holder organisations; ${ }^{413}$

- review statutorily-set royalty rates for the use of all categories of copyright works; ${ }^{414}$

\footnotetext{
${ }^{407} \mathrm{R}-14$.

${ }^{408} \mathrm{R}-10$

${ }^{409}$ Corthésy interview.

${ }^{410} \mathrm{R}-15$

${ }^{411} \mathrm{R}-10$.

${ }^{412} \mathrm{R}-44$

413 R-6.

${ }^{414}$ R-14.
} 
- determine the granting of licences in respect of orphan works (copyright works whose author cannot be identified or located ${ }^{415}$ including setting licence fees for such use. ${ }^{416}$

Given the need to promote the licensing of music use in Jamaica, enlarging the authority of the Copyright Tribunal may be helpful. ${ }^{417}$ However, legislative efforts strengthening the powers of the Jamaican Copyright Tribunal will be more effective if users' awareness of the Tribunal's presence and function is also raised and the culture of non-compliance changed.

\section{Membership of foreign CMOs favoured by Jamaican rights holders}

Another concern for indigenous CMOs is that many Jamaican rights holders opt for membership of foreign CMOs instead of local ones, which represents revenue losses for local CMOs in terms of administration fees. ${ }^{418}$ As one industry insider said: ${ }^{419}$

There are many of us who the management of their performance rights and other related rights are really done outside of the country.

Additionally, some rights holders are following their money by emigrating overseas: ${ }^{420}$

Lack of an effective system for collecting and protecting rights revenues has been an important, though not the only, factor in the rapid relocation of nearly all recent [Jamaican music industry] stars to other countries (in particular to the US).

The overseas migration of local talent could have negative implications for the long-term sustainability of indigenous CMOs and the Jamaican music industry in general. If funds generated from Jamaican rights holders' copyright earnings continue to be diverted, the

\footnotetext{
415 See Pamela Brannon "Reforming Copyright to Foster Innovation: Providing Access to Orphaned Works" (2006-2007) 14 J Intell Prop L 145 at 147.

${ }^{416}$ R-1. The Copyright Board of Canada is empowered under s 77 of the Canadian Copyright Act (RSC 1985, c C-42) to issue licences in respect of orphan works.

${ }^{417}$ The powers of the Jamaican Copyright Tribunal can be contrasted with an alternative regulatory model, such as the Copyright Board of Canada, which has a wider scope in that it handles all licensing matters. See generally: Daniel Gervais "A Uniquely Canadian Institution: The Copyright Board of Canada" in Ysolde Gendreau (ed) An Emerging Intellectual Property Paradigm: Perspectives from Canada (Edward Elgar, Cheltenham, UK, 2008) 197 and Howard Knopf "Canadian Copyright Collectives and the Copyright Board: A Snap Shot in 2008" (Paper presented to Law Society of Upper Canada Continuing Legal Education Program, Ottawa, 28 February 2008) at 14-21.

${ }^{418}$ Administrative costs can average between 25-50 per cent of collections, see: JACAP “JACAP's Response to a news article printed in the Daily Gleaner on Monday, December 20, 2010" (2011) <www.jacapjamaica.com>. 419 R-9.

${ }^{420}$ Dominic Power and Daniel Hallencreutz "Profiting from Creativity? The Music Industry in Stockholm, Sweden and Kingston, Jamaica" (2002) 34 Environment and Planning A 1883 at 1849.
} 
royalty income from which indigenous CMOs can deduct their fees, and thus their resource base, will shrink. This means fewer resources with which to carry out monitoring, collection and enforcement. Lack of resources would, in turn, affect CMOs' performance in these areas, making them less attractive to Jamaican rights holders.

How do music industry stakeholders evaluate the performance of indigenous CMOs? And why are foreign CMOs considered preferable to indigenous CMOs? The next two subsections discuss these issues.

\section{Performance of Jamaican CMOs}

Membership of some local CMOs has grown. For example, in the 60 years it operated in Jamaica, PRS had a local membership of approximately 1,100 rights holders; whereas, within 12 years of existence, JACAP's local membership stands at over 2,300. ${ }^{421}$ These statistics show that some music industry rights holders do recognise the value of local CMOs.

Furthermore, some rights holders expressed satisfaction with the performance and quality of representation of local CMOs. Based on their feedback, local CMOs appear to be proficient at a range of skills, such as:

- Gaining authority in the music industry and building the trust of rights holders; ${ }^{422}$

- Improving rights holders' awareness of copyright; ${ }^{423}$

- Marketing CMOs' role and services to both rights holders and users; ${ }^{424}$

- Penetrating the domestic market for licensing commercial music usage; ${ }^{425}$ and

- Increasing efficiency and improving collection networks regionally and internationally. ${ }^{426}$

\footnotetext{
${ }^{421} \mathrm{R}-49 \mathrm{~A}$ and R-28. JAMCOPY represents 250 publishers and creators (R-6) and JAMMS acts on behalf of 400 local record producers: Steven Jackson "Music Earnings Hit Sweet Note" The Gleaner (Jamaica, 5 April 2012). ${ }^{422} \mathrm{R}-22, \mathrm{R}-36$ and R-37A.

${ }^{423}$ See Davis interview.

${ }^{424}$ See R-49B.

${ }^{425}$ See R-29.
} 


\section{Reluctance of rights holders to join Jamaican CMOs}

Notwithstanding these positive reviews of indigenous CMOs, membership of foreign CMOs is still the norm within the music industry. ${ }^{427}$ Local CMOs have difficulty satisfying some rights holders that they can collect royalties as well as overseas CMOs. For example, a Jamaican performer (a first-time JACAP member and longstanding member of ASCAP, BMI and PRS) remarked: ${ }^{428}$

I'm just going to watch and see how they [JACAP] perform, if they are just as efficient as the other competitive companies that are out there dealing with royalties...ASCAP has been doing a good job over the years: because from time to time I get my royalties and my publishing rights really issued to me [from ASCAP]...they give you information too [and] tell you when they have cases; because right now they [are] out to sue some movie people [who are using] our thing.

A common view exists among rights holders that foreign CMOs are more vigilant and better resourced to collect royalties on behalf of their members. However, in reality, foreign CMOs often do not have mechanisms in place to fully capture the use of Jamaican music used overseas. ${ }^{429}$ According to one rights holder: ${ }^{430}$

Ironically, an artiste would register with ASCAP or...other agencies abroad, and not register locally because they think it's a bigger pool, even though those societies don't represent our music well and they really have no interest because the American pool and other society pools are much bigger. With JACAP, who I'm a member of also, they will collect in a lot of the small territories which will work for the minor artiste.

Jamaican rights holders who are members of overseas CMOs tend to be ignorant about indigenous CMOs' collection operations. A local singer with 24 years' experience in the music industry, who is a member of ASCAP said: ${ }^{431}$

I've never been signed up with a company [CMO] in Jamaica. My publishing house is in the [US]. And I'm not sure how much of [the Copyright Act] is really enforced in the collecting agencies around Jamaica.

\footnotetext{
${ }^{426} \mathrm{R}-7$ and R-28.

${ }^{427}$ Hilary Brown "National Strategy \& Action Plan to further develop the Jamaican Music Industry" (UNESCO Report, 2004) at 9.

428 R-36.

${ }^{429}$ Keith Nurse "The Cultural Industries in CARICOM: Trade and Development Challenges" (Caribbean Regional Negotiating Machinery Report, 2006 (revised 2007)) at 203.

${ }^{430} \mathrm{R}-3$.

$431 \mathrm{R}-5$
} 
The practice of favouring foreign $\mathrm{CMO}$ membership probably stems from the fact that foreign CMOs predate local CMOs, which were only formed in the late 1990s. This meant Jamaican rights holders grew accustomed to joining foreign CMOs: ${ }^{432}$

By the time I started writing my songs in the early 80s, I had gone with an American company. There was no [local] agency here...to collect on behalf of the artistes.

Another reason for the preference for foreign CMO membership is some rights holders' suspicion about indigenous CMOs' use of funds collected on their behalf. This distrust is apparent in the two rights holders' comments:

There are times when we think we should be getting more [money from JACAP] than we are actually getting. ${ }^{433}$

There's whispers within the industry that some time the collecting agency, they get your money and they put it in this fixed deposit and build interest on it and then they pay you after...the system that we have here, there's a lot of corruption in it and therefore it takes time sometime for artistes to get pay. ${ }^{434}$

This outlook could explain why, despite the higher costs associated with membership of overseas CMOs, local artistes favour joining those agencies. ${ }^{435}$

Rights holders' mistrust of local CMOs' handling of their contractual duties may be connected to a general misunderstanding about how royalty payments are calculated. ${ }^{436}$ For instance, the funds collected by JACAP are paid to rights holders based on the use of each song. If a JACAP member's song receives minimal airplay, JACAP will give that member an unlogged performance allocation (UPA) instead of a royalty. But receiving a UPA can contribute to the belief that JACAP is withholding royalties, as these respondents explained:

There's this great level of [rights holders being] not sure what to expect; what's a reasonable expectation. So somebody wrote a part of a song and come and say "listen, I wrote the song 5 years now and I don't see no royalties yet." ${ }^{437}$

\footnotetext{
432 R-5.

${ }^{433} \mathrm{R}-37 \mathrm{~A}$

${ }^{434} \mathrm{R}-40$.

435 Joan Webley "First World Copyright Law in Third World Jamaica: Is There a Need for a New Approach?" (Article prepared for the International Association of Entertainment Lawyers, 27 November 2009) at 4.

${ }^{436}$ See "Jamaican Artistes Sing The Blues" The Gleaner (Jamaica, 20 December 2010).

${ }^{437} \mathrm{R}-49 \mathrm{~B}$.
} 
...if your song don't play, you don't have anything to get...Because when distributions are made by copyright societies the songs that are active; the songs that have earned that money; form a part of that distribution, so it's not like..."JACAP get the thing [royalty] and hide it". ${ }^{438}$

\section{Summary}

Despite the creditable performance of indigenous CMOs, several factors cause Jamaican rights holders to be more willing to join foreign CMOs, including: foreign CMOs' perceived efficiency, historical reasons, concerns about indigenous CMOs' financial accountability as well as uncertainty about the mechanics of disbursement of royalties collected by indigenous CMOs. Increased membership of local CMOs would mean that Jamaican rights holders could benefit more from domestic collective administration. As one record producer argued: ${ }^{439}$

We have local organisations here but people join the foreign organisations and expect the [Jamaican] Government to help them to benefit from a foreign organisation...We need to support our own...We need to join organisations and...lobby collectively as Jamaicans and Jamaican entities.

\section{E The Absence of a Socio-Cultural Role for Local CMOs}

Another feature of collective administration in Jamaica is that indigenous CMOs operate as essentially rights management organisations which license the use of copyright works and collect and disburse royalties. As mentioned previously, the Jamaican Copyright Act does not give CMOs a cultural promotion directive. ${ }^{440}$ In this regard, Jamaican CMOs imitate the Anglo-American model, which emphasises the economic function of CMOs. ${ }^{441}$ Thus, any social and cultural assistance given by indigenous CMOs is voluntary and on an ad hoc basis, as these organisations have no charitable arms. The absence of a socio-cultural role is a weakness of the current Jamaican copyright regime because it limits CMOs' attractiveness to rights holders and users, thus indirectly affecting their commercial viability.

\footnotetext{
${ }^{438} \mathrm{R}-49 \mathrm{~A}$.

439 R-4.

${ }^{440}$ See Chapter 2.III.C.

${ }^{441}$ CMOs in the US have been criticised for not serving cultural functions: see Daniel Gervais "The Landscape of Collective Management Schemes” (2011) 34 Columbia Journal of Law \& the Arts 423 at 427.
} 
European CMOs, on the other hand, undertake various responsibilities towards their members over and above royalty collection, for example, training, insurance, career advice and health and retirement funds, as well as supporting rights holders' dependants. ${ }^{442}$ Moreover, from a public interest perspective, European CMOs are not solely private agents acting on rights holders' behalf. They are viewed by their respective governments as an important part of maintaining the copyright balance between private rights and users' interests. For example, German copyright law recognises that: ${ }^{443}$

...when fulfilling their legal, societal, cultural and social functions, CMOs in Germany discharge the State from those tasks that it would normally have to fulfil itself to safeguard the functionality of copyright.

Accordingly, European CMOs are charged with promoting the creation of new works and the use of national works. ${ }^{444}$ In stimulating cultural development, European CMOs generally work closely with or under the oversight of the ministries of culture and education. ${ }^{445}$ Monies are deducted from the funds collected by CMOs for use in furthering cultural and social purposes, such as grants to creators, competitions, awards, scholarships, educational or creative programmes and live stage performances. ${ }^{446}$ Given the high levels of cultural diversity in Europe, these CMOs ensure that the minority cultures represented by various local ethnic communities receive cultural support. ${ }^{447}$

However, there is some debate as to the appropriateness of giving CMOs a cultural promotion mandate. Those who support authorising CMOs to carry out these functions argue that this ultimately benefits CMOs' members by raising the public's respect for creators and copyright works. Proponents also suggest that CMOs' cultural promotion activities offer additional incentives to authors who are new or financially disadvantaged and showcase

\footnotetext{
${ }^{442}$ See Chapter 2.III.C.

443 Jorg Reinbothe "Collective Rights Management in Germany" in Daniel Gervais (ed) Collective Management of Copyrights and Related Rights (Kluwer, Netherlands, 2006) 193 at 199.

${ }^{444}$ See: Adolf Dietz "Legal Regulation of Collective Management of Copyright (Collecting Societies Law) in Western and Eastern Europe" (2002) 49 J Copyright Soc'y USA 897 at 912-913.

${ }^{445}$ For instance, in France the Minister of Culture may issue or withdraw approval for societies in certain collection sectors: Nathalie Piaskowski "Collective Management in France" in Daniel Gervais (ed) Collective Management of Copyrights and Related Rights (Kluwer, Netherlands, 2006) 153 at 166-167.

${ }^{446}$ See Roger Wallis, Charles Baden-Fuller, Martin Kretschmer and George Michael Klimis "Contested Collective Administration of Intellectual Property Rights in Music: The Challenge to the Principles of Reciprocity and Solidarity" (1999) 14 European Journal of Communication 5 at 12-13.

447 See KEA European Affairs "Collective Management of Rights in Europe: the Quest for Efficiency" (European Parliament Report, 2006) at 6-7.
} 
categories of works consumers may ordinarily overlook. ${ }^{448}$ Additionally, funding cultural promotion activities from royalty income collected by CMOs (instead of the government's coffers) relieves some of the burden on public revenues, thus freeing up resources for other government programmes. ${ }^{449}$

Conversely, European CMOs have been criticised for making cultural deductions. ${ }^{450} \mathrm{CMOs}$ ' performance of cultural tasks is thought to conflict with copyright owners' exclusive rights. This is because rights holders only give nominal consent to these cultural activities when they join CMOs that already engage in those activities. ${ }^{451}$ Additionally, it is claimed that in light of user groups' distrust of CMOs (because of their monopoly in the licensing market), the public may have further misgivings if CMOs' authority were to be enlarged in this way. ${ }^{452}$

In the Jamaican context, several respondents pointed to the dire financial conditions artistes sometimes encounter in the absence of government aid for impoverished artistes:

...Gregory Isaacs [eminent Reggae singer] pass away and they bury the King at Dovecot [burial grounds for the interment of paupers]. Even the heads of Government should have said "Boy, God Almighty, let me find even a piece of open land..." [for his burial]...there's nothing, no preparation here for the artistes. ${ }^{453}$

We [Recording Industry of Jamaica and Jamaica Association of Vintage Artistes and Affiliates] have been lobbying to Government to make it easier on musicians because our business, we don't have any pension...our business is up and down: today you're up and tomorrow you're down. And what do you do after that ${ }^{454}$

Respondents also identified other industry needs such as: musical equipment for schools, cultural programmes, state-of-the-art entertainment venues with first-rate acoustics for the

\footnotetext{
448 See Adolf Dietz "Legal Regulation of Collective Management of Copyright (Collecting Societies Law) in Western and Eastern Europe” (2002) 49 J Copyright Soc'y USA 897 at 913.

449 See Laurence Helfer "Collective Management of Copyright and Human Rights: An Uneasy Alliance" in Daniel Gervais (ed) Collective Management of Copyrights and Related Rights (Kluwer, Netherlands, 2006) 85 at 110 .

${ }^{450}$ Roger Wallis, Charles Baden-Fuller, Martin Kretschmer and George Michael Klimis "Contested Collective Administration of Intellectual Property Rights in Music: The Challenge to the Principles of Reciprocity and Solidarity" (1999) 14 European Journal of Communication 5 at 16 and 24-25.

${ }^{451}$ Laurence Helfer "Collective Management of Copyright and Human Rights: An Uneasy Alliance" in Daniel Gervais (ed) Collective Management of Copyrights and Related Rights (Kluwer, Netherlands, 2006) 85 at 108.

452 David Sinacore-Guinn Collective Administration of Copyrights and Neighboring Rights: International Practices, Procedures, and Organizations (Little Brown \& Co, Boston, 1993) at 499.

${ }^{453} \mathrm{R}-36$

${ }^{454}$ R-22.
} 
performance of live music, ${ }^{455}$ and studio facilities to enable the proper production of music. ${ }^{456}$ In light of these needs, Jamaican policymakers should consider emulating the European model.

Commentators have noted the importance of CMOs' socio-cultural duties in fostering the creative capacity in developing countries. ${ }^{457}$ The preservation and promotion of national heritage should be one of the Jamaican Government's aims for indigenous CMOs, particularly given the cultural value of music. ${ }^{458}$ The Copyright Act could be amended to require that indigenous CMOs use a fixed percentage (for example, 10 per cent) of their receipts to establish a socio-cultural fund for artistes' welfare schemes or assistance programmes as well as to promote and develop local content. ${ }^{459}$ These duties could be subject to monitoring by a regulator. As joining a $\mathrm{CMO}$ is not mandatory for rights holders in Jamaica, ${ }^{460}$ local creators who do not wish their royalties to be used for cultural purposes would be free not to seek membership of these organisations. Adding social and cultural duties to CMOs' functions could elevate their societal relevance in the minds of rights holders and users.

\section{F CMOs' Administrative and Capacity Challenges and Limited Powers to Initiate Criminal Action on Members' Behalf}

Finally, Jamaican CMOs encounter challenges in terms of internal administration and resource capabilities. Human resource limitations include few staff, high employee turnover,

\footnotetext{
${ }^{455}$ R-16, R-22, R-27, Cooper and Stanley-Niaah interviews.

${ }^{456}$ R-36 and R-14.

457 See, for example, Mihàly Ficsor Collective Management of Copyright and Related Rights (WIPO Pub, Geneva, 2002) at [35]. The Copyright Organisation of Trinidad and Tobago (COTT) does philanthropic work through its COTT Foundation which is geared at developing local music and helping rights holders identify opportunities for national and international performance of their work.

${ }^{458}$ Discussed in Chapter 2.I.A-B.

459 International Confederation of Societies of Authors and Composers of Music [CISAC] allows its CMO members to utilise up to 10 per cent of their revenue from the administration of public performance and broadcasting rights for social and cultural purposes: Martin Kretschmer "The Failure of Property Rules in Collective Administration: Rethinking Copyright Societies as Regulatory Instruments" [2002] EIPR 126 at 134.

${ }^{460}$ On mandatory collective administration see: Silke von Lewinski "Mandatory Collective Administration of Exclusive Rights- A Case Study on Its Compatibility with International and EC Copyright Law" (e-Copyright Bulletin, UNESCO, January - March 2004).
} 
and a limited range of highly experienced personnel due to the relatively low salaries. ${ }^{461} \mathrm{~A}$ lack of financial resources results from factors such as: the small market size, piracy, small pool of rights holders, under-licensing of copyright works, large account receivables, a high expense to income ratio and the huge cost of managing rights information and processing royalty distributions. ${ }^{462}$ Technological deficiencies also exist, such as problems in acquiring up-to-date software and the absence of sophisticated databases for storage of comprehensive client data. ${ }^{463}$ Rights holders and CMOs acknowledged the capacity problems faced by local CMOs. For example: ${ }^{464}$

So those [businesses] that we [JAMMS] haven't actively gone out to [collect royalties from] yet maybe that's because...we are still building our capacity. And so, you will find, of course, a lot of small operators like bars and even retail shops we have not approached many of them as yet.

As a result, CMOs are trying to adapt by becoming more strategic in their collection efforts: ${ }^{465}$

...we're targeting the more accessible, the more visible, the low hanging fruits, in terms of building the company value, reaching out to the larger ones, setting an example for the smaller ones.

In addition, CMOs have no power to initiate criminal litigation to enforce members' rights. Although the resultant fines do not flow back to rights holders, CMOs consider criminal proceedings a useful copyright enforcement mechanism because of their deterrent effect. In civil suits, individual members can authorise their CMO to act as an agent to bring action against commercial users who refuse to pay royalties. However, the police and prosecutors require complaints from copyright owners before criminal proceedings for copyright infringement can commence. ${ }^{466}$ As a senior police officer indicated, "if we don't have a complainant, we don't have a case." 467

\footnotetext{
${ }^{461}$ See, for example, Beverley Pereira "A Regional Approach to the Management of Copyright in the Caribbean Community" (PhD thesis, Queen Mary, University of London, 2009) at 92.

${ }^{462}$ Michael Witter "Music and the Jamaican Economy" (UNCTAD/WIPO Report, 2004) at 51.

${ }^{463}$ Vanus James "The Economic Contribution of Copyright-based Industries to the Jamaican Economy" (WIPO Report, 2007) at 43.

${ }^{464}$ R-29. See also: R-37A.

${ }^{465} \mathrm{R}-29$.

${ }^{466} \mathrm{R}-35$.

${ }^{467} \mathrm{R}-42 \mathrm{~B}$. See also: R-42A.
} 
In practice, the rights holder is also expected to appear in person at trial to provide evidence proving ownership. ${ }^{468}$ Both CMOs and rights holders consider this an impediment to criminal prosecutions, which not only causes trial delays, but also creates personal conflicts that threaten rights holders' safety:

[Rights holders' court appearance] somewhat creates a kind of a personal confrontation between offender and offendee and that in itself is a issue...[and] if an artiste whose works is being infringed [is] currently on tour [overseas] for 3 months...the case is going to fall apart or to pause... ${ }^{469}$

Many of our producers are unwilling to come forward and give evidence. For a lot of obvious reasons, they refuse to...some of them are afraid to give evidence because, of course, by giving evidence they are identified as the man who "ah stop ah man food" [is preventing people from earning a living]. And there could be ramifications for them. ${ }^{470}$

These statements highlight the important role CMOs could play as a buffer in the criminal litigation process, were they given the power to represent members in criminal actions ${ }^{471}$ and if greater use were made of technology in securing evidence in criminal prosecutions (so as to make rights holders' personal appearance unnecessary). ${ }^{472} \mathrm{CMOs}$ also propose that the police should be able to exercise greater powers of arrest in circumstances of suspected copyright infringement: ${ }^{473}$

The EU, for example, was looking at that and they have issued directives...wherein the police officer sees the materials and is able to act, as they would in any other criminal case, and so, without the necessity of the rights holder being physically there to lodge a physical complaint. So we [JAMCOPY] think that also needs to be addressed [in Jamaica].

\section{Summary}

Despite successes in some areas, Jamaican CMOs still face a number of resource challenges that restrict their overall efficiency in collecting royalties. CMOs also face prosecutorial

\footnotetext{
468 See Evon Mullings “Copyright Infringement as a Major Economic Loss to Rights-Owners and the Broader Cultural Industry: Can this Problem be Fixed?" (Paper presented to the Broadcasting Commission's Payola and Anti-Piracy Seminar, Kingston, 22 March 2011) at 10.

469 R-4.

${ }^{470} \mathrm{R}-29$.

471 See R-6.

472 See R-29.

${ }^{473}$ R-6. See also: R-4.
} 
obstacles in discharging their functions which limits their effectiveness in the criminal enforcement of members' copyright.

Until the challenges discussed thus far in this Chapter are addressed (namely, the net outflow of royalties, low compliance from commercial users, piracy by the public, rights holders' preference for overseas CMOs, the absence of a socio-cultural function for CMOs and capacity challenges), the Government's ambitions for CMOs to contribute to the music industry's growth and Jamaica's economic development will remain unrealised. These performance inhibitors may account for the reservation expressed by a policymaker that: "the jury is out on whether collecting societies are a good or a bad thing."

\section{Economic Development through Income Maximisation}

Collective administration is only one way of managing copyright. Individual administration also offers a means of commercial returns from copyright works. Unlike the European model, members of Jamaican CMOs do not give these organisations the right to exclusively license their rights. ${ }^{475}$ Rights holders can still negotiate with users directly in respect of their copyright and thus have full control over the exercise of their rights, including licensing certain uses.

For some stakeholders interviewed in this study, another way in which copyright protection of the music industry could lead to economic development is through individual income maximisation or the aggregation of the highest possible income for every rights holder. ${ }^{476} \mathrm{~A}$ rights holder's income can be maximised by combining revenues from individual licensing agreements together with royalties generated from collective management. For example, one respondent, when asked about how copyright protection of the music industry facilitates economic development, mentioned not only CMOs but also the potential for internet

\footnotetext{
${ }^{474} \mathrm{R}-31$.

475 Daniel Gervais “The Landscape of Collective Management Schemes” (2011) 34 Columbia Journal of Law \& the Arts 423 at 430.

${ }^{476}$ For example, R-9, R-12, R-47A, R-47B, R-49A, R-49B and R-50.
} 
distribution of local music and the greater number of local producers signing negotiating deals with companies for the use of their copyright works. ${ }^{477}$

One factor influencing stakeholders' adoption of an income maximisation approach is the structure of the Jamaican music industry. The local music industry is essentially a cluster of small to medium enterprises, comprised of mostly single-entity creative entities "whose bloodline is driven by the IP of the core person." ${ }^{\text {478 }}$ Respondents argued that with their copyright earnings, music industry rights holders engage in financial activities, which support both their employees and other segments of the economy: ${ }^{479}$

A guy will walk in here and say: "hey, I'm looking for my copyright [income] because I have bills to pay." And you say: "well, what bills are you talking about?" [And he says] "Don't forget that I had to rent studio time. And I had to bring musicians in" or "I had to do this and that and I have to pay for that."

Second, stakeholders' favouring of the income maximisation approach is unsurprising given its direct link to the incentive argument for copyright. ${ }^{480}$ The connection between the two concepts is evident in the comments of jurists, broadcasters and policymakers:

A copyright system is like yin and yang: it encourages creativity by protection and by ensuring a return to the creators. ${ }^{481}$

The purpose of copyright legislation...is for the protection of the whole concept of wealth creation, because...the idea is that you are giving people a monopoly over the use of their ideas, for a specific period of time...you would want the creator or creators to have some protection in terms of being able to benefit from the fruits of their imagination. ${ }^{482}$

[Copyright law] was a means to provide for...a set period of time, some exclusive rights... really to give the creator a period of time to recoup their investment...to recover the money spent in developing the work. ${ }^{483}$

...the underlying theory [in copyright] is that if a person is able to improve his economic wellbeing because of his intellectual output and he has a means to protect and therefore to market it to the best of his ability and to exploit it, then that will lead to more creativity. ${ }^{484}$

\footnotetext{
${ }^{477}$ R-27.

${ }^{478}$ Davis interview.

${ }^{479}$ R-28.

${ }^{480}$ The incentive argument will be discussed in Chapter 4.II.A.2.

${ }^{481}$ R-47B. See also: R-47A.

482 R-9.

${ }^{483} \mathrm{R}-32$
} 
The income maximisation approach emerging from the interview findings can also be found in the literature. One study has argued that investment in copyright-based industries is critical to Jamaica's progress, because copyright presents a way to "claim income created by investment in novel knowledge and other new forms of domestic capital." ${ }^{\text {"45 }}$ Accordingly, the key to income maximisation (and, by extension economic development) would be to increase Jamaica's overall competitiveness: ${ }^{486}$

In the globalization process, every nation must improve its capacity to compete for the opportunity to grow and consume, or face persistent unemployment, underemployment, and poverty. Only by this means can its people make the necessary move from low to high earning activities, expanding opportunity in the process.

Proponents of the income maximisation approach believe that once Jamaica is able to increase its overall competitiveness in copyright-based industries such as music, it is likely to experience growth in national earnings in a manner similar to developed countries: ${ }^{487}$

....a significant part of the income, of the Gross National Product of the [US] comes from movies, films, music and entertainment. The whole entertainment industry in the [US] contributes very significantly to the Gross National Product. They export a lot of their products overseas and that, in turn, provides employment and wealth...and the same thing can be done for Jamaica as well, so, yes, if properly managed [copyright] can become a significant contributor to economic development.

This comment is reflective of the mind-set that income generation for rights holders necessarily translates into economic development. As a policymaker contended: ${ }^{488}$

...even though [copyright is] a private right, the country as a whole benefits because the more people who are producing, we get more revenue coming into the country, and once you are producing, you're developing...If we're always importing music and not producing music

\footnotetext{
${ }^{484}$ R-34. See also: R-52: “I think it's a good thing that we have a copyright law because I don't think anybody could argue about creators not being able to protect their intellectual output." R-5 said: The copyright system "should defend creativity, defend intellectual property...something that comes from your brain and comes into manifestation. That law should protect you."

${ }^{485}$ Vanus James "The Economic Contribution of Copyright-based Industries to the Jamaican Economy" (WIPO Report, 2007) at 17.

${ }^{486}$ Ibid.

${ }^{487} \mathrm{R}-34$.

${ }^{488}$ R-31.
} 
then the balance of power [is] gone, and so, you lose as a State. So I think in terms of encouraging more persons to produce, that's what I think we [Government] need to do.

However, two features of the Jamaican music industry situation pose practical impediments to the income maximisation model of economic development; (a) Jamaican rights holders generally lack knowledge about how to commercialise their copyright work so as to generate income and (b) the Government gives very little assistance to rights holders in the commercialisation of their copyright:

\section{A Rights Holders' Ignorance about the Commercialisation of Copyright}

Although institutional and legal frameworks allow rights holders to gain income from their copyright, many Jamaicans struggle with how to commodify their copyright or negotiate deals that add value to their business models. For example, an industry insider noted that rights holders were unaware of the importance of publishing rights in enabling a songwriter to benefit from the use of his or her work in video games, movie soundtracks and advertisements. ${ }^{489}$ Similarly, other rights holders, policymakers and legal practitioners noted that many rights holders do not understand how to commercially exploit their creations: ${ }^{490}$

In Jamaica...there is a general ignorance of the importance and value of intellectual property generally, and I would say, of copyright in works in particular. So, notwithstanding the richness of cultural works in music, dance, poetry etcetera, there is a great need perhaps for public education and infrastructure to facilitate persons who create intellectual property to protect it, claim it as their own, and to provide them with assistance in their dealings in that work and how they assign it, license it, publicise it, exploit it.

Rights holders' ignorance directly limits the copyright earning potential of not only the industry but also the economy. A copyright law researcher indicated: ${ }^{491}$

...the [music industry's] contribution to GDP has not been significant because the people are not earning from licensing or secondary exploitations or that sort of thing that a developed market would be earning from. So yes, we have a lot of creative people but there is still a challenge in how to commercialise and how to realise the commercial benefits of those works.

\footnotetext{
${ }^{489}$ Davis interview.

${ }^{490}$ R-44. See also: R-3, R-15 and R-49A.

${ }^{491}$ R-14.
} 
A public sector official observed that music industry rights holders still do not fully grasp the revenue possibilities that copyright protection creates, despite JIPO's public education initiatives: ${ }^{492}$

We've had workshops on how do you exploit your music on the internet...especially with a decline in the sales of CDs and so on, but are they [rights holders] taking sufficient advantage of the system? I don't necessarily think so...It seems as if you cannot do enough public education, there's always going to be a well-known artiste who says "well, I never knew that I should protect my copyright."

Rights holders' weak management of their copyright is compounded by the competitive nature of the music industry and the lack of access to capital necessary for new artistes to break into the industry, factors which negatively affect rights holders' earning potential. ${ }^{493}$

Given the global major labels' control over traditional distribution channels in the international music market, direct online e-commerce ${ }^{494}$ could provide an inexpensive way to broaden and strengthen the Jamaican music industry's commercial dimensions, especially the promoting and marketing of music-related products and services. ${ }^{495}$ Currently local producers do not have direct, cost-effective access to foreign wholesale and retail outlets. ${ }^{496}$ However, with the expansion of internet and digital technology, new formats for instant product delivery to consumers have emerged, such as, online downloads or audio-streaming. According to figures from the International Federation of the Phonographic Industry, digital music sales are on the rise. ${ }^{497}$ Chapter One ${ }^{498}$ mentioned the increase in broadband connectivity internet in Jamaica following the liberalisation of the telecommunications sector, prioritised as part of Jamaica's development strategy. The widening of public access to telecommunications infrastructure has meant the diffusion of information and communication

\footnotetext{
492 R-7.

493 See: R-16, R-27 and R-47B.

${ }^{494}$ I use the word "e-commerce" to refer to the web-based electronic transactions between businesses and consumers involving in the trade of digitalised creative content, specifically, music (whether the medium for these transactions is via desktop computer, laptop or handheld technologies, such as mobile phones): see European Commission "A European Initiative in Electronic Commerce" (EC, 15 April 1997, Document Reference COM(97)157) at 2.

${ }^{495}$ United Nations Conference on Trade and Development (UNCTAD) "Jamaica: The Science, Technology and Innovation Policy Review” (United Nations, New York and Geneva, 1999) at 41.

${ }^{496}$ Compton Bourne and SM Allgrove "Prospects for Exports of Entertainment Services From the Caribbean: The Case of Music" (Report prepared for the World Bank, May 1995, revised March 1996) at 20.

${ }^{497}$ International Federation of the Phonographic Industry "IFPI Digital Music Report 2011: Music at the Touch of a Button" (2011) noting that in 2010 the global digital music sector was worth an estimated US\$ 4.6 billion, accounting for 29 per cent of record companies' trade revenues. <www.ifpi.org >

${ }^{498}$ See Chapter 1.I.E.
} 
technologies (ICTs), particularly telephony and broadband internet service. ${ }^{499}$ These ICTs carry potential for the creation and marketing of creative goods and services. ${ }^{500}$ Harnessing this trading opportunity should enable quicker penetration of international markets and revenue generation for Jamaica. ${ }^{501}$

However, using the internet to upload music is not common among Jamaican artistes. Moreover, those artistes who are using the internet do so in a limited way. Their practice is to post their music on free social networking websites in an effort to boost popularity, drive offline sales of records or gain bookings for live shows. Respondent 5, a typical example, uses websites such as YouTube, MySpace, Facebook, Blogspot and Linkedin to promote his music. However, this kind of online activity differs from instant, fee-based digital delivery of music (for example, online purchase and downloads of albums or webcasting of performances). Even artistes with their own websites generally do not facilitate electronic purchases of their music for instant downloading. ${ }^{502}$ One reason for this is the fear that music sold online is more likely to get stolen. As one singer said: ${ }^{503}$

...sometimes you might sell a CD online and the person that you sell it to start pirate it and because you don't know all the intricacies of it; the ins and outs and the different places and he might be in a different territory, he'll be selling your music and making millions and you're not making any money out of it.

In the Jamaican music industry there is thus very little implementation of new business models geared towards digitising and distributing music in an online environment. There was the feeling that, although the internet poses intriguing new opportunities to meld media, music and technology, Jamaica is too small a player to garner the lion's share of the profits earned from online sales. ${ }^{504}$ This concern raises doubts as to whether Jamaican rights holders

${ }^{499}$ See UNCTAD/UNDP The Creative Economy Report 2010 (United Nations, 2010) at 190-194.

${ }^{500}$ Roger Wallis and Zelijka Kozul-Wright "Best Practice Cases in the Music Industry and their Relevance for Government Policies in Developing Countries" (Report prepared for WIPO and UNCTAD, December 2001) at 14.

501 See Andrea Davis "Marketing for the 21st Century" (Report prepared for the Jamaica Promotions Corporation's Film, Music and Entertainment Commission, May 1996) at 45-48.

${ }^{502}$ For example, the official website for R-22's band lists the band's catalogue but to access an album one must order the CD via email. Physical CDs are shipped once the customer has wired money to the band's bank account. R-36's website links to VP Records' website for customers to buy CDs. R-27's band has an e-store on its website where fans can order the band's official apparel and merchandise, but does not offer its albums for digital download.

${ }^{503} \mathrm{R}-40$.

${ }^{504} \mathrm{R}-30$. 
are ready to make use of the e-commerce framework ${ }^{505}$ to capitalise on the technology so as to maximise their income.

\section{B The Lack of Government Assistance to Rights Holders in the Commercialisation of Copyright}

Another condition, which challenges the income maximisation approach to economic development in the Jamaican context, is the Government's position on its proper role with regard to assisting copyright owners to commercialise their copyright.

From the perspective of some policymakers, the Government's primary obligations to rights holders are to: enact copyright legislation, provide a court system to deal with copyright infringement and facilitate the creation of local CMOs. Once the Government has discharged its role, they believed rights holders should have the onus of managing their copyright in a way that generates income, as this public sector official commented: 506

I think the Government should facilitate [copyright] but it's a private right and at the end of the day, the benefits are accruing to private individuals...it's like owning a house. You don't own a house to say "I own a house." You own a house so that you can provide shelter. You have copyright and you protect your copyright not to say "Oh. I'm an author." You have that so that you can get money from being an author to allow you to live.

However, given Jamaican rights holders' general lack of sophistication about how to commercially exploit their work (discussed in the previous sub-section), this Government approach may be better suited to a larger, more developed music industry environment. According to this economist: $:^{507}$

We [in Jamaica] are still, in my view, not sufficiently knowledgeable enough to be able to take advantage of capitalising on the intellectual property that we create to allow for the property-less among us to participate in economic development in a meaningful way.

Rights holders, copyright lawyers and other public sector officials also stressed the need for increased Government involvement (which could take various forms, such as greater

\footnotetext{
${ }^{505}$ The Electronic Transactions Act 2007, Act 15 of 2006 (in force 2 April 2007).

${ }^{506}$ R-31. See also: R-7 and R-32.

${ }^{507}$ Witter interview.
} 
assistance with rights enforcement, investment-promotion support or more effective educational programmes about copyright management):

We [JAMPRO, a public sector investment promotion agency] have serious financial constraints and our budget has been cut and so while we'd want to support music in a more fulsome way...we simply don't have the money to do it...it's fine to have you go out there and cut a tune [record a song] but...many people ask us "what are the distribution channels that you can assist me with?" 508

What we [the industry] need is actual assistance with developing our business modules, with developing our marketing structures, with making large scale overtures in international or foreign territories. ${ }^{509}$

[Government] must add professional training for the industry...where our people need to understand, to learn more about intellectual property, how the industry is organised, what they need to do, live performance versus whatever, and the various ways in which they can distribute their products, the internet and all kinds of things having to do with digitisation. ${ }^{510}$

The disparity between rights holders' expectations and the Government's approach was evident not long after the Copyright Act was passed in 1993, as the drafter of the Copyright Act recalled: $:^{511}$

I heard some comments [from right holders] which would suggest some disappointment...because now the responsibility of the rights holders now became clear: Government give you the law, now what you going to do with it? And I think there seemed to have been some expectation that Government would have been more proactive in managing rights...

A compelling reason for the Government to heed current and past calls for greater Government involvement in copyright management within the music industry is the history of exploitative practices that began in the industry's early years. ${ }^{512}$ As a policymaker recalled: $:^{513}$

We never understood artiste management so a lot of us got burnt. A lot of us had our music taken away from us...we never understood something called "intellectual property" that said that you could make money off whatever you were creating.

\footnotetext{
${ }^{508}$ R-25A. See also: R-36.

${ }^{509}$ Webley interview.

${ }^{510} \mathrm{R}-50$.

${ }^{511} \mathrm{R}-15$

${ }^{512}$ See Chapter 2.II.A.4(b).

${ }^{513} \mathrm{R}-50$.
} 


\section{Summary}

According to the income maximisation approach, economic development occurs when the greatest number of rights holders can generate as much income as possible from their copyright works (through a combination of individual management and collective administration). However, challenges exist for individual members of the Jamaican music industry with regard to generating returns from their musical products. Rights holders generally lack the expertise to efficiently maximise financial returns from their copyright works. Having provided the legal framework, the Government has placed the responsibility on rights holders to protect and exploit their work.

Given rights holders' lack of commercialisation know-how, the Government's stance is not appropriate for Jamaica. It is suitable for the advanced music industries found in developed economies. As a rights holder/copyright lawyer remarked: "the copyright system ought to provide a facility by which people's rights can result more efficiently in a benefit. I don't think we have a sufficiently robust system."

\section{Economic Development through Equitable Resource Distribution}

On its own, generating more income for Jamaican rights holders (whether through CMOs and/or individual rights management) does not automatically result in economic development. Previous research has shown that, while individual rights holders in the Jamaican music industry have achieved commercial success internationally, the domestic economy has not benefitted significantly from this income. ${ }^{515} \mathrm{CMO}$-focussed and income maximisation approaches therefore appear to be inadequate on their own, as a policymaker commented: ${ }^{516}$

There should, though, be a programme which looks at economic development of the creative industries and for your case, music...I do agree there needs to a holistic programme in place.

\footnotetext{
${ }^{514} \mathrm{R}-20$.

515 See Keith Nurse "The Caribbean Music Industry: Building Competitiveness and Enhancing Export Capabilities in an Emerging Sector" (Caribbean Export Development Agency Report, 2003) at 5. See also Chapter 1.I.A.

${ }^{516}$ R-7.
} 
Although Gross National Income is obviously closely linked with individual income generation, how this income is distributed within society is significant in gauging economic welfare, as the next Chapter will discuss. ${ }^{517}$ Equitable resource distribution is thus a vital component of economic development. Consistent with this approach, some stakeholders believed the copyright system should lead to economic development through ensuring equitable resource distribution. For example, the economist observed: ${ }^{518}$

We live in a society in which the majority of the people have historically been property-less and it probably is going to be very difficult to get any re-distribution of property in the country and therefore if one can convert creative works in whatever form, into property, that would then provide a basis for people to participate in a market economy.

Beyond simply increasing the earnings of individual rights holders, rights holders envisaged generating income in a way which benefits not only the overall economy but a wider crosssection of the population as well:

Good copyright legislation... means that some poor, humble youth in the inner-city in Jamaica can create a song and know that that song belongs him and he is entitled to exploit it and deal with it as he sees fit. ${ }^{519}$

In the Jamaican context, the relative social positions of rights holders can influence the way in which they financially benefit from the copyright system. Two conditions appear to favour adopting an equitable resource distribution approach to economic development: (1) educational and (2) income inequalities among music industry stakeholders. Both features are examined below.

\section{A Educational Inequalities among Music Industry Stakeholders}

Equitable resource allocation aims to prevent wealth from being concentrated in the hands of a minority, while the poor remain uneducated about the value of their copyright that others are exploiting. Educational asymmetries in the Jamaican music industry have contributed to an inequitable distribution of copyright income. A cultural studies academic explained the

\footnotetext{
${ }^{517}$ The human development approach will be discussed in Chapter 4.I.B.2, below.

${ }^{518}$ Witter interview.

${ }^{519}$ R-44. See also: R-9 and Davis interview.
} 
historical socio-cultural reason behind informational inequalities in the Jamaican music industry: ${ }^{520}$

...access to information and access to literary information [in Jamaican society] was always something that was considered a part of status, and your position and your prestige. And even literacy versus illiteracy was also a part of the kind of social divide that existed preIndependence, post-Independence, in the early Colonial era. And so, the individuals who were the creators of most of the Jamaican music and those forms...were not really accessing...the kind of information that did exist and could have given them an opportunity to understand the value of what they were producing and how to protect it.

Several respondents commented that these informational inequalities still persist:

The history of our music is the creators are not lettered people...are not stars in academia...And you have this sort of apathy for what the people "those people down there" are...it is so ingrained in our culture... what I have noticed in Jamaica, whenever our upper class comes into an industry they take the whole industry for themselves. ${ }^{521}$

...there are a lot of major players in the industry who understand copyright better than the regular man does, but who don't seem to be very interested in getting other people to understand it because it allows them to be able to exploit the works of others. ${ }^{522}$

Respondents' perception of knowledge gaps obviously highlights the need to raise the knowledge level of music industry rights holders about copyright. However, educational attainment in Jamaica is closely connected to social status. Given that many rights holders' generally limited formal education places them in a less powerful social position, simply knowing they have rights may not affect the actual exercise of those rights. A policymaker gave this analogy: ${ }^{523}$

The social dynamics and hierarchy of the music impact on how people use [copyright]. So it's not even always that they are unaware of [copyright]. It's "do I have the power in this?" It's almost like...Sex Education. I mean, [saying] "we should use condoms", that's great. Not every woman...has the power to negotiate the use of the condom; and that's very different from ignorance of it.

Therefore, merely emphasising income generation (whether through CMOs and/or individual management) as an economic development strategy may do little to remedy existing socioeconomic inequalities among rights holders.

\footnotetext{
${ }^{520} \mathrm{R}-16$.

${ }^{521} \mathrm{R}-30$

${ }^{522} \mathrm{R}-20$. A similar point was made by R-10, R-22, R-36, R-37A, R-37B and R-49A.

${ }^{523} \mathrm{R}-25 \mathrm{~B}$.
} 


\section{B Uneven Distribution of Copyright Income at the Domestic and International Levels}

The uneven distribution of copyright income from Jamaican music at the domestic and international levels also points to the need for an equitable approach to economic development. The next sub-sections look at the inequalities (1) between creators and intermediaries and (2) between Jamaica and foreign corporations:

\section{Between creators and intermediaries}

Entities such as recording companies and publishing houses often act as intermediaries between music creator and consumer. Copyright models tend not to regulate how the financial returns from copyright are distributed among creators and these intermediaries, as this is a matter for contract law. ${ }^{524}$ However, copyright commentators have criticised the increasing control of intermediaries; for instance, the commonplace practice of assignment ${ }^{525}$ has created contractual arrangements between creators and these industry entrepreneurs that raise the question of the extent to which creators actually realise economic benefits from copyright. ${ }^{526}$ Unequal bargaining power in negotiations as well as creators' inability to accurately value their copyright can result in third parties profiting more from the commercialisation copyright works than creators.

Researchers have observed that Jamaican creators are often among the last to earn and earn the least, ${ }^{527}$ and respondents' experiences appear to align with this observation. For example, a music industry academic recognised: $:^{528}$

I don't get the impression from my research that copyright and the legislation worked to benefit, particularly, the creators on the ground: the songwriters, the singers and individuals

\footnotetext{
524 Although some respondents thought that the copyright system should act as a mediator of commercial relationships: R-8, R-31 and R-49A.

525 Creators typically assign rights to a publisher, producer or distributor: Jessica Litman "Real Copyright Reform" (2010) 96 Iowa L Rev 1 at 11 and 35-37.

526 Tzen Wong, Molly Torsen and Claudia Fernandini "Cultural Diversity and the Arts: Contemporary Challenges for Copyright Law" in Tzen Wong and Graham Dutfield (eds) Intellectual Property and Human Development: Current Trends and Future Scenarios (Cambridge University Press, New York, 2011) 279 at 289. 527 Howard interview and Dennis Howard "Copyright and the Music Business in Jamaica- Protection for Whom?” (2009) IX Revista Brasileira do Caribe 503 at 524.

${ }^{528} \mathrm{R}-16$.
} 
who didn't really understand how valuable they were in the process. It worked more to benefit rapacious capitalist-minded producers and promoters, whether Jamaican or foreign, who so understood the network and understood the legislation that could benefit them if they bought the full copyright of a piece of creative work, music or song from an individual with a one-shot payment and then could redound unto themselves multiple times over, for many years the value added that this piece of music could bring.

The greatest potential for earnings thus tends to lie in the distribution of the work, as a policymaker noted: ${ }^{529}$

...we are the creators of the product, but we did not realise that in the way in which the world has been delineated and aligned, maligned, the centre where creativity occurs is the poorest area because the wealth is in the distribution...the studios or the recording companies, the VPs and the MTVs and the channels and the networks...So when you create your little product, they take it and they take it through all that network, and you get $\mathrm{X}$ percentage of it but they are getting the major percentage...

A music industry entrepreneur expressed a similar view: ${ }^{530}$

For example, Sean Paul as a property might have generated maybe a billion dollars or more...in terms of touring, in terms of records...but the fact is that only a very small portion of what he earns comes back to him.

Increased corporate ownership of copyright in the international music market has challenged the notion of the individual author or creator being the prime beneficiary of copyright protection. Conglomerates have gained dominance in the global music industry through vertical integration (increasing control over the production and distribution process) and horizontal integration (mergers and buy-outs of other businesses). ${ }^{531}$ For example, the five major music labels account for over 70 per cent of the world music market, with independent firms sharing the remainder. ${ }^{532}$ Commentators have suggested that artistes' earnings from

\footnotetext{
${ }^{529} \mathrm{R}-50$.

530 R-9.

${ }^{531}$ Roger Wallis "Best Practice Cases in the Music Industry and their Relevance for the Government Policies in Developing Countries" (WIPO/UNCTAD Report, 2001) at 6-8.

532 Keith Nurse "The Cultural Industries in CARICOM: Trade and Development Challenges" (Caribbean Regional Negotiating Machinery Report, 2006 (revised 2007)) at 29: The market division in 2005 was: Universal (23.5 per cent of world market sales), EMI (13.4 per cent), Sony (13.2 per cent), Warner (12.7 per cent), BMG (11.9 per cent) and independents (25.3 per cent). Since then, BMG and Sony have become a joint venture: Sony BMG.
} 
copyright have been adversely affected by the prevalence of oligopolies in the global music market. $^{533}$

The growing corporate concentration occurring internationally has had a tremendous impact on the Jamaican music industry. During the 1970s and 1980s, when Reggae began to receive attention from the major foreign labels, ${ }^{534}$ many local artistes signed with these overseasbased entities for the chance of greater exposure, which meant giving up ownership and control over their work. A record producer observed: ${ }^{535}$

[The music industry] became more pro-label in the late [19]80s...because the labels saw where "okay, we're facilitating the artiste. We're giving them all this exposure. We have to now look into it because it's a business." ... and as a result, it became kind of- I wouldn't say "cannibalistic", it just became rigid so, if you were not educated you would not have negotiated the best deal for yourself and you would have ended up with a bag of problems.

A cultural studies academic captured the same dilemma that new artistes currently face: ${ }^{536}$

...it may be a long, hard road to get to the kind of success that could come if you signed off at least some of the ownership for a period of time of your creative work to one of the majors or one of the labels affiliated with a major, that could give you the kind of push internationally, that you can't really give yourself with limited resources...you need money to make money...Without some of that appeal, how far can you get?

Pragmatism dictates signing certain contracts to get one's music into the market, even if it means compromising creators' copyright earnings in respect of these earlier works: ${ }^{537}$

People who want to make music are more concerned with making music than they are concerned with what types of contracts they sign. And unfortunately, if they don't sign away their rights to initial works they don't get an opportunity to call the shots when they are recognisable faces.

Two other features of the music industry can work against the Jamaican creators' interests. First, there has been greater consolidation of functions. Typically, a company brokers a deal with the artiste for ownership of the recording rights, while the rights to publish and distribute

\footnotetext{
533 See, for example, Ruth Towse "The Singer or the Song? Developments in Performers' Rights from the Perspective of a Cultural Economist" (2007) 3 Review of Law and Economics 745 at 760-761.

${ }^{534}$ See Chapter 2.II.A.5.

535 R-3.

${ }^{536} \mathrm{R}-16$.

537 Corthésy interview. This point was supported by R-49A and R-15 who also stressed the importance of contracts in enabling rights holders to exploit their copyright in their creations.
} 
the products are owned by a sister company, holding company, or subsidiary. ${ }^{538}$ While there may be cost advantages, this consolidation can also create conflicts of interest, as described by a rights holder: ${ }^{539}$

So you now have a label who is a distributor, a record label, a publisher and so therefore you now are funnelling through them. So, if they have a song it now is in their interest to sell the song to somebody at a lower price but still keep you [the artiste] in the dark, so that creates a whole host of problems.

The second challenge to creators' income which respondents identified is that foreign labels may not always act in the best interests of local artistes: ${ }^{540}$

American labels going to look out for American music first and foremost; "you come from Jamaica, what do you know?" They don't even too care about that. It's [your music] a thing [for the label] to earn off of.

It can be seemingly harder for a Jamaican artiste to access and succeed in mainstream global markets.

This is not to suggest that overseas record labels (and other third parties) always take unfair advantage of local rights holders and these rights holders do not improve their financial position as a result of income earned through copyright. ${ }^{541}$ However, in many cases creators do not realise the full income earned from the exploitation of their work by others who later acquire the copyright. Stakeholders' perspectives endorse the recommendation by commentators that copyright law should have a more author-centric focus. ${ }^{542}$ As a copyright academic remarked: ${ }^{543}$

I think that a lot of energy has been spent in earlier copyright regimes on ensuring that the business end was protected and I would hope that, futuristically, the Copyright Act...would move towards a more artist-benefit centred regime, rather than an industry, business-related focussed regime.

\footnotetext{
538 See Trajce Cvetkovski “The Great Rock n’ Roll Firesale: The Politics of Popular Music Production and Consumption" (paper published in Vol 6(1) Dialogue E-Journal, the University of Queensland, 2008).

539 R-3.

${ }^{540} \mathrm{R}-12$.

${ }^{541}$ See R-40.

542 See Jane Ginsburg "The Copyright Future: Authors, Owners, Orphans, Users and Repeat Infringers" (presentation to New Zealand Centre of International Economic Law Symposium, Wellington, 30 October 2009).

${ }^{543}$ Corthésy interview.
} 


\section{Between Jamaica and foreign corporations}

The distributional variances between individual creator and copyright owner also appear to manifest on a larger scale: between Jamaica and foreign multinational music corporations. According to the economist: ${ }^{544}$

[In Jamaica] we have generated a remarkable volume of cultural expressions and other forms of creative work which we give away. And one of the things that inspired Marx's work in alienation was the notion that the creator of the object would soon be exploited by the owner of that object. And in a curious kind of way that is happening to us with our creative expression. Many of the large [foreign] record companies, for instance, are just buying up titles and eventually, when we want to play an oldies session, we're going to have to pay somebody to play an old Maytals or an old Bob Marley [song].

A music industry policy writer held similarly strong views: ${ }^{545}$

[Jamaica has] spawned a global movement [with Reggae music] which, for the most part, has benefitted those outside of us far more than it has benefitted ourselves. We tend to be, continue to be, the exporter of raw talent and raw product but the value-added that's necessary to realise profit is added from outside of ourselves, as is the direction and the marketing of this genre.

Therefore, a development strategy that concentrates on maximising the income of individual stakeholders in the music industry (whether through individual rights management or collective administration) runs the risk of reinforcing current local and international patterns of unequal income returns.

\section{Summary}

Educational and social disparities between Jamaican rights holders can translate into marked variations in earnings from copyright. There can also be significant income distinctions between the creators of copyright works and the intermediaries who exploit the copyright work, whether at the individual or national level. For these reasons, economic development through copyright protection of the music industry should be concerned not only with maximising rights holder income but also with ensuring that resources (particularly, earnings from copyright) are more equitably distributed.

\footnotetext{
${ }^{544}$ Witter interview.

${ }^{545}$ Davis interview.
} 
While an in-depth analysis of the conditions required for achieving economic development through the music industry is beyond the scope of this research, the next part of the Chapter briefly identifies some areas that copyright policymakers could address in order to lead to an increase in copyright income for the Jamaican economy.

\section{Recommended Government Strategies to Support the Copyright System}

Previous studies have documented the Government's lack of support for the music industry. ${ }^{546}$ The Jamaican music industry is largely the product of individual entrepreneurial efforts "without a proactive public policy, institutional infrastructure or formalized venture funding. ${ }^{, 547}$ In view of this, there are three main strategies the Jamaican Government could implement in order to realise greater economic benefits from copyright protection of the music industry: (a) direct investment in the value chain, (b) exploring linkages between the music industry and other sectors and (c) greater involvement in collective administration.

\section{A Direct Government Investment in the Value Chain and Channelling of Resources}

\section{from Traditional Export Sectors into the Music Industry}

As part of their economic strategy, many states are increasingly focussing their efforts on industries in which they have a competitive advantage. ${ }^{548}$ Competitive advantage is the "dynamic and localized process whereby differences in national values, culture, economic structures, institutions, and histories all contribute to attaining a competitive edge."549 The literature has identified the music industry as an area of competitive advantage for Jamaica. ${ }^{50}$

\footnotetext{
${ }^{546}$ See, for example, Keith Nurse "The Cultural Industries in CARICOM: Trade and Development Challenges" (Caribbean Regional Negotiating Machinery Report, 2006 (revised 2007)) at 202 and Hilary Brown "National Strategy \& Action Plan to further develop the Jamaican Music Industry" (UNESCO Report, 2004) at 12.

${ }^{547}$ Andrea Davis "Brand Jamaica as the Home of Reggae" in UNCTAD/UNDP "The Creative Economy Report 2010" (United Nations, 2010) 59 at 60.

${ }^{548}$ Vanus James "The Economic Contribution of Copyright-based Industries to the Jamaican Economy" (WIPO Report, 2007) at 17.

${ }^{549}$ Keith Nurse "The Caribbean Music Industry: Building Competitiveness and Enhancing Export Capabilities in an Emerging Sector" (Report prepared for Caribbean Export Development Agency, Barbados, 2003) at 6.

${ }^{550}$ For example, Andrea Davis "Brand Jamaica as the Home of Reggae" in UNCTAD/UNDP "The Creative Economy Report 2010" (United Nations, 2010) 59 at 59.
} 
Indeed, several respondents used the concept of "competitive advantage" or "comparative advantage. ${ }^{, 551}$ One music industry expert noted: ${ }^{552}$

We have a strategic advantage on cultural products like music. We have the raw material: it's coming out of the pores of Jamaicans, the fingertips, when they open their eyes it falls on the ground.

In terms of the return on investment, the music industry is one of the highest-productivity sectors of the Jamaican economy. A 2007 study found that each dollar invested in the core copyright sector (which includes the music industry) contributes about J\$6.18 of value added to Jamaica, mainly in the form of wages and indirect taxes, compared to a $\mathrm{J} \$ 1.49$ return from investment in the communications sector. ${ }^{53}$ Notwithstanding its high rate of return, stakeholders cited the low level of investment actually received by the industry and suggested that the Government should become more directly involved at various stages of the music industry's value chain, such as in the publishing, marketing and distribution of music. This Government funding might facilitate an environment in which more Jamaican creators sign with local companies, ensuring a greater portion of the revenue generated from commercial exploitation of their copyright work remains in Jamaica. ${ }^{554}$

Respondents felt that the Government should divert resources from traditional export sectors (such as agriculture and manufacturing) which are underperforming and place them into the music sector instead. The copyright earnings from the music industry could surpass those sectors, as this CMO representative said: ${ }^{555}$

[In] [20]08 we had a trade surplus in...the creative industries because the value of what we are earning exceeds what we are importing in terms of, for instance, musical content...[The Government should not] throw [money] away at sectors and industries that give you very low rates of return...in fact, you are subsidising a lot of them and struggling to keep up, in terms of costs per unit of production; meaning, you're producing bananas in Jamaica and you're

\footnotetext{
${ }^{551}$ For example, R-29, R-30, R-38 and Davis interview.

552 R-16.

${ }^{553}$ Vanus James “The Economic Contribution of Copyright-based Industries to the Jamaican Economy” (WIPO Report, 2007) at 8-9.

${ }_{554}$ R-9. Specifically, he suggested that funds could be raised from the Government floating a bond issue to finance entertainment which could be marketed particularly to the large Jamaican Diaspora resident abroad.

${ }^{555}$ R-29. See also: Steven Jackson "Culture Exports Trump Financial Services" The Sunday Gleaner (Jamaica, 23 October 2011) noting that in 2010 Jamaica earned US\$23.8 million in net foreign exchange from cultural services (which includes music, sport and film) which was more than from services in finance, business, insurance and construction combined.
} 
competing against Chiquita in a Latin American country and the cost of production is ridiculous in terms of the difference.

Similarly, an industry academic and a policymaker mentioned the futility of ignoring the value of the music industry in favour of other sectors:

[W]hile we have heard discussions [that] "the music industry can bring a billion US [dollars] to Jamaica"...none of it has been taken seriously [by the Government], we are still working with agriculture, the sugar industry, we are working with all kinds of industries that many of them have been lost with the end of the colonial project and the end of preferential agreements that would have allowed us to continue. [Industries] we are not able to manipulate...in the way that larger economies with all the various subsidies and economies of scale are able to do. ${ }^{556}$

...we just keep plodding and plodding in the morass of traditional industries and no matter how we get sinking deeper and deeper...we're still only prepared to deal with what we think we know...banana, coffee, sugar and bauxite and "to hell with everything else." 557

Both the economist and the brand expert spoke about the immense value of the Jamaican brand in global music markets. ${ }^{558}$ They suggested that making a gradual shift to greater Government investment in the music sectors would result in returns, which would benefit the wider economy. This suggestion echoes the argument in the literature that Government should invest in the cultural industries to boost employment, production and exports, as part of an industrial and export upgrading agenda. ${ }^{559}$ Government spending is preferable to investment from foreign entities, as profits from foreign investors tend to be repatriated overseas.

\section{B Exploring and Leveraging Linkages between the Music Industry and other Sectors}

Respondents frequently commented on the connections between music and other industries. Music "can be used as a standalone [product] and as packaging every single service that you can think of." 560 If the Government were to capitalise on these relationships, these

\footnotetext{
${ }^{556} \mathrm{R}-16$.

${ }^{557}$ R-50.

${ }^{558}$ Dr. Michael Witter and Andrea Davis, respectively.

559 See Roger Wallis "Best Practice Cases in the Music Industry and their Relevance for the Government Policies in Developing Countries” (WIPO/UNCTAD Report, 2001) at 47.

${ }^{560}$ Witter interview.
} 
respondents argued, this would allow the music industry to support the growth of other sectors, such as film, tourism and sport. ${ }^{561}$ As a policymaker pointed out: ${ }^{562}$

...the interesting thing about the culture and the creative industries is that it also serves other industries...the culture in fact pervades various industries and is linked into several industries which also strengthens it...so that when you add value to the culture, you ultimately add value to the other industries.

Accordingly, stakeholders suggested that the Government could do a better job of harnessing the music industry's value, in terms of potential positive spillover effects on other sectors, for example, tourism. Respondents noted that live performances attract overseas visitors: ${ }^{563}$

[The music industry] brings in a lot of foreign exchange...you can't get a [hotel] room on the North Coast during the Jazz Festival time...so [music] does have long term benefits from one little Copyright Act affecting the tourism industry, affecting the people who are selling food, the JUTA [taxi van operators who transport patrons], so all of those levels are protected.

This finding supports previous research, which underscores the importance of using the linkages between music and other sectors, such as fashion, visual arts and film in order to grow the domestic economy. ${ }^{564}$ One way to leverage the link between music and tourism, for example, would be state sponsorship of local music festivals which are marketed to an overseas audience.

In summary, the music industry and the creative industries as a whole are key growth sectors in the economy because of their contribution to GDP, exports and employment as well as impact on the national brand. ${ }^{565}$ However, the Government has not placed priority on the sector in terms of investment. This lack of priority has copyright implications, as the music industry has not been equipped to make the most of earnings from its copyright works.

\footnotetext{
${ }^{561}$ Music can be used in the promotion of sporting events as well as in the marketing of sport teams. An example of the linkage is seen in the national football team: the Reggae Boyz. See also: R-51.

${ }^{562} \mathrm{R}-50$.

${ }^{563}$ R-31. R-22, R-30 and R-40 made a similar point.

${ }^{564}$ See UNCTAD/UNDP “The Creative Economy Report 2010" (United Nations, 2010) at 61 and Andrea Davis "Brand Jamaica: Creative Industries as an Economic Strategy" (Presentation to the Secretaries of Culture and Development to the State of São Paulo/ United Nations Development Programme's International Forum on Creative Economy, Sao Paulo, Brazil, 5 December 2007).

${ }^{565}$ Keith Nurse "The Creative Sector in CARICOM: The Economic and Trade Policy Dimensions" (CARICOM Secretariat Regional Symposium on Services Report, 2009) at 2.
} 


\section{Greater Government Involvement in Collective Administration}

As was noted earlier, exploitative practices within the music industry continue to directly affect rights holders' earnings. ${ }^{566}$ If the Government were to play a greater role in copyright management this could reduce their financial losses. However, the costs and resources required to manage the rights of individual rights holders make it impracticable for the state to focus on individual rights management. ${ }^{567}$ It would be more practical for greater Government intervention in the music industry to take the form of increased state involvement in and influence over collective administration. Research in the Latin American region has found that for countries that lack stability in their institutions and economy, governmental guidance is a necessary component of successful collective management. ${ }^{568}$ Ideally, government aid should be provided until CMOs gain the expertise to manage their affairs independently and stakeholders in the market have a better appreciation for copyright. $^{569}$

States can exercise power over CMOs in different ways. ${ }^{570}$ While an exhaustive account is outside the objectives of this Chapter, examples of state influence in various jurisdictions range from granting CMOs authorisation to act as representatives of right owners for works of a particular kind to detailed preventative regulations or corrective procedures in response to complaints (including mediation or arbitration). ${ }^{571}$ Governments can engage in surveillance and control of tariffs, prohibit certain CMO practices or impose special obligations such as state representation on CMO boards. Governments may regulate rights owners' relationships with CMOs, the internal structures of CMOs and their relationship with other CMOs nationally and internationally.

Jamaica's copyright system is in keeping with the common law tradition: there are indirect or de minimis state controls. The state does little to interfere with CMOs' daily business. The

\footnotetext{
${ }^{566}$ See Chapter 3.II.B.

567 However, there could be state-supported programmes for individual artistes to build their expertise in individual licensing negotiation.

${ }^{568}$ Karina Correa Pereira "Collective Management of Copyright in Latin America" in Daniel Gervais (ed) Collective Management of Copyrights and Related Rights (Kluwer, Netherlands, 2006) 421 at 452.

569 Ibid.

570 See: Stanley Besen and Sheila Kirby "Compensating Creators of Intellectual Property: Collectives that Collect" (RAND Corporation Report, 1989) at 64-75.

${ }^{571}$ Gunnar Karnell and Silke von Lewinski "Collective Administration of Copyrights and Neighbouring Rights" in Gerhard Schricker (ed) International Encyclopedia of Comparative Law (Martinus Nijhoff Publishers, Lancaster, 2006) vol xiv: Copyright and Industrial Property ch 6 at [41].
} 
external control exercised over CMOs is primarily in regard to tariffs, through special tribunals such as the Copyright Tribunal empowered to hear users' complaints. ${ }^{572}$ Indigenous CMOs are thus left to operate under the generally applicable rules for their legal entity (nonprofit private companies) since the Jamaican Copyright Act does not address the regulation of CMOs' activities nor their permanent supervision by an external authority. In view of the limitations of indigenous CMOs previously discussed in this Chapter, ${ }^{573}$ increased Government influence over the internal affairs of indigenous CMOs may be appropriate for Jamaica.

Examples of greater state intervention can be found in Canada as well as in some European countries with a strict approach to CMO supervision. ${ }^{574}$ In Germany, for instance, the Law on the Administration of Copyright and Neighboring Rights 1965 (LACNR) ${ }^{575}$ created a regulatory system whereby CMOs are subject to the control of the German Patent and Trademark Office (GPTO). Persons who wish to undertake the collective management of rights must obtain prior authorisation, ${ }^{576}$ and once authorisation is obtained, the entity remains under the GPTO's permanent supervision. ${ }^{577}$ The GPTO decides whether a CMO is faithfully discharging its duties under the LACNR. ${ }^{578}$ The GPTO has the right to demand information from collecting societies on any matters concerning their conduct of business as well as to see their books or other business papers. ${ }^{579}$ It is also entitled to be represented at the meetings of members and any meeting of the CMO's supervisory board or advisory board. ${ }^{580}$ Additionally, the GPTO has the power to dismiss CMO officers. ${ }^{581}$ There is also an

\footnotetext{
572 See Gunnar Karnell and Silke von Lewinski "Collective Administration of Copyrights and Neighbouring Rights" in Gerhard Schricker (ed) International Encyclopedia of Comparative Law (Martinus Nijhoff Publishers, Lancaster, 2006) vol xiv: Copyright and Industrial Property ch 6 at [48]. The Jamaican Copyright Tribunal was discussed above at Chapter 4.I.C.

${ }^{573}$ Chapter 3.I.

${ }^{574}$ Such as Portugal and Austria. See also: Law No. 22/1987 of November 11, 1987 on Intellectual Property (Spain): copyright management societies are governed by Title IV of Book Three of the Intellectual Property Law, which provides for their authorisation by the Ministry of Culture.

${ }^{575}$ Law on the Administration of Copyright and Neighboring Rights of 9 September 1965 [LACNR].

${ }^{576}$ LACNR, s 1(1).

577 LACNR, s 18(1). See also: Nils Bortloff "Collective Management of Rights in Musical, Literary and Dramatic Works in Europe” (1997) 6 German American LJ 67 at 74-75.

${ }^{578}$ LACNR, s 19(1).

${ }^{579}$ LACNR s 19(2).

${ }^{580}$ LACNR s 19(3).

${ }^{581}$ LACNR s 19(4).
} 
arbitration board which not only handles disputes where users allege that licensing fees are unreasonable but also cases in which a user group refuses to negotiate. ${ }^{582}$

A major advantage of closer state supervision in Jamaica would be greater transparency in CMOs' operations. A regulator could ensure that a CMO makes members and users fully aware of its financial policies, is properly equipped to perform its duties satisfactorily, and lawfully distributes the royalties collected. A regulatory framework like the model found in German law prevents a CMO from abusing its relationship with rights holders and users as well as ensuring that CMOs are accountable to society at large. ${ }^{583}$ However, such a framework could result in an added layer of bureaucracy, which might prevent CMOs from quickly adapting to changes in the licensing market, thus negatively impacting rights holders' income.

\section{Chapter Summary}

This chapter focussed on the copyright regime's impact on economic development in relation to the Jamaican music industry. It argued that there are pitfalls associated with both the CMO-dependent and income maximisation-based approaches to achieving economic development through copyright. A different way of viewing copyright's role is as a means of equitable resource distribution (that is, as a mechanism by which persons with limited financial resources can convert their creative works into wealth, thus re-distributing income within the society). This approach is appropriate given the existing informational and income asymmetries between industry players and earning inequalities between Jamaica and foreign multinational corporations involved in music distribution.

However, the existence of alternative theories about how copyright protection of the music industry can lead to economic development suggests that there may be no single optimal way to foster economic development through the copyright system. Therefore, policymakers might consider taking a multi-pronged approach; in which collective administration is strengthened and individual management improved, even as public welfare concerns about

\footnotetext{
${ }^{582}$ LACNR s 14. See also: Stanley Besen and Sheila Kirby "Compensating Creators of Intellectual Property: Collectives that Collect" (RAND Corporation Report, 1989) at 68.

${ }^{583}$ Lucie Guibault and Stef van Gompel "Collective Management in the European Union" in Daniel Gervais (ed) Collective Management of Copyrights and Related Rights (Kluwer, Netherlands, 2006) 117 at 127-128.
} 
equity are incorporated into copyright policymaking. Combining complementary approaches in this way could make the copyright regime a more effective economic development tool. There are several ways in which greater Government intervention might have a positive effect on the music industry's contribution to economic development. This intervention could take the form of direct investment in the music industry value chain, leveraging connections with other sectors and increased control over collective administration. 


\section{CHAPTER FOUR}

\section{COPYRIGHT FOR DEVELOPMENT: THE INTERSECTION OF DEVELOPMENT AND COPYRIGHT LAW}

Any development in any part of the third world has an importance that far outweighs the size, wealth or power of that particular part of the world. ${ }^{584}$

\section{Overview}

Economic development as described in Chapter 3 has certain limitations. It does not take into account social and cultural aspects of national welfare. This Chapter will discuss a more holistic understanding of development that also links with the copyright regime's broader objectives. I will argue that a developmental rationale for copyright lawmaking is supported at the international and domestic levels.

This chapter has four main parts. The first introduces the concept of human development and argues that it is a relevant definition of development for copyright purposes.

The second part outlines the theoretical justifications for copyright that are pertinent to the Jamaican copyright system (the natural rights and personality perspectives, the incentivebased model and the economic efficiency rationale); and provides examples of how these theories are mirrored in Jamaican copyright policy and law. It will also address the Berne Convention and TRIPS, two major copyright treaties of which Jamaica is a member. This part also analyses the post-TRIPS debate on the developmental impact of stronger copyright protection on developing countries.

The third part argues that the human development approach is consistent with the relevant copyright theories and supported by Berne. Using the Vienna Convention on the Law of

\footnotetext{
${ }^{584}$ Michael Manley “Overcoming Insularity in Jamaica” in Foreign Affairs (Council on Foreign Relations Inc., October 1970) <www.foreignaffairs.com>.
} 
Treaties $1969^{585}$ (VCLT), I will discuss how TRIPS can be interpreted in line with human development goals. I also discuss how the human development approach is exemplified in WIPO's developmental mandate. Further, I argue that human development forms part of the existing international IP acquis $^{586}$ (which is applicable to construing IP agreements such as TRIPS).

The final part looks at whether the human development approach to copyright is reflected in the Jamaica's policy in local and bilateral copyright lawmaking.

\section{Human Development (or the Capabilities Approach to Development)}

\section{A Introduction}

Despite the United Nations' adoption of the Declaration on the Right to Development as an inalienable human right in $1986,{ }^{587}$ and international institutions' increasing engagement with development, there is no one accepted definition of "development." Within the development studies discipline itself, many definitions and theories exist. ${ }^{588}$ In this thesis, in discussing whether it is possible for copyright law to create an environment for development in Jamaica, I am referring to the concept of human development (alternatively known as the "capabilities approach").

Unlike many other development theories, human development incorporates multidimensional aspects of human wellbeing. Development scholars have underscored the need for a concept of development that incorporates "not only economic variables and objectives but also social

\footnotetext{
${ }^{585}$ Vienna Convention on the Law of Treaties (23 May 1969, entered into force on 27 January 1980) [VCLT].

586 Graeme Dinwoodie and Rochelle Dreyfuss A Neofederalist Vision of TRIPS: The Resilience of the International Intellectual Property Regime (Oxford University Press, New York, 2012) at 176 (defining the international intellectual property acquis as "a set of basic principles that form the background norms animating the intellectual property system.”).

${ }^{587}$ UN Declaration on the Right to Development, G.A. Res. 41/128, Annex, U.N., GAOR 41st Sess., No. 53, U.N. Doc. A/4/53, 4 December 1986. See Maxwell Abbott “The Right to Development" (2011, Volume 4, UNDP News Brief) at 7.

588 The theories I examined included: traditional neo-classical views (which cover an array of linear and dualistic theories such as right-wing development concepts of Adam Smith and David Ricardo, modernisation theory, top-down, hierarchical diffusion, and unbalanced and unequal growth concepts); alternative theories (such as Latin American structuralism, marginality, internal colonialism and Caribbean dependency theories, as well as World Systems Theory); "another development" theories (bottom-up, neo-populism, ecodevelopment/sustainable development, basic needs, self-reliance and agropolitan approaches) and antidevelopment theories (such as post-colonialism and post-modernism).
} 
objectives and values for which societies strive." 589 In human development theory, "development" is concerned with the economic, cultural, social, environmental and political aspects of national welfare. ${ }^{590}$ This approach has been utilised by international organisations and cited frequently in development literature. ${ }^{591}$ The broad-based nature of human development allows for synergistic associations with copyright protection. ${ }^{592}$ Several IP scholars also favour the human development approach. ${ }^{593}$

Further, human development theorists see development as being concerned with increasing a population's overall well-being or "people's capabilities to function, that is, their effective opportunities to undertake the actions and activities that they want to engage in, and to be whom they want to be." ${ }^{594}$ Given its emphasis on the fair distribution of social welfare benefits across a country's population, human development is an appropriate development model for developing country contexts (in which marked income and social inequalities often exist).

Additionally, human development's ultimate objective is the expansion of freedom. The fulfilment of human rights is essential to attaining certain socio-economic aims. Developmental policies can have human rights consequences, for example, in terms of an individual's or group's access to and the distribution of resources. ${ }^{595}$ The human development approach thus offers a conceptual framework within which human rights principles can be

\footnotetext{
589 Anthony Thirlwall "Development and Economic Growth" in Vandana Desai and Robert Potter (eds) The Companion to Development Studies (2nd ed, Hodder Education, London, 2008) 37 at 38.

590 See Balakrishnan Rajagopal "Counter-hegemonic International Law: rethinking human rights and development as a Third World strategy” (2006) 27 Third World Quarterly 767 at 776.

591 See: United Nations Millennium Declaration and Development Goals, G.A. Res. 55/2, U.N. Doc. A/RES/55/2 (18 September 2000) and David Clarke "The Capability Approach: Its Development, Critiques and Recent Advances" (2006) (Global Poverty Research Group Working Paper Series, Paper 32, 2006) <www.gprg.org>.

${ }^{592}$ See Chapter 4.III.A.

${ }^{593}$ See, for example: Margaret Chon "Substantive Equality in International Intellectual Property Norm Setting and Interpretation" in Daniel Gervais (ed) Intellectual Property, Trade and Development: Strategies to Optimize Development in a TRIPS-Plus Era (Oxford University Press, New York, 2007) 475; Olufunmilayo Arewa "Freedom to Copy: Copyright, Creation and Context" (2007) 41 UC Davis L Rev 477; Julie Cohen "Creativity and Culture in Copyright Theory" (2007) 40 UC Davis L Rev 1151; Madhavi Sunder "IP"” (2006) 59 Stan L Rev 257; Keith Aoki "Distributive and Syncretic Motives in Intellectual Property Law (With Special Reference to Coercion, Agency, and Development)" (2007) 40 UC Davis L Rev 717 and Haochen Sun "Overcoming the Achilles Heel of Copyright Law" (2007) 5 NW J Tech \& Intell Prop 265.

${ }^{594}$ Ingrid Robeyns "Capability Approach, a Theoretical Survey" (2005) 6 Journal of Human Development 93 at 95.
}

595 Alfredo Sfeir-Younis "Human Rights Must Be a Consideration for Economic Development Organizations" (2006) Policy Innovations <www.policyinnovations.org>. 
incorporated into development planning and action. ${ }^{596}$ But even though their goals may align and their subject matter overlap, ${ }^{597}$ development and human rights are distinct disciplinary realms ${ }^{598}$ with differences in strategies, design, implementation, practice and theories. ${ }^{599}$ In light of this divergence, and given that the research question concerns the developmental impact of copyright protection, this thesis will concentrate on development scholarship.

\section{B The Emergence of Human Development within Development Theory}

Within development literature, human development is in counterpoint to the neoliberal approach. Indeed, the notion of human development arose as a challenge to the neoliberal view. The principles that underpin the neoliberal approach to development are described in the following section, followed by an analysis of the emergence of human development theory:

\section{The Neoliberal approach to development}

Within neoliberal development theory, the market is seen as critical for efficiency and economic welfare. Development is considered as a process of the global economy and barriers to development (such as corruption) are largely domestic in origin. Accordingly, the growth of the world market is viewed as paramount and should not be prevented by domestic governments. Deregulation and free trade are important since the market can regulate itself

\footnotetext{
${ }^{596}$ Sakiko Fukuda-Parr "Human Rights and Human Development" (The Human Rights Institute, University of Connecticut, Economic Rights Working Paper Series, Working Paper 4, 2007) at 3. On the relationship on human development and human rights, see: Amartya Sen "Human Rights and Capabilities" (2005) 6 Journal of Human Development 151.

${ }^{597}$ See Laure-Helene Piron and Tammie O’Neil “Integrating Human Rights into Development” (Paper prepared for the OECD DAC Network on Governance, 2005) at ii (describing human rights and development as interdependent and mutually enforcing) and Siobhan McInerney-Lankford "Human Rights and Development: A Comment on Challenges and Opportunities from a Legal Perspective" (2009) 1 Journal of Human Rights Practice 51.

${ }^{598}$ Philip Alston "Ships Passing in the Night: The Current State of the Human Rights and Development Debate seen through the Lens of the Millennium Development Goals" (2005) 27 Human Rights Quarterly 755.

599 See UNDP "Human Development Report 2000: Human Rights and Human Development" (Oxford University Press, New York, 2000) at 19 and Adrian Di Giovanni "Introduction to the Human Rights and Development Panel" (presented to the Canadian Council on International Law 40th Annual Conference, Ottawa, 5 November 2011).
} 
better and more cheaply than government. ${ }^{600}$ From a neoliberal perspective, globalisation not only means increased entry into domestic markets and economies, but arguably, also has become "the new word for mainstream development." 601

Because the short term costs of free trade are thought to produce long term benefits globally as countries achieve economic growth, ${ }^{602}$ neo-liberalism urges policies geared at trade liberalisation, FDI, extension of formal property rights, structural adjustment and reduced state intervention in the economy. ${ }^{603}$ Under neoliberal theory, economic growth is the fundamental indicator of development and therefore receives the most emphasis. The neoliberal view is typified by the philosophy underpinning the WTO. ${ }^{604}$

Although an exhaustive examination of the limitations of neoliberal theory is outside the scope of this thesis, there is research which challenges the apparent causal relationship between trade liberalisation and economic growth. ${ }^{605}$ Other researchers have argued that in some cases trade liberalisation can even be inimical to economic growth. ${ }^{606}$ Additionally, although neoliberals may argue that the economic benefit of free trade is an overall increase

${ }^{600}$ David Simon "Neoliberalism, Structural Adjustment and Poverty Reduction Strategies" in Vandana Desai and Robert B. Potter (eds) The Companion to Development Studies (2nd ed, Hodder Education, London, 2008) 86 at $86-87$.

${ }^{601}$ Björn Hettne "Current Trends and Future Options in Development Studies" in Vandana Desai and Robert B. Potter (eds) The Companion to Development Studies (2nd ed, Hodder Education, London, 2008) 8 at 9.

${ }^{602}$ Robert Howse "From Politics to Technocracy - And Back Again: The Fate of the Multilateral Trading Regime" (2002) 96 Am J Int'l L 94 at 99. Economic growth is the increase in output of goods and services produced by a country over an accounting period, usually one year.

${ }^{603}$ See: David Kennedy “The 'Rule of Law,' Political Choices, and Development Common Sense” in David Trubek and Alvaro Santos (eds) The New Law and Economic Development: A Critical Appraisal (Cambridge University Press, New York, 2006) 95 at 128-150. However, the rise of the regulatory state at the global level since the 1980s should be acknowledged, see: Fabrizio Gilardi, Jacint Jordana and David Levi-Faur "Regulation in the Age of Globalization: The Diffusion of Regulatory Agencies Across Europe and Latin America" (IBEI Working Paper 2006/1, 2006) at 4 and Jacint Jordana and David Levi-Faur "The Politics of Regulation in the Age of Governance" in Jacint Jordana and David Levi-Faur (eds) The Politics of Regulation: Institutions and Regulatory Reforms for the Age of Governance (Edward Elgar, Cheltenham, 2005) 1 at 11 (noting the escalation in state regulation in modern free trade economies) but see: John Braithwaite Regulatory Capitalism: How it works, ideas for making it work better (Edward Elgar, Cheltenham, 2008) at 4 (arguing that corporate governance has eclipsed state governance as a key driver of regulatory growth).

${ }^{604}$ David Sapsford "Smith, Ricardo and the World Marketplace, 1776 - 2007: Back to the Future?" in Vandana Desai and Robert B. Potter (eds) The Companion to Development Studies (2nd ed, Hodder Education, London, 2008) 75 at 79.

${ }^{605}$ Dani Rodrik “The Global Governance of Trade As If Development Really Mattered” (UNDP Background Paper, 2001) at 6-7.

${ }^{606}$ Ibid, at 5 . 
in social welfare, a neoliberal approach to development is less concerned with equity in the distribution of that welfare. ${ }^{607}$

\section{The growth of the Human Development model}

The limitations of neoliberal theory led to the creation of the concept of human development. Neoliberal theory focussed almost exclusively on economic growth and assumed that welfare and human rights issues ${ }^{608}$ would naturally flow, ${ }^{609}$ thus very little attention was given to the ethics of development. ${ }^{610}$ However, in view of the positive correlation between economic growth in developing countries and greater levels of relative and absolute poverty, human development theorists posited that economic growth was only one indicator of national welfare. The other indicators of development included sustainability, equitable wealth distribution and social welfare. According to Denis Goulet, a development ethicist, ${ }^{611}$ the core values of development can be divided into three parts: life sustenance (involving basic needs such as: education, food, housing and clothing), self-esteem (independence and respect) and freedom (the majority's ability to determine their destiny). ${ }^{612}$ Goulet said: ${ }^{613}$

Development's true task is precisely this: to abolish all alienation - economic, social, political and technological.

Economist Amartya Sen's formulation is even more wide-ranging. For Sen, development is about increasing what he calls "entitlements" as well as the "capabilities" they generate. Entitlements are the set of alternative commodity bundles which a person can command in a

\footnotetext{
${ }^{607}$ Margaret Chon "Intellectual Property and the Development Divide" (2006) 27 Cardozo L Rev 2821 at 2872.

${ }^{608}$ The so-called "first generation" of human rights: civil and political liberties including the right to life, liberty and security, the right to vote, to a free press and freedom of speech and due process. Human rights has since been broadened to include cultural, social and economic rights.

${ }^{609}$ Jennifer Elliott "Development and Social Welfare/Human Rights" in Vandana Desai and Robert Potter (eds) The Companion to Development Studies (2nd ed, Hodder Education, London, 2008) 40 at 41.

${ }^{610}$ See Stuart Corbridge "Development, Post-development and the Global Political-economy" in Paul Cloke, Philip Crang and Mark Goodwin (eds) Introducing Human Geographies (Hodder Arnold, London, 1999$) 67$.

${ }^{611}$ Development ethics is concerned with the values embedded in development (such as the extent of its means, the ethics of its ends, ethical dilemmas in its practice, and moral guidelines of those with power and the meaning of ethical development) as well as with how development interacts with basic needs, social justice, theology and human rights: International Development Ethics Association "What is Development Ethics?" <www.development-ethics.org/what_is>.

${ }^{612}$ See Denis Goulet The Cruel Choice: A New Concept on the Theory of Development (Atheneum, New York, 1971).

${ }^{613}$ Denis Goulet “A New Discipline: Development Ethics” (The Kellogg Institute Working Paper No 231, 1996) at 21 .
} 
society using the totality of rights and opportunities that that person faces. ${ }^{614}$ Entitlements are affected by unemployment, state assistance, commodity prices, social power imbalances and resource and opportunity distribution. Capabilities have to do with how human beings are able to function, as Sen explains: ${ }^{615}$

A person's 'capability' refers to the alternative combinations of functionings that are feasible for her to achieve. Capability is thus a kind of freedom: the substantive freedom to achieve alternative functioning combinations (or, less formally put, the freedom to achieve various lifestyles).

Under the human development approach, development is as mindful of general human wellbeing (such as civil and political liberties) as it is with material and physical needs and achieving those basic needs. ${ }^{616}$ For example, the United Nations Development Programme (UNDP) Human Development Report 2001 stated: ${ }^{617}$

Development is...about expanding the choices people have to lead lives that they value...Fundamental to enlarging these choices is building human capabilities- the range of things that people can do or be in life...to lead long and healthy lives, to be knowledgeable, to have access to the resources needed for a decent standard of living and to be able to participate in the life of the community.

The capabilities approach to development, therefore, considers expanding human capabilities and genuine choices to be a vital objective of development policies. It places importance on empowerment and social justice which may be "blind spots in pure income measures of development." 618

Although the human development model integrates issues of social justice and multiple aspects of wellbeing including social and cultural factors, it does not diminish the importance of economic factors. The concept of human development does, however, acknowledge that demographic, social and other differences between people within the same population can

\footnotetext{
${ }^{614}$ See generally: Amartya Sen Commodities and Capabilities (Elsevier Science Publishers, Oxford, 1985).

${ }^{615}$ Amartya Sen Development as Freedom (Oxford University Press, Oxford, 1999) at 74-75.

${ }^{616}$ Jennifer Elliott "Development and Social Welfare/Human Rights" in Vandana Desai and Robert Potter (eds) The Companion to Development Studies (2nd ed, Hodder Education, London, 2008) 40 at 40.

617 United Nations Development Programme [UNDP] "Human Development Report 2001: Making New Technologies Work for Human Development" (Oxford University Press, New York, 2001) at 9.

${ }^{618}$ Tzen Wong "Intellectual Property through the Lens of Human Development" in Tzen Wong and Graham Dutfield (eds) Intellectual Property and Human Development: Current Trends and Future Scenarios (Cambridge University Press, New York, 2011) 1 at 4.
} 
result in different opportunities or qualities of life even with similar income levels. ${ }^{619} \mathrm{~A}$ human development approach also accepts that dimensions of human development which enlarge people's choices are wide-ranging and change over time and by country. ${ }^{620}$

In order to analyse the connection between human development and copyright, I will next examine the major copyright theories applicable to Jamaica as well as the major copyright treaties. It is beyond the focus of the research to provide an exhaustive critique of these theories. Instead, their fundamental arguments are summarised and the way each theory is reflected in the Jamaican copyright context is illustrated.

\section{Major Theoretical Justifications for Copyright Protection and Copyright Treaties}

\section{A Copyright Theories}

\section{$1 \quad$ Natural Rights and Personality perspectives}

The natural rights and personality perspectives justify copyright protection on the basis of individual rights and society's moral obligations to creators. More specifically, these approaches connect the created work to the creator's natural property rights and personality, respectively.

The natural rights approach to copyright stemmed from John Locke's statement that "since every Man has a Property in his own Person [which] no Body has any Right to but

\footnotetext{
${ }^{619}$ Amartya Sen Development as Freedom (Oxford University Press, Oxford, 1999) at 69-70. Using a Gross National Product (GNP) measure for development ignores differences in income distribution and may not attention to non-income related dimensions of poverty such as social life, education, spiritual and political freedom and health.

${ }^{620}$ For this reason Sen has avoided compiling or endorsing an exhaustive list of human capabilities: Amartya Sen "Capability and Well-being" in Martha Nussbaum and Amartya Sen (eds) The Quality of Life (Clarendon Press, Oxford, 1993) 30 at 47.
} 
himself," 621 when persons labour on un-appropriated resources they have a natural property right in the product of their efforts. ${ }^{622}$ Under this theory, copyright law merely formally recognises an innate property right. ${ }^{623}$ Natural rights: ${ }^{624}$

...are those which always appertain to [human beings] in right of [their] existence. Of this kind are all the intellectual rights, rights of the mind, and also all those rights of acting as individuals of [their] own comfort and happiness, which are not injurious to the rights of others.

A corollary of this natural right is that the creator ${ }^{625}$ should be empowered to protect the work from theft, adaptation or unauthorised use. ${ }^{626}$

The personality perspective has been attributed to Immanuel Kant and GW Friedrich Hegel. According to Kant, property is the "right to the private use of a thing of which I am in (original or instituted) possession in common with all others. ${ }^{, 627}$ In Kantian philosophy, property rights give people the freedom to carry out projects that would be impossible without the physical control of things. The right to property is thus justified on the basis of individual autonomy and the ability of people to conduct self-motivated projects. ${ }^{628}$ Hegel posited that a modern constitutional state ought to institute a private property regime because

\footnotetext{
${ }^{621}$ John Locke Two Treatises of Government (1698) (Peter Laslett ed., Cambridge University Press, Cambridge, 1988 ) at 287-288.

${ }^{622}$ Subject to the proviso that the person seeking property has left 'enough, and as good' in the common for others to use: Wendy Gordon "Intellectual Property" in Peter Can and Mark Tushnet (eds) The Oxford Handbook of Legal Studies (Oxford University Press, New York, 2003) 617 at 624. This proviso has been used to limit the reach of copyright: Wendy Gordon "A Property Right in Self-Expression: Equality and Individualism in the Natural Law of Intellectual Property” (1993) 102 Yale LJ 1533.

${ }^{623}$ Lionel Bently and Brad Sherman Intellectual Property Law (3rd ed, Oxford University Press, New York, 2008) at 35.

${ }^{624}$ Thomas Paine "The Rights of Man: Being an Answer to Mr. Burke's Attack on the French Revolution" (3rd ed, I. Thomas and E.T. Andrews, Boston, 1791).

${ }^{625}$ The creator and copyright owner are not necessarily the same person as the author can part with the ownership/ exploitation of the economic rights in the copyright work.

${ }^{626}$ Kevin Garnett, Gillian Davies and Gwilym Harbottle Copinger and Skone James on Copyright (15th ed, Sweet \& Maxwell, London, 2005) at [2-05]. For an in-depth look at Locke see: Lior Zemer The Idea of Authorship in Copyright (Ashgate, Hampshire, 2007) at ch 6.

${ }^{627}$ Immanuel Kant The Metaphysics of Morals (Mary Gregor ed., Cambridge University Press, Cambridge, 1996) at 49.

${ }^{628}$ Robert Merges Justifying Intellectual Property (Harvard University Press, Cambridge, Mass., 2011) at ch 3.
} 
of the role property plays in the constitution of personality. ${ }^{629} \mathrm{He}$ argued that property was one way in which a person's will could be objectively conveyed. ${ }^{630}$

Both Kant and Hegel rationalised copyright on the ground that an individual's personality is manifested in his or her intellectual expressions. ${ }^{631}$ These creations are thought to be infused with and connected with their creator's personality. Copyright protection is therefore required to limit the expropriation of these inalienable characteristics of a creator's personality embodied in the creation. ${ }^{632}$ Adherents to this personality approach consider private property rights a component of basic human needs such that policymakers are obliged to allocate resources in a manner that best allows people to meet those needs. ${ }^{633}$

Both the natural rights and personality approaches have been linked to the human rights approach to copyright. Essentially, human rights-based approaches to copyright protection emphasise a creator's right to the fruits of his or her creation. This approach is seen in art 15.1(c) of the International Covenant on Economic, Social and Cultural Rights (ICESCR) ${ }^{634}$ and art 27 of the United Nations Universal Declaration of Human Rights (UDHR). ${ }^{635}$ However, the debate about the status of IP as a human right has not been settled. ${ }^{636}$

${ }^{629}$ Jeanne Schroeder "Unnatural Rights: Hegel and Intellectual Property” (Benjamin N Cardozo School of Law Working Paper No. 8, 2004) at 2.

${ }^{630}$ Anthony D'Amato and Doris Estelle Long International Intellectual Property Law (Kluwer Law International, London, 1997) 35.

${ }^{631}$ See Margaret Radin "Property and Personhood" (1982) 34 Stanford L Rev 957 arguing that property rights can be justified because people attain self-identification through external objects.

${ }^{632}$ Lior Zemer "On the Value of Copyright Theory" (2006) 1 IPQ 55 at 64. See also: Justin Hughes "Philosophy of Intellectual Property" (1988) 77 Georgetown LJ 287.

${ }^{633}$ William Fisher "Theories of Intellectual Property" in Stephen Munzer (ed) New Essays in the Legal and Political Theory of Property (Cambridge University Press, Cambridge, 2001) 168 at 171.

${ }^{634}$ International Covenant on Economic, Social and Cultural Rights [ICESCR], art 15.1(c) states: "1. The States Parties to the present Covenant recognize the right of everyone: ... (c) To benefit from the protection of the moral and material interests resulting from any scientific, literary or artistic production of which he is the author."

${ }^{635}$ United Nations Universal Declaration of Human Rights [UDHR], art 27: "(1) Everyone has the right freely to participate in the cultural life of the community, to enjoy the arts and to share in scientific advancement and its benefits. (2) Everyone has the right to the protection of the moral and material interests resulting from any scientific, literary or artistic production of which he is the author." For a further discussion of these points, see: Laurence Helfer and Graeme Austin Human Rights and Intellectual Property: Mapping the Global Interface (Cambridge University Press, New York, 2011).

${ }^{636}$ ICESCR, art 15(1)(c) has been accepted as a human right according to Resolution 2000/7 of the SubCommission on the Promotion and Protection of Human Rights: UN Doc. E/CN.4/Sub.2/RES/2000/7 (17 August 2000). However, the Committee on Economic, Social and Cultural Rights has distinguished between the moral and material rights found in art 15(1)(c) and intellectual property rights, noting that "human rights are fundamental as they are inherent to the human person" while "intellectual property rights are first and foremost 
In Jamaica, the framers of the Copyright Act 1993 were informed by the natural rights, personality and human rights justifications for copyright protection, as evidenced by Parliamentarians' statements during the passage of the Copyright Bill:

[IP is] property which this Copyright Act seeks to protect, because [it] is the manifestation of the highest level of the human mind. ${ }^{637}$

The direct connection between the quality of the work, and the honour and reputation of the maker, is a fusion between cultural expression and the individual human being from whom that cultural expression emanates. ${ }^{638}$

[IP] is now recognized as a human right having been enshrined in the United Nations Universal Declaration of Human Rights Article 27 (2). ${ }^{639}$

The natural rights and personality approaches to copyright protection are demonstrated in the Jamaican Copyright Act 1993 in several ways. One example is the moral rights provisions copied from the UK Copyright, Designs and Patents Act (CDPA) of $1988 .{ }^{640}$ Like the UK CDPA, the Copyright Act 1993 protects the moral rights of paternity (right to be identified as creator) and integrity (right to protect the work from derogatory treatment). ${ }^{641}$

Another example is the protection of original works of authorship. ${ }^{642}$ To qualify for copyright, work cannot merely be copied from another source. Though "originality" is not statutorily defined, implicitly this requirement recognises that what is protectable in copyright law is the author's unique contribution. ${ }^{643}$ Further illustrations of the natural rights and

means by which States seek to provide incentives for inventiveness and creativity." See General Comment No. 17 (UN Doc. E./C.12/GC/17 (17 January 2006).

637 Jamaican Hansard 26 January 1993 (PJ Patterson).

${ }^{638}$ Hansard 27 January 1993 (Carl Rattray).

${ }^{639}$ Hansard 26 January 1993 (PJ Patterson). UDHR, art 27 was also cited by Edward Seaga, the Leader of the Opposition: Hansard 27 January 1993.

${ }^{640}$ Elizabeth Adeney The Moral Rights of Authors and Performers: An International and Comparative Analysis (Oxford University Press, New York, 2006) at [14.02]. See also: Jane Ginsburg “'Une Chose Publique'? The Author's Domain and the Public Domain in Early British, French and US Copyright Law" in Paul Torremans (ed) Copyright Law: A Handbook of Contemporary Research (Edward Elgar, Cheltenham, 2007) 133 at 136 arguing that natural rights formed part of early British law: "By the late seventeenth century, authors' claims may, therefore, have been recognized as a matter of natural justice." Civil law jurisdictions have a more authorbased approach to copyright: see Jane Ginsburg “A Tale of Two Copyrights: Literary Property in Revolutionary France and America" (1989-1990) 64 Tul L Rev 991.

${ }^{641}$ Copyright Act, 1993, ss 9, 18, 27-28, 36-43.

642 Copyright Act 1993, s 6(1)(a).

${ }^{643}$ In common law jurisdictions, the courts have, through case law, articulated what is required for the originality threshold to be met; see: Daniel Gervais "Feist Goes Global: A Comparative Analysis of the Notion of Originality in Copyright Law" (2002) 49 J. Copyright Soc'y U.S.A. 949 and Elizabeth Judge and Daniel Gervais "Of Silos and Constellations: Comparing Notions of Originality in Copyright Law" (2009) 27 Cardozo Arts \& Entertainment 375. With regard to originality in music see: Valeria Castanaro “'It's the Same Old Song': 
personality paradigms can be seen in copyright's duration. Copyright protection in a literary, dramatic, musical or artistic work continues for the author's life plus 50 years. ${ }^{644}$ Although a natural rights/personality approach does not necessarily mandate a perpetual copyright term, ${ }^{645}$ life plus 50 years arguably aligns with these theories because it allows the author and his or her immediate descendants time to benefit from substantially all of the fruits of the author's labour. ${ }^{646}$ The term of moral rights, which continue to subsist during the term of copyright protection, ${ }^{647}$ also points to a natural rights/personality approach in that the author's moral rights are protected as long as copyright continues in the work. ${ }^{648}$

Finally, to qualify for copyright protection under the Jamaican Copyright Act 1993, an author does not need to comply with formalities, such as: registration of the copyright, deposit of copies of the copyright work, or marking copies of the work with a copyright notice. ${ }^{649}$ Arguably, the absence of formal prerequisites for copyright protection accords with the natural rights and personality approaches ${ }^{650}$ because the statute treats the copyright work as existing as an outflow of the exercise of the creator's natural rights. Copyright derives from the act of creation (subject to the requirement that the work has been fixed in material form). ${ }^{651}$

The counter-argument is that formalities are not inconsistent with natural rights. Although natural rights theories preclude conditions being placed on the subsistence of copyright, they do permit formalities in relation to its exercise. ${ }^{652}$ Moreover, copyright has never been

The Failure of the Originality Requirement in Musical Copyright” (2008) 18 Fordham Intell Prop Media \& Ent L J 1271.

${ }^{644}$ Copyright Act 1993, s 10.

645 Christopher Sprigman "Reform(aliz)ing Copyright" (Unpublished paper, 25 March 2004) at 27-28. <www.cyberlaw.stanford.edu>

646 Ibid.

${ }^{647}$ Copyright Act 1993, s 18(1).

${ }^{648}$ The right to object to false attribution only exists for the author's lifetime and 20 years after death: Copyright Act 1993 s 18(2). On moral rights generally, see Lionel Bently and Brad Sherman Intellectual Property Law (3rd ed, Oxford University Press, New York, 2008) at 241-259.

${ }^{649}$ See Brad Greenberg "More Than Just a Formality: Instant Authorship and Copyright's Opt-Out Future in the Digital Age" (2012) 59 UCLA L Rev 1028 on the advantages and disadvantages of formalities.

${ }^{650}$ See: Jane Ginsburg "A Tale of Two Copyrights: Literary Property in Revolutionary France and America" in Brad Sherman and Alain Strowel (eds) Of Authors and Origins: Essays on Copyright Law (Clarendon Press, Oxford, 1994) 131 at 133-134.

${ }^{651}$ Copyright Act 1993, s 6(2).

${ }^{652}$ See Stef van Gompel "Formalities in the digital era: An Obstacle or Opportunity?" in Lionel Bently, Uma Suthersanen and Paul Torremans (eds) Global Copyright: Three Hundred Years Since the Statute of Anne, from 1709 to Cyberspace (Edward Elgar, Cheltenham, 2010) 395. 
absolute and unconditional. ${ }^{653}$ The Statute of Anne (UK) 1710 imposed formalities. While this argument has merit, it is indisputable that the removal of formalities (as opposed to their imposition) around the subsistence of copyright is closely aligned to the principles of the natural rights/personality argument.

\section{The Incentive-based model}

There are three basic propositions associated with the incentive argument for copyright. The first is that information goods (such as copyright works) are a type of public goods. Unlike private goods, several people can simultaneously consume public goods without diminishing the value of consumption to any one of those individuals. ${ }^{654}$ Like other public goods, copyrighted expressions are thus characterised by two features: non-rivalry and nonexcludability. ${ }^{655}$ Non-rivalry means that a person's use of copyright goods does not decrease the possibilities for others to use them. ${ }^{656}$ Because of non-excludability, the producer of a copyright work cannot prevent consumption by non-payers and these goods can be redistributed by others at a price close to zero. ${ }^{657}$ The original creator is therefore unable to recover the costs of supplying the good. Acknowledgement of copyright works as public goods is noticeable in this lawmaker's contribution to the Parliamentary debate on the Jamaican Copyright Bill: ${ }^{658}$

[A copyright work] has some attributes which are common with the ownership of moveable property, but it cannot be controlled by mere possession of the property.

\footnotetext{
${ }^{653}$ Stef van Gompel "Les formalités sont mortes, vive les formalités! Copyright Formalities and the Reasons for their Decline in Nineteenth Century Europe" in Ronan Deazley, Martin Kretschmer and Lionel Bently (eds) Privilege and Property: Essays on the History of Copyright (Open Book Publishers, Cambridge, 2010) 157 at 186-187.

${ }^{654}$ See Paul Samuelson "The Pure Theory of Public Expenditure" (1954) 36 The Review of Economics and Statistics 387.

655 James Boyle "The Second Enclosure Movement and the Construction of the Public Domain" (2003) 66 Law \& Contemp Probs 33 at $41-42$.

${ }^{656}$ David Barnes “The Incentives/Access Trade off” (2010) 9 NW J Tech \& Intell Prop 96.

${ }^{657}$ But see: David Barnes "Congestible Intellectual Property and Impure Public Goods" (2011) 9 NW J Tech \& Intell Prop 533 arguing that copyrighted expressions are partially rivalrous and therefore impure public goods.

${ }^{658}$ Hansard 26 January 1993 (PJ Patterson).
} 
The second proposition is that, because copyright works are public goods, their creation would cease without some form of encouragement. ${ }^{659}$ This encouragement, theorists argue, should take the form of the State granting creators exclusive rights for a limited time so they can financially exploit their work to the exclusion of non-creators. Copyright enables copyright owners to exclude competition and charge prices above the marginal cost of copying. The intended result of the incentive-based framework is a system that rewards creators while increasing overall public welfare through innovation and creativity. During the copyright term, public use of copyright works is allowed by the exceptions to copyright protection and in some circumstances, non-voluntary licences. The public has unlimited access when the work enters the public domain. ${ }^{660}$

An example of this second proposition is seen in declarations the Jamaican Prime Minister and the Leader of the Opposition made during the debate on the Copyright Bill:

As a right concerning cultural assets, [copyright] serves to ensure a framework that is conducive to creative activity... ${ }^{661}$

[Copyright] has two purposes: to encourage the production of creative works and to provide incentives for the dissemination of creative works. Without constant dissemination of new cultural works, the intellectual needs of people who enjoy art, music, theatre, literature, etc would not be met, and at the same time if there are no incentives for dissemination such that the producers of works continue to create, there will be less cultural production. ${ }^{62}$

The incentive model's third assumption is the belief that the greater social good (the overall public interest) is achieved from stimulating the generation of creative works and cultural and informational products. ${ }^{663}$ Incentives are viewed as the best way to serve the public interest since they encourage the publication of the work by authors who can have reasonable

\footnotetext{
659 See Gideon Parchomovsky and Peter Siegelman "Towards an Integrated Theory of Intellectual Property" (University of Connecticut School of Law Working Paper No. 35, 2002) arguing that copyright is predicated on the need to provide an economic incentive for the creation of public goods, such as expressive works.

${ }^{660}$ The term "public domain" is generally understood to be the realm of elements in which no party (whether an author or successor in title) can exercise any exclusive private right over creations because these works are not or no longer protected by copyright, whether because they are not liable to protection (for example, ideas or works that are not original) or where protection has expired due to lapse of time: Valérie-Laure Benabou and Séverine Dusollier "Draw me a Public Domain" in Paul Torremans (ed) Copyright Law: A Handbook of Contemporary Research (Edward Elgar, Cheltenham, 2007) 161 at 164-165 (noting the imprecision of the term). Public domain works can be freely used, reproduced, adapted, translated and communicated to the public. ${ }^{661}$ Hansard 26 January 1993 (PJ Patterson).

${ }^{662}$ Hansard 27 January 1993 (Edward Seaga).

${ }^{663}$ See Sharon Le Gall "Justifying Intellectual Property Rights" (2002) 12 Caribbean L Rev 15.
} 
expectations of obtaining a return on their investment of creativity, skill, effort and financial resources involved in creating the work. As Jamaican Parliamentarians noted:

The dynamic nature of technology and the creative cultural reservoir of our people, will ensure ever expanding boundaries of cultural expression. New forms [of creative expression] will need legal protection. ${ }^{664}$

[W]e regard the Copyright Act as one step in a long process of affording protection to our authors and artistes as well as creating the economic and legal environment which will inspire our artistes to give of their skills and their talents. ${ }^{665}$

The incentive-based approach to copyright protection found in the Jamaican copyright statute mirrors domestic copyright legislation in the UK and the US. ${ }^{666}$ Within the Jamaican Act, this incentive-based approach is demonstrated by the extensive economic rights provided to rights holders. ${ }^{667}$

One limitation of the incentive argument is that it assumes that creators of copyright works have an opportunity to earn income from the creation, which is not always the case. Moreover, the absence of opportunity to earn does not necessarily mean creativity would cease, in view of the non-financial motivations behind creation. ${ }^{668}$ The incentive argument also assumes that the proliferation of copyright works is a primary means of advancing social welfare, such that, for the purposes of entitlement to copyright protection, there is no differentiation on the basis of works' quality or their effect on society. For example, the Copyright Act 1993 s 6(1) provides that "copyright may subsist in a work irrespective of its quality or the purpose for which it was created." While copyright can serve some social welfare objectives, in extreme cases excessive protection can lead to potential abuse of exclusive rights which manifests in unaffordable pricing, stymieing of competitors,

\footnotetext{
${ }^{664}$ Hansard 27 January 1993 (Carl Rattray, Attorney-General).

${ }^{665}$ Hansard 27 January 1993 (PJ Patterson).

${ }^{666}$ The Statute of Anne 1710 (UK) is entitled "An Act for the encouragement of learning..." and Article 1, Section 8, Clause 8 of the US Constitution enables Congress to "promote the progress of science and useful arts" through granting exclusive rights.

${ }^{667}$ Copyright Act 1993, s 9.

${ }^{668}$ Non-financial motivations such as: the desire for fame or respect, social recognition from being first in the market, or a need to share ideas for the public benefit: Steve Calandrillo "An Economic Analysis of Intellectual Property Rights: Justifications and Problems of Exclusive Rights, Incentives to Generate Information, and the Alternative of a Government-run Reward System" (1998) 9 Fordham Intell Prop Media \& Ent LJ 301 at $316-$ 323.
} 
prevention of new entrants to the market and other anti-competitive behaviour. ${ }^{669}$ A balance in copyright protection is required which incentivises creativity in a way which allows society and authors to benefit. ${ }^{670}$

\section{The Economic Efficiency Argument}

Under the economic efficiency argument, a system that recognises exclusive private property ownership (such as copyright protection) is the best means of attaining optimal resource allocation and profit maximisation. Theorists claim that, in a system of either common ownership or no ownership resources will either be over-exploited, under-exploited or undervalued. ${ }^{671} \mathrm{~A}$ free market is said to enable equilibrium between demand and supply. The role of copyright protection is therefore to ensure that the value of resources is preserved. ${ }^{672}$

Copyright preserves this value by preventing free-riders ${ }^{673}$ and market failure. As public goods, copyright works are susceptible to duplication and use by free-riders, which creates the risk that copyright owners might not recover production costs, ${ }^{674}$ thereby negatively affecting the production of socially valuable intellectual products. It is therefore essential for

\footnotetext{
${ }^{669}$ See Tobias Schonwetter "Economics of IP" (paper presented to the WIPO Summer School, South Africa, December 2011).

670 See: Francis Gurry "The Future of Copyright" (speech to the Blue Sky Conference: Future Directions in Copyright Law, Queensland University of Technology, Sydney, 25 February 2011) raising the question of how much financial reward is needed to incentivize creativity.

671 These hypotheses have been empirically challenged in relation to copyright works: see Paul Heald "Bestselling Musical Compositions (1913-32) and their Use in Cinema (1968-2007)" (2009) 6 Review of Economic Research on Copyright Issues 31.

${ }^{672}$ See Lionel Bently and Brad Sherman Intellectual Property Law (3rd ed, Oxford University Press, New York, 2008) at 37-38.

${ }^{673}$ Peter Drahos "Introduction" in Peter Drahos and Ruth Mayne (eds) Global Intellectual Property Rights: Knowledge, Access and Development (Palgrave Macmillan, Hampshire and New York, 2002) 1 at 3-4: "A freerider is a person who takes the benefit of an economic activity without contributing to the costs needed to generate that benefit. In the case of intellectual property the freerider takes the benefit of information for which the costs of discovery/creation have been met by the producer. The producer does not lose the information (for this reason information is described as a public good), but rather faces competition from the freerider who gains use of it as well."

${ }^{674}$ William Landes and Richard Posner “An Economic Analysis of Copyright Law” (1989) 18 Journal of Legal Studies 325.
} 
the State to allocate exclusive rights of authorship to creators in order to prevent economically inefficient outcomes. ${ }^{675}$ The rationale is that: ${ }^{676}$

[Copyright] trades off the costs of limiting access to a work against the benefits of providing incentives to create the work in the first place.

The necessary state intervention is the granting of exclusive rights that restrict competition (copyright protection). Then, the market for copyright works will operate to bring benefits to creators and suppliers. Consequently, for lawmakers who apply an economic efficiency approach the central issue is how to balance private and public interests: ${ }^{677}$

Striking the correct balance between access and incentives is the central problem in copyright law. For copyright law to promote economic efficiency, its principal legal doctrines must, at least approximately, maximize the benefits from creating additional works minus both the losses from limiting access and the costs of administering copyright protection.

This cost-benefit formulation, which is a defining feature of the economic efficiency argument, ${ }^{678}$ is seen in the balancing exercise the Jamaican Attorney-General implied in the Parliamentary debates: ${ }^{679}$

It is always a regulatory dilemma to determine the boundaries between the necessary protection of rights, and the freedom of enjoyment of the rest of us in the public, who are not creators.

A member of the judiciary also demonstrated the economic efficiency approach in interpreting the function of the Copyright Act: ${ }^{680}$

Our [Jamaican copyright] model is more compatible with...the market-driven approach or the economic-based approach to the protection of copyright...why should persons essentially

\footnotetext{
675 Joseph Stiglitz "Knowledge as a Global Public Good" in Inge Kaul, Isabelle Grunberg and Marc Stern (eds) Global Public Goods: International Cooperation in the $21^{\text {st }}$ Century (Oxford University Press, New York, 1999) 311 arguing that the "central public policy implication of public goods is that the state must play some role in the provision of such goods; otherwise they will be undersupplied."

${ }^{676}$ William Landes and Richard Posner "An Economic Analysis of Copyright Law" (1989) 18 Journal of Legal Studies 325 at 326.

${ }^{677}$ Ibid.

${ }^{678}$ Anne Barron "Copyright Infringement, 'free-riding' and the lifeworld" in Lionel Bently, Jennifer Davis and Jane Ginsburg (eds) Copyright and Piracy: An Interdisciplinary Critique (Cambridge University Press, New York, 2010) 93.

${ }^{679}$ Hansard 27 January 1993 (Carl Rattray).

${ }^{680}$ R-34. Because there is very little copyright litigation in Jamaica (see Dianne Daley Jamaica (Roger Blanpain and Michele Colucci (eds) Kluwer Law International: International Encyclopaedia of Laws (Intellectual Property-Supplement 47, Wolters Kluwer, Eastbourne, 2008) at [61]-[62]) not many judgments exist which could be examined to determine the applicable copyright theory.
} 
have what economists call "free-riders"? Why should they be allowed to utilise your work without acknowledging it in some way?

Further, Jamaica is a member of the WIPO internet treaties, which adapt and extend rights in the digital environment in response to the increased opportunities for free-riding created by the internet and duplication technologies. ${ }^{681}$ These treaties limit the circumvention of Digital Rights Management (DRM) systems, thereby allowing rights holders to physically control users' access to information. ${ }^{682}$ Because they seek to correct deficiencies in the market which could occur if private rights are not strengthened, these treaties arguably reflect an economic efficiency approach to copyright. The internet treaties can be viewed as attempts to recalibrate the economic efficiency's cost-benefit equation (or creator/user balance), in light of new digital and communication technologies.

However, laws designed to attain economic efficiency may not necessarily advance social welfare. For example, economic efficiency may not be a socially desirable outcome if it reinforces inequalities in wealth distribution. ${ }^{683}$

\section{Summary}

This section examined the major copyright theories that influence Jamaican copyright policy and legislation. Outlining the principles of each theory contextualises the later discussion on the connection between human development and copyright. However, before that discussion, the subsequent sections examine the Berne Convention and the TRIPS Agreement, which influence the Jamaican copyright regime.

\footnotetext{
${ }^{681}$ WIPO Copyright Treaty, arts 6 and 7 create new exclusive distribution rights relating to the subsequent exploitation of tangible copies of literary and artistic works at least up to and including the first sale (distribution right). Art 8 confers on authors the exclusive right of authorising the "communication of their works to the public by wire or wireless means, including the making available to the public of their works in such a way that members of the public may access these works from a place and at a time individually chosen by them" (communication right). This treaty also has prohibitions on modifying digital rights management and the circumvention of technological measures which protect copyright works: (arts 11 and 12 of WIPO Copyright Treaty). Jamaica's Copyright Act has not yet been amended to implement these treaties.

${ }^{682}$ See Anne Barron “Copyright Infringement, 'free-riding' and the lifeworld” in Lionel Bently, Jennifer Davis and Jane Ginsburg (eds) Copyright and Piracy: An Interdisciplinary Critique (Cambridge University Press, New York, 2010) 93 at 98-99.

${ }^{683}$ See Amartya Sen On Ethics and Economics (Blackwell, Oxford, 1987) at 31-32.
} 


\section{B Berne and TRIPS}

\section{The Berne Convention}

The Berne Convention ${ }^{684}$ laid the foundation for the establishment of the international copyright regime. Berne mandated members of the Berne Union to protect certain minimum rights of the authors of literary and artistic works, such as the rights of translation, ${ }^{685}$ reproduction, ${ }^{686}$ adaptation, ${ }^{687}$ public performance ${ }^{688}$ and broadcasting. ${ }^{689}$ The duration of protection conferred should be at least the life of the author plus 50 years. ${ }^{690}$ Berne was the first treaty to create obligations for national treatment of copyrighted works. ${ }^{691}$ It requires every member to grant nationals of other members the same level of protection that member country affords its own nationals. ${ }^{692}$

Despite the important role played in strengthening the content of copyright protection and creating copyright obligations among states, Berne's limitations included its lack of specific rules about domestic rights enforcement ${ }^{693}$ and an effective mechanism for dealing with disputes between members on matters contained in the convention. TRIPS corrected Berne's weak enforcement mechanism.

\footnotetext{
${ }^{684}$ Berne Convention, art 2 defines "literary and artistic works" broadly to include "every production in the literary, scientific and artistic domain whatever may be the mode or form of its expression..." The Article then gives an indicative list of the categories of works encompassed by the definition, such as books, pamphlets and other writings, lectures, addresses, dramatico-musical works; choreographic works and musical compositions with or without words.

${ }^{685}$ Berne, arts 8 and 11(2).

${ }^{686}$ Berne, art 9.

${ }^{687}$ Berne, arts 12 and 14.

${ }^{688}$ Berne, arts 11 and 11 ter.

${ }^{689}$ Berne, art 11bis. Berne union members may allow limited exception to these rights in their domestic law. Exceptions to the reproduction right must comply with the conditions in Article 9(2).

${ }^{690}$ Berne, art 7.

691 See: Sam Ricketson and Jane Ginsburg International Copyright and Neighbouring Rights: The Berne Convention and Beyond (2nd ed, Oxford University Press, New York, 2006) vol 1 at [6.74-6.100]. National treatment is considered more efficient than a system in which each country protects only its nationals because in some countries the domestic market may be too small to sufficiently incentivise creations or cover the cost of innovations: Peter Menell and Suzanne Scotchmer "Intellectual Property" (Public Law Research Paper No. 741724, University of California at Berkeley, 2005) at 57.

${ }^{692}$ Berne, art 5(1). The national treatment principle is subject to limited exceptions.

${ }^{693}$ Under Berne authors could initiate legal proceedings to enforce their rights in national courts (see arts 2 and 12). Berne, art 13 provided for the seizure of imported pirated works.
} 


\section{TRIPS}

(a) TRIPS provisions

TRIPS owes its existence to developed countries' recognition of the importance of the international trade in IP goods which were under threat from piracy and counterfeit goods. ${ }^{694}$ These countries felt that stronger copyright protection was necessary and since WIPO, which administered Berne, is not a trade venue, developed countries used regime-shifting ${ }^{695}$ to bring the issue of IP protection to the WTO through TRIPS.

TRIPS sets out minimum standards for IP protection, which are binding on all its members. TRIPS adopts many of Berne's substantive provisions, in that its art 9 requires members to comply with arts $1-21$ of Berne. ${ }^{696}$ TRIPS' main provisions on copyright are:

- A 50-year minimum term for works (other than photographic or applied artworks) owned by legal persons, including corporations, and for phonogram producers and performers ${ }^{697}$

- Enhanced protection for the rights of broadcasting organisations, performers and producers of phonograms, ${ }^{698}$

- Protection of compilations of data and computer programs as literary works; ${ }^{699}$

- Exceptions to exclusive rights are limited to special cases which do not conflict with a normal exploitation of the work and which do not unreasonably prejudice the rights-holder's legitimate interests; ${ }^{700}$ and

- Rental rights for computer programs, phonograms and cinematographic works (provided rental has led to widespread copying, materially impairing the reproduction right). ${ }^{701}$

The TRIPS Agreement contains a national treatment principle ${ }^{702}$ and introduces the MostFavoured-Nation (MFN) principle (commonly used in trade agreements) into copyright

\footnotetext{
${ }^{694}$ Robert Gutowski "The Marriage of Intellectual Property and International Trade in the TRIPS Agreement: Strange Bedfellows or a Match made in Heaven?” (1999) 47 Buff L Rev 713.

695 Laurence Helfer "Regime Shifting: The TRIPS Agreement and the New Dynamics of International Intellectual Property Law-Making” (2004) 29 Yale J Int'l L 1 at 18-23.

${ }^{696}$ With the exception of the obligation to protect moral rights in Article 6 bis of Berne.

${ }^{697}$ TRIPS, arts 12 and 14(5).

${ }^{698}$ TRIPS, art 14. In this area, TRIPS built upon the Rome Convention.

699 TRIPS, art 10.

700 TRIPS, art 13.

701 TRIPS, arts 11 and 14(4). This is subject to certain limitations.

${ }^{702}$ TRIPS, art 3(1) requires member states to accord to nationals of other member states no less favourable treatment in regard to the "protection of intellectual property" of those foreign nationals than the protection given to their own nationals. The term "protection" is defined to include matters affecting the "availability,
} 
protection. The MFN obligation under TRIPS states that in respect of IP protection, "any favour, privilege or immunity granted by a Member to the nationals of any other country should be accorded immediately and unconditionally to the nationals of all Members."703

A well-recognised outcome of TRIPS has been the strengthening of enforcement of copyright. $^{704}$ TRIPS members are obliged to make enforcement measures available which would permit "effective action against any act of infringement of [IP] rights protected by this Agreement." 705 TRIPS establishes a complete set of obligations dealing with enforcement, including procedural matters, ${ }^{706}$ evidence, ${ }^{707}$ remedies,${ }^{708}$ border measures ${ }^{709}$ and criminal procedures. ${ }^{710}$ Moreover, disputes among members on the implementation of TRIPS fall within the purview of WTO's Dispute Settlement Body. ${ }^{711}$ Under the Dispute Settlement Understanding, art 19(1), once a Panel or the Appellate Body determines that a member's measures are inconsistent with TRIPS, it must recommend that measures be brought into compliance.

TRIPS is an overall enhancement of the copyright protection given to authors in Berne because of its recognition of new rights, stronger enforcement mechanisms and buttressing of binding obligations by a compulsory dispute settlement process. ${ }^{712}$

acquisition, scope, maintenance and enforcement of intellectual property rights as well as those matters affecting the use of intellectual property rights specifically addressed" in TRIPS.

${ }^{703}$ TRIPS, art 4. There are exceptions to the MFN requirement, including the exception with respect to those obligations under the Berne or Rome Conventions that are subject to reciprocity rather than national treatment: art 4(b).

${ }^{704}$ TRIPS, part III.

705 TRIPS, art 41(1). These measures are to be fair and equitable and not subject to unreasonable delay: art 41(2).

706 TRIPS, art 42.

707 TRIPS, art 43.

708 TRIPS, art 44-50. This includes interim measures.

709 TRIPS, arts 51-60.

710 TRIPS, art 61.

${ }^{711}$ According to Article 64 of TRIPS, the provisions of Articles XXII and XXIII of GATT 1994, as applied in the Understanding on Rules and Procedures Governing the Settlement of Disputes, 15 April 1994, WTO Agreement, Annex 2, Legal Instruments) [Dispute Settlement Understanding or DSU] shall apply to consultations and the settlement of disputes arising under TRIPS. TRIPS also has a dispute prevention provision (art 63) which allows for greater transparency in that each member can be aware of the laws, decisions, regulations which may affect its rights under TRIPS.

${ }^{712}$ See Rochelle Dreyfuss and Andreas Lowenfeld "Two Achievements of the Uruguay Round: Putting TRIPS and Dispute Settlement Together" (1997) 37 Virginia J Int'l L 275. 
(b) Post-TRIPS arguments about the developmental impact of heightened copyright protection

Given the research question's development focus, analysis of TRIPS would be incomplete without reference to the post-TRIPS debate on whether increasing copyright protection (through TRIPS-plus international bilateral or regional agreements) negatively affects lower income countries like Jamaica.

This is important given certain trends since the advent of TRIPS: namely, the proliferation of TRIPS-plus agreements, the elevation of global standards of copyright protection and the concerns IP scholars have raised about the consequences in developing countries. ${ }^{713}$ These concerns are in stark contrast to the position of various private interests and state actors which have suggested that increased copyright protection not only protects developed country industries but is also beneficial for developing countries' national economic growth. ${ }^{714}$ Developed country corporations are more likely to invest in countries with greater copyright protection, since stronger protection increases the cost of imitation. The premises underpinning this argument are that $\mathrm{FDI}^{715}$ is the primary means of technology transfer, ${ }^{716}$ technology transfer occurs through the importation of goods and services, and both FDI flows and technology transfer are dependent upon the existence of a strong copyright regime. ${ }^{717}$

\footnotetext{
713 See: Justin Malbon “TRIPS-Plus Treaty Terms: Dealing with Coercion" in Justin Malbon and Charles Lawson (eds) Interpreting and Implementing the TRIPS Agreement: Is it Fair? (Edward Elgar, Cheltenham, UK and Northampton, Massachusetts, USA, 2008) 159; Ruth Okediji "Back to Bilateralism? Pendulum Swings in International Intellectual Property Protection" (2003-2004) 1 UOLTJ 125; Graham Dutfield "Knowledge Diplomacy and the New Intellectual Property Fundamentalism" in Justin Malbon and Charles Lawson (eds) Interpreting and Implementing the TRIPS Agreement: Is it Fair? (Edward Elgar, Cheltenham, UK and Northampton, Massachusetts, USA, 2008) 31 and Duncan Matthews "Challenges to Enforcement- An International Perspective" (World Intellectual Property Day Public Lecture, University of the West Indies, Mona, Kingston, 26 April 2011) recommending caution and questioning whether developing countries need to agree to TRIPS-Plus provisions in Economic Partnership Agreements.

${ }^{714}$ See Commission on Intellectual Property Rights [CIPR] "Integrating Intellectual Property Rights and Development Policy" (London, 2002); Kamil Idris Intellectual Property: A Power Tool for Economic Growth (2nd ed, World Intellectual Property Organization Publication No 888, Geneva, 2003); Ralph Oman CopyrightEngine of Development (UNESCO Publishing, Paris, 2000) and Michael Ryan "Knowledge-Economy Elites, the International Law of Intellectual Property and Trade, and Economic Development" (2002) 10 Cardozo J Int'l \& Comp L 271 at 303.

${ }^{715}$ Defined earlier at Chapter 1.I.B.2.

${ }^{716}$ Defined at Chapter 1.I.B.2.

${ }^{717}$ Under this rationale for copyright protection, FDI and technology transfer are often linked together: see Ermias Tekeste Biadgleng "The Development-balance of the TRIPS Agreement and Enforcement of Intellectual Property Rights" in Justin Malbon and Charles Lawson (eds) Interpreting and Implementing the TRIPS Agreement: Is it Fair? (Edward Elgar, Cheltenham, UK and Northampton, Mass., 2008) 97 at 107.
} 
The subsequent section highlights key studies dealing with the relationship between $\operatorname{IP}^{718}$ and FDI in order to establish that the effect of increased copyright protection on these areas in developing countries is unclear. I argue that if the national interests of a developing country member of TRIPS run counter to increasing copyright protection (for example, because it is a net user of copyright), then that country should privilege domestic concerns by avoiding additional copyright protection. However, whether that country can successfully do so is dependent on its existing international obligations; its domestic law must comply with TRIPS' minimum standards.

(i) Findings in the empirical literature

The conclusions of major studies are inconsistent. For example, Mansfield's ${ }^{719}$ study on the attitude of American executives towards low levels of IP protection in developing countries concluded that IP primarily affected decision-making in high technology businesses. His finding is often used to support the proposition that developing countries will attract FDI and technology transfer if they increase their IP protection (particularly in the area of patents). ${ }^{720}$ However, other researchers have found higher IP protection to be beneficial in sectors other than high technology. ${ }^{721}$

Conversely, Falvey, Foster and Greenaway ${ }^{722}$ found that different national income levels had varying effects on how IP protection influenced FDI and technology transfer. They argued that, whereas greater IP protection brought technology to low-income countries and encouraged innovation in high-income countries, middle-income countries experienced limited capacity for domestic imitation (and the resulting reduced dispersal of knowledge),

\footnotetext{
${ }^{718}$ Many of the studies have examined intellectual property broadly and do not focus exclusively on copyright.

${ }^{719}$ Edwin Mansfield "Intellectual Property Protection, Foreign Direct Investment, and Technology Transfer" (Int'l Fin Corp Discussion Paper No 19, 1994). He looked at the chemical, transportation equipment, electrical equipment, food, metal and machinery Industries.

${ }^{720}$ See Paul Heald "Misreading a Canonical Work: An Analysis of Mansfield's 1994 Study" (2003) 10 J Intell Prop L 309, doubting whether the findings support that argument.

${ }^{721}$ See Carsten Fink and Carlos Primo Braga "How Stronger Protection of Intellectual Property Rights Affects International Trade Flows" in Carsten Fink and Keith Maskus (eds) Intellectual Property and Development: Lessons from Recent Economic Research (World Bank and Oxford University Press, New York, 2005) 19 at 2628.

${ }^{722}$ Rod Falvey, Neil Foster, David Greenaway "Intellectual Property Rights and Economic Growth" (Internationalisation of Economic Policy Research Paper No 2004/12, 2004).
} 
which cancelled out the effect of inward FDI and trade. Interestingly, the beneficial impact on low-income countries: ${ }^{723}$

...clearly does not result from the encouragement of domestic R\&D [Research \& Development] and innovation. The explanation is more likely to be that stronger IPR protection encourages imports and inward FDI from advanced countries without adversely affecting a domestic industry relying on imitation.

This observation raises questions for middle-income developing countries as to the long term suitability of FDI over domestic Research \& Development. Falvey, Foster and Greenaway also noted that, by joining the WTO developing countries can "reap the broad benefits of freer trade without sacrificing growth in order to meet the accompanying TRIPS obligations." ${ }^{, 724}$ Because patents were the primary focus of their study, the possibility remains that stronger protection might lead to negative consequences for growth in other areas of IP. Conversely, it is also possible that the consequences could be positive.

Other research has found adequate IP protection is a critical criterion for greater inflows of FDI and trade only for countries with competitive economies. Specifically, Cottier found that insufficient protection primarily affects highly competitive economies and sectors, but had little effect on non-competitive goods (which cannot displace competitive products): ${ }^{725}$

Intellectual property does not really matter in such constellations [countries which produce products that are not competitive on the world market] that may frequently be found in DCs [developing countries], in particular LDCs [least developed countries].

Other researchers have acknowledged the multi-pronged decision-making process of a developed country company concerning FDI and technology transfer. ${ }^{726}$ Considerations include the economy's willingness to engage in international trade, the level of state intervention in markets or regulation, the supply of human capital, fiscal policies, the level of

\footnotetext{
${ }^{723}$ Ibid, at 17 .

724 Ibid.

${ }^{725}$ Thomas Cottier "From Progressive Liberalization to Progressive Regulation in WTO Law" (2006) 9 J Int'l Econ L 779 at 802.

${ }^{726}$ See Keith Maskus "The Role of Intellectual Property Rights in Encouraging Foreign Direct Investment and Technology Transfer" in Carsten Fink and Keith Maskus (eds) Intellectual Property and Development: Lessons from Recent Economic Research (World Bank and Oxford University Press, New York, 2005) 41 at 70-71; Keith Maskus “Intellectual Property Rights and Economic Development” (2000) 32 Case W Res J Int'l L 471 at 477 and Anselm Kamperman Sanders "Intellectual Property Treaties and Development" in Daniel Gervais (ed) Intellectual Property, Trade and Development: Strategies to Optimize Development in a TRIPS-Plus Era (Oxford University Press, New York, 2007) 157 at 170.
} 
corruption, the tax and labour environment, market conditions for the sale and manufacture of the product and competitors' behaviour and state policies on technology development and competition. The complex conditions involved in decision-making may explain why some countries with high levels of IP protection have relatively less FDI than countries with less protection. $^{727}$

Therefore, empirical evidence does not appear to support the argument that developing countries will necessarily experience automatic economic benefit from adopting stronger copyright protection. ${ }^{728}$ According to Fink and Braga: $:^{729}$

The implications of IP [rights] for economic welfare are complex. The simple fact that trade flows rise or fall in response to tighter IPRs is not sufficient for drawing conclusions regarding economic welfare. Both static and dynamic effects need to be considered.

Gervais has also recognised that "the IP/FDI correlation is not universally supported by available data, probably because there are several other key factors at play."730 Maskus has noted that, while strengthening IP rights might be an effective incentive for inward FDI, it is only one of a broad set of factors. ${ }^{731}$ Therefore, in order for countries to experience net gains from stronger protection, policymakers would need to become aware of the necessary trade-

${ }^{727}$ Robert Sherwood "Global Prospects for the Role of Intellectual Property in Technology Transfer" (2002) 42 IDEA 27 at 33-34. China exemplifies this complexity. Although China became a WTO member on 11 December 2001, its FDI multiplied 10 times before TRIPS-compatible standards were initiated domestically, see: Keith Maskus "The Role of Intellectual Property Rights in Encouraging Foreign Direct Investment and Technology Transfer" (1998) 9 Duke J Comp \& Int'l L 109 at 115 - 119 and Peter Yu "Intellectual Property, Economic Development, and the China Puzzle" in Daniel Gervais (ed) Intellectual Property, Trade and Development: Strategies to Optimize Economic Development in a TRIPS-Plus Era (Oxford University Press, New York, 2007) 173.

${ }^{728}$ See Pedro Roffe "Comment: Technology Transfer on the International Agenda" in Keith Maskus and Jerome Reichman (eds) International Public Goods and Transfer of Technology Under a Globalized Intellectual Property Regime (Cambridge University Press, Cambridge, 2005) 257 at 260-261 and Walter Park and Douglas Lippoldt "International Licensing and the Strengthening of Intellectual Property Rights in Developing Countries During the 1990s" (OECD Economic Studies No 40, 2005/1, 2005).

${ }^{729}$ Carsten Fink and Carlos Primo Braga "How Stronger Protection of Intellectual Property Rights Affects International Trade Flows" in Carsten Fink and Keith Maskus (eds) Intellectual Property and Development: Lessons from Recent Economic Research (World Bank and Oxford University Press, New York, 2005) 19 at 21.

730 Daniel Gervais "TRIPS and Development" in Daniel Gervais (ed) Intellectual Property, Trade and Development: Strategies to Optimize Economic Development in a TRIPS-Plus Era (Oxford University Press, New York, 2007) 3 at 31.

731 Keith Maskus "Intellectual Property Rights and Foreign Direct Investment" (Centre for International Economic Studies, University of Adelaide, Policy Discussion Paper No. 0022, 2000) at 15. 
offs and complementarities among IPRs, market liberalisation and deregulation, technology development policies, and competition regimes. ${ }^{732}$

In light of these findings, what position should developing countries like Jamaica adopt?

(ii) Developing Countries' Recommended Response to the Pressure to Increase Copyright Protection

As the previous sub-section concluded, the economic research does not indicate that strengthening domestic copyright protection necessarily draws in FDI or technology transfer to a developing country. On the other hand, there is no evidence to support the view that increasing protection cannot lead to FDI or technology transfer. Although increasing IP protection may not lead directly to FDI, some developing countries view increasing IP protection as part of a strategy to gain more imports from developed markets, market access for their exports and/or FDI in non-IP industries. Nonetheless, for some countries, increasing IP protection domestically can result in an increase in the cost of obtaining IP products locally as well as a reduction in FDI and technology transfer. ${ }^{733}$

Because of the inconclusive findings, my argument is that for developing countries (like Jamaica) who are already TRIPS members, where there is a conflict between demands for heightened copyright protection from trading partners and national interests, local interests should prevail. This position is consistent with the literature advocating various tactics for developing countries to adopt in response to external demands for stronger domestic copyright regimes. For example, one recommendation is that, instead of increasing protection in order to gain FDI, developing countries should try to obtain IP as cheaply as possible and "grow their IP protection level in parallel with economic development and

\footnotetext{
732 Ibid.

${ }^{733}$ Increased intellectual property laws and enforcement can encourage foreign firms in developing countries to close local manufacturing facilities in favour of importing intellectual property based goods which are produced more cheaply elsewhere: Carlos Correa "Can the TRIPS Agreement Foster Technology Transfer to Developing Countries?" in Keith Maskus and Jerome Reichman (eds) International Public Goods and Transfer of Technology Under a Globalized Intellectual Property Regime (Cambridge University Press, Cambridge, 2005) 227 at 231.
} 
according to their own industrial and commercial strengths." ${ }^{, 734}$ Developing countries are thus encouraged to "seriously consider minimal compliance [with TRIPS]. Under no circumstances should a developing country accept the confident assertions made by some commentators that adopting a maximalist posture towards all protection will stimulate foreign investment." 735

Further, researchers have argued that the copyright law regimes needed in developing countries are those that respond to niche markets/ local industries (areas of strength). ${ }^{736}$ Simply enacting more copyright laws may not be productive, since more IP laws are not necessarily synonymous with greater economic development. ${ }^{737}$ The costs (and benefits) of IP vary considerably between countries, particularly depending on the level of (technological) development of the economy in question. As Kumar noted: ${ }^{738}$

History reveals that countries have carefully managed their IP systems in light of their particular developmental needs, as they arose over time. Economies in East Asia, for example, have strategically used weaker forms of IP protection, thereby helping local firms in early stages to build technological capabilities or allowing reverse engineering and imitation. Developed countries have shown similar patterns of behaviour in the process of their industrial and economic development.

Similarly, Schonwetter stated: ${ }^{739}$

$[\mathrm{M}]$ ost developed countries (including the U.S.) went through phases of widespread IP infringement when they were developing countries still to kick start their innovative industries. And only once they became developed countries - and had passed a certain threshold of own IP creation - they started to argue for stronger IP protection.

\footnotetext{
${ }^{734}$ Robert Ostergard Jr "Economic Growth and Intellectual Property Rights Protection: A Reassessment of the Conventional Wisdom" in Daniel Gervais (ed) Intellectual Property, Trade and Development: Strategies to Optimize Economic Development in a TRIPS-Plus Era (Oxford University Press, New York, 2007) 115 at 154.

${ }^{735}$ Paul Heald "Misreading a Canonical Work: An Analysis of Mansfield's 1994 Study" (2003) 10 J Intell Prop L 309 at 318.

${ }^{736}$ Ikechi Mgbeoji "TRIPS and TRIPS-Plus Impacts in Africa” in Daniel Gervais (ed) Intellectual Property, Trade and Development: Strategies to Optimize Economic Development in a TRIPS-Plus Era (Oxford University Press, New York, 2007) 259 at 296-297.

${ }^{737}$ Ibid, at 297. At page 294 Mgbeoji notes that IPR holders are "over compensated" in African IP law.

738 Mohan Kumar, "Intellectual Property in the World Trade Organization: Turning it into Developing Countries' Real Property" (United Nations Conference on Trade and Development Report, 2010) at 1.

739 Tobias Schonwetter "Economics of IP" (paper presented to the WIPO Summer School, South Africa, December 2011).
} 
These statements suggest developing countries should approach to copyright in a manner mindful of national interests.

TRIPS was largely the product of lobbying by powerful corporate interests. ${ }^{740}$ Although developing countries believed that becoming WTO members (by signing on to the package of WTO agreements such as TRIPS) would gain them increased access to developed country markets for their agricultural and textile exports, some commentators have criticised the harmonisation of copyright protection in TRIPS as being harmful to developing countries. ${ }^{741}$ A harmonised international copyright regime is more restrictive than a regime that simply establishes minimum standards of protection, which allow for domestic differences and variations, albeit within a narrow framework.

The harmonisation of copyright protection TRIPS (along with other international copyright agreements) has achieved is capable of creating domestic legal regimes that are disadvantageous to developing countries. This is because there is no international entity with authority to act as a global optimiser in order to ensure copyright laws are harmonised as efficiently as possible. Although, arguably, the international copyright agreement negotiation process is geared at arriving at this efficient position, in the absence of such an entity, individual countries push for the level of harmonisation of copyright protection that advances their own national interests. ${ }^{742}$ As a consequence, the actual harmonisation which results: ${ }^{743}$

\footnotetext{
${ }^{740}$ On the influence of the US-based multinational corporations which formed the 12 member Intellectual Property Committee, and their counterparts in Europe and Japan, see: Susan Sell Private Power, Public Law: The Globalization of Intellectual Property Rights (Cambridge University Press, Cambridge 2003) at 96-98.

${ }^{741}$ See William Kingston “An Agenda for Radical Intellectual Property Reform” in Keith Maskus and Jerome Reichman (eds) International Public Goods and Transfer of Technology Under a Globalized Intellectual Property Regime (Cambridge University Press, Cambridge, 2005) 653 at 661 describing the harmonisation in TRIPS as "the Trojan horse of intellectual property" which must be kept "outside the walls of our City." See also: Susan Sell Private Power, Public Law: The Globalization of Intellectual Property Rights (Cambridge University Press, Cambridge 2003) at 121 noting the high costs of TRIPS enforcement and implementation on developing countries.

${ }^{742}$ See Suzanne Scotchmer "The Political Economy of Intellectual Property Treaties" (2004) 20 Journal of Law, Economics and Organizations 415.

743 Peter Menell and Suzanne Scotchmer "Intellectual Property" (Public Law Research Paper No 741724, University of California at Berkeley, 2005) at 57. For a critique of TRIPS' harmonisation of minimum standards, see: Graeme Dinwoodie 'Remarks: 'One Size Fits All' Consolidation and Difference in Intellectual Property Law" in Annette Kur and Vytautas Mizaras (eds) The Structure of Intellectual Property Law: Can One Size Fit All? (Edward Elgar, Cheltenham and Northampton, Mass., 2011) 3. See also: Zorina Khan Intellectual Property and Economic Development: Lessons from American and European History (British Commission on Intellectual Property Rights Report, Study Paper 1a, London, 2002) at 10 and Ha-Joon Chang Kicking Away the Ladder: Development Strategy in Historical Perspective (Anthem Press, London, 2002) at 139-140.
} 
...will be a negotiated solution from these preferred outcomes, and there is no presumption that they will be efficient... harmonization will generally increase protections and...countries that advocate stronger protection (either more subject matters or longer protection) are those that either have large markets or are more innovative.

Aside from its harmonising effect, commentators have indicated that adopting the higher standards of copyright protection found in TRIPS can result in adverse consequences for developing countries. ${ }^{744}$ One extreme view is that TRIPS "facilitates, even enforces with the aid of trade sanctions, what is in the main a payment by the poor countries (which consume IP) to the rich countries (which produce it)." ${ }^{, 75}$ Commentators have argued that TRIPS can lead to greater royalty payments by developing countries and strengthening of monopolistic behaviour of IP owners. ${ }^{746}$ A further challenge is that instead of adapting IP protection to address domestic contexts, developing countries seeking to comply with TRIPS often import laws from developed jurisdictions without having the safeguards and balances present in those countries. ${ }^{747}$ One motivation for this copying is a desire to avoid the risk of enforcement action in the event developing country's laws are not TRIPS-compliant. ${ }^{748}$

\section{Summary}

In the previous part of the Chapter I discussed Berne and TRIPS, given their applicability to Jamaica and their effect on the content of Jamaican copyright legislation. I also drew attention to empirical deficiencies and critiques from the academic literature in order to show

\footnotetext{
744 See, for example, Commission on Intellectual Property Rights [CIPR] "Integrating Intellectual Property Rights and Development Policy" (London, 2002) at 25-26 and the United Nations Development Programme "Human Development Report 2001: Making New Technologies Work for Human Development" (Oxford University Press, New York, 2001) at 105.

${ }^{745}$ Jagdish Bhagwati “Afterword: A Question of Linkage - Symposium: The Boundaries of the WTO” (2002) 96 AJIL 126 at 127.

${ }^{746}$ Joseph Stiglitz and Andrew Charlton Fair Trade for All: How Trade Can Promote Development (Oxford University Press, New York, 2005) at 103; Frederick Abbott "TRIPS and Human Rights: Preliminary Reflections" in Frederick Abbott, Christine Breining-Kaufmann and Thomas Cottier (eds) International Trade and Human Rights- Foundations and Conceptual Issues (University of Michigan Press, Ann Arbor, 2006) 145 at 165 and Duncan Matthews Globalising Intellectual Property Rights- The TRIPS Agreement (Routledge, London and New York, 2002) at ch 1.

${ }^{747}$ See E. Richard Gold and Jean-Frederic Morin "From Agenda to Implementation: Working Outside the WIPO Box" in Jeremy de Beer (ed) Implementing the WIPO Development Agenda (Wilfrid Laurier University Press, Ottawa, 2009) at 57.

${ }^{748}$ Earlier in the chapter I discussed TRIPS' enforcement mechanisms.
} 
that the post-TRIPS approach to copyright which emphasises attracting FDI and technology transfer through higher copyright protection, does not necessarily result in developmental benefits in developing countries.

The next question is: can there be an approach to copyright protection which has development at its core and which is consistent with the theoretical justifications for copyright, Berne and TRIPS? To answer this question, I will return to the human development model (introduced at the beginning of this Chapter) and connect it to copyright. In the next part, I will examine the possible implications of adopting a human development approach to copyright in domestic lawmaking. I argue that the human development approach is consistent with the major copyright theories, and is also supported by Berne, TRIPS, WIPO practice and the international IP acquis.

III The Interface between Development and Copyright Theory: A Human Development Approach to Copyright

A General Implications of Applying a Human Development Approach to Copyright in Domestic Copyright Lawmaking

Under the human development approach, the objective of copyright protection is not only to incentivise creativity, but to encourage the kind of creativity that is needed by a wide range of stakeholders, including those with limited financial resources. Copyright protection is viewed as a means to achieving larger social goals than mere economic returns: ${ }^{749}$

A broader understanding of intellectual property, as both an end and means of development, recognizes the importance of not just producing more knowledge of goods, but also of participating in the process of knowledge creation.

A human development approach would therefore be concerned with the impact of copyright works on the capabilities of various persons within society (including marginalised individuals and communities) and whether copyright policies benefit a wide range of

\footnotetext{
${ }^{749}$ Madhavi Sunder "The Invention of Traditional Knowledge” (2007) 70 Law and Contemporary Problems 97
} at 122 . 
stakeholders and build a national capacity for innovation. Accordingly, this model would consider development differentials between countries. A human development approach: ${ }^{750}$

...not only stimulates innovation but also protects knowledge goods that enhance human capabilities, which in turn build national capacity for innovation. For all countries, the dynamic benefits of intellectual property include the promise of increasing innovation capacity over the long term. But for developed countries the path to innovation may diverge quite sharply from that for developing countries, and each may require different kinds of policy and flexibility.

Second, a human development approach to copyright would also impact the substantive content of the copyright law, for instance, the extent of the exclusive rights conferred domestically, the duration of protection, and exceptions to copyright. For example, in determining what uses of a work should be exceptions to copyright, a human development framework would consider factors such as whether the public could access copyright works on reasonable terms and if public access would enhance users' capabilities for social participation, engagement in creative processes, knowledge creation and self-expression. ${ }^{751}$

However, these considerations do not suggest that a human development approach disregards or deemphasises the rights of creators or focuses on users entirely. Human development's concern for distributional equity also applies to the allocation of returns from copyright among rights holders. This framework would have regard to authors' well being and their social arrangements (for instance, whether their differential socio-economic positions are affecting the way they benefit from copyright), whether the creation of diverse, socially desirable works is being sufficiently incentivised and whether the copyright regime is fostering an improvement in creators' various capabilities (for example, the capability to work or the capability of being literate or educated). In these ways, the human development approach supports the rights of creators and encourages the creation of authorial works.

\footnotetext{
750 See Margaret Chon "Substantive Equality in International Intellectual Property Norm Setting and Interpretation" in Daniel Gervais (ed) Intellectual Property, Trade and Development: Strategies to Optimize Development in a TRIPS-Plus Era (Oxford University Press, New York, 2007) 475 at 476.

751 See Madhavi Sunder "Intellectual Property and Development as Freedom" in Neil Netanel (ed) The Development Agenda: Global Intellectual Property and Developing Countries (Oxford University Press, New York, 2009) 453 and Brett Frischmann and Mark Lemley "Spillovers" (2007) 107 Columbia Law Review 257 (on the beneficial effects of spillovers upon society). The practical implications of interpreting copyright obligations in light of human development will be discussed later in this Chapter: see Chapter 4.III.B.2 and Chapter 4.III.B.4 below.
} 
Third, utilising the human development approach affects the way lawmakers evaluate the domestic copyright regime. Because improvement of local capabilities becomes the copyright system's ultimate goal, the effectiveness of the regime is assessed with reference to its effect on human development ${ }^{752}$ and proposals for legal reform are made in light of developmental impacts. Wong, Torsen and Fernandini exemplify this position: ${ }^{753}$

[T] here is a strong case for copyright protection to be coordinated with the broader policy goals of cultural development as part of human development.

Towse's suggestion also reflects this approach: ${ }^{754}$

[C]opyright policy must be thought of as part of cultural policy...logically, therefore, the objectives of cultural policy- fostering creativity, cultural diversity, freedom of information and expression, broadening audiences for cultural events, etc.- should be used to judge whether a reform to copyright law is a welfare improvement or not.

\section{B Support for a Human Development Approach to Copyright within the International Copyright Regime}

\section{Copyright Theory and Berne}

Human development and copyright theories are generally compatible. Evidence of this can be seen with the natural rights and personality justifications, both of which centre on the rights of the individual author. The Lockean philosophy is that persons have an innate property right in the product of their efforts. The Kantian idea is that copyright gives people freedom to carry out projects of their own choosing. The Hegelian view emphasises the part property plays in the constitution of personality. All of these ideas resonate to some extent with Sen's idea of development as freedom, which does not see control of property as an end in itself. Control over resources (or "commodity command") is "a means to the end of wellbeing"

\footnotetext{
${ }^{752}$ See International Expert Group on Biotechnology Innovation and Intellectual Property “Towards a New Era of Intellectual Property: from Confrontation to Negotiation" (2008) at 14.

753 Tzen Wong, Molly Torsen and Claudia Fernandini "Cultural Diversity and the Arts: Contemporary Challenges for Copyright Law" in Tzen Wong and Graham Dutfield (eds) Intellectual Property and Human Development: Current Trends and Future Scenarios (Cambridge University Press, New York, 2011) 279 at 319. ${ }^{754}$ Ruth Towse "The Singer or the Song? Developments in Performers' Rights from the Perspective of a Cultural Economist (2007) 3 Review of Law and Economics 745 at 759.
} 
since goods are not valuable in themselves but to only the extent that they are helpful to the person. $^{755}$

The incentive-based justification for copyright is girded by utilitarian philosophy. ${ }^{756}$ Copyright should be encouraged because, ultimately, society benefits (or gains utility) from the increasing number of works incentivised by copyright. Insofar as it emphasises positive returns for society, the incentive-based theory is in line with human development. Concern for overall societal impacts explains why, under a human development approach, development is not only measured by the national income level (which can obscure social and other inequalities within a population). Instead, development is about increasing the range of things that people can achieve or become, including the ability to express themselves creatively and to gain knowledge or access to resources such as intellectual creations. ${ }^{757}$

The rationale for the economic efficiency argument has some synergy with human development's concern for the fulfilment of people's material and physical needs. ${ }^{758}$ For instance, market failure would affect public access to certain goods and limit their ability to increase their well-being. Moreover, the economic efficiency theory maintains that copyright works are public goods whose value is preserved when equilibrium is reached between market supply and demand. Within human development, the price of commodities in a market is a factor that is germane to a person's ability to command resources. ${ }^{759}$ In this regard, there is a parallel between economic efficiency and human development, provided goods are not priced out of reach of the under-resourced persons within a society. While both approaches share some common ground theoretically, if an economic efficiency argument for copyright is used in a way which places economic efficiency above human welfare, then it would conflict with the aims of human development.

\footnotetext{
755 Amartya Sen Commodities and Capabilities (Elsevier Science Publishers, Oxford, 1985) at 19.

${ }^{756}$ See the incentive model's third assumption at Chapter 4.II.A.2, above.

757 United Nations Development Programme (UNDP) "Human Development Report 2001: Making New Technologies Work for Human Development" (Oxford University Press, New York, 2001) at 9.

${ }^{758}$ Jennifer Elliott "Development and Social Welfare/Human Rights" in Vandana Desai and Robert Potter (eds) The Companion to Development Studies (2nd ed, Hodder Education, London, 2008) 40 at 40.

${ }^{759}$ See "entitlements" discussed above at Chapter 4.I.B.2.
} 
The human development approach can also be reconciled with the objectives of the Berne Convention, particularly since natural rights and incentive arguments underlie Berne. ${ }^{760}$ The goal of Berne was to establish a property regime internationally in which authors had the possibility of having their creative efforts financially rewarded and their moral rights recognised, as well as for the public to have the opportunity to access copyright works on specified terms. The copyright protection in Berne creates an environment in which the capabilities ${ }^{761}$ of both creators and users can be enlarged.

The next issue is: can the TRIPS Agreement, which incorporates much of Berne's provisions, be interpreted in a way which is consistent with a human development approach to copyright?

2 A Vienna Convention on the Law of Treaties (VCLT) analysis of articles 7 and 8 of TRIPS

Articles 7 and 8 were included in TRIPS at the behest of developing countries. ${ }^{762}$ While reproducing TRIPS' drafting history is beyond the scope of this study, ${ }^{763}$ a common observation in the literature is that developing countries insisted on including developmentoriented objectives and principles because of concerns about the negative developmental impacts of extending IP protection. ${ }^{764}$ Their proposal became the final text of arts 7 and 8 , despite an opposing draft of developed countries. The relevance of this historical detail about TRIPS' conclusion is that it suggests that TRIPS' drafters intended for the developmental

\footnotetext{
${ }^{760}$ See Silke von Lewinski International Copyright Law and Policy (Oxford University Press, Oxford, 2008) 119.

${ }^{761}$ Capabilities, as defined in Chapter 4.I.B.2.

762 Daniel Gervais "Intellectual Property, Trade \& Development: The State of Play" (2005) 74 Fordham L Rev 505 at 508 .

${ }^{763}$ The negotiating history of TRIPS has been extensively documented. See, for example, Daniel Gervais The TRIPS Agreement: Drafting History and Analysis (3rd ed, Sweet \& Maxwell, London, 2008), Carlos Correa Trade Related Aspects of Intellectual Property Rights: A Commentary on the TRIPS Agreement (Oxford University Press, New York, 2007) and Hiroko Yamane Interpreting TRIPS: Globalisation of Intellectual Property Rights and Access to Medicines (Hart Publishing, Oxford and Portland (Oregon), 2011) at ch 4.

${ }^{764}$ See: UNCTAD/ICTSD Resource Book on TRIPS and Development (Cambridge University Press, New York, 2005) at 120-125 and Peter Yu "The Objectives and Principles of the TRIPS Agreement" (2009) 46 Houston L Rev 979 at 1000 - 1004.
} 
objectives in arts 7 and 8 to be central to the interpretation of TRIPS' provisions. ${ }^{765}$ TRIPS' negotiating history: ${ }^{766}$

...may lead a panel to take a longer look at how these provisions [Articles 7 and 8] should be interpreted in the context of the Agreement as a whole, especially with respect to the need for 'balance'.

Articles 7 and 8 refer to concepts such as "social and economic welfare" and "socioeconomic and technological development." Article 7 states:

The protection and enforcement of intellectual property rights should contribute to the promotion of technological innovation and to the transfer and dissemination of technology, to the mutual advantage of producers and users of technological knowledge and in a manner conducive to social and economic welfare, and to a balance of rights and obligations.

Article 8 provides:

1. Members may, in formulating or amending their laws and regulations, adopt measures necessary to protect public health and nutrition, and to promote the public interest in sectors of vital importance to their socio-economic and technological development, provided that such measures are consistent with the provisions of this Agreement.

2. Appropriate measures, provided that they are consistent with the provisions of this Agreement, may be needed to prevent the abuse of intellectual property rights by right holders or the resort to practices which unreasonably restrain trade or adversely affect the international transfer of technology.

However, TRIPS does not define "social and economic welfare" or "socio-economic and technological development." This lack of specificity may be due to the drafters' recognition that the concepts of "welfare" and "development" are fluid and dependent on an individual country's circumstances.

Although disputing WTO members have relied on arts 7 and 8 to support their positions, the Dispute Settlement Panels and Appellate Body have not given a definitive interpretation of those $^{\text {articles. }^{767}}$ A Dispute Panel has, however, identified these articles as two of the

\footnotetext{
765 VCLT, art 32 provides that recourse can be had to supplementary means of interpretation (such as negotiating history) to confirm the meaning resulting from an application of VCLT, art 31; or when such interpretation leaves the meaning ambiguous or lead to an absurd result.

${ }^{766}$ Daniel Gervais The TRIPS Agreement: Drafting History and Analysis (2nd ed, Sweet \& Maxwell, London, 2003) at 120.

${ }^{767}$ Henning Ruse-Khan "The (Non)Use of Treaty Object and Purpose in Intellectual Property Disputes in the WTO” (Max Planck Institute for Intellectual Property and Competition Law Research Paper No 11-15, 2011) at
} 
provisions indicating TRIPS' object and purpose. ${ }^{768}$ Articles 7 and 8 are essentially interpretative tools. Although they do not contain standalone rights, they are guides to be applied by the Dispute Settlement Body $(\mathrm{DSB})^{769}$ in interpreting substantive obligations found in other TRIPS provisions. It is therefore important to consider their meaning. I apply the Vienna Convention on the Law of Treaties (VCLT) to show that, in view of arts 7 and 8 , TRIPS can be interpreted in a way that supports a developmental approach to copyright.

How might such a development-based interpretation work in practice? Articles 7 and 8 could be used by the DSB to interpret the scope of exceptions under art 13 of TRIPS, ${ }^{770}$ the extent of other copyright obligations and the definition of concepts such as "abuse" in arts 40 and 50(3). Such interpretation could also legitimise various state practices such as the exclusion of FDI in certain sectors or regulation of royalty rates and conditions of licensing agreements. ${ }^{771}$ Furthermore, in states that are net users of copyright, a human development approach to copyright could prevent the extension of the domestic copyright term beyond that stipulated in Berne and art 12 of TRIPS on the basis that it might unduly affect public use of the work. Additionally, although members are free to implement more extensive copyright protection than required by TRIPS, ${ }^{772}$ a human development approach could mean that minimum thresholds of copyright protection are not exceeded where the state determines developmental interests are at risk.

Article 3(2) of the Dispute Settlement Understanding provides the foundation for a VCLT interpretation of TRIPS. ${ }^{773}$ It stipulates that WTO Agreements must be interpreted "in accordance with customary rules of interpretation of public international law." These rules

\footnotetext{
2 and Ruth Okediji "Public Welfare and the Role of the WTO: Reconsidering the TRIPS Agreement" (2003) 17 Emory Int'l L Rev 819 at 914-915.

${ }^{768}$ Canada - Patent Protection of Pharmaceutical Products WTO DOC WT/DS114/R (2000) (Panel Report).

${ }^{769}$ The WTO's Dispute Settlement Body has the authority to perform an interpretative role in respect of the TRIPS Agreement provided it does not "add to or diminish the rights and obligations" provided in that agreement: art 3(2) of the Understanding on Rules and Procedures Governing the Settlement of Disputes, 15 April 1994, WTO Agreement, Annex 2, Legal Instruments [Dispute Settlement Understanding or DSU].

${ }^{770}$ TRIPS, art 13 will be discussed later in this Chapter and in Chapter 5.II.3(b).

771 See Carlos Correa Trade Related Aspects of Intellectual Property Rights: A Commentary on the TRIPS Agreement (Oxford University Press, New York, 2007) at 92, 94-95,103 and 105.

772 TRIPS, art 1(1).

773 The Understanding on Rules and Procedures Governing the Settlement of Disputes, 15 April 1994, WTO Agreement, Annex 2, Legal Instruments.
} 
are encapsulated in the VCLT and the WTO Panels and Appellate Body have relied on the VCLT in dealing with cases brought to the DSB. ${ }^{774}$

Article 31(1) of the VCLT sets out the general rule of interpretation:

A treaty shall be interpreted in good faith in accordance with the ordinary meaning to be given to the terms of the treaty in their context and in the light of its object and purpose.

The rule is holistic and its elements are not hierarchical in order. ${ }^{775}$ However, for ease of analysis, I will separate the rule into its constituent parts: (i) good faith interpretation of the ordinary meaning of the terms; (ii) in light of their context; and (iii) the treaty's object and purpose. This method of treaty interpretation combines textual, subjective and teleological approaches. ${ }^{776}$ My argument is that applying these elements makes it clear that development (specifically, human development) is highly relevant to the interpretation of TRIPS, in view of arts 7 and 8.

(a) Good faith interpretation of the ordinary meaning of the terms

The principle of good faith is a fundamental precept of the international law on treaties. Under to the universally recognised pacta sunt servanda rule, parties to a treaty must perform treaty obligations in good faith. ${ }^{777}$ The WTO Appellate Body has held that a good faith interpretation of TRIPS involves the interpreter having regard to the legitimate expectations of its members and rights holders, as reflected in the treaty's language. ${ }^{778}$ Therefore, treaty interpretation should not be used to import new meanings into the text which the parties did not intend. Neither should treaty interpretation give preference to a particular treaty norm

\footnotetext{
774 See: India - Patent Protection for Pharmaceutical and Agricultural Chemical Products WTO DOC WT/DS50/AB/R (1997) at [45-46] (Appellate Body Report) and United States - Standards for Reformulated and Conventional Gasoline WTO DOC WT/DS2/AB/R (1996) (Appellate Body Report) at 16.

${ }^{775}$ United States - Section 301-310 of the Trade Act of 1974 WTO DOC WT/DS152/R (1999) at [7.22] (Panel Report).

${ }^{776}$ A textual (or objective) approach centres on the actual text and emphasises analysis of the actual words used. A subjective approach focuses on the intention of the parties in the event that the terms are ambiguous and refers to the negotiation and drafting process leading to the treaty's conclusion. A teleological school of thought concentrates on the treaty's object and purpose as the overriding standard against which each treaty provision is measured: Malcolm Shaw International Law (4th ed, Cambridge University Press, Cambridge, 1997) at 655656.

777 VCLT, art 26.

${ }^{778}$ India - Patent Protection for Pharmaceutical and Agricultural Chemical Products WTO DOC WT/DS50/AB/R (1997) (Appellate Body Report) at [45-46].
} 
where apparent conflicts between norms exist which the treaty itself does not resolve. ${ }^{779}$ Instead, the ordinary meaning of the words must be carefully examined. In keeping with this principle, the Appellate Body has noted that interpretation of any WTO treaty's article must "take adequate account of the words actually used."

Article 7 states: "The protection and enforcement of [IP] rights should contribute to..." The word "should" is prescriptive in character: suggesting that intellectual property rights (IPRS) do not always result in the outcomes portrayed in the remainder of the provision but that they ought to. ${ }^{781}$ Article 7 sets out the desired goals for members to achieve through their protection of IPRS, including technological innovation and technology transfer and dissemination "in a manner conducive to social and economic welfare."

Article 7 is positioned in Part I of TRIPS under the heading "General Provisions and Basic Principles." Although by no means peripheral to the treaty, ${ }^{782}$ art 7 (along with art 8) is a general provision without the affirmative obligations found in other TRIPS provisions that contain "shall" language. ${ }^{783}$ There are no specific obligations in TRIPS for members to craft domestic IP laws in defined ways so as to achieve the objectives expressed in art 7 (or 8). Article 7 is thus a general principle which cannot derogate from other specific obligations in TRIPS (for example, the scope of exclusive rights given to copyright holders in art 11). However, the interpretative value of art 7 is that it clarifies that IP protection is not an end in itself. Members should be able to reach the stated objectives (innovation, technology transfer and so on) through the protection and enforcement of IP. ${ }^{784}$ Moreover, the central position of

\footnotetext{
779 Susy Frankel "The WTO's Application of 'the Customary Rules of Interpretation of Public International Law' to Intellectual Property" (2005) 46 Va J Int'l L 365 at 368.

${ }^{780}$ United States - Standards for Reformulated and Conventional Gasoline WTO DOC WT/DS2/AB/R (1996) (Appellate Body Report) at 18.

${ }^{781}$ See Carlos Correa Trade Related Aspects of Intellectual Property Rights: A Commentary on the TRIPS Agreement (Oxford University Press, New York, 2007) at 97.

${ }^{782}$ See Daniel Gervais The TRIPS Agreement: Drafting History and Analysis (2nd ed, Sweet \& Maxwell, London, 2003) at 116.

${ }^{783}$ See Peter Yu "The Objectives and Principles of the TRIPS Agreement" (2009) 46 Houston L Rev 979 at 1003.

${ }^{784}$ UNCTAD/ICTSD Resource Book on TRIPS and Development (Cambridge University Press, New York, 2005) at 125-126.
} 
art 7 (and 8) in TRIPS suggests these articles should be systematically applied in the interpretation of TRIPS as a whole. ${ }^{785}$

It is also significant art 7 mentions "balance of rights and obligations" and "the mutual advantage of producers and users" given that developing countries lacking technological capabilities and capital to invest in innovation tend to be users of IPRS. In such countries IPRS are unlikely to promote innovation. ${ }^{786}$ Recognition of this could explain why TRIPS places obligations on its developed country members to promote technology transfer in leastdeveloped countries (LDCs) and to give technical and financial cooperation to LDCs and developing countries. ${ }^{787}$

With respect to the language of art 8(1), provided TRIPS' provisions are not violated, members have discretion to implement measures domestically that protect public health and nutrition, as well as promoting "the public interest in sectors of vital importance to their socio-economic and technological development." Article 8(1) does not itemise the "sectors of vital importance", implicitly acknowledging each member's sovereignty in determining this issue. This phrase is wide enough to incorporate any copyright-based sector which a country considers critical to its economy. The limiting condition, of course, is consistency with TRIPS. ${ }^{788}$ Article $8(2)$ allows for measures to counter anticompetitive practices, and in this regard is consistent with other TRIPS provisions. ${ }^{789}$

So what does applying a good faith interpretation of the ordinary meaning of the words in arts 7 and 8 indicate in relation to TRIPS and development? As previously discussed, a strictly textual approach to the wording of these articles suggests that development was at the forefront of TRIPS' negotiators' minds. For instance, words such as "mutual advantage" and "balance" in art 7 demonstrate that the negotiators did not intend for IP protection to be viewed in isolation from concerns about overall social welfare. This language is also

\footnotetext{
${ }^{785}$ See Carlos Correa Trade Related Aspects of Intellectual Property Rights: A Commentary on the TRIPS Agreement (Oxford University Press, New York, 2007) at 93.

${ }^{786}$ UNCTAD/ICTSD Resource Book on TRIPS and Development (Cambridge University Press, New York, $2005)$ at 126.

${ }^{787}$ TRIPS, arts 66-67.

${ }^{788}$ This also recognizes that rule that a State cannot use its internal law as an excuse for failure to perform its treaty obligations: VCLT, art 27.

789 TRIPS, arts 31 and 40 .
} 
reflective of the incentive-based justification for IPRS which posits that IPRS are meant to benefit society through innovation and the stimulation of new creations.

But even after the terms in arts 7 and 8 are given their ordinary meaning it is obvious that these provisions contain concepts that can compete with each other. This conflict is suggested by the following phrases in those articles: "mutual advantage of producers and users", "balance of rights and obligations" and "measures...may be to needed to prevent the abuse of [IPRS] by right holders." The next step in interpretation is to look at:

(b) The meaning of the terms in their context

(i) Context as evident from the surrounding text and related agreements

The text of a treaty must be read in its totality, instead of focussing on a single paragraph, article, section, chapter or part. ${ }^{790}$ Article $31(2)$ of the VCLT outlines that:

2. The context for the purpose of the interpretation of a treaty shall comprise, in addition to the text, including its preamble and annexes:

(a) any agreement relating to the treaty which was made between all the parties in connection with the conclusion of the treaty;

(b) any instrument which was made by one or more parties in connection with the conclusion of the treaty and accepted by the other parties as an instrument related to the treaty.

The VCLT explicitly indicates to interpreters that a treaty's preamble can be used as part of its interpretation. This is because the preamble not only depicts the backdrop against which the treaty arose but it is also a pithy distillation of its core principles and motivation. ${ }^{791}$ Although preambular clauses cannot be used to override explicit obligations contained

\footnotetext{
${ }^{790}$ See United States-Section 110(5) of the U.S. Copyright Act WTO DOC WT/DS160/R (2000) (Panel Report) at 17.

${ }^{791}$ See Daniel Gervais The TRIPS Agreement: Drafting History and Analysis (2nd ed, Sweet \& Maxwell, London, 2003) at 80.
} 
elsewhere in a treaty, because of their value, it has become the practice for the WTO Panels and Appellate Body to use preambles to aid in interpretation of the particular WTO agreement involved in a dispute. ${ }^{792}$

The two most relevant preambles are the TRIPS Preamble and the Preamble of the WTO Agreement to which TRIPS is annexed. ${ }^{793}$ In the fifth recital of TRIPS' Preamble, members affirmed "the underlying public policy objectives of national systems for the protection of [IP], including developmental and technological objectives." The sixth paragraph of TRIPS' Preamble recognises:

...the special needs of the least-developed country Members in respect of maximum flexibility in the domestic implementation of laws and regulations in order to enable them to create a sound and viable technological base;

Similarly, the WTO Agreement's Preamble notes:

...there is need for positive efforts designed to ensure that developing countries, and especially the least developed among them, secure a share in the growth in international trade commensurate with the needs of their economic development.

Both preambles identify the achievement of developmental goals as being among the negotiators' intentions. The context therefore suggests that development is not restricted to the language of arts 7 and 8, but is highly relevant to understanding the entire TRIPS Agreement.

Moreover, given the juxtaposition of arts 7 and 8 and their related subject matter, it would be unreasonable to assume the parties intended the phrases "social and economic welfare" (art 7) and "socio-economic and technological development" (art 8) to mean different things in each article. It is more likely that parties meant for both phrases to have the same meaning. ${ }^{794}$ It also makes sense for their meaning to be consistent with the "developmental and

\footnotetext{
${ }^{792}$ Andrew Mitchell Legal Principles in WTO Disputes (Cambridge University Press, New York, 2008 ) at 81.

${ }^{793}$ Marrakesh Agreement Establishing the World Trade Organization (15 April 1994) [WTO Agreement]. The WTO Agreement qualifies for consideration under the VCLT, art 31(2)(a).

${ }^{794}$ See EC - Measures Concerning Meat and Meat Products (Hormones) WTO DOCS WT/DS26/AB/R (16 January 1998) at [164] (Appellate Body Report) which states that an interpreter should not assume that the use of different words in different parts of a text was inadvertent. See also: Joshua Meltzer "Comment: Interpreting the WTO Agreements - A Commentary on Professor Pauwelyn's Approach” (2004) 25 Michigan J of Int'l L 917 at 918.
} 
technological objectives" mentioned in the fifth paragraph of TRIPS' Preamble and “economic development" in the WTO Agreement's Preamble.

When read in light of the context, references to "welfare" or "development" in arts 7 and 8 seem aligned to human development. This can be deduced from the words used in both articles that are associated with "welfare" or "development". "Technological innovation", "dissemination of technology," "users of technological knowledge", "public health and nutrition" and "public interest" evoke wide-ranging approaches to national development. This approach aims to benefit society and expand human capabilities in ways greater than the financial returns generated from the protection of IP, or even the trade in IP-related goods.

(ii) Subsequent events to be considered with Context

According to art 31(3) of the VCLT:

3. There shall be taken into account, together with the context:

(a) any subsequent agreement between the parties regarding the interpretation of the treaty or the application of its provisions;

(b) any subsequent practice in the application of the treaty which establishes the agreement of the parties regarding its interpretation;

Because subsequent agreement reflects parties' intent, it can be used to interpret a treaty's actual terms. Subsequent practice can also evidence agreement among a treaty's members regarding its interpretation. The Appellate Body has held that the subsequent practice must form a "concordant, common and consistent sequence of acts or pronouncements which is sufficient to establish a discernible pattern implying the agreement of the parties regarding its interpretation.",795

Do subsequent agreement and subsequent practice illustrate that TRIPS is to be read in light of development concerns?

\footnotetext{
795 Japan - Taxes on Alcoholic Beverages WTO DOC WT/DS8/AB/R (1996) at 18 (Appellate Body Report). This position is supported by EC - Customs Classification of Frozen Boneless Chicken Cuts WTO DOCS WT/DS269/AB/R and WT/DS286/AB/R (12 September 2005) at [250] (Appellate Body Report).
} 
In November 2001, parties to TRIPS adopted the Doha Ministerial Declaration ${ }^{796}$ (Ministerial Declaration) and the Declaration on the TRIPS Agreement and Public Health (Doha Declaration). ${ }^{797}$ These declarations arose out of developing countries' need to affordably access essential medicines in order to safeguard public health and address national health emergencies. Countries were concerned that overly strong patent protection would prevent governments from adequately responding to health crises. It was feared that a restrictive interpretation of TRIPS would not consider IP users' legitimate interests, in light of pandemics such as HIV/AIDS. ${ }^{798}$ The aim of these declarations is not to add to the wording of TRIPS, but to clarify the parties' intention to assist in TRIPS' interpretation. ${ }^{799}$

Paragraph 19 of the Ministerial Declaration urges the Council for TRIPS to be "guided by the objectives and principles set out in arts 7 and 8 of the TRIPS Agreement and...take fully into account the development dimension." Similarly, the Doha Declaration emphasises the importance of developmental issues contained in arts 7 and 8 in the application of TRIPS and underscores the role of arts 7 and 8 (which were placed in the TRIPS text under the headings "Objectives" and "Principles" respectively) as interpretative provisions. Specifically, paragraph 5(a) of the Doha Declaration states that:

In applying the customary rules of interpretation of public international law, each provision of the TRIPS Agreement shall be read in the light of the object and purpose of the Agreement as expressed, in particular, in its objectives and principles.

Paragraph 5(a) confirms that TRIPS gives its members sufficient flexibility to make laws which protect public health. ${ }^{800}$ Scholars disagree as to whether the Doha Declaration qualifies as subsequent practice and subsequent agreement under art 31(3)(a) and (b) of the VCLT. ${ }^{801}$

\footnotetext{
${ }^{796}$ World Trade Organization "Ministerial Declaration" WT/MIN(01)/DEC/1 (adopted at Doha on 14 November 2001).

${ }^{797}$ World Trade Organization "Declaration on the TRIPS Agreement and Public Health" WT/MIN(01)/DEC/2 (adopted at Doha on 14 November 2001).

798 James Gathii "The Legal Status of the Doha Declaration on TRIPS and Public Health Under the Vienna Convention on the Law of Treaties" (2002) 15 Harvard Journal of Law \&Technology 291 at 294 and 296.

799 See Daniel Gervais The TRIPS Agreement: Drafting History and Analysis (3rd ed, Sweet \& Maxwell, London, 2008) at 58-59.

${ }^{800}$ Particularly when paragraph 5(a) is read with paragraph 4 of the Doha Declaration: see Daya Shanker "The Vienna Convention on the Law of Treaties, the Dispute Settlement System of the WTO and the Doha Declaration on the TRIPs Agreement" (2002) 36 Journal of World Trade 721 at 722.

${ }^{801}$ See: Daniel Gervais The TRIPS Agreement: Drafting History and Analysis (3rd ed, Sweet \& Maxwell, London, 2008) at 58 and James Gathii "The Legal Status of the Doha Declaration on TRIPS and Public Health Under the Vienna Convention on the Law of Treaties" (2002) 15 Harvard Journal of Law \&Technology 291 at 299 (arguing that the Doha Declaration satisfies Article 31(3)(a) and (b) of the VCLT). But see: Hiroko
} 
While there are cases in which the WTO Panels and Appellate Body have relied on ministerial declarations (where such declarations were pertinent to the facts in the dispute), ${ }^{802}$ the Doha Declaration would have little relevance to disputes which do not concern public health. Nonetheless, the salient issue is: how might Doha be relevant to using arts 7 and 8 in the interpretation of TRIPS' substantive copyright provisions?

The Doha Declaration constitutes formal recognition and articulation of state practice in regard to IP's role in human development, albeit primarily from a health perspective. But just as the Doha Declaration applied TRIPS principles to public health, those principles can be applied to copyright. Such an application would be a legitimate approach under the VCLT. The WTO Agreement gives the Ministerial Conference the power to adopt interpretations of TRIPS. ${ }^{803}$ Although the Doha Declaration does not alter the legal status of arts 7 and 8 , it confirms their interpretative importance in regard to every TRIPS provision. ${ }^{804}$ As paragraph 5(a) of the Doha Declaration indicates, TRIPS' parties intended for developmental concerns ("as expressed...in its objectives and principles") to be a sufficiently weighty consideration in the interpretation of the entire agreement, including its copyright provisions ("each provision"). The Doha Declaration establishes "an interpretative baseline that requires balancing the interests of [IPRS] producers and consumers." $" 805$ This baseline allows for the competing interests within TRIPS to be fairly determined in the interests of development. By requiring that TRIPS be read in light of arts 7 and 8, the Doha Declaration is an example of how countries can use TRIPS as a platform upon which to argue for development-oriented IP

Yamane Interpreting TRIPS: Globalisation of Intellectual Property Rights and Access to Medicines (Hart Publishing, Oxford and Portland (Oregon), 2011) at 308 and Claus-Dieter Ehlermann and Lothar Ehring "The Authoritative Interpretation Under Article IX(2) of the Agreement Establishing the World Trade Organization: Current Law, Practice and Possible Improvements" (2005) 8 Journal of Int'l Econ L 803 at 807-808 (arguing that the Doha Declaration does not qualify as subsequent agreement or practice under the VCLT).

${ }^{802}$ See, for example, United States - Import Prohibition of Certain Shrimp and Shrimp Products WTO DOC WT/DS58/AB/R (1998) (Appellate Body Report) at [168] (in which the Appellate Body considered the 1996 Singapore Ministerial Declaration) and Japan - Taxes on Alcoholic Beverages WTO DOC WT/DS8/AB/R (4 October 1996) (Appellate Body Report) at 24 (in which the Appellate Body had regard to a subsequent agreement).

${ }^{803}$ According to Article IX(2) of the WTO Agreement "The Ministerial Conference and the General Council shall have the exclusive authority to adopt interpretations of this Agreement and of the Multilateral Trade Agreements." This decision must be taken by a three-fourths majority of the members.

${ }^{804}$ Some scholars would, however, argue that the Doha Declaration is merely a political declaration or a supplementary means of interpretation, but see: Zhang Naigen "Dispute Settlement under the TRIPS Agreement from the Perspective of Treaty Interpretation” (2003) 17 Temple Int'l \& Comp LJ 199 at 215 and 219-220.

${ }^{805}$ James Gathii "The Legal Status of the Doha Declaration on TRIPS and Public Health Under the Vienna Convention on the Law of Treaties" (2002) 15 Harvard Journal of Law \&Technology 291 at 316. 
policies. In considering whether those public policies violate their TRIPS obligations, TRIPS provisions must be interpreted in view of their impact upon copyright owners' interests, as well as in terms of how consumers' interests are protected. ${ }^{806}$

(iii)Relevant rules of international law to be considered with Context

Under this limb of interpretation in art 31(3)(c) of the VCLT, the context must be considered alongside "any relevant rules of international law applicable in the relations between the parties." ${ }^{\prime 807}$ These rules include customary law and other treaties. ${ }^{808}$ The word "any" in art 31(3)(c) suggests that external treaties need not be confined to the same field of international law as the treaty to be interpreted. But what does the phrase "between the parties" mean?

Based on how the word "parties" is used throughout art 31, one could reasonably treat its usage in subs (3)(c) as a general reference to the parties to the treaty being interpreted (as opposed to only the immediate parties directly embroiled in an interpretation dispute). It could further be argued that art 31(3)(c) gives interpreters some leeway in that it does not expressly state the external agreements must be signed or ratified by all of the parties to the treaty to be interpreted. ${ }^{809}$ While States cannot be bound by agreements to which they are not a party, international rules found in other multilateral agreements could provide evidence of norms that the parties to the treaty under examination intended to be applicable.

However, the WTO Panels and Appellate Body have interpreted art 31(3)(c) more narrowly. For example, the EC - Measures Concerning Meat and Meat Products (Hormones) ${ }^{810}$ decision suggests that external rules must be binding on all WTO members in order to be

\footnotetext{
${ }^{806}$ Ibid, at 305-306.

${ }^{807}$ See Malcolm Shaw International Law (4th ed, Cambridge University Press, Cambridge, 1997) at 657.

${ }^{808}$ Campbell McLachlan "The Principle of Systemic Integration and Article 31(3)(c) of the Vienna Convention" (2005) 54 Int'l \& Comp LQ 279 at 290.

${ }^{809}$ While the rule need not be legally binding on all members, it must reflect the parties' common intentions, see: Joost Pauwelyn "The Role of Public International Law in the WTO: How Far Can We Go?" (2001) 95 Am J Int'l L 535 at 575-576. But see: Joshua Meltzer "Comment: Interpreting the WTO Agreements - A Commentary on Professor Pauwelyn's Approach" (2004) 25 Michigan J of Int'l L 917.

810 EC - Measures Concerning Meat and Meat Products (Hormones) WTO DOCS WT/DS26/AB/R, WT/DS48/AB/R (16 January 1998) at [123 -124] (Appellate Body Report).
} 
considered under art 31(3)(c). Commentators have criticised the WTO's position as being logically flawed and unduly restrictive. ${ }^{811}$

The developmental concerns of arts 7 and 8 are buttressed by rules outside the realm of IP law, which explicitly deal with the promotion of social and economic welfare. These rules can be found in instruments such as the Universal Declaration of Human Rights, the International Covenant on Economic, Social and Cultural Rights 1966, the International Covenant on Civil and Political Rights 1966 and International Labour Organization agreements as well as in human rights and other development-oriented norms within customary international law. As TRIPS does not contain a definition of developmental and welfare terms in arts 7 and 8, the WTO Panel and Appellate Body would need to refer to other sources outside of TRIPS to interpret their meaning. In United States - Import Prohibition of Certain Shrimp and Shrimp Products ${ }^{812}$ the Appellate Body considered the Convention on International Trade in Endangered Species of Wild Fauna and Flora (CITES), the Convention on Biological Diversity (CBD) and the Inter-American Convention for the Protection and Conservation of Sea Turtles, in order to examine the meaning of "exhaustible natural resources" in art XX(g) of the GATT despite the disputing party not being a party to all those conventions.

Developmental references within TRIPS can possibly be interpreted in an evolutionary manner, as these developmental rules continue to evolve over time. ${ }^{813}$ The VCLT does not preclude such a dynamic interpretation and the open-textured nature of TRIPS' provisions arguably lends itself to this approach. ${ }^{814}$ This view is affirmed by the fact that WTO law is

\footnotetext{
${ }^{811}$ See Lukasz Gruszczynski "Customary Rules of Interpretation in the Practice of WTO Dispute Settlement Bodies" in Fauchald, Ole and Nollkaemper, Andre (eds) The Practice of International and National Courts and (De)Fragmentation of International Law (Hart Publishing, Oxford and Portland (Oregon), 2012) 35 at 40 and 49 and Benn McGrady “Fragmentation of International Law or 'Systemic Integration' of Treaty Regimes: EC Biotech Products and the Proper Interpretation of Article 31(3)(c) of the Vienna Convention on the Law of Treaties" (2008) 42 Journal of World Trade 589 at 590.

${ }^{812}$ United States - Import Prohibition of Certain Shrimp and Shrimp Products WTO DOC WT/DS58/AB/R (1998) (Appellate Body Report).

${ }^{813}$ See Joost Pauwelyn Conflict of Norms in Public International Law: How WTO Law Relates to Other Rules of International Law (Cambridge University Press, Cambridge, 2003) at 265. See also: China - Measures Affecting Trading Rights and Distribution Services for Certain Publications and Audiovisual Entertainment Products WTO DOC WT/DS363/R (2009) (Panel Report) which took an evolutionary approach to treaty interpretation.

${ }^{814}$ See Susy Frankel “The WTO's Application of 'the Customary Rules of Interpretation of Public International Law’ to Intellectual Property” (2005) 46 Va J Int'l L 365 at 408-410.
} 
not a self-contained regime isolated from international law. ${ }^{815}$ However, one limiting factor of arts 7 and 8 is that these interpretative provisions cannot override specific, positive obligations found elsewhere in TRIPS.

(c) Meaning of the terms in light of the treaty's object and purpose

After looking at the ordinary meaning of the terms and their meaning in context, the third element of interpretation under art 31(1) of the VCLT is to consider their meaning in light of the "object and purpose" of the treaty. Many treaties do not have a "single, undiluted object and purpose but rather a variety of different, and possibly conflicting, objects and purposes." $" 816$ The same can be said of TRIPS.

TRIPS is essentially a trade agreement dealing with IPRS. According to the first clause of its preamble, TRIPS' objects and purposes include:

To reduce distortions and impediments to international trade...taking into account the need to promote effective and adequate protection of intellectual property rights, and to ensure that measures and procedures to enforce intellectual property rights do not themselves become barriers to legitimate trade...

This shows that part of TRIPS' goal is to balance the ends of "effective and adequate" IP protection and liberalising trade, the two of which can conflict if IPRS become strong enough to distort (instead of promote) trade. ${ }^{817}$ The protection of IP itself also involves a balance of rights and obligations between rights holders and users. This is why the fifth and sixth clauses of TRIPS' preamble recognise that encouraging trade and protecting IP must allow countries

\footnotetext{
${ }^{815}$ United States - Standards for Reformulated and Conventional Gasoline WTO DOC WT/DS2/AB/R (1996) (Appellate Body Report) at 17 (in which the Appellate Body stated that "the General Agreement is not to be read in clinical isolation from public international law."). See also: United States - Import Prohibition of Certain Shrimp and Shrimp Products WTO DOC WT/DS58/AB/R (1998) (Appellate Body Report) [ShrimpTurtles case] (in which reference to the concept of "sustainable development" in the WTO Agreement affected the Appellate Body's interpretation of the GATT 1994); European Communities - Regime for the Importation, Sale and Distribution of Bananas WTO DOC WT/DS27/AB/R (1997) (Appellate Body Report) and European Communities - Measures Concerning Meat and Meat Products WTO DOC WT/DS26/AB/R and WT/DS48/AB/R (1998) (Appellate Body Report): both cases in which the Appellate Body considered principles of customary international law.

${ }^{816}$ United States - Import Prohibition of Certain Shrimp and Shrimp Products WTO DOC WT/DS58/AB/R (1998) (Appellate Body Report) [Shrimp-Turtles case] at para 17.

817 Susy Frankel "The WTO's Application of 'the Customary Rules of Interpretation of Public International Law’ to Intellectual Property”' (2005) 46 Va J Int'l L 365 at 393.
} 
to realise developmental and technological benefits from IP protection. ${ }^{818}$ Articles 7 and 8 reflect the different, possibly competing, objectives and purposes of trade, IP and development; ${ }^{819}$ and represent a compromise between the disparate views of the TRIPS negotiating states. ${ }^{820}$

Development is therefore not extrinsic to the purposes of TRIPS: attaining developmental ends is part of a legitimate reading of TRIPS' objectives. In EC-Protection of Trademarks and Geographical Indications for Agricultural Products and Foodstuffs ${ }^{821}$ the Panel looked at the public interest principles in art 8 and noted that TRIPS generally provides for the grant of negative rights allowing right holders to prevent certain acts (as opposed to positive rights to use or exploit certain subject matter). And because of this, the Panel noted, TRIPS members were free to pursue public policy objectives that fell outside the province of IPRS, without reliance on TRIPS' exceptions. ${ }^{822}$ This is not to say that reference to the developmental balance in arts 7 and 8 can be invoked by TRIPS members to overrule express obligations contained in TRIPS. Such an approach would not be consistent with a good faith interpretation of the Agreement.

\section{Summary}

According to the ordinary meaning of the terms in arts 7 and 8 in their context, IP protection must be balanced with development needs. TRIPS must be interpreted in accordance with its objects and purposes, as expressed in arts 7 and $8 .{ }^{823}$

Admittedly, commentators frequently discuss TRIPS and development in the context of food, ${ }^{824}$ nutrition, ${ }^{825}$ the prevention or treatment of diseases, ${ }^{826}$ the right to health, ${ }^{827}$ public

\footnotetext{
${ }^{818}$ For TRIPS Preamble, see page 172 of this thesis.

${ }^{819}$ See: Canada - Patent Protection of Pharmaceutical Products WTO DOC WT/DS114/R (2000) at [4.41] (Panel Report) in which the WTO Panel found that the object and purpose of TRIPS can be discerned from the Agreement's general structure which strikes a balance of rights and obligations.

${ }^{820}$ Susy Frankel, above n 817 , at 393.

${ }^{821}$ EC - Protection of Trademarks and Geographical Indications for Agricultural Products and Foodstuffs WTO DOC WT/DS174/R (2005) (Panel Report).

${ }^{822}$ Ibid, at [7.210]. See also: Henning Ruse-Khan "The (Non)Use of Treaty Object and Purpose in Intellectual Property Disputes in the WTO" (Max Planck Institute for Intellectual Property and Competition Law Research Paper No 11-15, 2011) at 22-23.

${ }^{823}$ Given that the meaning is clear, there is no need to rely on supplementary means of interpretation: VCLT, art
} 32 . 
heath, ${ }^{828}$ health-related pharmaceuticals (medicines) ${ }^{829}$ and patents. ${ }^{830}$ However, there is no logical reason that the development discourse cannot be extended to copyright, especially since art 8(1) makes explicit reference to promoting public interest in other areas of vital socio-economic importance, which would include copyright-based sectors. Certainly, the VCLT-method of interpretation leaves the door open for such an approach. A VCLT analysis supports the argument that development should be given a greater role in the interpretation of TRIPS' copyright provisions.

\section{In the WIPO Development Agenda}

\footnotetext{
${ }^{824}$ Peter Straub "Farmers in the IP Wrench - How Patents on Gene-Modified Crops Violate the Right to Food in Developing Countries" (2006) 29 Hastings Int'l and Comparative L Rev 187, Chidi Oguamanam "AgroBiodiversity and Food Security: Biotechnology and Traditional Agricultural Practices at the Periphery of International Intellectual Property Regime Complex" (2007) Michigan State Law Review 215 and Geoff Tansey "Food Security, Biotechnology and Intellectual Property: Unpacking Some Issues Around TRIPS" (Quaker United Nations Office Discussion Paper, 2002) <www.quno.org>.

${ }^{825}$ Carmen Gonzalez "Markets, Monocultures, and Malnutrition: Agricultural Trade Policy through an Environmental Justice Lens" (2006) 14 Michigan St J Int'l L 345 at 357-358 and Kojo Yelpaala, "Quo Vadis WTO? The Threat of TRIPS and the Biodiversity Convention to Human Health and Food Security" (2012) 30 Boston U Int'1 L J 55 at 101. See also: Chantal Blouin, Mickey Chopra and Ralph van der Hoeven "Trade and Social Determinants of Health" (2009) The Lancet 502 at 504.

${ }^{826}$ Kojo Yelpaala, "Quo Vadis WTO? The Threat of TRIPS and the Biodiversity Convention to Human Health and Food Security" (2012) 30 Boston U Int'l L J 55 at 77-88 and Kevin Outterson "Should Access to Medicines and TRIPS Flexibilities Be Limited to Specific Diseases?" (2008) 34 Am J Law \& Medicine 279.

${ }^{827}$ Ping Xiong An International Law Perspective on the Protection of Human Rights in the TRIPS Agreement An Interpretation of the TRIPS Agreement in Relation to the Right to Health (Martinus Nijhoff Publishers, Leiden and Boston, 2012) at ch 3 and ch 6 and Philippe Cullet "Patents and Medicines: The Relationship between TRIPS and the Human Right to Health" (2003) 79 International Affairs 139.

${ }^{828}$ Commission on Intellectual Property Rights, Innovation and Public Health "Public Health, Innovation and Intellectual Property Rights" (Report, World Health Organization, Switzerland, 2006), and Carlos Correa "Integrating Public Health Concerns into Patent Legislation in Developing Countries" (Report, South Centre, Geneva, 2000) <www.southcentre.org>.

829 KM Gopakumar "Product Patents and Access to Medicines in India: A Critical Review of the Implementation of TRIPS Patent Regime" (2010) 3 L \& Dev Rev 325, Richard Smith, Carlos Correa and Cecilia Oh "Trade, TRIPS, and Pharmaceuticals" (2009) 373 The Lancet 684 and Nuno Pires de Carvalho The TRIPS Regime of Patent Rights (2nd ed, Kluwer Law, The Hague, 2005) 52-55 and 336-337.

${ }^{830}$ Carlos Correa "Pro-Competitive Measures under the TRIPS Agreement to Promote Technology Diffusion in Developing Countries" (2001) 4 Journal of World Intellectual Property 481 and Robert Sherwood, Vanda Scartezini, and Peter Dirk Siemsen "Promotion of Inventiveness in Developing Countries through a More Advanced Patent Administration" (1999) 39 IDEA 473.
} 
A development approach to copyright is not only consistent with the copyright theories, Berne and a VCLT-analysis of TRIPS, it is also embodied in WIPO's Development Agenda. ${ }^{831}$

Prior to the Development Agenda, WIPO's main mandate was promoting the worldwide protection of IP. ${ }^{832}$ WIPO's practice tended to favour extending IP and international harmonisation of stronger IP laws while de-emphasising developmental issues. ${ }^{833}$ However, developing countries pushed for the adoption of a Development Agenda within WIPO in order to highlight their socio-economic concerns. ${ }^{834}$ Their goal was to incorporate development more fully into WIPO's work in a manner befitting its status as a specialised UN agency. ${ }^{835}$ Commentators have noted that the Agenda: ${ }^{836}$

[The Agenda] places the benefits of a rich and accessible public domain, national flexibilities in implementing IP treaty norms, access to knowledge, UN development goals, curbing of IPrelated anti-competitive practices, and the need to balance the costs and benefits of [IP] protection firmly within WIPO's central mission...for the first time in WIPO's history, it places the need for balance, flexibility, and a robust public domain on par with promoting IP protection in all WIPO matters affecting developing countries.

${ }^{831}$ The WIPO Development Agenda (WIPO Doc A/43/16 Annex A) was adopted in October 2007 and includes 45 proposals for enlarging WIPO's development role.

${ }^{832}$ See the Convention Establishing the World Intellectual Property Organization (signed on 14 July 1967), art 3.

${ }^{833}$ Carolyn Deere "Reforming Governance to Advance the WIPO Development Agenda" in Jeremy de Beer (ed) Implementing the WIPO Development Agenda (Wilfrid Laurier University Press, Ottawa, 2009) 43 at 43 and Christopher May The World Intellectual Property Organization: Resurgence and the Development Agenda (Routledge, Abingdon (UK) 2006) at 4.

834 In 2004, a coalition of developing country member States (Friends of Development) proposed the "Establishment of a Development Agenda for WIPO." See: WIPO "Proposal by Argentina and Brazil for the Establishment of a Development Agenda for WIPO” Doc. WO/GA/31/11 (27 August 2004). The proposal by Argentina and Brazil was joined by twelve other member states: Bolivia, Cuba, Dominican Republic, Ecuador, Egypt, Iran, Kenya, Peru, Sierra Leone, South Africa, Tanzania and Venezuela. See generally: Peter Yu "A Tale of Two Development Agendas" (2009) 35 Ohio N.U. L Rev 465.

${ }^{835}$ The Agreement between the United Nations and the World Intellectual Property Organization (entered into effect 17 December 1974), art 1 gives WIPO responsibility for "promoting creative intellectual activity and facilitating the transfer of technology related to industrial property to developing countries in order to accelerate economic, social and cultural development."

${ }^{836}$ Neil Netanel "Introduction: The WIPO Development Agenda and Its Development Policy Context" in Neil Netanel (ed) The Development Agenda: Global Intellectual Property and Developing Countries (Oxford University Press, New York, 2009) 1 at 2. See also: Denis Borges Barbosa, Margaret Chon, Andres Moncayo von Hase "Slouching Towards Development in International Intellectual Property" (2007) 2007 Michigan State L Rev 71 at 120-123 and Graeme Dinwoodie and Rochelle Dreyfuss "Designing a Global Intellectual Property System Responsive to Change: The WTO, WIPO and Beyond" (University of Oxford Legal Research Paper Series Paper No. 50/2009) at 32 and 36. 
However, the WIPO Development Agenda's significance should not be overstated in light of the uncertainty that exists about its practical implementation. ${ }^{837}$

The WIPO Development Agenda is, nevertheless, important for four main reasons. First, explicit incorporation of development into WIPO's mandate affords developing countries greater opportunities to nuance their engagement with copyright according to development considerations (such as meeting basic needs, increasing capabilities for education, attaining human rights and protecting cultural heritage) ${ }^{838}$ Second, the WIPO Development Agenda contrasts with the current tendency within the WTO regime to over-emphasise trade (despite the fact that the WTO has its own Development Agenda). ${ }^{839}$ The WIPO Agenda recognises that copyright lawmaking should be cognisant of the needs of development.

Third, the Development Agenda potentially affects WTO decision-making on the basis of the WIPO and WTO relationship. The final clause of TRIPS' Preamble foreshadowed this relationship, stating the parties' desire:

...to establish a mutually supportive relationship between the WTO and the World Intellectual Property Organization...as well as other relevant international organizations.

This relationship was later formally established by the cooperation agreement between these two organisations. ${ }^{840}$ WTO's engagement with WIPO can be seen in decisions such as: European Communities-Protection of Trademarks and Geographical Indications for Agricultural Products and Foodstuffs ${ }^{841}$ (in which the WTO Dispute Panel consulted WIPO about the interpretation of the Paris Convention administered by WIPO) and United StatesSection 110(5) of the U.S. Copyright Act. ${ }^{842}$ In the United States-Section 110(5) of the U.S.

\footnotetext{
${ }^{837}$ See Sara Bannerman "The WIPO Development Agenda Forum and Its Prospects for Taking into Account Different Levels of Development" in Jeremy de Beer (ed) Implementing the WIPO Development Agenda (Wilfrid Laurier University Press, Ottawa, 2009) 24 at 24.

${ }^{838}$ Tzen Wong "Intellectual Property through the Lens of Human Development" in Tzen Wong and Graham Dutfield (eds) Intellectual Property and Human Development: Current Trends and Future Scenarios (Cambridge University Press, New York, 2011) 1 at 3.

839 Dani Rodrik “The Global Governance of Trade As If Development Really Mattered” (UNDP Background Paper, 2001) at 7-8.

${ }^{840}$ The Agreement between the World Intellectual Property Organization and the World Trade Organization (22 December 1995).

${ }^{841}$ European Communities-Protection of Trademarks and Geographical Indications for Agricultural Products and Foodstuffs WTO DOC WT/DS174/R (2005) (Panel Report) at annex D-2. WIPO was consulted in regard to interpreting the Paris Convention for the Protection of Industrial Property 1967.

${ }^{842}$ United States-Section 110(5) of the U.S. Copyright Act WTO DOC WT/DS160/R (2000) (Panel Report), attachment 4 [United States-Section 110(5) of the U.S. Copyright Act].
} 
Copyright Act case, the European Union alleged that section 110(5) of the US Copyright Act (as amended by the Fairness in Music Licensing Act 1998) was inconsistent with TRIPS. The US provisions allowed small businesses to play radio or television without paying royalties to collecting societies or copyright owners. The Dispute Panel considered whether these exceptions complied with art 13 of TRIPS, and consulted WIPO about the fair use norm in copyright law. ${ }^{843}$

Finally, the Development Agenda has wider implications for the DSB interpreting TRIPS from a development perspective. In United States-Section 110(5) of the U.S. Copyright $A c t^{844}$ the Panel had regard to the WIPO Copyright Treaty in its interpretation of TRIPS (even though the WIPO treaty had not yet been ratified or brought into force). This suggests that the Panels and Appellate Body could consider the WIPO Development Agenda in future decisions.

\section{Within the International IP Acquis}

Another approach to incorporating development into multilateral copyright treaties (including TRIPS) is through an IP acquis that recognises development.

The consequence of an acquis (or agreed set of rules) is that, even if a certain principle is not apparent on the face of a treaty's text, once it is part of the existing acquis, that rule should affect the treaty's interpretation. An example of an acquis is seen in United States-Section 110(5) of the U.S. Copyright Act, where the WTO Panel had to consider the relationship between art 13 of TRIPS and its predecessor, art 9(2) of Berne. A major issue was whether the minor exceptions to copyright doctrine was a part of Berne, and therefore of TRIPS, under art 9(1). ${ }^{845}$ The Panel made repeated references to Berne's acquis (that is, the body of principles reflected in Berne which may not always be expressed). ${ }^{846}$ The Panel concluded that, in the absence of any explicit exclusion in art 9(1) of TRIPS, the incorporation of arts 11 and 11bis of the Berne Convention (Paris Revision, 1971) into TRIPS included the entire

\footnotetext{
${ }^{843}$ Ibid. See also: [1.7], [4.1] and [6.64].

${ }^{844}$ Ibid, at [6.70].

${ }^{845}$ Ibid, at [6.30].

${ }^{846} \mathrm{Ibid}$, at [6.42] and [6.60-6.65].
} 
acquis of these provisions, including the possibility of providing minor exceptions to the respective exclusive rights. ${ }^{847}$

Dinwoodie and Dreyfuss argue that an acquis can be extended beyond individual treaties. ${ }^{848}$ They demonstrate that an underpinning acquis already exists within the international IP regime. ${ }^{849}$ The content of these core principles, which have historically undergirded both national and international IP systems, ${ }^{850}$ can be gleaned from state practice, national laws, international sources and IP scholarship. This acquis is made up of: (1) basic norms related to access (subject-matter exclusions, minimum thresholds for protection, IP exceptions and limitations as well as provisions that curb abuse of IPRS, such as allowances for compulsory licensing and rules against anti-competitive practices); (2) principles that protect proprietary interests; (3) rules that recognise national autonomy (seen in the level of flexibility given to states to legislate IP in ways that are suited to local conditions) while (4) reflecting the interdependence of nations (the national treatment requirement).

Dinwoodie and Dreyfuss note the structural significance of arts 7 and 8 of TRIPS, showing that the IP acquis they have identified would add greater interpretative weight to those provisions, because arts 7 and 8 explicitly recognise the broader objectives and principles forming part of the ethos underlying IP law. ${ }^{851}$ The concept of balancing public interest concerns and the rights of authors found in arts 7 and 8 is also reflected elsewhere, for example: in Berne, ${ }^{852}$ in the negotiation of the WIPO Copyright Treaty, ${ }^{853}$ the Doha Ministerial Declaration, ${ }^{854}$ the Doha Declaration on Public Health ${ }^{855}$ and the Anti-

\footnotetext{
${ }^{847}$ Ibid, at [6.63].

${ }^{848}$ Graeme Dinwoodie and Rochelle Dreyfuss A Neofederalist Vision of TRIPS: The Resilience of the International Intellectual Property Regime (Oxford University Press, New York, 2012) at 176.

${ }^{849}$ Ibid, at ch 7.

${ }^{850}$ Ibid, at $\mathrm{X}$.

${ }^{851}$ Ibid, at 196.

${ }^{852}$ See Sam Ricketson and Jane Ginsburg International Copyright and Neighbouring Rights: The Berne Convention and Beyond (2nd ed, Oxford University Press, New York, 2006) at 756 [13.02].

${ }^{853}$ See WIPO Copyright Treaty, Preamble (mentioning the "balance between the rights of authors and the larger public interest, particularly education, research and access to information.").

${ }^{854}$ World Trade Organization "Ministerial Declaration" WT/MIN(01)/DEC/1 (14 November 2001) at [17] and [19].

${ }_{855}$ World Trade Organization "Declaration on the TRIPS Agreement and Public Health" WT/MIN(01)/DEC/W/2 (14 November 2001) at [4] and [5a].
} 
Counterfeiting Trade Agreement. ${ }^{856}$ The references to social and economic welfare and development in arts 7 and 8 of TRIPS support the point that IP is not completely insulated from broader public policy concerns. ${ }^{857}$ Therefore, Dinwoodie and Dreyfuss suggest that greater regard to the acquis would help to reorient international IP law by placing the interests of consumers, follow-on innovators and competitors on the same level as rights holders' interests. ${ }^{858}$

The interpretative value of the acquis goes beyond arts 7 and 8 of TRIPS. For example, the DSB could use principles in the acquis to interpret other concepts in TRIPS such as, clarifying what is meant by "legitimate interests" and "normal exploitation" in the exceptions test in art 13. ${ }^{859}$ Moreover, the acquis would highlight the weakness of the WTO Panels' and Appellate Body's practice of treating the three steps of the art 13 exceptions test as cumulative. ${ }^{860}$ Once the Panel finds that a state exception is not "limited," 861 it need not go on to consider the other two steps of the exceptions test, for which societal interests are critical factors. However, if the acquis' concept of balance were applied, whenever there are public interests at stake the concept of "limited" could yield to the broader exceptions that the other steps justify. ${ }^{862}$

An acquis is a fluid concept which takes into account divergent norms, such as: different state practices, conflicts between domestic laws, inconsistencies between various international IP instruments and the fragmented international IP treaty system (evidenced by the increase in TRIPS-Plus bilateral agreements and Free Trade Agreements). Dinwoodie and Dreyfuss

\footnotetext{
${ }^{856}$ The Final text of the Anti-Counterfeiting Trade Agreement [ACTA] (May 2011) at the sixth paragraph of the Preamble: "Desiring to address the problem of infringement of intellectual property rights...in a manner that balances the rights and interests of the relevant right holders, service providers, and users."

857 Graeme Dinwoodie and Rochelle Dreyfuss A Neofederalist Vision of TRIPS: The Resilience of the International Intellectual Property Regime (Oxford University Press, New York, 2012) at 177.

${ }^{858}$ Ibid, at X.

${ }^{859}$ Ibid, at 195.

${ }^{860}$ Ibid. This cumulative approach has been adopted on the ground that it complies with the principle of effective treaty interpretation which requires the Panel to avoid a reading which would make any of the conditions redundant, see: United States-Section 110(5) of the U.S. Copyright Act at [6.97].

${ }^{861}$ See United States-Section 110(5) of the U.S. Copyright Act at [6.107- 6.110] (in which the Panel interpreted the phrase "certain special cases" in the first step of the test as requiring that the measure be "limited in its field of application or exceptional in its scope.").

862 Graeme Dinwoodie and Rochelle Dreyfuss A Neofederalist Vision of TRIPS: The Resilience of the International Intellectual Property Regime (Oxford University Press, New York, 2012) at 195.
} 
acknowledge that "comprehensively fleshing out [the acquis'] underlying principles will...take time and will require the efforts of numerous scholars and policymakers." ${ }^{863}$

In sum, the concept of an acquis offers a useful way to detect developmental concerns within the international copyright regime.

\section{Summary}

Part A examined how a human development approach to copyright might affect the objectives, content and reform of a domestic copyright regime. Part B discussed the support at the international level. Specifically, I argued that the major copyright theories, Berne, TRIPS, WIPO's Development Agenda and the international IP acquis are all supportive of a development approach to copyright.

On the basis of the state sovereignty principle in international law, countries are free to adopt a human development approach to domestic copyright lawmaking. ${ }^{864}$ But because of the minimum standards contained in copyright treaties such as TRIPS, member countries do not have the freedom to make copyright laws for developmental ends if those laws would contravene substantive treaty obligations.

In the final part of this Chapter, I examine whether evidence of the human development approach is found in the Jamaican context (in copyright policy, legislation and bilateral agreements).

\section{Illustrations of the Human Development Approach in Jamaican copyright law}

\footnotetext{
${ }^{863}$ Ibid, at 194.

${ }^{864}$ See: Jerome Reichman "Universal Minimum Standards of Intellectual Property Protection under the TRIPS Component of the WTO Agreement" (1995) 29 The International Lawyer 345 and Ha-Joon Chang "Intellectual Property Rights and Economic Development: Historical Lessons and Emerging Issues" (2001) 2 Journal of Human Development 287 at 303.
} 


\section{A Evidence in Domestic Copyright Policy and Law}

The sub-sections below discuss how policymakers viewed copyright protection from a human development perspective, in terms of copyright's impact on (1) social and cultural development and (2) economic development in Jamaica.

\section{Social and Cultural Development}

Policy statements from Jamaican legislators indicate their awareness of copyright law's impact on the nation's social and cultural development. In 1993, during the passage of the then Copyright Bill, several lawmakers advanced justifications that centred on the social and cultural enhancement of Jamaicans:

This legislation is designed to enable, not restrict the expansion of our [vistas] of culture...the fullest development of our culture and its availability to the general public is the measuring stick of the depth of our civilization. I commend the Bill for the very positive effect which I believe that it can have today on that development. ${ }^{865}$

[W]e believe that this Act...is really going to give new meaning to the creative talents which undoubtedly abound...and we want to ensure that this tradition [of creativity] not only continues but indeed that this process is allowed to deepen and to expand. ${ }^{866}$

We only have to look around us to realize the historical wealth we have...it is from this that we will begin to be able to build the kind of identity, the kind of development, and hopefully, the kind of industry which is well known to be a part of this creative element. ${ }^{867}$

Copyright protection is desirable for serving the social and cultural aspects of development, which are evidenced by enlarged capabilities. One key aspect of capability expansion is access to education. The Parliamentary Secretary in the Ministry of Education and Culture noted: ${ }^{868}$

[Copyright] provisions...must be put forward on the basis of protecting and enhancing the learning process...Rights enjoyed with respect to works, which assist in the educational process [such as] musical works...are not infringed if such works satisfy certain conditions when they are copied. It is important...because we live in a country where education lies at

\footnotetext{
${ }^{865}$ Hansard 27 January 1993 (Carl Rattray).

${ }^{866}$ Hansard 26 January 1993 (PJ Patterson).

${ }^{867}$ Hansard 26 January 1993 (Mike Henry, Opposition Member of Parliament and former Minister of State in the Ministry of Culture).

${ }^{868}$ Hansard, 26 January 1993 (AJ Nicholson).
} 
the root of all our moving forward...where illiteracy has not yet gone through the window... where the cost of education is a burning issue day in and day out.

In terms of educational exceptions to copyright, the Government's position was that: ${ }^{869}$

[I]n the education process the rights of the user, the person who seeks to get an education, ought really to take precedence over any other right in all the circumstances.

Like similar provisions in other jurisdictions, ${ }^{870}$ statutory exceptions to copyright in Jamaica allow users to access copyright work for educational purposes as well as use by libraries and archives. ${ }^{871}$ For instance, s 56(1) states that copyright in a literary or musical work "is not infringed by its being copied in the course of instruction or of preparation for instruction, provided the copying is done by a person giving or receiving instructions and is not by means of a reprographic process." However, ss 59(1) and (2) permit tertiary institutions ${ }^{872}$ to make reprographic copies of multiple passages from published literary or musical works without infringing copyright, provided not more than five per cent of the work is copied per quarter. ${ }^{873}$ Section $59(3)$ contains a proviso that, if licenses authorising reprographic reproduction are available and the person making copies knew or ought to have been aware of this, the allowance becomes inapplicable. An example of a uniquely Jamaican provision that balances the interests of rights holders and users is s 86 of the Copyright Act. ${ }^{874}$ Section 86 allows for a statutory licence to use copyright works in the case of festivals and national cultural events. It illustrates the cultural concerns of the Jamaican legislature.

Exceptions such as ss 59 and 86 are critical because they are the primary means through which governments can balance owners' rights with other crucial social objectives, such as the proliferation of knowledge and art, freedom of expression and cultural enhancement. ${ }^{875}$ Once the conditions in art 13 of TRIPS are met, a state may choose from various options for

\footnotetext{
${ }^{869}$ Hansard 26 January 1993 (AJ Nicholson).

${ }^{870}$ See Carlos Correa Trade Related Aspects of Intellectual Property Rights: A Commentary on the TRIPS Agreement (Oxford University Press, New York, 2007) at 140.

${ }^{871}$ Copyright Act, 1993, ss 56-65.

872 This is defined in the Copyright Act, s 2 as "any school, college or other educational body designated by the Minister." See: The Copyright (Educational Establishments) Order 1993, which states that only educational institutions providing tertiary education as defined in the Education Act would qualify for this statutory licence. ${ }^{873}$ UK CDPA, s 36(2) provides for one per cent. To be even more beneficial to Jamaica, the Government may wish to extend the provisions to give educational institutions an even greater allowance than five per cent.

${ }^{874}$ Referred to in Chapter 2.I.C.

${ }^{875}$ Laurence Helfer "World Music on a US Stage: An Analysis of the section 110(5) WTO Dispute" in Hugh Hansen (ed) International Intellectual Property Law \& Policy (vol 6, Juris Publishing, Huntington, 2001) 48-1 at 48-3.
} 
limiting the rights holder's right, such as legislating that use of a copyright work will be free of charge or does not require the copyright owner's authorisation. ${ }^{876}$ If exceptions and limitations in TRIPS were restrictively interpreted this would mean that member states would be unable to enact copyright law which accomplishes these societal aims. ${ }^{877}$ The VCLTinterpretation of arts 7 and 8 of TRIPS discussed above ${ }^{878}$ provides an analytical framework for assessing whether domestic copyright exceptions satisfy the criteria in art 13. This issue will be discussed in the next Chapter. ${ }^{879}$

In summary, in regard to the public's use of copyright works, the provisions of the Jamaican copyright law are compatible with a human development approach to copyright.

\section{Economic Development}

Economic development is a component of human development. However, economic development within the human development model is a much wider concept than economic growth. ${ }^{880}$ Human development's idea of economic development considers, among other things, the equitable distribution of what is produced among the population, conditions of production and what kinds of products are produced. ${ }^{881}$ Such an approach is broadly consistent with Jamaican lawmakers' vision that copyright law should contribute to national economic development:

...the difference between First World and Third World rests in how you protect your intellectual property and the use to which you put it...to build the fibre of the society...When I reflect on the Copyright Bill...I recognize how much we have failed to realize and capitalize on this use of culture and this copyright ownership...in the development of the country. ${ }^{882}$

The kind of economic development which the Copyright Act was intended to cultivate was not externally-induced (for example, by foreign corporations) but internally-directed through

\footnotetext{
${ }^{876}$ Hiroko Yamane Interpreting TRIPS: Globalisation of Intellectual Property Rights and Access to Medicines (Hart Publishing, Oxford and Portland (Oregon), 2011) at 218-219.

${ }^{877}$ Ibid.

${ }^{878}$ Chapter 4.III.B.2.

${ }^{879}$ See Chapter 5.II.A.3(b), which also makes reference to whether s 86 fulfils the requirements of TRIPS, art 13.

${ }^{880}$ It is also wider than the economic efficiency justification for copyright discussed in Chapter 4.II.A.3.

${ }^{881}$ Margaret Chon "Intellectual Property and the Development Divide" (2006) 27 Cardozo L Rev 2821 at 2875.

${ }^{882}$ Hansard 26 January 1993 (Mike Henry).
} 
the encouragement of local industries, ${ }^{883}$ and, in particular, the creative efforts of the poorest Jamaicans working in the music industry: ${ }^{884}$

[In] the recording industry the wealth of creativity that has been expressed in this country has not flow[ed] from the middle-class nor...those who are in more fortunate circumstances and enjoy very good income. This creativity has flowed from the lowest income areas; in a large sense, persons who have little academic background and have less skills that are available to them to make a living.

The Government also considered the Copyright Act to be consistent with its overall policy of economic deregulation and liberalisation, which led to the passage of key financial legislation in the 1990s. ${ }^{885}$ The copyright legislation's grant of exclusive rights to rights holders was a vital part of the Government's fiscal policy of stimulating production in the local economy. Parliamentarians thought that without the Copyright Act "we are stymied in our efforts" as far as economic development was concerned. ${ }^{886}$ A human development approach to economic development is signalled by policymakers' concern for fairness in market conditions. As this lawmaker observed: ${ }^{887}$

...more and more modern legislation is introducing an ethical dimension to buttress the protection of property rights, for example, in the way business is conducted...The [deregulation] of our economy and the liberalisation process, does demand the establishment of the restraints and the delineation of ethical parameters if the economic environment is not to deteriorate into being a virtual jungle.

In summary, Jamaican lawmakers had a very expansive idea of a copyright legal system functioning in the social, cultural and economic interests of a wide cross-section of stakeholders. As the Attorney-General concluded: ${ }^{88}$

Government [has] the legislation before Parliament because we do recognise that such legislation is undoubtedly in the national interest, in the interest of Government, in the interest of the producer of copyright material, and in the interest of the legitimate users of that material.

\footnotetext{
${ }^{883}$ See Hansard 26 January 1993 (PJ Patterson).

${ }^{884}$ Hansard, 27 January 1993 (Edward Seaga).

${ }^{885}$ Legislation such as: the Banking Act 1992, the Financial Institutions Act 1992, the Securities Act 1993 and the Fair Competition Act 1993.

${ }^{886}$ Hansard 26 January 1993 (AJ Nicholson).

${ }^{887}$ Hansard, 27 January 1993 (Carl Rattray).

${ }^{888}$ Ibid.
} 
Moreover, evidence of Jamaican policymakers' human development approach to copyright can be found in a major IP-related international agreement entered into by Jamaica, which is discussed in the next sub-section.

\section{B Evidence in the Economic Partnership Agreement with the European Community}

The Jamaican Government's acceptance of the human development principle is demonstrated in the Economic Partnership Agreement (EPA) between the European Community (EC), its member States and the Caribbean Forum of African, Caribbean and Pacific (ACP) States ${ }^{889}$ (of which Jamaica is a member) (CARIFORUM) (EC-CARIFORUM EPA). ${ }^{890}$

Although some of the EC-CARIFORUM EPA's IP provisions are TRIPS-Plus, ${ }^{891}$ the EPA emphasises the idea of sustainable development as the measuring stick for evaluating its performance and the interpretative guide for its provisions. ${ }^{892}$ Article 3(2)(a) of the EPA defines what its sustainable development objective means in mandating the parties to "fully take into account the human, cultural, economic, social, health and environmental best interests of their respective population and future generations." ${ }^{893}$ Article 131(2) of the EPA

${ }^{889}$ CARIFORUM countries include Antigua and Barbuda, the Bahamas, Barbados, Belize, Commonwealth of Dominica, Dominican Republic, Grenada, Guyana, Haiti, Jamaica, St. Kitts and Nevis, Saint Lucia, St Vincent and the Grenadines, Suriname, and Trinidad and Tobago.

${ }^{890}$ This Agreement [EC-CARIFORUM EPA] (which was concluded in 2007 and signed on 15 October 2008) was enabled by the Cotonou Agreement which had been signed in June 2000. The Cotonou Agreement established a framework for relations between the EU and ACP countries with the objective of bringing about ACP's economic development, poverty elimination and assimilation into the global economy. It allowed preferential access to the EC market for specific products from ACP countries. This was found to be inconsistent with the General Agreement on Tariffs and Trade (GATT): EEC-Member States' Import Regime for Bananas WTO DOC DS32/R (1993) (Panel Report) and EEC-Member States' Import Regime for Bananas WTO DOC DS38/R (1994) (Panel Report). The EPA was concluded to allow continued preferential access in a way which was compatible with GATT. EC-CARIFORUM countries have an agreement that not only covers trade in goods but also services, investment and trade-related issues such as innovation and IP. The EU has granted greater market access to cultural practitioners in the music industry, who will not be subject to entry quotas, subject to some controls. There is also a Protocol on Cultural Cooperation with special provisions on heightened cooperation in the audiovisual sector.

${ }^{891}$ See: Title IV, Chapter 2 on Innovation and Intellectual Property, EC-CARIFORUM EPA.

${ }^{892}$ See Article 3(1) of the EC-CARIFORUM EPA which establishes a "trade partnership for sustainable development" and stipulates that sustainable development "is to be applied and integrated at every level of their economic partnership." Article 131(1) also provides that parties agree that "fostering innovation and creativity improves competitiveness and is a crucial element in their economic partnership, in achieving sustainable development..." See generally: Article 132 which outlines the objectives for Title IV, Chapter 2 on Innovation and Intellectual Property.

893 See also: United Nations "Report of the World Commission on Environment and Development: Our Common Future" UN Doc A/42/427 (4 August 1987) Annex at para 1 defining sustainable development as development which meets the needs of the current generation without compromising those of the future. 
acknowledges that "the protection and enforcement of [IP] plays a key role in fostering creativity, innovation and competitiveness" and speaks of the parties' determination "to ensure increasing levels of protection appropriate to their levels of development."

Commentators have noted that the concept of sustainable development in the EPA provides "policy space to tailor national IP laws to the domestic development needs" social, cultural, economic and other interests. The creation and enforcement of these laws should "reflect the comparative advantage (in innovation or imitation) of the country concerned." $" 895$ Concepts such as sustainable development and allowing policy space in lawmaking in the EC-CARIFORUM EPA are consistent with a human development approach to copyright.

There is a sense, however, in which the Jamaican Government, through TRIPS-Plus agreements like the EC-CARIFORUM EPA, has used the copyright system as a bargaining tool to gain trade benefits for Jamaica's non-copyright products. As the JIPO representative noted: $:^{896}$

Some of these TRIPS-Plus negotiations, as we've had, for example, with the European Partnership Agreement and now we're negotiating with Canada...are trade-related. Sometimes, you cannot get out of them because if there are going to be trade benefits in the long run I think that they tie you into these commitments.

Jamaica's policy of creating a stronger domestic copyright system in order to conclude multilateral and bilateral trade negotiations differs from the position of many developing countries. In order to address social issues and distributional claims, those countries are looking to other regimes (outside of trade) to act as rationales for IP lawmaking that are favourable to development. ${ }^{897}$

\footnotetext{
${ }^{894}$ Henning Ruse-Khan "The Concept of Sustainable Development in International IP Law- New Approaches from EU Economic Partnership Agreements?" in Annette Kur and Vytautas Mizaras (eds) The Structure of Intellectual Property Law: Can One Size Fit All? (Edward Elgar, Cheltenham, UK and Northampton, Massachusetts, USA, 2011) 308 at 309.

${ }^{895} \mathrm{Ibid}$, at 323. If a country's comparative advantage in a certain industry is in imitation rather than innovation, economic theory supports adopting an IP regime which allows some level of imitation: Michael Trebilcock and Robert Howse The Regulation of International Trade (3rd ed, Routledge, London, 2005) at 400-401. In ECCARIFORUM EPA, art 139(2) parties agreed that "an adequate and effective enforcement of intellectual property rights should take account of development needs of the CARIFORUM States." ${ }_{896}$ R-7.

${ }^{897}$ Margaret Chon “A Rough Guide to Global Intellectual Property Pluralism” (Seattle University School of Law, Legal Studies Paper 09:01, 2009) at 12.
} 
EPAs can themselves have negative developmental impacts in regard to their domestic implementation because of the costs of more stringent border measures and educating customs officials and police. ${ }^{898}$ This problem is compounded by limited resources, the lack of promised technical assistance and bureaucratic hurdles in accessing funding for public education: ${ }^{899}$

When you try, for example, to seek funding for public awareness [under the ECCARIFORUM EPA], which is a major part of our [JIPO] mandate that we've always had a shortfall in budget for, it's so challenging. The documentation alone is frustrating. They will turn down your application because you didn't fill it out in triplicates. Whoever told you that you should have filled it out in triplicates? Nobody did...it's almost like they make it impossible for you to benefit under this fund.

Despite the implementation difficulties, policymakers feel that the EC-CARIFORUM EPA's TRIPS-Plus arrangements could potentially benefit Jamaica's copyright-based music industry: 900

If we're going to look at the exploitation of, say, Jamaican works outside of the Jamaica, our problem of piracy is not so much only what is exploited in our own country, it's what is exported to the [US] that we can't touch. The mama and the papa shops [abroad] are selling Reggae music, pirated music, left, right and centre, we can't touch them. These are certainly outside of our borders, so if it is that there's going to be increased vigilance to protect our creators' works outside of our borders then certainly we would welcome that.

In sum, references to developmental concerns in IP-related agreements like the ECCARIFORUM EPA which Jamaica has signed show the Government's recognition of human development principles in regard to copyright lawmaking.

\section{Chapter Summary}

This chapter discussed the merits of the human development theory and contrasted it with the economic-growth based model of development. I argued for the legitimacy of a human

\footnotetext{
${ }^{898}$ See Duncan Matthews "The Fight Against Counterfeiting and Piracy in the Bilateral Trade Agreements of the EU" (Briefing Paper for the European Parliament Committee on International Trade, Brussels, June 2008) urging reconsideration of stringent enforcement measures in EU bilateral trade agreements with developing countries which go beyond Part III of TRIPS by harmonising procedural rules for intellectual property enforcement.

${ }^{899} \mathrm{R}-7$.

${ }^{900}$ R-7. See also: R-14 and R-38.
} 
development approach within the international copyright regime on the basis of its consistency with the major copyright theories, Berne, a VCLT-interpretation of TRIPS, the WIPO Development Agenda as well as because its principles form a constituent norm in the international IP acquis. In terms of domestic lawmaking, I demonstrated the ways in which Jamaican policymakers used human development principles to ground the passage of the Copyright Act in 1993 as well as the presence of human development within a major IPrelated agreement, the EC-CARIFORUM EPA. 


\section{CHAPTER FIVE}

\section{COPYRIGHT LEGISLATION APPLIED TO THE JAMAICAN MUSIC INDUSTRY: REFORM IN LIGHT OF DEVELOPMENT}

We should not hesitate to amend [the Copyright Act] from time to time, as our experience dictates. It is certainly not espousal commitment, until death do us part. ${ }^{901}$

[The Copyright Act] has remained static for well over a decade... and we're just going along as if we have a great copyright law and it's functioning for everybody and I don't think it's functioning efficiently. So we really need to...just do a full-scale update of the law. ${ }^{902}$

Copyright legislation confers rights on creators and outlines the extent to which rights holders may exploit these rights, subject to certain exceptions and limitations. By giving rights to creators and allowing for specified circumstances in which the public can use works without remunerating rights holders or obtaining their consent, copyright statutes determine the extent to which copyright can be commercially exploited domestically.

TRIPS provides that its members are free to choose the appropriate method of implementing the provisions of that Agreement within their own legal system and practice. ${ }^{903}$ TRIPS' language gives members a margin of discretion in interpreting its provisions, subject to certain norms of interpretation and dispute settlement rules. The flexibilities that members enjoy have been defined as "legal tools that countries can use as they see fit in their national developmental plans and within the framework of the mandatory standards of international obligations." $"$ Consequently, countries have various means through which TRIPS obligations "can be transposed into national law so that national interests are accommodated and yet TRIPS provisions and principles are complied with." ${ }^{905}$ Examples of the substantive

\footnotetext{
${ }^{901}$ Hansard, 27 January 1993 (Carl Rattray, Attorney-General).

902 R-14.

903 TRIPS, art 1(1).

${ }^{904}$ WIPO Committee on Development and Intellectual Property, Fifth Session "Patent Related Flexibilities in the Multilateral Legal Framework and their Legislative Implementation at the National and Regional Levels" (WIPO Secretariat, Geneva, April 2010) at [9].

905 Ibid, at [20].
} 
flexibilities found in TRIPS include compulsory licensing, exceptions to rights and members' freedom to determine their own regime for the exhaustion of rights. ${ }^{906}$

Jamaican legislators used UK and US copyright legislation as blueprints for the construction of the legal framework that would govern domestic copyright-based industries. ${ }^{907}$ Because Jamaica's legislation is not particularly indigenous in design, and given the music industry's prominent position in the Government's economic development strategy, an important question arises. In relation to the local music industry, are there areas in which Jamaican copyright law can be reformed to make better use of the legal flexibilities which the international copyright regime allows?

The previous Chapter concluded that copyright protection and human development can be reconciled and that the domestic copyright system can seek to achieve human development objectives. The goal of this Chapter is to illustrate how the Copyright Act 1993 could be amended to better achieve developmental objectives, in a manner consistent with the development-friendly interpretation of TRIPS expanded on in Chapter Four. ${ }^{908}$ In order to contextualise the discussion on proposed statutory reforms, this chapter will first outline the existing characteristics of the Jamaican music industry and highlight areas of incompatibility between copyright norms and the music industry's customs, business and creative practices.

The second part of the Chapter will examine two major areas of the copyright legislation to suggest how the statute can be changed to better encapsulate the needs of the music industry and local culture, while still allowing Jamaica to comply with its international copyright obligations. These areas relate to derivative works and fair dealing.

\section{Music Industry Conditions}

\footnotetext{
${ }^{906}$ The flexibilities to which the TRIPS Agreement explicitly refers are the transitional rules which reduce compliance obligations for least-developed countries: TRIPS, art 66(1). But these provisions are designed for national problems which existed at the time TRIPS went into force, which means that new developments must be dealt with through provisions like article 13, see: Graeme Dinwoodie and Rochelle Dreyfuss "TRIPS and the Dynamics of International Property Lawmaking” (2004) 36 Case W Res J Int'l L 95 at 109.

${ }_{907}$ See Chapter 2.IV.B.3.

${ }^{908}$ See Chapter 4.III.B.2.
} 
The following sub-sections will discuss various music industry conditions which might have implications for the practical application of the Copyright Act to the industry.

\section{A Business Orthodoxies and Industry Structure}

Although local artistes produce songs for overseas consumption, the Jamaican music industry itself is relatively isolated from the global music market. There is a general absence of direct institutional linkages between the domestic firms in the local music production system and the multinational corporations which are the key actors in the global music circuit. ${ }^{909}$ Unlike many other music production centres worldwide, the leading international record companies (or majors), have no local offices directly involved in the domestic music scene in Jamaica. In some markets where the majors have a domestic presence, they also provide capital for financing music production as well as deal with the related copyright issues. Because of the limited role of foreign corporations, firms and individual actors in the Jamaican music sector are able to operate in a way that is more suited to the Jamaican context.

This separation between the local industry and the global market has allowed Jamaican rights holders to have greater autonomy in music production. This autonomy accounts for the emergence of business orthodoxies in the Jamaican music industry that substantially differ from the larger music markets, including Jamaica's neighbour, the US. These orthodoxies concern the organisational structure, market dynamics and mode of delivery of the music product. While responsible for Jamaica's dynamic musical product (resulting from the indigenous growth in innovative activity), these orthodoxies also affect the copyright system's operation.

\section{$1 \quad$ Fragmented Organisational and Firm Structure}

The Jamaican music industry has a distinctive organisational form. Its corporate structure is highly fragmented, informal, uncoordinated and lacking a formal market institutional

\footnotetext{
${ }^{909}$ See Dominic Power and Daniel Hallencreutz "Profiting from Creativity? The Music Industry in Stockholm, Sweden and Kingston, Jamaica" (2002) 34 Environment and Planning A 1833 at 1843-1844.
} 
configuration. ${ }^{910}$ While a plurality of influences has contributed to this particular organisational form, the two main influences are: the operations of music production companies and activities of sound systems.

(a) Music Production Companies without exclusive deals with artistes

Jamaican record labels are more akin to small-scale music production companies than typical record labels. The traditional division of labour is that the production company handles the actual recording of an artiste's performance, at the request of (and with financing from) the record label. ${ }^{911}$ The music production company (headed by a producer) is responsible for ensuring that master recordings of songs are produced so as to be ready for manufacture and commercial release (which is the record label's responsibility). Record labels contract with production companies in order to ensure that they own the master recording that the production company produces. While the record label coordinates the overall production process, its main emphasis is in distribution, in other words, marketing, delivery and sale of the final musical product to consumers. Record labels also sign exclusive deals with artistes precluding them from moving to other labels.

Jamaican record labels are essentially sites for music production which differ from their music production counterparts in major music markets like North America. Aside from smaller economies of scale, Jamaican production companies also operate as one-stop shops in which activities such as Artists \& Repertoire (A\&R), ${ }^{912}$ artiste management and distribution are all brought in-house. Because the Jamaican music production market is highly competitive, unlike overseas record labels, Jamaican record labels generally do not sign exclusive recording contracts with artistes. Historically, artistes have always been independent and free to work with different record producers: ${ }^{913}$

\footnotetext{
910 See: Andrea Davis "Entertainment Sector Policy Proposal - Discussion Paper" (Report prepared for the Ministry of Tourism and Sport, 2001) at 3.

${ }_{911}$ In large record labels that are vertically integrated, production is done in-house and not contracted out.

${ }^{912}$ A\&R refers to talent scouting. The A\&R division of a record label is responsible for seeking, recruiting and overseeing the marketing of new talent as well as acting as an intermediary between the artiste and the record label. See generally, Allison Klein "How Record Labels Work" (2011) How Stuff Works <entertainment.howstuffworks.com/record-label.htm>

${ }^{913}$ Howard interview.
} 
People were itinerants, moving from one studio...to the next...and if they recorded a song for one label and that song was not released, they would re-record the same song for another label. So sometimes a song might have 5 different versions, because people were just moving from stable to stable. You have some situations where some artistes develop a good relationship with a label and they stick to that label for a little while and put out a body of songs and sometimes there is some management thing happening, but it was very loose.

Artistes did not generally seek permission from previous producers before re-recording songs.

The free movement of music industry rights holders was effective in fostering innovation. ${ }^{914}$ The rapid spread of innovations in the tight cluster of music production companies located in Kingston (driven by the free movement of personnel) is comparable to the experience of California's Silicon Valley. Silicon Valley had a culture of open relationships between employees of competing firms which freely exchanged ideas. ${ }^{915}$ The rewards from being first to the new idea were the motivation for firms to invest in innovations. Yet, the benefits were not confined to the individual innovating firm. This is due to the existence of "strategic complementarities", which means that each firm's return from innovating increases in the amount of the innovation by the other firms. ${ }^{916}$ Innovation is thus cumulative, as each entity adds to the stock that is the sum of previous contributions. Similarly, within the Jamaican music industry, the culture of mobility and sharing and musical experimentation (allowed by such mobility and sharing) means that the returns from rights holders' innovation benefit other firms.

The advantages of innovation could explain why the practice of free movement of rights holders and sharing in creativity still continues within the local music industry. An entertainment lawyer noted that: ${ }^{917}$

...each producer is really not the traditional producer like back in the day where you just guided the engineering process. A producer in Jamaica now is somebody who creates

\footnotetext{
${ }^{914}$ See Dominic Power and Daniel Hallencreutz "Profiting from Creativity? The Music Industry in Stockholm, Sweden and Kingston, Jamaica" (2002) 34 Environment and Planning A 1833 at 1843: "[Kingston] is at once the production and innovation centre for a small but complex and dynamic domestic music market, as well as being a strong global supplier both of music product and of innovation."

915 John McMillan “Trench Town Rock: The Creation of Jamaica's Music Industry” (unpublished paper, Graduate School of Business, Stanford University, June 2005) at 16.

916 Ibid, at 16-17.

917 R-46.
} 
riddims ${ }^{918} \ldots$ and a dancehall artiste's inspiration comes from riddims. So what [an artiste] does is he hears riddims and he gets riddims sent to him...from various producers and if he gets inspiration from any of those riddims, then he is to go to that producer and record that song.

Given the autonomy artistes enjoy, the broadcasting regulator remarked that "every artiste in Jamaica is an independent label." 919 This lack of exclusivity in the relationship between artiste and producer enables artistes to re-record songs based on the work of previous producers: ${ }^{920}$

You might record a song for one producer and the potential for it to [become a] "hit" was not there. But you...re-record the same song for another producer who have a better feel and know how to produce a hit song and the same lyrics "hit" with that person.

This goes against the idea that the existence of copyright protection encourages record companies to invest their revenues in the creative process because that protection gives them exclusive ownership of the creative product. ${ }^{921}$ Jamaican record companies are mindful of the fact that other firms are likely to benefit from their investment, as riddims can be copied by artistes and quickly diffuse within the market.

However, the situation becomes more complicated when local artistes sign exclusive recording deals with foreign record companies seeking popular local talent. If these foreign companies wish to release an album for a local artiste, they would need to either get a licence from the local producers of songs that were previously recorded or acquire the rights in those recordings. This rights clearance may prove challenging: ${ }^{922}$

So let's just say these artistes...get hit songs from 10 different producers. What [the foreign label]...would do is say: "okay, I need to get a licence of the master recording so that I can put it on [our] album for this artiste." And a lot of the times the [local] producers say: "well, I own it" ... [and] "no. I'm not selling it to you." And then the record company will say "but that's our exclusive recording artiste."

\footnotetext{
918 See Chapter 2.II.A.4(c)(i) for the definition of "riddim."

919 R-10.

${ }^{920}$ Howard interview.

${ }_{921}^{921}$ International Federation of the Phonographic Industries, December 2001 <www.ifpi.org>

${ }^{922} \mathrm{R}-46$.
} 
Nonetheless, foreign record labels tend to accept that Jamaican music is made in a way which does not always adhere to copyright rules (in that they allow artistes with whom they have exclusive deals to record with local producers). ${ }^{923}$

This does not mean, however, that copyright protection is unimportant. The existence of strong copyright legislation has helped to protect the music industry from the exploitative behaviour of foreign music entities. This behaviour was encouraged in the past by an inadequate copyright framework that allowed the global majors to appropriate a sizeable portion of pre-1990s Jamaican music recordings and rights with little or no revenue returning to the original artistes or producers. ${ }^{924}$ The resulting revenue losses to Jamaican rights holders have been significant since sales of back-catalogues tend to bring the greatest profits. The current copyright legislation has therefore been crucial for protecting local rights holders against foreign labels' unauthorised use of locally produced copyright work.

In summary, there is duality in the relationship between the music industry and the copyright legislation. On the one hand, music industry rights holders largely overlook copyright protection on the domestic music production scene, but they also rely on copyright protection for their music in their interaction with foreign record labels.

\section{(b) The Sound System Culture}

Sound systems (previously defined as mobile discotheques that play music at different venues across the island ${ }^{925}$ ) were critical in spawning the unique style and sound which characterise the local music industry. Sound systems remain key actors in the music production system. They operate not only as venues for extemporised performances by deejays to riddim tracks but also as A\&R sites and production centres. Some sound systems also record and release these live sessions into the recorded music market. It is not uncommon for artistes to work with rival sound systems, for multiple artistes to perform a song on the same riddim track or for riddims to be copied by others, given the generally informal nature of the arrangements.

\footnotetext{
923 R-46.

${ }^{924}$ See Dominic Power and Daniel Hallencreutz "Profiting from Creativity? The Music Industry in Stockholm, Sweden and Kingston, Jamaica" (2002) 34 Environment and Planning A 1833 at 1843-1844.

${ }^{925}$ Chapter 2.II.A.2.
} 
These practices, coupled with the fact that sound system operators are often directly involved in the creative process, can make it hard to establish the source of the original creative content and the parties' relative proportion of ownership.

\section{Market Dynamics: Singles-driven Music Market}

Aside from the industry's organisational structure, another relevant feature of the industry is the market dynamics, seen in music production patterns.

In Jamaica there is a relatively short time lag between successive releases of an artiste's new singles to the market. In music markets in Europe and North America, product releases are spaced out in order to draw consumers' attention to higher value items, such as albums, which are released years apart. ${ }^{926}$ However, in Jamaica, because the market is driven by the sale of singles or compilations of singles by various artistes, an artiste can release a new single every two weeks. Local producers' strategy is to sell the greatest number of records in the shortest time. This means that, within the music market, priority is placed on the rapid production and release of records, which are tested on radio stations and sound systems before they become available for retail purchase. ${ }^{927}$ As one veteran musician observed: ${ }^{928}$

Jamaica records more songs and releases more songs than any other country per capita. So therefore, good God man, you can imagine somebody from Irie FM or RJR [radio stations] getting, I mean, 300 songs a week [to play on air]?... In the good old days of the ' 60 s and ' 70 s you probably had 10 songs released every week...[Now] songs last an average of about 6 weeks and then they fade and dead and gone forever and ever, Amen.

The emphasis placed by the industry on rights holders' rapid release of singles has resulted in high productivity in the music market. However, the pressure to quickly and continuously release recordings means rights holders are more likely to neglect enforcement of their rights under copyright law in the pursuit of speedy record production and sales.

\footnotetext{
${ }^{926}$ See Dominic Power and Daniel Hallencreutz "Profiting from Creativity? The Music Industry in Stockholm, Sweden and Kingston, Jamaica" (2002) 34 Environment and Planning A 1833 at 1846.

${ }_{927}$ Howard interview.

${ }^{928}$ R-22.
} 


\section{B Artistes' Practices: Collaborative Creative Process}

As mentioned earlier, the process of music making in Jamaica is typically a collaborative exercise. ${ }^{929}$ The musicologist noted that: ${ }^{930}$

You'll go into the studio, somebody have a song and you say to them: "no man, that lyrics don't sound right" and you give them all five, six lines and it don't mean anything to you. You don't say "alright, I need credit."

Although copyright law does make allowance for more than one rights holder to share ownership of a single musical work, ${ }^{931}$ because of the way local music is made, ascribing ownership to collaborators in these collective works ${ }^{932}$ is not clear-cut. Identifying authors in a collaborative work is usually problematic because some contributions can be quantitatively or qualitatively more significant than others, and assessing the size and value of the contribution is likely to be subjective. ${ }^{933}$ Other reasons for the difficulty in determining authorship are that: participants may have different expectations (unstated during the creative process) about what their ultimate authorship status will be and, post-creation, participants may be vague as to what each person's contribution was. ${ }^{934}$ As a state investment-promotion agency representative and a record producer/songwriter recognised:

...there is a social aspect to this whole copyright situation, particularly in music, whereby, when music is made...how hard it is to distinguish who owns what and then figuring out "at what stage does ownership get attributed to people?" 935

...talking about the business of music [is] something that we don't like to do particularly; especially when you work in a creative atmosphere and people making things, the last thing people want to talk about sometimes is "okay, so how we gonna share up this song now?" 936

Three accepted customs in the Jamaican music industry complicate the attribution of ownership to the various rights holders in collective works. First, an industry convention

\footnotetext{
${ }^{929}$ See Chapter 2.II.A.4(a).

${ }^{930}$ Howard interview.

${ }^{931}$ See, for example, Copyright Act, ss 7, 20 and 22 on works of joint authorship and collective works.

932 A "collective work" as defined in Copyright Act, s 2 is (a) work of joint authorship (a work produced by the collaboration of two or more authors in which the contribution of each author is not separate from the contribution of other authors); or (b) a work in which there are distinct contributions by different authors or in which works or parts of works of different authors are incorporated.

${ }^{933}$ Mary LaFrance "Who is An Author?" in Peter Yu (ed) Intellectual Property and Information Wealth: Issues and Practices in the Digital Age - Volume One (Praeger, Connecticut, 2007) 53 at 57. See also: Aalmuhammed v Lee 202 F. 3d 1227 at 1232 (9 $9^{\text {th }}$ Cir. 2000, US).

934 Ibid, at 57.

935 R-25B.

${ }^{936} \mathrm{R}-49 \mathrm{~B}$.
} 
exists in which rights holders tend to liberally use the contributions made by co-creators of the musical work without giving credit: ${ }^{937}$

[People don't] believe for example, that if somebody comes into a session and assists you with writing a chorus and gives you a melody or gives you something, makes some modification of the work...that that is sufficient to make you a co-author. It's like "where you come from with that?! All you do is to give me one line for the chorus!"

Second, in attempting to gain publicity, industry newcomers who are authors of collective works tend not to take steps to ensure that their copyright in the musical work is formally acknowledged: ${ }^{938}$

There is still this culture that says: "Boy, you know, I just want to put out something and I just want people to see me and I get my name out there."

Third, there is a general absence of contractual arrangements among rights holders who create music together, as an entertainment lawyer noted: ${ }^{939}$

...there's a total disregard for any type of legal protections. Most transactions happen very loosely or informally. It's a brethren [casual] thing. You just jump on the riddim and "yeah, he said he's going to do something with it"... and there was never any paperwork to say that you were even there to begin with.

In view of these accepted norms and the communal nature of music making, a musicologist suggested the Copyright Act might not be an ideal fit for the Jamaican music industry: ${ }^{940}$

We are from a different orientation...In the 1980s, when Dancehall ${ }^{941}$ was just starting, a lot of the lyrics that...these guys recorded...they heard them at a dance and just adopt them. One man does it and [another man] says "boy, I like those lyrics" and he starts to do it. By the time it come to recording...nobody says "hey, you're infringing and taking away my things."

These customs concerning the collaborative process of music creation are not entirely consistent with the notions in the copyright regime, such as, originality, individual authorship, exclusion and identifiable ownership. However, this tension is not unique to the Jamaican music industry: commentators have criticised copyright law for failing to come to

\footnotetext{
${ }^{937} \mathrm{R}-20$

${ }^{938} \mathrm{R}-20$

${ }^{939}$ Webley interview. See also: R-46 and R-31.

${ }^{940}$ Howard interview.

${ }^{941}$ A contemporary form of Jamaican music closely associated with the cultural space of public dance venues and the sound system music played therein.
} 
terms with the complexities of various forms of literary and artistic collaboration and borrowing. ${ }^{942}$

\section{Summary}

The behaviour of Jamaican record labels, sound systems and individual stakeholders has contributed to the fragmented nature of domestic music production. While these practices encourage innovation, the industry complexity they have created has affected the practical application of copyright protection to the music industry, because in some respects, industry practices conflict with adherence to copyright rules.

Accordingly, the second part of the Chapter addresses particular aspects of the copyright legislation that could be amended to better suit the music industry.

\section{Specific Areas requiring Legislative Reform}

Apart from two notable exceptions, ${ }^{943}$ the Copyright Act's provisions do not appear to have been drafted with the local music industry's concerns specifically in mind. A respondent who was formerly Manager of Copyright at JIPO and Director of Entertainment Policy noted: ${ }^{944}$

Certainly, [from] the layout of section 9 and the other sections [of the Copyright Act] relating to what kinds of rights are protected and related rights, and so on, it's clear that a very expansive regime was intended...I do not believe that the Government had any specific intentions of crafting the Copyright Law, amending it in any way to suit any directives or desires expressed by the music industry.

In light of this observation, the following sub-sections examine two key areas in which the statutory provisions might be changed to address the music industry's needs.

\footnotetext{
942 See: Peter Jaszi “On the Author Effect: Contemporary Copyright and Collective Creativity" (1992) 10 Cardozo Arts \& Ent LJ 293 at 314-318 and Olufunmilayo Arewa "From JC Bach to Hip Hop: Musical Borrowing, Copyright and Cultural Context" (2006) 84 NC L Rev 547 at 567 and 631. While these Jamaican music industry norms may be at odds with individual rights management, they are not necessarily in conflict with the collective administration of rights, see Chapter 3.

${ }^{943}$ For example, Copyright Act, s 86 described in Chapter 2.I.C, in relation to the cultural value of the music industry. Another section was s 110 pertaining to musicians' royalties in respect of subsequent use of riddims, which will be discussed in this chapter.

${ }^{944}$ Corthésy interview. See also: R-20.
} 


\section{$1 \quad$ Remixes and Sampling}

The exclusive rights of copyright holders mean they own all the rights extending from their work, including the right to make new works which derive from the earlier work, ${ }^{945}$ or to authorise its adaptation and reproduction. ${ }^{946}$ However, copyright legislation can give third parties the right to make derivative works. A derivative work is based upon one or more preexisting works which, as a whole, represents an original work of authorship. ${ }^{947}$ For instance, the US Copyright Act 1976 allows individuals other than the copyright owner to create and copyright derivative works. ${ }^{948}$ The copyright protection given to owners of derivative works applies only to material original to the derivative work itself. ${ }^{949}$ The author of the original work continues to hold the exclusive right to the original work and to its presence in the derivative work. ${ }^{950}$ A derivative work would be considered an infringing work if the material derived from a pre-existing work had been taken without the copyright owner's consent. ${ }^{951}$

Unlike the US position, the Jamaican Copyright Act does not have explicit provisions dealing with copyright subsisting in derivative works. It is surprising that the Copyright Act 1993 does not address derivative works since digital sampling originated from the dub experimentation of Jamaican innovators in the 1960s. ${ }^{952}$ It is still common for Jamaican

\footnotetext{
${ }^{945}$ On the right to make derivative works, see Michael Abramowicz “A Theory of Copyright's Derivative Right and Related Doctrines" (2005) 90 Minnesota L Rev 317.

${ }^{946}$ See Copyright Act 1993, s 9(1)(a) and (e). Adaptation in relation to a musical work means an arrangement or transcription of the work: Copyright Act s 2(1)(a). For a discussion on the differences between the reproduction and adaptation right, see: Orit Fischman Afori "Copyright Infringement Without Copying - Reflections on the Thebérge case" (2007-2008) 39 Ottawa L Rev 23.

${ }^{947}$ US Copyright Act 1976, 17 USC $\$ 101$.

${ }^{948}$ See US Copyright Act 1976, 17 USC § 103(a) which states that:“[P]rotection for a work employing preexisting material in which the copyright subsists does not extend to any part of the work in which such material has been used unlawfully."

${ }^{949}$ United States Copyright Act 1976, 17 USC § 103(b): limiting the copyright in a derivative work "only to the material contributed by the author of such work, as distinguished from the preexisting material employed in the work."

${ }^{950}$ Ibid: copyright earned for a derivative work is independent of, and does not affect or enlarge the scope, duration, ownership, or subsistence of, any copyright protection in the pre-existing material.

${ }^{951}$ On the differences between derivative works, joint works and collective works: see: Mary LaFrance "Who is An Author?" in Peter Yu (ed) Intellectual Property and Information Wealth: Issues and Practices in the Digital Age-Volume One (Praeger, Connecticut, 2007) 53 at 55-56.

${ }^{952}$ See Siva Vaidhyanathan Copyrights and Copywrongs (New York University Press, New York and London, 2003) at 135-136; Randy Kravis "Does a Song by any Other Name still Sound as Sweet?: Digital Sampling and
} 
artistes to remix ${ }^{953}$ the works of others to create derivative works and to make use of samples. ${ }^{954}$ Jamaican artistes use digital sampling devices to electronically capture and manipulate previous sound recordings. The sampled sound varies in length and is often cut, paste, looped (electronically repeated) or otherwise manipulated in order to create a new song. The Jamaican copyright law is neither clear about the ownership of the resulting song nor which party is entitled to be paid royalties for the performance of the musical composition. Both the musicians and composers of the original work sampled from may attempt to claim a copyright interest in the new work.

The lack of explicit legislative provisions has added to stakeholders' uncertainty about authorship of derivative musical works and how they can be lawfully created in Jamaica. This is evident in the comments of two copyright lawyers and a CMO representative:

If I did a track and you "voice" [provide the vocals] on the track, who owns copyright in what it does at the end? ... I'm an IP lawyer and I'm not entirely sure myself so I can imagine the layman not quite understanding everything. ${ }^{955}$

With derivative works it's interesting because where is that line drawn between what is...a completely new work or what is just borrowed material that is cut and pasted together? And it's such a subjective call. ${ }^{956}$

Its Copyright Implications" (1993-1994) 43 Am U L Rev 231 at 238-239 (noting that Jamaican disc jockeys would mix Jamaican and non-Jamaican records together, add lyrics, modify various elements such as the bass and vocal tracks or insert reverberation and echo to create a single musical work) and David Sanjek "“Don't Have to DJ No More': Sampling and the 'Autonomous' Creator" (1992) 10 Cardozo Arts \& Ent J 607 at 610611. Dub is a form of art created by mixing different sounds together in a single work. See the explanation given in Chapter 2.II.A.4(c).

${ }^{953}$ The term "remix" refers to the derivative work created by literally "remixing" a single song in the recording studio to create a new version of the work. A remix incorporates new elements into the song (vocals, instrumentation) or alters the original elements (for example, changing the beat) in order to create a new work. Often used interchangeably, the difference between a remix (called a "version" in Jamaica) and a "mashup" is that a mashup is the song which results from the mere combination or "mashing" of two or more pre-existing songs (for instance, by splicing together the vocal track of one song with the instrumental track of another) without the addition of original material: see Andrew Long "Mashed Up Videos and Broken Down Copyright: Changing Copyright to Promote the First Amendment Values of Transformative Video" (2007) 60 Oklahoma L Rev 317 at 317. In Jamaica, mash-ups are a much less common phenomenon than remixes. See generally: Michael Pote "Mashed-Up in Between: The Delicate Balance of Artists' Interests Lost Amidst the War on Copyright" (2010) 88 NC L Rev 639.

${ }_{954}$ Sampling is the incorporation of previously recorded works into new musical compositions. Broadcast Music Incorporated (BMI) "A Guide to Music Publishing Terminology" (1990) defined sampling as the process in which "sound bytes are removed electronically from a master recording and through technological imitation placed within the context of another composition."

${ }_{955} \mathrm{R}-47 \mathrm{~A}$.

${ }^{956}$ Webley interview. 
I don't think the law addresses remixes. The basic law is there to support the composer, author, publisher. John Brown the producer...wants to remix a record...I don't think the law spells it out; crossing the t's and dotting the i's. ${ }^{957}$

Moreover, stakeholders' uncertainty caused by this legislative silence has given rise to different industry practices in regard to the creation of derivative works. Conflicting views exist as to whether permission from and payment to the original copyright owners are necessary prior to use. The more conservative approach is to view any unauthorised use of copyright works as prohibited, regardless of whether a new copyright work is created by the remixing. For example, this record producer stated: ${ }^{958}$

...if you want to re-record an existing work, you need to communicate with the original creators of the work and get permission...Even if someone here in Jamaica takes a melody of a song, put new words, new music, it is an infringement. If you take even two lines, three, four lines out of somebody's song and put 96 lines in your song, you have infringed copyright.

Another practice is to take different approaches based on how the creator of the derivative work uses the earlier work. A record producer explained: ${ }^{959}$

If you sampled a body of work, you have to get clearance [permission from the original copyright owners] because you're using the work directly. But if you interpolate the work, you don't have to get clearance per se but you still have to credit where the work is coming from...[In] a sample you actually take the body of work, literally, whether you have chopped it or time-stretched it or compressed it, you've used the actual composition. An interpolation is: you've used the composition but you've actually re-created it.

This producer distinguished between sampling (which directly uses the earlier sound recording) and interpolations (such as doing a cover version of the previous song) for the purposes of whether permission from (and royalty payment to) the original copyright owner is necessary; or whether simply crediting the owner (without prior authorisation) is sufficient.

A third approach is to treat the issue of acceptable use as contingent upon the quantity of material borrowed from the earlier work. Thus, if less than a certain amount of a musical work is used in the creation of the derivative work, crediting the original composer (without paying royalties) will suffice. As one record producer stated: ${ }^{960}$

\footnotetext{
${ }^{957} \mathrm{R}-28$.

$958 \mathrm{R}-4$.

${ }^{959} \mathrm{R}-3$.

${ }^{960}$ R-40.
} 
The thing is, there is a minimum you can use; I think if you use four bars of a man's song you have to pay him royalties. But if you use two, you don't.

When it comes to recording a version of a foreign song, the dominant practice in the industry is to make use of original material without seeking permission from the original copyright owners in the hopes such use will go undetected. Although instances exist where local artistes' use of foreign material has been challenged by overseas rights owners, ${ }^{961}$ this infringement largely goes unnoticed because of the small size of the local market: ${ }^{962}$

A lot of it [unauthorised derivative work] slides through the cracks because some aspects of Reggae and Dancehall are not big enough to be threatened so they get away with it...It would never sell or it hasn't sold enough [in foreign markets].

It is clear that considerable confusion exists in the music industry on the legal position concerning derivative works. In light of the factual situations just discussed, what would be the likely legal outcome under existing Jamaican law in the event of a copyright dispute?

\section{(a) Legal Position}

There is extensive international literature on how copyright law should treat derivative works such as remixes and samples. ${ }^{963}$ Within Jamaican law, derivative works are not a designated category within the specified statutory exceptions to copyright protection. ${ }^{964}$ Therefore, unless the underlying work was in the public domain, a derivative work may well be an infringement of copyright (because it is an unauthorised reproduction or adaptation of the work). ${ }^{965}$ The copyright owner of the underlying work can thus allege infringement; and the

\footnotetext{
${ }^{961}$ For example, the case of Jamaican artistes Vybz Kartel and Spice's "Ramping Shop," a cover of a song originally performed by American Hip Hop artiste Ne-Yo (see Davis interview) and Jamaican artiste JC Lodge's "Someone Loves You Honey," a cover of the Charley Pride song, which later became a hit in the British market (see Howard interview). In both cases, the overseas copyright owners threatened to pursue copyright infringement lawsuits.

962 R-3.

963 See, for example, Emily Harper "Music Mashups: Testing the Limits of Copyright Law as Remix Culture Takes Society By Storm" (2010) 39 Hofstra L Rev 405 and Robert Vrana "The Remix Artist's Catch-22: A Proposal for Compulsory Licensing for Transformative, Sampling-Based Music" (2011) 68 Wash and Lee L Rev 811.

${ }^{964}$ Such as fair dealing with the work for the purposes of criticism, review or current events reporting, use of the work for educational purposes, exceptions affecting libraries and archives: Copyright Act ss 52-84.

${ }^{965}$ Unless the creator of the derivative work can show that the making and use of the derivative work is done in a way which falls within the uses expressly permitted by the Copyright Act, for example, copying by educational establishment (s 59) or for the purposes of instruction or examination (s 56).
} 
court would then make a determination on whether, on the facts, copyright infringement has occurred. In order to establish infringement, the claimant is required to prove that there has been substantial ${ }^{966}$ reproduction of their work, that there is sufficient objective similarity and a causal link between their work and the derivative work. ${ }^{967}$ If copyright infringement is not established, the next question is whether the derivative work itself has satisfied the test of originality to qualify for copyright protection. In other words, has the derivative work's creator exercised independent skill, judgement or labour in producing the work? ${ }^{968}$

Contrary to common industry belief, there is no minimum percentage or proportion of a plaintiff's work that a defendant can lawfully copy, as even small parts of a work can be qualitatively significant. ${ }^{969}$ The court is unlikely to differentiate between various kinds of techniques or technical usages which could be made of the existing work by the defendant (for example, whether the plaintiff's work was sampled or interpolated), except insofar as relevant to ascertaining whether a substantial part of the earlier work has been taken. It is likely many creators of derivative works would be held liable for copyright infringement as their works are based on earlier works and incorporate identifiable parts of pre-existing works. It would not be very difficult to establish that the defendant has copied a substantial part of the plaintiff's work, particularly if listeners can readily identify it without needing to hear a large quantity of the song. ${ }^{970}$ The plaintiff could also easily show a causal connection between the two works, that is, that the defendant copied the plaintiff's work.

However, in the event that the court is satisfied there has been no substantial copying of the plaintiff's work and that the derivative work is original, the derivative work would have

\footnotetext{
${ }^{966}$ Whether the defendant has copied a substantial part is more a qualitative than quantitative test: per Reid LJ in Ladbroke (Football) Ltd v William Hill (Football)Ltd [1964] 1 WLR 273 at 276 (House of Lords).

${ }^{967}$ See the New Zealand Court of Appeal case of Wham-O MFG Co v Lincoln Industries [1984] 1 NZLR 641.

${ }^{968}$ Copyright Act s 6(1)(a) states that copyright subsists in "original" literary, dramatic, musical or artistic works. On the threshold for originality, see: University of London Press Ltd v University Tutorial Press Ltd [1916] 2 Ch 601, Express Newspapers Plc v News (UK) Ltd [1990] FSR 359, Newspaper Licensing Agency Ltd v Marks \& Spencer plc [2002] RPC 4 (House of Lords) and Sawkins v Hyperion Records [2005] EWCA Civ 565 (Court of Appeal). In contrast, the US case of Feist Publications Inc v Rural Telephone Service Co 499 US 340 (1991) adopts a higher standard for originality, requiring more than pure labour but also a modicum of creativity. Given the lack of local authorities, the Jamaican court would have recourse to British case law. On originality generally, see Alexandra Sims "Arrangements and Originality in Copyright Law" (2007) 4 New Zealand Intellectual Property Journal 286.

${ }^{969}$ See Francis Day \& Hunter v Bron [1963] 2 All ER 16 in which the English Court of Appeal found that the defendant's copying of eight bars of the plaintiff's work amounted to a substantial part of the plaintiff's musical work.

${ }^{970}$ See Hawkes \& Son (London) Ltd v Paramount Film Service Ltd [1934] Ch 593 (EWCACiv).
} 
copyright protection separate from any copyright attaching to the underlying, pre-existing work (as its authorship remains unaltered).

\section{Riddims}

Within Jamaican music terminology, a "riddim" refers to a distinctive combination of a bassline, drum pattern, and an associated melody. ${ }^{971}$ Once a riddim is created, a producer reuses it multiple times to record different songs with several singers (derivative works), without paying royalties to the musicians who performed when the original track was laid. Within the Jamaican music industry, the initial motivation for this practice was to reduce record production costs when record sales started to shrink. ${ }^{972}$

When the Copyright Act was being drafted in the early 1990s, musicians lobbied for a provision that would allow them to be paid royalties for every subsequent use of their work on top of the one-time fee received from the producer for the original recording session. Parliamentarians accepted the session musicians' position, ${ }^{973}$ and enacted s 110 of the Copyright Act, which states that a performer's rights are infringed if the original recording of the performance is used for making an adaptation of the recording, without the performer's consent and payment of a royalty. An adaptation is a recording which contains lyrics and music not contained in the original recording. ${ }^{974}$

Although it might appear that, in regard to riddims, s 110 of the Copyright Act successfully addressed a salient issue, some music industry stakeholders believed that the free use of riddims engenders creativity ${ }^{975}$ which could be hindered by s 110 's stipulation requiring permission and royalty payment.

Other rights holders argued that s 110 does not go far enough in dealing with copyright ownership of riddims. First, the statutory provision does not give explicit guidance on the

\footnotetext{
${ }^{971}$ Explained in Chapter 2.II.A.4(c).

972 R-49B.

${ }^{973}$ See Hansard, 26 January 1993 (contributions of PJ Patterson and AJ Nicholson).

${ }^{974}$ Copyright Act, s 110(2).

${ }^{975}$ Not all respondents favoured riddims. One view was that recording multiple songs on the same riddim diminished both the value of the copyright in and the appeal of each song as well as drove down the possibility of creating hits by diffusing the potency of the track: see Davis interview.
} 
extent of the record producers' and musicians' copyright ownership of riddims, which are usually created through both parties' efforts. As a result of the statutory ambiguity, disagreement exists within the music industry. For example, a CMO representative took one position: ${ }^{976}$

I [the producer] can come into you [the musician] and say "listen, build me a riddim," and I give you some off-the-cuff sound that I hear in my head and I say: "I want it to sound like this." And you go on your computer and you build a riddim...I now pay you for that riddim...I register the riddim. I own the riddim [and] can do anything with that riddim.

On the other hand, a studio operator had a different view: ${ }^{977}$

[A] record producer goes to a musician and says "build a riddim for me"... He goes to a recording artiste: "I want you to voice a song on this riddim."... They go to the studio and book the studio. The engineer in there produces the song by putting the vocals to it... the guy who created the riddim performed two services: the service of a musician building the riddim, and the service of a creator who owns the copyright. Usually, that so-called producer puts his name on the record saying he owns the copyright of the musician...his justification is: "I paid the man to build the riddim, then isn't it my riddim?" So I said to him: "did you pay the singer to sing?" He says: "Yeah." I say: "then why you don't own the singer's song?"

What is the effect of the statutory provision? Since the language of s 110 does not address ownership of riddims, case law principles on copyright ownership would need to be applied in interpreting stakeholders' legal position.

\section{(a) Legal Position}

If the musician's and producer's contributions to a musical work and the recording of it are indistinguishable, they would be considered joint authors of the work. ${ }^{978}$ The Copyright Act provides that except where expressed to the contrary, "author" as it applies to a work of joint authorship refers to all authors of the work. ${ }^{979}$ Joint authors are co-owners of the copyright in the work. ${ }^{980}$ The position in case law is that joint authors hold copyright in the work as

\footnotetext{
976 R-28.

977 R-4.

${ }^{978}$ See Copyright Act, s 2 (1)'s definition of a "work of joint authorship."

${ }^{979}$ Copyright Act, s 2(1).

${ }^{980}$ Copyright Act, s 22(3).
} 
tenants in common entitled in equal shares. ${ }^{981}$ UK case law shows that this does not mean that a joint author is free to do any of the restricted acts (including copying the work) ${ }^{982}$ without the permission of the other joint authors (even if those authors later receive a share of the profits). ${ }^{983}$ Thus, subsequent uses of the work would require a licence obtained with the consent of all authors.

For a collaborator to be considered a joint author, simply making creative suggestions about the construction of a riddim is insufficient. The collaborator's creative input must be significant: the contributor must share responsibility for the skill and labour of authorship of the work. ${ }^{984}$ The courts have held that the contributor must create something which is protectable by copyright and which finds its way into the finished work, ${ }^{985}$ that is, the form of expression of the idea and not the idea itself. ${ }^{986}$

In cases where a producer employs a musician to create a riddim and the work is created during the course of employment, the Copyright Act provides that the author-employee is the original copyright owner of the work, unless there is a contractual arrangement to the contrary. $^{987}$

Disputes can arise as to whether the musical artiste or the record producer is the "author" when the riddim is recorded. Section 2(1) of the Copyright Act defines "author" in relation to a sound recording as "the person by whom the arrangements necessary for the making of the recording are undertaken." But determining who the "author" is can be contentious, as Jamaican artistes often play a proactive role in the recording process. As a copyright lawyer pointed out: ${ }^{988}$

\footnotetext{
${ }^{981}$ Ray v Classic FM Plc [1998] EWHC Patents 333 at [33].

982 Copyright Act, s 9(1).

${ }^{983}$ Ray v Classic FM Plc [1998] EWHC Patents 333 at [34]. See, in support: Cescinsky v George Routledge [1916] 2 KB 325 and Cala Homes (South) Limited v Alfred McAlpine [1995] FSR 818 at 836.

${ }^{984}$ Fylde Microsystems Ltd v Key Radio Systems Ltd [1998] EWHC Patents 340 per Laddie J at [25].

985 See Cala Homes, above n 983.

${ }^{986}$ See Tate v Thomas [1921] 1 Ch 503 and Evans v E Hulton \& Co Ltd [1923-1928] MCC 51.

${ }^{987}$ Copyright Act s 22(1). This is in contrast to both the UK position (CDPA s 11) and the "work made for hire" concept in the US where the employer or the person who commissions the work is deemed the author and owns the copyright in the work, unless a signed written agreement to the contrary exists: see United States Copyright Act, s 101 and s 201 (a). See also: Natalie Corthésy "Copyright Ownership of Employee Works in Jamaica" (2009) 34 West Indian L J 181. ${ }^{988} \mathrm{R}-1$.
} 
Another [case I handled] involved a[n]...issue between an artiste and a producer...[The recording] was done at this person's studio, although based on [the artiste's] instructions: he had made the appointment at the studio and the payments and whatever...If [under the Copyright Act], the producer is the person that is supposed to undertake all the arrangements, is [copyright] really supposed to go to this studio that put it out on their LP?

Given the unambiguous language of the Act, the preferred statutory interpretation is that, if the musician makes the arrangements for recording then he or she is author of the sound recording, but if a record producer handles those arrangements he or she becomes the author of the sound recording for the purposes of the Act, whereas the musician would be author/owner of the copyright in the musical work embodied in the recording. Deciding who made the arrangements will be a question of fact for a judge to determine.

One limitation of the Copyright Act is that the current statutory provisions do not address the respective copyright entitlements in circumstances where third parties use riddims to create subsequent works (derivative works). Usage of riddims by multiple parties remains an enduring part of Jamaican music making, as a music academic explained: ${ }^{989}$

[T] he "riddim" has become an important means for composition, and so, riddims are used by a range of people. So there's still a sense in which there's a lot of duplication, replication of the same riddim pattern.

A copyright lawyer argued: ${ }^{990}$

If I come and write a song using that music bed [riddim] there's nothing in our copyright laws that would specifically speak to what that is. It doesn't envision that scenario [where] I create this music bed, or if I wrote a song and this music bed is created for my song....and the producer then takes that music bed and gets somebody else to write a song for it.

The legal analysis in the previous sub-section on derivative works ${ }^{991}$ could be applicable to resolving copyright disputes concerning works made from earlier riddims. However, the fact that riddims are often re-used and modified several times over could add an additional layer

\footnotetext{
989 Cooper interview.

990 R-20.

${ }^{991}$ Chapter 5.II.A.1(a).
} 
of complexity for the courts in determining whether subsequent riddim modifications satisfy the test of originality (independent skill and labour) ${ }^{992}$ and where copyright ownership lies.

\section{Recommended Amendments to the Copyright Act to Accommodate Derivative Works}

(a) Proposals from the literature

Based on the discussion in the preceding sub-sections, Jamaican policymakers should consider amending the Copyright Act to specifically address: (1) how derivative works can be lawfully created and (2) the conditions under which derivative works would be entitled to independent copyright protection (separate from the earlier copyright works incorporated therein). Obviously, the issue as to whether a derivative work is sufficiently original to merit independent copyright protection is likely to be a question of degree for the courts and the statute may never completely remove grey areas. However, instituting legislative change could have the benefit of eliminating industry uncertainty.

From the literature, two major proposals emerge for altering the copyright legislation to deal with the issue of derivative works in a way which gives their creators greater freedom to create these new works.

First, given artistes' practice of building upon the works of others, as well as the high transaction costs of negotiating and obtaining licences to use works, ${ }^{993}$ the Government may wish to consider introducing a system of compulsory licences ${ }^{994}$ in respect of the use of music and sound recordings. ${ }^{995}$ The copyright statute could have a provision allowing artistes a licence to sample or cover a copyrighted musical composition or sound recording, provided

\footnotetext{
992 See: the landmark House of Lords case Walter v Lane [1900] AC 539. See also: Krishna Hariani and Anirudh Hariani “Analyzing 'Originality' in Copyright Law: Transcending Jurisdictional Disparity” (2011) 51 IDEA 491 at 498-499.

${ }^{993}$ See Webley interview, noting that the average fee to obtain a license to sample a work is over US $\$ 2,000$; an onerous figure given that musicians pay J\$2,000 [US\$23] for their studio time to record a song. Currently, licensing fees for samples are determined by contract: see R-28.

${ }^{994}$ A compulsory or non-voluntary licence is one obtained without the rights owner's authorisation. The rights holder is unable to restrict the licensee from using the work in the manner allowed in the licence and is entitled to receive reasonable remuneration. See: Susan Corbett “Going Grey: the Copyright Debate" [2004] NZ LJ 386$387,390$.

995 See J Michael Keyes "Musical Musings: The Case for Rethinking Music Copyright Protection” (2004) 10 Mich Telecomm \& Tech L Rev 407 at 439-440.
} 
certain criteria are met and procedures followed. These procedures would involve the artiste paying a fee set pursuant to the Copyright Act's compulsory licence. The compulsory licensing provision could state that once the copyright owners in a musical composition and sound recording have authorised the creation and distribution of a phonogram, anyone who follows the procedures set out in the statute and pays the statutorily stipulated fees can sample (up to a prescribed length), cover or create a version of the original recording without the express permission of the copyright owners.

The Copyright Tribunal could establish the licensing fee, revising the rate annually according to industry standards and market conditions, in proportion to changes in the Consumer Price Index. This rate should be reasonable enough to permit public access to copyright works without placing an undue financial burden on the creators of derivative works or preventing the copyright owners of the original works from recovering competitive returns. Additionally, copyright owners should be given the choice to opt out of this compulsory licensing scheme through registration. ${ }^{996}$ These kinds of statutory amendments would assist in reducing the transaction costs of remixing by creating uniform rates, as well as implement a system for the speedy grant of licences and royalties. In order to limit free-riding, the statute should place an obligation on artistes to disclose the source of all samples or face criminal penalties. ${ }^{997}$

The second proposal is to amend the Copyright Act to include a more comprehensive definition of "musical work" would offer greater clarity to creators of derivative works as to which elements of a musical work are original (and protected by copyright) and which are not (and are therefore free for them to use). ${ }^{999}$ Musical elements include melodies, rhythms and harmonies. ${ }^{1000}$ The Act

\footnotetext{
${ }^{996}$ See Lawrence Lessig "Free(ing) Culture for Remix” (2004) 2004 Utah L Rev 961 at 973.

${ }^{997}$ See Jeffrey Brown, “Comments: 'They Don’t Make Music The Way They Used To': The Legal Implications of 'Sampling' in Contemporary Music” (1992) 1992 Wis L Rev 1941.

998 The current definition is "a work consisting of music, exclusive of any words or action intended to be sung, spoken or performed with the music": Copyright Act, s 2 .

${ }^{999}$ In contrast, the position in respect of sound recordings is more clear-cut: because there is no originality requirement for copyright protection, copying an actual sound recording infringes copyright in the sound recording: see Copyright Act, s 6(b).

1000 The melody can be described as the arrangement of musical notes in a tune, which is a series of notes sung or played in a particular order to form a piece of music. The harmony is the way in which different notes that are played or sung together combine to make a pleasing sound. The rhythm is the regular, repeated pattern of sound: Oxford Advanced Learner's Dictionary (8th ed, Oxford University Press, 2010). The structure, harmonic embellishments, chord progressions and rhythmic patterns of a song tend not to be original enough to merit
} 
could either specify the originality threshold to be met for a particular musical element to be afforded copyright protection or expressly exclude those musical elements that are inherently unoriginal. $^{1001}$

Although these suggested statutory revisions represent viable solutions to some of the copyright difficulties posed by derivative works, they would need to be shown to be compliant with TRIPS before they could be implemented domestically. However, this thesis proposes a more far-reaching reform to the Copyright Act. The next sub-section analyses the reform along with its compatibility with art 13 of TRIPS as interpreted by the WTO Panel in United States-Section 110(5) of the U.S. Copyright Act.

(b) Specified Copyright Exception for Derivative Works

The Jamaican Copyright Act could be amended to provide that the creation of derivative works becomes one of the categories of statutory exceptions to copyright infringement. This exception would allow creators of derivative works to make greater use of the music of other authors. Article 13 of TRIPS enables members to allow the free use of protected works and sets the standard by which any limitation on copyright must be measured. Article 13 states:

Members shall confine limitations or exceptions to exclusive rights to certain special cases which do not conflict with a normal exploitation of the work and do not unreasonably prejudice the legitimate interests of the right holder.

My argument is that a copyright exception for derivative works would be consistent with art 13 of TRIPS, particularly in light of the development-friendly interpretation of TRIPS (examined earlier in Chapter Four). ${ }^{1002}$

The first step of art 13's three-part test is that the exception must be "certain" (clearly delineated) and "special" (apply to a well-defined area). ${ }^{1003}$ The WTO Panel has said that, to

copyright protection as they are frequently duplicated in a single genre of music, see, for example, the US case: Tisi v Patrick 97 F. Supp. 2d 539 (SDNY 2000).

${ }^{1001}$ Such as an individual artiste's vocal or musical style. See generally: Stephen des Landes "Rethinking Musical Works in Copyright Law" (Bachelors of Commerce Dissertation, Victoria University of Wellington, 2012).

1002 See Chapter 4.III.B.2.

1003 See Daniel Gervais The TRIPS Agreement: Drafting History and Analysis (3rd ed, Sweet \& Maxwell, London, 2008) at 239. 
satisfy this requirement, an exception or limitation must be limited in its field of application or exceptional in its scope; that is, narrow both quantitatively and qualitatively. 1004 "Special" does not mean the exception must have a "special purpose" or be justified in terms of a legitimate public policy purpose. ${ }^{1005}$ However, lawmakers' public policy purposes could be useful for drawing inferences about the exception's scope or the clarity of its definition. ${ }^{1006}$ The Panel stated that the exception need not set out "each and every possible situation" to which it applied. ${ }^{1007}$ In Jamaica's case, the suggested exception's objective is distinctive: to help to maintain the flow or increase the output of derivative works that are at the heart of the music industry's creative process. Instead of being open-ended, the provision could specify some of the circumstances in which it would be applicable, so as to give greater certainty as to its scope.

The second part of the art 13 test is that the domestic copyright exception must not conflict with rights holders' normal exploitation of the work. The Panel regarded this test as involving both an empirical and a normative question. The empirical connotation of the term "normal" denotes the way in which the work was actually exploited, or exploitation that is "regular, usual, typical or ordinary." ${ }^{1008}$ Whether a limitation or an exception conflicts with a normal exploitation of a work should be judged for each exclusive right individually, as: ${ }^{1009}$

...a possible conflict with a normal [dominant] exploitation of a particular exclusive right cannot be counter-balanced or justified by the mere fact of the absence of a conflict with a normal exploitation of another exclusive right (or the absence of any exception altogether with respect to that right), even if the exploitation of the latter right would generate more income.

The normative connotation of "normal" applies to exploitation that is potential, permissible or desirable, or "conforming to a type or standard. ${ }^{1010}$ One must consider, in addition to those forms of exploitation that currently generate significant or tangible revenue, forms of exploitation which "with a certain degree of likelihood and plausibility, could acquire

\footnotetext{
${ }^{1004}$ United States-Section 110(5) of the U.S. Copyright Act WTO DOC WT/DS160/R (2000) at [6.109] (Panel Report).

${ }^{1005}$ Ibid, at [6.105] and [6.111-6.112].

${ }^{1006}$ Ibid, at [6.112].

${ }^{1007}$ Ibid, at [6.108].

${ }^{1008}$ Ibid, at [6.166].

${ }^{1009}$ Ibid, at [6.172]

${ }^{1010}$ Ibid, at [6.166].
} 
considerable economic or practical importance." ${ }^{1011}$ However, the Panel noted that not every use of a work that is covered by the scope of exclusive rights and involves commercial gain necessarily conflicts with a normal exploitation of the work. Otherwise: ${ }^{1012}$

..hardly any exception or limitation could pass the test of the second condition and Article 13 might be left devoid of meaning, because normal exploitation would be equated with full use of exclusive rights.

The uses which would conflict with a normal exploitation of the work are those which enter into economic competition with the ways right holders normally extract economic value from that right to the work, "depriving them of significant or tangible commercial gains."1013

Scholars have criticised the Panel's approach to this test on the basis that it is purely economic and subordinates policy concerns, which means it could restrict traditional allowable free uses. ${ }^{1014}$ For example, an exception for educational purposes could conflict with a normal exploitation of the work if a market develops for the licensing of those uses. ${ }^{1015}$ However, as other commentators have argued, ${ }^{1016}$ the case before the Panel concerned an economic matter, and it is thus conceivable that in a dispute involving issues of copyright policy (for instance, whether the exception furthered creative activities), the Panel would more closely examine (and articulate) the normative element of "normal exploitation" in order to determine if the right holder should be allowed to control the market for the particular use in question.

Applying the empirical test to Jamaica, while derivative works may compete in the same market as the pre-existing works, they are part of longstanding industry practice and there is no evidence that these works displace original works from their market or negatively affect these rights holders' income streams. In relation to the normative question, the commercial use of the work to make derivative creations does not conflict with the normal exploitation as

\footnotetext{
${ }^{1011}$ Ibid, at [6.180].

1012 Ibid, at [6.182].

${ }^{1013}$ Ibid, at [6.183].

1014 Jo Oliver "Copyright in the WTO: The Panel Decision on the Three-Step Test" (2002) 25 Colum J L \& Arts 119 at 151.

1015 See Pamela Samuelson "The US Digital Agenda at WIPO” (1997) 37 Va J Int'l L 369 at $402-403$ and Neil Netanel "The Next Round: The Impact of the WIPO Copyright Treaty on TRIPS Dispute Settlement" (1997) 37 Va J Int'l L 441 at 486-487.

1016 Jane Ginsburg “Toward Supranational Copyright Law? The WTO Panel Decision and the 'Three-Step Test' for Copyright Exceptions" (The Center for Law and Economic Studies, Columbia Law School Working Paper No. 181, 2001) at 12-14.
} 
it is not likely to economically compete with the way rights holders' various modes of commercial exploitation (how they normally extract value from their work) or significantly compromise their ability to earn.

The final element of the art 13 test is that the exception must not "unreasonably prejudice" the "legitimate" "interests" of the rights holder. The terms "interests" can apply to legal or proprietary rights, potential detriment or advantage as well as "something that is of some importance" to the rights holder.1017 The Panel applied both legal positivist and normative perspectives to the term "legitimate." "Legitimate" thus applies to interests authorised or protected by law (positivist) as well as, from a normative perspective: ${ }^{1018}$

...the protection of interests that are justifiable in the light of the objectives that underlie the protection of exclusive rights.

While some level of prejudice is acceptable, prejudice becomes unreasonable if the exception "causes or has the potential to cause an unreasonable loss of income to the copyright owner." 1019 However, a system of compulsory licensing with equitable remuneration could alleviate the prejudice. ${ }^{1020}$

In the case of an exception for derivative works in Jamaica, the degree of prejudice to the rights holders' interests is not unreasonable ${ }^{1021}$ in light of the public policy objectives such an exception would achieve: the stimulation of music creation in the aid of cultural and socioeconomic development. ${ }^{1022}$ The revenue loss to authors is justified on the basis that derivative works have considerable value to the local music industry. Derivative works (such as remixes, sampling and riddims) have made a significant cultural contribution which is specific to Jamaica. ${ }^{1023}$ To offset any actual or potential revenue losses, the Copyright Act could provide for adequate compensation to rights holders whose works are used to create derivative works. The developmental concerns of arts 7 and 8 of TRIPS would require that

\footnotetext{
${ }^{1017}$ United States - Section 110(5) of the U.S. Copyright Act at [6.223].

1018 Ibid, at [6.224].

${ }^{1019}$ Ibid, at [6.229].

${ }^{1020}$ Ibid, at $\mathrm{n} 205$.

${ }^{1021}$ Ibid, at [6.225] (where the Panel said "not unreasonable" in art 13 connotes a slightly stricter threshold than "reasonable") and [6.229].

${ }^{1022}$ On the public interest justification's relevance to exceptions, see: Daniel Gervais "Making Copyright Whole: A Principled Approach to Copyright Exceptions and Limitations" (2008) 5 U Ottawa L \& Tech J 1 at 30 .

${ }^{1023}$ See Chapter 2.II.A.4(c).
} 
sufficient weight be attached to the public interests affected by the exception or limitation (interests which must be considered in both the second and third steps of the art 13 test).

There is precedent for such a culturally specific copyright exception in the Jamaican context: s 86 of the Copyright $\mathrm{Act}^{1024}$ is an example of compliance with the art 13 test. First, it is narrowly defined. Jamaican lawmakers' statements ${ }^{1025}$ show that the income stream intended to be affected by s 86 was from licensing the use of works in annual cultural events. As the size of this market is not substantial, income may not be sufficiently commercially significant to interfere with the rights holders' normal exploitation of the work (so as to fail the second step of art 13). Section 86(3) passes the third limb because the provision for equitable remuneration gives rights holders compensation, reducing income losses. The public interest factors of relevance are fair dealing, cultural dissemination and preservation, which are legitimate considerations, given arts 7 and 8 of TRIPS.

In summary, a derivative works exception would be permissible in Jamaica's circumstances, especially if a development-based approach were applied to art 13 in light of the interpretative guidance offered by arts 7 and $8 .{ }^{1026}$

\section{B Fair Dealing}

The Copyright Act gives copyright owners the exclusive right to engage in or license a wide range of restrictive acts. However, the Jamaican Government felt that there were "certain acts falling within that range, the doing of which it would not be appropriate, in certain circumstances, for the copyright owner to prevent." 1027 Accordingly, the Act permits various acts that would otherwise be an infringement of copyright. ${ }^{1028}$ These exceptions can be relied on as defences to alleged infringement of copyright. The rationale behind such statutory

\footnotetext{
${ }^{1024}$ Outlined in Chapter 2.I.C.

1025 See Hansard, 26 January 1993 (AJ Nicholson) and Ministry Paper No 5 of 1993 at 61.

${ }^{1026}$ See Chapter 4.III.B.2.

${ }^{1027}$ Ministry Paper No 5 of 1993 at 42.

${ }^{1028}$ Copyright Act ss 51-83.
} 
exceptions is to allow the use of copyright works in cases where access would support learning, innovation and knowledge sharing. ${ }^{1029}$

Sections 52 and 53 provide that fair dealing with a literary or musical work for the purposes of research or private study, criticism or review or reporting current events does not infringe copyright in the work. Section 116 allows fair dealing with a sound recording only for the purposes of criticism or review or reporting current events. Under the statutory heading of "General Exceptions", s 54 of the Copyright Act deals with fair dealing and was taken directly from the "fair use" provision in the US Copyright Act. ${ }^{1030}$ Section 54 states that:

For the purpose of determining whether an act done in relation to a work constitutes fair dealing, the court determining the question shall take account of all factors which appear to it to be relevant, including-

(a) the nature of the work in question;

(b) the extent and substantiality of that part of the work affected by the act in relation to the whole of the work;

(c) the purpose and character of the use; and

(d) the effect of the act upon the potential market for, or the commercial value of, the work.

As it is in the US context, in the Jamaican provision there appears to be no internal hierarchy among these four factors. ${ }^{1031}$ The statute does not articulate the weight to be assigned to each factor and the relationship between them. The statute also does not define terms such as "purpose and character", "extent and substantiality" and "potential market", nor spell out

\footnotetext{
${ }^{1029}$ See Abiola Inniss "Fair Usage in Caribbean Intellectual Property" (2011) Intellectual Property Watch: Inside Views <www.ip-watch.org>. On the value of fair dealing exceptions, see: Alexandra Sims "Abundant Pest or Endangered Species? The Future of Fair Dealing in Copyright Law" (2008) 14 New Zealand Business Law Quarterly 231.

${ }^{1030}$ The United States' Copyright Act 1976 (17 USC $\left.\S 107\right)$. This doctrine is said to originate from Folsom $v$ Marsh 9 F Cas 342 (CCD Mass, 1841) at 348 where Story J said that the courts should "look to the nature and objects of the selections made, the quantity and value of the materials used, and the degree in which the use may prejudice the sale, or diminish the profits, or supersede the objects, of the original work." But see: Ray Patterson "Folsom v Marsh and Its Legacy" (1998) 5 J Intell Prop L 431 at 431 criticising the reasoning in Folsom v Marsh and arguing that the case merely redefined infringement and actually expanded the copyright monopoly.

${ }^{1031}$ US case law also does not give a hierarchy, see, for example, the decision in American Geophysical Union $v$ Texaco Inc 60 F. 3d 913 (2d Cir. 1994). There is, however, dicta from the US Supreme Court that the fourth factor is most important: Harper \& Row Publishers $v$ Nation Enterprises 471 US 539 (1985) at 566. Nonetheless, in the interest of equity the statute gives the court power to emphasise different factors in each case.
} 
what other factors might be relevant. ${ }^{1032}$ Thus, the extent to which an act qualifies as fair dealing will be a question for the court to resolve on the facts of each case. ${ }^{1033}$

Section 54 was intended to give the court greater leeway in balancing the interests of rights holders and users in cases of alleged infringement. In this regard, there is a marked difference between the US fair use position (reflected in the Jamaican statute's fair dealing provision) and the traditional UK approach towards fair dealing; which is to codify the permitted acts in the copyright legislation. ${ }^{1034}$ This codification means that UK courts have less flexibility in permitting certain uses of their own volition. For instance, in the UK Court of Appeal case of Pro Sieben Media AG v Carlton UK Television $L_{t} d^{1035}$ the court noted that although the permitted uses outlined in the Copyright Act were designed to deal with specific circumstances where public policy grounds existed for restricting copyright owners' rights, the statute does not give courts the general authority to refuse to enforce copyright where, in the court's opinion, such refusal would be fair and reasonable: ${ }^{1036}$

Instead, Chapter III of the [Copyright] Act consists of a collection of provisions which define with extraordinary precision and rigidity the ambit of various exceptions to copyright protection...it is the legislature which has specified where and the extent to which the public policy overrides the copyright.

Under s 54, a Jamaican court, unlike its UK counterpart, can take into account public policy factors in deciding whether a third party's use of a copyright work qualifies as fair dealing. In this regard, the position in Jamaica is more closely aligned to Canada. ${ }^{1037}$ Because the list of ${ }^{1032}$ Michael Madison "Fair Use and Social Practices" in Peter Yu (ed) Intellectual Property and Information
Wealth: Issues and Practices in the Digital Age - Volume One (Praeger, Connecticut, 2007) 177 at 181.
${ }^{1033}$ See Harper \& Row Publishers v Nation Enterprises 471 US 539 (1985) at 552. See generally: Sony
Corporation of America v Universal City Studios Inc 464 US 417 (1984) in which the court ruled that
videotaping television programmes for subsequent viewing was "fair use".
${ }^{1034}$ See Geoff McLay "Being Fair to Users: The Welcome Arrival of a New, More Liberal Approach to Fair
Dealing" (1999) 2 NZ Intell Prop J 135 at 135 (commenting on the distinction between New Zealand's
narrowly drawn exceptions and the flexibility of the fair use doctrine in the US).
${ }^{1035}$ Pro Sieben Media AG $v$ Carlton UK Television Ltd \& Twenty Twenty Television Limited [1999] 1 WLR 605.
The alleged infringement concerned the defendants including in their programme a 30-second extract from a
German Television programme which was originally broadcast by Pro Sieben. The defendants relied on the fair
dealing provision of s 30 of the UK CDPA (for criticism or review and current events reporting).
1036 Ibid, at 607-608 (per Robert Walker LJ).
1037 See: CCH Canadian Ltd $v$ Law Society of Upper Canada [2004] 1 SCR 339 at [48] and [53] (in which the
court incorporated the US fair use doctrine and observed that fair dealing is a user's right which must not be
interpreted restrictively, given its public policy purpose of balancing copyright owners' rights and users"
interests). See also: Society of Composers, Authors and Music Publishers of Canada v Bell Canada 2012 SCC
36 at [11] (concerning fair dealing in relation to song previews streamed online) and Giuseppina D'Agostino 
permitted uses is not closed, the court can potentially apply the principles in s 54 to authorise a myriad of uses.

The advantage of s 54 is that the fair use principles it incorporates "[permit] courts to avoid rigid application of the copyright statute when, on occasion, it would stifle the very creativity which that law is designed to foster." ${ }^{1038}$ The objective of this provision is thus to make certain rights holders do not unduly prevent downstream creation of new works, while ensuring that their exclusive rights are not unreasonably prejudiced or their financial incentives for creation diminished. In this way the fair use provision acts as a counterbalance to the limited monopoly rights conferred on copyright holders. ${ }^{1039}$ This is significant for a developing country like Jamaica in which the public's access to copyrighted materials has cultural and socio-economic importance.

However, because the US' fair use approach leaves the fairness of a particular use open to judicial interpretation, a major disadvantage which commentators have identified is that openness can lead to uncertainty for prospective users as to what uses are fair and permissible. ${ }^{1040}$ Indeed, US courts have observed that the fair use doctrine is "so flexible as virtually to defy definition."1041 Risk-averse users, wishing to avoid lawsuits, may be reluctant to make use of works that could expose them to liability for copyright infringement. ${ }^{1042}$ At the same time, the statutory vagueness of the fair use provision enables

\footnotetext{
"Healing Fair Dealing? A Comparative Copyright Analysis of Canada's Fair Dealing to UK Fair Dealing and US Fair Use" (2008) 53 McGill LJ 309 at 324-325.

1038 Stewart $v$ Abend 495 US 207 (1990) at 236. See also: Campbell v Acuff-Rose Music Inc 510 US 569 (1994) at 579, (a case involving 2 Live Crew's commercial rap parody of Roy Orbison's rock ballad "Oh Pretty Woman") in which the US Supreme Court noted that fair use guarantees "breathing space within the confines of copyright."

1039 Lydia Loren "Redefining the Market Failure Approach to Fair Use in an Era of Copyright Permission Systems" (1997) 5 J Intell Prop L 1 at 5.

${ }^{1040}$ See, for example, Susy Frankel Intellectual Property in New Zealand (2nd ed, LexisNexis, Wellington) at 338 and Gideon Parchomovsky and Kevin Goldman "Fair Use Harbors" (2007) 93 Va L Rev 1483 at 1485 1486. See also: Graeme Austin "Four Questions about the Australian Approach to Fair Dealing Defenses to Copyright Infringement" (2010) 57 J Copyright Soc'y USA 611 at 628 noting that uncertainty can also occur with fair dealing cases as "definitional issues can creep into the analysis as courts struggle to determine whether defendants' uses fall within the particular categories." But see: Barton Beebe "An Empirical Study of the US Copyright Fair Use Opinions 1978-2005" (2008) 156 U Pa L Rev 549 at 622 and Pamela Samuelson "Unbundling Fair Use" (2009) 77 Fordham L Rev 2537 at 2541-2542 identifying patterns in the US which show some level of predictability in the outcome of fair use cases.

${ }^{1041}$ Princeton University Press v Michigan Document Services Inc 99 F 3d 1381 (6th Circuit 1996) at 1392 citing Time Inc v Bernard Geis Associates 293 F Supp 130 (SDNY 1968) at 144.

1042 See Thomas Cotter "Fair Use and Copyright Overenforcement" (2008) 93 Iowa L Rev 1271 at 1289 and Christopher Newman "Transformation in Property and Copyright" (2011) 56 Villanova L Rev 251 at 253.
} 
authors in the United States to go beyond the scope of their rights in requiring licences for uses that properly fall within the category of fair use.

Some Jamaican music industry stakeholders maintained that more well-defined parameters governing acceptable uses were needed, particularly given the dearth of local case law on s 54. For instance, a public library representative argued that the statute's fair dealing provision was too broad: ${ }^{1043}$

One of the weaknesses in the Copyright Act [is] that...when they talk about [fair dealing], we would really like some more precise guidelines...We need a quantity, something quantifiable.

Setting out clear statutory guidelines would give greater clarity about whether users can lawfully use copyright works without rights holders' permission and royalties. This certainty could be obtained without needing to pursue a court determination on the issue.

On the other hand, a JIPO official and a copyright lawyer argued that it would be impractical for the legislation to be more precise:

Persons, I know, would want some specific determination: "I can photocopy 22 pages out of the 62 page book or I cannot." We wouldn't be able to determine [that] because...you might copy 22 pages and it has no economic impact on the creator because the most important page was at page 23 or the number of 23 pages... ${ }^{1044}$

As with everything, things depend on a case by case basis. You can't say "well if this man uses 10.3 seconds of this [song] and if it's this part of the chord then it's fair [dealing]." No. I think the Act is quite correct in the way it is: to leave it to the court to decide based on all the material factors and circumstances whether this is something which really qualifies as fair [dealing]. ${ }^{1045}$

It would be unreasonable to detail fair dealing down to the minutiae. Whether copying amounts to infringement necessarily involves a qualitative judgment about the use of the work as a whole and not a purely quantitative assessment. However, while the principles stated in s 54 are clear, their practical implications appear less so. It is therefore recommended that the legislators examine whether room exists for amending the law to offer greater clarity without unduly compromising the flexibility of s 54's broad fair dealing defence. The statute could give more guidance to users who would not need to resort to court

\footnotetext{
${ }^{1043}$ R-52.

${ }^{1044} \mathrm{R}-32$.

1045 R-1.
} 
proceedings to determine whether their use of the work is acceptable. A properly calibrated framework for copyright exceptions/permitted acts should protect rights holders while assisting in cultural development. Fostering the public's use of copyright works allows people to participate in the life of the community, enlarging their capabilities, thus enabling society to benefit from copyright works that derive from its culture.

\section{Chapter Summary}

In this Chapter I analysed the applicability of the Jamaican copyright law to the local music industry by looking at some industry-specific/cultural factors that have shaped the landscape of music-making in Jamaica. I also proposed reforming the law in relation to derivative works and fair dealing, as both areas directly relate to the research question; that is, the relationship between copyright protection of the music industry and development. Suggested changes were measured against international obligations using the development analysis from Chapter Four. 


\section{CHAPTER SIX}

\section{CONCLUSION}

The passage of this [copyright] legislation does not mean an end to a consideration of some of the difficult areas in which serious decisions are likely to arise in the future. ${ }^{1046}$

\section{The Issue}

Copyright law recognises and aims to protect the ability of rights holders to exercise control over the commercial exploitation of their creations. The property rights granted by copyright give copyright owners the ability to restrict others from dealing with their work in various ways - subject to certain statutory exceptions. The copyright regime thus establishes a framework in which individual rights holders can derive income. However, the concern is whether this system of exclusive property rights ownership enables a developing country to achieve developmental goals through the protection of its cultural products.

Given the local Reggae music industry's potential economic contribution and cultural significance, Jamaica has an interest in both the societal benefits and earnings to be derived from increased music production. According to copyright theory, one way to incentivise this creation is by protecting copyright. At the same time however, copyright protection must be balanced with the needs of the public in gaining access to and making use of copyrighted material. Balancing the protection of copyright owners' rights with the public interests is thus a delicate exercise for the Government.

This thesis' concern was: how does the copyright regime's protection of the local Reggae music industry affect development in Jamaica? The main research questions were: did the Jamaican Copyright Act allow the industry to make a useful contribution to Jamaica's development? And, if not, could reforming the copyright statute solve this problem?

\footnotetext{
${ }^{1046}$ Hansard, 27 January 1993 (PJ Patterson, Prime Minister).
} 


\section{Summary of Thesis}

The thesis' analysis of the research questions began with Chapter Two's examination of the historical relationship between the Jamaican music industry and the copyright legislation, (including the social, political and cultural forces at work behind the enactment of the Copyright Act 1993). I argued that one of the Government's objectives was that the Copyright Act 1993 would contribute to national development by means of its protection of the music industry's cultural, commercial and economic value. Chapter Two also discussed the tensions between copyright norms and industry practices. I proposed that industry innovations such as riddims, versions/remixes and dub are one illustration of the complex relationship between Jamaica's music industry and its copyright regime. I showed that Jamaican creators have treated the copyright regime in contradictory ways: for instance, rights holders' non-enforcement of copyright legislation played a key role in the birth of the Jamaican music industry in the 1950s, but their insistence on greater copyright protection in the 1970s eventually led the Government to strengthen the copyright system.

Chapter Three looked at the alternative ways that copyright protection of the music industry can lead to economic development. Several limitations associated with reliance on collective management and individual income maximisation approaches were assessed as well as the possibility of an equitable resource distribution model. I made various recommendations for improving the copyright management framework, including: adopting the European approach (which emphasises collecting societies' socio-cultural role) and greater Government supervision and control of collective management organisations.

In light of the multiple meanings of "development", Chapter Four considered whether a concept of development existed that could be harmonised with the theoretical justifications for copyright protection. I argued that a human development approach to copyright is supported by the traditional rationales for copyright, as well as in Berne, TRIPS, the WIPO Development Agenda and the international IP acquis. A development-based interpretation of TRIPS is particularly important because TRIPS shapes the extent to which the Jamaican Government can enact domestic laws to advance development while complying with its international obligations. I concluded that copyright lawmaking for the purposes of human development was a valid objective for the domestic copyright regime and gave examples 
from Jamaican copyright policy and bilateral agreements in which a human development approach to copyright could be discerned.

Chapter Five outlined structural features of the Jamaican music industry, some of which are at odds with the protection of copyright, and identified two important areas for law reform, namely, copyright exceptions to allow the production of derivative works and introduction of more comprehensive fair dealing guidelines. I used the development-based approach to TRIPS (which was explained in Chapter Four) to evaluate whether an exception to allow derivative works would be TRIPS-compliant.

The discussion in the previous Chapters highlights two main points. First, in Jamaica a mix of historical events, political forces, and socio-cultural and economic factors as well as institutional structures, has influenced the copyright system's effectiveness in achieving national development by means of the local music industry. These agents affect the way rights holders, users and policymakers perceive, value and use the copyright infrastructure as well as the weight they attach to adherence to copyright norms. In order to create more effective copyright law, policymakers should therefore have regard to the existing challenges stakeholders are encountering with copyright in the music industry.

The second point is related to the traditional views that responsibility for realising the economic benefit of copyright ultimately rests on rights holders themselves, and that copyright protection incentivises creative output, investment and stimulates the growth of industries. My thematic analysis of interviews with stakeholders indicates that these notions do not necessarily apply to Jamaica, a small developing country in which rights holders are neither very organised nor creative industries mature or cohesive. The Jamaican music industry (having grown largely without Government assistance) is highly fragmented and individualised in nature. Therefore, at this stage of the industry's development, maximising the economic returns for rights holders and widening access for users and follow-on innovators will require more than updating the copyright legislation to comply with international standards in treaties like TRIPS.

To be more effective as a development tool, the Jamaican copyright regime should be buttressed by other mechanisms: namely, greater Government intervention (for instance, statutory extension of the powers of the Copyright Tribunal, imposing minimum local content 
requirements on broadcasters, increasing the resource capabilities of regulatory agencies such as JIPO, and offering rights holders incentive programmes such as publicly-funded loans). ${ }^{1047}$ Without structured governmental efforts to put these types of frameworks in place, the developmental potential of the copyright regime as far as the Jamaican music industry is concerned will be limited.

\section{Contribution to Scholarship and Areas for Further Research}

This thesis makes a contribution to the literature in two ways. First, through the use of firsthand accounts in interviews, secondary material and archival research at the Parliament library, this study adds to the body of Jamaican copyright legal studies by more fully documenting the background of (and local and international forces behind) the Jamaican Copyright Act 1993.

Second, although an extensive body of literature exists, ${ }^{1048}$ scholars have noted that the precise manner in which law impacts on development remains uncertain. Commentators have concluded that: ${ }^{1049}$

...the next research frontier is likely to entail a much more labor-intensive and contextsensitive analysis of particular legal regimes and institutions (both formal and informal) in particular societies and potential reforms thereto evaluated against some set of broad or more generalizable development goals.

In light of this, this thesis provides Jamaican policymakers and legislators with a fuller picture about the developmental impact of copyright protection in an industry of national importance, specifically in regard to current practices of collective and individual rights management within the music industry. While copyright might not be a panacea for lack of development, understanding the practical implications of domestic copyright law is valuable. No previous study has fully examined the developmental effects of the copyright system as it

\footnotetext{
1047 See Chapter 3.

1048 See generally: David Trubek and Alvaro Santos (eds) The New Law and Economic Development: A Critical Appraisal (Cambridge University Press, New York, 2006) and "Symposium: The Future of Law and Development, Part 1" (2009) 104 Northwestern Univ L Rev Colloquy 164-173 and Brian Tamanaha "The Primacy of Society and the Failures of Law and Development" (St. John's Univ. Legal Studies Research Paper Series, Paper No. 09-0172, 2009).

${ }^{1049}$ Kevin Davis and Michael Trebilcock “The Relationship between Law and Development: Optimists versus Skeptics" (2008) 56 Am J Comp L 895 at 946.
} 
relates to the local music industry. ${ }^{1050}$ Future researchers may wish to explore whether variations exist in the way the copyright law affects other local copyright-based industries (such as fashion, art, literature and drama).

During the course of the research, issues arose that related to other aspects of copyright. These issues were not analysed as part of this thesis because they were tangential to the core research question. They included: the merits of a system of domaine public payant ${ }^{1051}$ for the protection of traditional cultural expressions, parallel importation of copyright materials ${ }^{1052}$ and the international exhaustion of rights, extension of the duration of copyright protection in literary and musical works as well as in sound recordings and performances ${ }^{1053}$ and proposals for strengthening domestic civil and criminal enforcement mechanisms and border measures. Given their importance, these areas are worthy of further analysis.

In summary, by offering an illustration from the Jamaican context, this thesis may prove to be a useful resource for other small developing countries (especially those in the Caribbean region) seeking to assess the copyright regime's contribution to indigenous industries and national development.

\footnotetext{
${ }^{1050}$ In studies on the music industry that do mention copyright, this is often deal with as an adjunct or cursorily: see, for example, Hilary Brown "National Strategy \& Action Plan to further develop the Jamaican Music Industry" prepared for the Ministry of Education Youth \& Culture, Jamaica, and the Global Alliance Programme, UNESCO 2004 at 12.

${ }^{1051}$ Domaine public payant is a legislative scheme in which fees are levied by the State for the economic exploitation of works in the public domain. See: Carlos Mouchet "Problems of the "Domaine Public Payant"" (1983-1984) 8 Columbia Journal of Art and the Law 137; Delia Lipszyc and Carlos Villalba "Preserving and Accessing Our Cultural Heritage: Argentina's Experience through the Domaine Public Payant" in Estelle Derclaye (ed) Copyright and Cultural Heritage: Preservation and Access to Works in a Digital World (Edward Elgar, Cheltenham, 2010) 179 and Cathryn Berryman "Toward More Universal Protection of Intangible Cultural Property" (1993-1994) 1 J Intell Prop L 293 at 307-309.

1052 Parallel importation refers to the purchase of genuine/non-counterfeit/non-pirated copyright goods in a foreign market (source country) by a third party at a relatively lower price; and their subsequent re-sale in the domestic market (destination country) without the authorisation of domestic rights owners. See: Frederick Abbott "Parallel Importation: Economic and Social Welfare Dimensions" (Swiss Agency for Development and Cooperation Report, June 2007) and Alexander Pope "Note: A Second Look at First Sale: An International Look at U.S. Copyright Exhaustion" (2011) 19 J Intell Prop L 201.

${ }^{1053}$ See Tyler Ochoa "Copyright Duration: Theories and Practice" in in Peter Yu (ed) Intellectual Property and Information Wealth: Issues and Practices in the Digital Age - Volume One (Praeger, Connecticut, 2007$) 133$.
} 


\section{APPENDIX}

Table of Interviewees

\begin{tabular}{|c|c|c|c|c|}
\hline Number & Name & Organisation and Title & $\begin{array}{l}\text { Category of } \\
\text { Stakeholder }\end{array}$ & $\begin{array}{c}\text { Date of } \\
\text { Interview }\end{array}$ \\
\hline $\mathrm{R}-1$ & - & $\begin{array}{l}\text { Attorney-at-Law and Partner } \\
\text { in an IP firm }\end{array}$ & Legal & 29 May 2011 \\
\hline 2 & Andrea Davis & $\begin{array}{l}\text { Creative industries brand } \\
\text { consultant, publicist and } \\
\text { researcher, former policy } \\
\text { writer (drafter of National } \\
\text { Entertainment Policy), } \\
\text { organiser of annual } \\
\text { International Reggae Day, } \\
\text { member of the Copyright } \\
\text { Tribunal, talent agent and } \\
\text { manager of Reggae group, } \\
\text { Toots \& The Maytals }\end{array}$ & Industry and policy & 21 April 2011 \\
\hline $\mathrm{R}-3$ & - & $\begin{array}{l}\text { Record producer and radio } \\
\text { disc jockey }\end{array}$ & $\begin{array}{l}\text { Rights holder and } \\
\text { commercial user }\end{array}$ & 12 April 2011 \\
\hline R-4 & - & $\begin{array}{l}\text { Record producer, music } \\
\text { publisher and studio operator }\end{array}$ & Rights holder & 4 May 2011 \\
\hline $\mathrm{R}-5$ & - & $\begin{array}{l}\text { Singer, songwriter, producer, } \\
\text { musician }\end{array}$ & Rights holder & 26 May 2011 \\
\hline R-6 & - & $\begin{array}{l}\text { Representative from Jamaica } \\
\text { Copyright Licensing Agency } \\
\text { (JAMCOPY), a reproduction } \\
\text { rights organisation } \\
\text { representing music composers, } \\
\text { songwriters and publishers }\end{array}$ & $\begin{array}{l}\text { Collective } \\
\text { administration }\end{array}$ & 5 May 2011 \\
\hline $\mathrm{R}-7$ & - & $\begin{array}{l}\text { Jamaica Intellectual Property } \\
\text { Office (JIPO) Senior } \\
\text { Representative }\end{array}$ & Policy & 4 May 2011 \\
\hline $\mathrm{R}-8$ & - & $\begin{array}{l}\text { Attorney-at-Law and music } \\
\text { entrepreneur }\end{array}$ & Legal and industry & 24 May 2011 \\
\hline R-9 & - & $\begin{array}{l}\text { Broadcaster, producer, artiste } \\
\text { manager, audio-visual content } \\
\text { creator for television, former } \\
\text { member of Entertainment } \\
\text { Advisory Board to the } \\
\text { Government }\end{array}$ & Industry and policy & $\begin{array}{l}17 \text { March } \\
2011\end{array}$ \\
\hline
\end{tabular}




\begin{tabular}{|c|c|c|c|c|}
\hline Number & Name & Organisation and Title & $\begin{array}{l}\text { Category of } \\
\text { Stakeholder }\end{array}$ & $\begin{array}{c}\text { Date of } \\
\text { Interview }\end{array}$ \\
\hline $\mathrm{R}-10$ & - & $\begin{array}{l}\text { Representative of the } \\
\text { Broadcasting Commission of } \\
\text { Jamaica }\end{array}$ & Regulator & 13 May 2011 \\
\hline $\mathrm{R}-11$ & - & Member of the public & User & 22 May 2011 \\
\hline $\mathrm{R}-12$ & - & $\begin{array}{l}\text { Saxophonist, producer, } \\
\text { arranger, band leader and } \\
\text { songwriter }\end{array}$ & Rights holder & 8 April 2011 \\
\hline 13 & $\begin{array}{l}\text { Dr. Dennis } \\
\text { Howard }\end{array}$ & $\begin{array}{l}\text { Musicologist, University of the } \\
\text { West Indies (UWI) Cultural } \\
\text { Studies lecturer, member of } \\
\text { the media (music journalist } \\
\text { and former editor of Reggae } \\
\text { Times magazine), musicology } \\
\text { researcher, copyright owner }\end{array}$ & $\begin{array}{l}\text { Academic, Media, } \\
\text { Rights holder }\end{array}$ & $\begin{array}{l}8 \text { April and } \\
12 \text { April } 2011\end{array}$ \\
\hline $\mathrm{R}-14$ & - & $\begin{array}{l}\text { Partner in an IP law firm, UWI } \\
\text { Copyright law lecturer, Board } \\
\text { member of a private copyright } \\
\text { registration company } \\
\text { (Intellectual Property Service } \\
\text { Centre), former Legal Officer } \\
\text { with the Copyright Unit } \\
\text { (JIPO's predecessor), } \\
\text { songwriter and musician }\end{array}$ & $\begin{array}{l}\text { Legal, Academic, } \\
\text { Policy and Rights } \\
\text { holder }\end{array}$ & 8 April 2011 \\
\hline $\mathrm{R}-15$ & - & $\begin{array}{l}\text { Attorney-at-Law and drafter of } \\
\text { the Copyright Act } 1993\end{array}$ & Legal and Policy & $\begin{array}{l}30 \text { March } \\
2011\end{array}$ \\
\hline R-16 & - & $\begin{array}{l}\text { Cultural Studies researcher of } \\
\text { Jamaican music, lecturer at the } \\
\text { Institute of Caribbean Studies } \\
\text { (UWI) }\end{array}$ & Academic & $\begin{array}{l}30 \text { March } \\
2011\end{array}$ \\
\hline 17 & $\begin{array}{l}\text { Dr. Michael } \\
\text { Witter }\end{array}$ & Economist, UWI Lecturer & Economist & 24 May 2011 \\
\hline 18 & $\begin{array}{l}\text { Dr. Sonjah } \\
\text { Stanley-Niaah }\end{array}$ & $\begin{array}{l}\text { Cultural Studies Lecturer, } \\
\text { UWI }\end{array}$ & Academic & 11 May 2011 \\
\hline R-19 & - & $\begin{array}{l}\text { User who observed } \\
\text { commercial sale of bootleg } \\
\text { DVDs by his business partner }\end{array}$ & User & 11 May 2011 \\
\hline $\mathrm{R}-20$ & - & $\begin{array}{l}\text { Attorney-at-Law, musician } \\
\text { (band leader, arranger), artiste } \\
\text { manager, producer, musical } \\
\text { director with a LLM in IP } \\
\text { (University of Turin), lecturer }\end{array}$ & $\begin{array}{l}\text { Legal, Rights } \\
\text { holder and } \\
\text { Academic }\end{array}$ & 20 May 2011 \\
\hline
\end{tabular}




\begin{tabular}{|c|c|c|c|c|}
\hline Number & Name & Organisation and Title & $\begin{array}{l}\text { Category of } \\
\text { Stakeholder }\end{array}$ & $\begin{array}{c}\text { Date of } \\
\text { Interview }\end{array}$ \\
\hline $\mathrm{R}-21$ & - & Tertiary Institution librarian & Librarian & 26 May 2011 \\
\hline $\mathrm{R}-22$ & - & $\begin{array}{l}\text { Musician, band manager, } \\
\text { producer, representative of the } \\
\text { Recording Industry } \\
\text { Association of Jamaica } \\
\text { (RIAJAM) and the Jamaica } \\
\text { Association of Vintage } \\
\text { Artistes and Affiliates (JAVA) }\end{array}$ & $\begin{array}{l}\text { Rights holder and } \\
\text { Industry } \\
\text { Associations }\end{array}$ & 4 April 2011 \\
\hline $\mathrm{R}-23$ & - & $\begin{array}{l}\text { Purchaser of bootleg DVDs } \\
\text { and CDs }\end{array}$ & User & 29 May 2011 \\
\hline $\mathrm{R}-24$ & - & Purchaser of bootleg DVDs & User & 29 May 2011 \\
\hline $\mathrm{R}-25 \mathrm{~A}$ & - & $\begin{array}{l}\text { Member of the Creative } \\
\text { Industries and Film } \\
\text { Commission at the Jamaica } \\
\text { Promotions Corporation } \\
\text { (JAMPRO/formerly Jamaica } \\
\text { Trade and Invest) }\end{array}$ & Policy & 12 May 2011 \\
\hline $\mathrm{R}-25 \mathrm{~B}$ & - & $\begin{array}{l}\text { Member of the Film } \\
\text { Commission-JAMPRO }\end{array}$ & Policy & 12 May 2011 \\
\hline $\mathrm{R}-26$ & - & $\begin{array}{l}\text { Member of the public who } \\
\text { downloads copyright material } \\
\text { from the internet }\end{array}$ & User & 23 May 2011 \\
\hline $\mathrm{R}-27$ & - & $\begin{array}{l}\text { Musician, Lecturer at the } \\
\text { School of Music, Edna } \\
\text { Manley College for the } \\
\text { Visual and Performing Arts, } \\
\text { former Research Fellow for } \\
\text { Reggae Studies(UWI), } \\
\text { executive member of the } \\
\text { Jamaica Reggae Industry } \\
\text { Association (JARIA) and } \\
\text { Member of the } \\
\text { Entertainment Board } \\
\text { advising the Government }\end{array}$ & $\begin{array}{l}\text { Rights holder, } \\
\text { Academic, } \\
\text { Industry } \\
\text { Association and } \\
\text { Policymaker }\end{array}$ & $\begin{array}{l}16 \text { March } \\
2011\end{array}$ \\
\hline $\mathrm{R}-28$ & - & $\begin{array}{l}\text { Representative from the } \\
\text { Jamaica Association of } \\
\text { Composers, Authors and } \\
\text { Publishers, (JACAP) }\end{array}$ & $\begin{array}{l}\text { Collective } \\
\text { Administration }\end{array}$ & $\begin{array}{l}7 \text { March } \\
2011\end{array}$ \\
\hline $\mathrm{R}-29$ & - & $\begin{array}{l}\text { Representative from } \\
\text { Jamaica Music Society } \\
\text { Limited (JAMMS) which }\end{array}$ & $\begin{array}{l}\text { Collective } \\
\text { Administration }\end{array}$ & $\begin{array}{l}10 \text { March } \\
2011\end{array}$ \\
\hline
\end{tabular}




\begin{tabular}{|c|c|c|c|c|}
\hline Number & Name & Organisation and Title & $\begin{array}{l}\text { Category of } \\
\text { Stakeholder }\end{array}$ & $\begin{array}{c}\text { Date of } \\
\text { Interview }\end{array}$ \\
\hline & & $\begin{array}{l}\text { represents record producers' } \\
\text { rights in sound recordings } \\
\text { and performers' rights }\end{array}$ & & \\
\hline $\mathrm{R}-30$ & - & $\begin{array}{l}\text { Musician, singer, songwriter } \\
\text { and representative from the } \\
\text { Jamaica Federation of } \\
\text { Musicians (JFM) }\end{array}$ & $\begin{array}{l}\text { Rights holder and } \\
\text { Industry } \\
\text { Association }\end{array}$ & 6 April 2011 \\
\hline $\mathrm{R}-31$ & - & JIPO Legal Representative & Legal and Policy & $\begin{array}{l}25 \text { March } \\
\text { and } 6 \text { April } \\
2011\end{array}$ \\
\hline $\mathrm{R}-32$ & - & $\begin{array}{l}\text { JIPO Copyright } \\
\text { Management Representative }\end{array}$ & Policy & $\begin{array}{l}18 \text { March } \\
2011\end{array}$ \\
\hline 33 & Joan Webley & $\begin{array}{l}\text { Entertainment Lawyer, } \\
\text { Media Entrepreneur, } \\
\text { Activist, Board member of } \\
\text { Jamaica Reggae Industry } \\
\text { Association (JARIA), } \\
\text { member of Visual and } \\
\text { Performing Arts Jamaica, } \\
\text { Board member- Creative } \\
\text { production and Training } \\
\text { Centre }\end{array}$ & $\begin{array}{l}\text { Legal and } \\
\text { Industry } \\
\text { Association }\end{array}$ & 4 April 2011 \\
\hline $\mathrm{R}-34$ & - & $\begin{array}{l}\text { Judge of the Supreme Court } \\
\text { of Judicature of Jamaica }\end{array}$ & Judiciary & $\begin{array}{l}9 \text { March } \\
2011\end{array}$ \\
\hline $\mathrm{R}-35$ & - & $\begin{array}{l}\text { Criminal Prosecutor/ Clerk } \\
\text { of the Court at the } \\
\text { Corporate Area Resident } \\
\text { Magistrate's Court }\end{array}$ & Enforcement & $\begin{array}{l}15 \text { April } \\
2011\end{array}$ \\
\hline R-36 & - & $\begin{array}{l}\text { Reggae Singer/Recording } \\
\text { Artiste }\end{array}$ & Rights holder & $\begin{array}{l}\text { 11 March } \\
2011\end{array}$ \\
\hline $\mathrm{R}-37 \mathrm{~A}$ & - & $\begin{array}{l}\text { Reggae Singer/Recording } \\
\text { Artiste }\end{array}$ & Rights holder & $\begin{array}{l}\text { 11 March } \\
2011\end{array}$ \\
\hline $\mathrm{R}-37 \mathrm{~B}$ & - & $\begin{array}{l}\text { Publicist and Public } \\
\text { Relations manager }\end{array}$ & Industry & $\begin{array}{l}\text { 11 March } \\
2011\end{array}$ \\
\hline R-38 & - & $\begin{array}{l}\text { Senior official, Foreign } \\
\text { Trade in the Ministry of } \\
\text { Foreign Affairs and Foreign }\end{array}$ & Foreign Trade & $\begin{array}{l}\text { 13 May } \\
2011\end{array}$ \\
\hline
\end{tabular}




\begin{tabular}{|c|c|c|c|c|}
\hline Number & Name & Organisation and Title & $\begin{array}{l}\text { Category of } \\
\text { Stakeholder }\end{array}$ & $\begin{array}{c}\text { Date of } \\
\text { Interview }\end{array}$ \\
\hline & & Trade & & \\
\hline $\mathrm{R}-39$ & - & $\begin{array}{l}\text { Seller, renter of original } \\
\text { DVDs and music CDs }\end{array}$ & Retailer & $\begin{array}{l}11 \text { May } \\
2011\end{array}$ \\
\hline $\mathrm{R}-40$ & - & $\begin{array}{l}\text { Reggae singer/Recording } \\
\text { Artiste and Record Producer }\end{array}$ & Rights holder & $\begin{array}{l}23 \text { May } \\
2011\end{array}$ \\
\hline 41 & $\begin{array}{l}\text { Natalie } \\
\text { Corthésy }\end{array}$ & $\begin{array}{l}\text { Lecturer in the Faculty of } \\
\text { Law, UWI, founder of the } \\
\text { Jamaica Anti-piracy } \\
\text { Alliance (JAPA), former } \\
\text { Copyright Manager in the } \\
\text { Copyright Unit, former } \\
\text { Director of Entertainment } \\
\text { Policy and Convenor of the } \\
\text { Entertainment Advisor } \\
\text { Board in the Ministry of } \\
\text { Tourism }\end{array}$ & $\begin{array}{l}\text { Academic, } \\
\text { Industry } \\
\text { Association and } \\
\text { former } \\
\text { policymaker }\end{array}$ & $\begin{array}{l}14 \text { April } \\
2011\end{array}$ \\
\hline $\mathrm{R}-42 \mathrm{~A}$ & - & $\begin{array}{l}\text { Inspector in the IP Unit of } \\
\text { the Organised Crime } \\
\text { Investigation Division } \\
\text { (OCID) of the Jamaica } \\
\text { Constabulary Force }\end{array}$ & Police & $\begin{array}{l}21 \text { March } \\
2011\end{array}$ \\
\hline $\mathrm{R}-42 \mathrm{~B}$ & - & Detective Corporal, OCID & Police & $\begin{array}{l}21 \text { March } \\
2011\end{array}$ \\
\hline $\mathrm{R}-43$ & - & $\begin{array}{l}\text { Representative from the } \\
\text { Contraband Enforcement } \\
\text { Team, Border Protection, } \\
\text { Jamaica Customs }\end{array}$ & Customs & $\begin{array}{l}26 \text { April } \\
2011\end{array}$ \\
\hline $\mathrm{R}-44$ & - & $\begin{array}{l}\text { Attorney-at-Law, partner in } \\
\text { law firm and UWI } \\
\text { Copyright law lecturer }\end{array}$ & $\begin{array}{l}\text { Legal and } \\
\text { Academic }\end{array}$ & 5 May 2011 \\
\hline 45 & $\begin{array}{l}\text { Professor } \\
\text { Carolyn } \\
\text { Cooper }\end{array}$ & $\begin{array}{l}\text { Founder of Global Reggae } \\
\text { Studies Centre, Professor in } \\
\text { the Reggae Studies Unit, } \\
\text { UWI }\end{array}$ & Academic & $\begin{array}{l}13 \text { April } \\
2011\end{array}$ \\
\hline $\mathrm{R}-46$ & - & $\begin{array}{l}\text { Entertainment Attorney, } \\
\text { Partner in law firm, former } \\
\text { artiste manager, event } \\
\text { promoter and music video }\end{array}$ & $\begin{array}{l}\text { Legal and } \\
\text { Industry }\end{array}$ & $\begin{array}{l}20 \text { May } \\
2011\end{array}$ \\
\hline
\end{tabular}




\begin{tabular}{|c|c|c|c|c|}
\hline Number & Name & Organisation and Title & $\begin{array}{l}\text { Category of } \\
\text { Stakeholder }\end{array}$ & $\begin{array}{l}\text { Date of } \\
\text { Interview }\end{array}$ \\
\hline & & director & & \\
\hline $\mathrm{R}-47 \mathrm{~A}$ & - & IP Associate in law firm & Legal & $\begin{array}{l}\text { 3 March } \\
2011\end{array}$ \\
\hline $\mathrm{R}-47 \mathrm{~B}$ & - & IP Partner in law firm & Legal & $\begin{array}{l}3 \text { March } \\
2011\end{array}$ \\
\hline $\mathrm{R}-48$ & - & $\begin{array}{l}\text { Representative from the } \\
\text { Attorney- General's } \\
\text { Chambers }\end{array}$ & Legal & $\begin{array}{l}18 \text { May } \\
2011\end{array}$ \\
\hline $\mathrm{R}-49 \mathrm{~A}$ & - & $\begin{array}{l}\text { Musician, songwriter, } \\
\text { founding board member of } \\
\text { JACAP and the the Music } \\
\text { Copyright Society for } \\
\text { songwriters and music } \\
\text { publishers }\end{array}$ & $\begin{array}{l}\text { Rights holder and } \\
\text { Industry }\end{array}$ & $\begin{array}{l}15 \text { March } \\
2011\end{array}$ \\
\hline $\mathrm{R}-49 \mathrm{~B}$ & - & $\begin{array}{l}\text { Songwriter, producer, artiste } \\
\text { manager, recording studio } \\
\text { owner, and industry liaison } \\
\text { with Government on policy }\end{array}$ & $\begin{array}{l}\text { Rights holder and } \\
\text { Industry }\end{array}$ & $\begin{array}{l}\text { 15 March } \\
2011\end{array}$ \\
\hline R-50 & - & $\begin{array}{l}\text { Senior culture and } \\
\text { entertainment representative } \\
\text { in the Ministry of Youth, } \\
\text { Sports and Culture }\end{array}$ & Policy & $\begin{array}{l}28 \text { April } \\
2011\end{array}$ \\
\hline R-51 & - & $\begin{array}{l}\text { Member of the Department } \\
\text { of Culture and } \\
\text { Entertainment in the } \\
\text { Ministry of Youth, Sports } \\
\text { and Culture, author and } \\
\text { journalist }\end{array}$ & $\begin{array}{l}\text { Policy, Rights } \\
\text { holder and Media }\end{array}$ & $\begin{array}{l}16 \text { May } \\
2011\end{array}$ \\
\hline R-52 & - & $\begin{array}{l}\text { Public Library } \\
\text { representative and } \\
\text { Board Member- Intellectual } \\
\text { Property Service Centre }\end{array}$ & Librarian & 4 May 2011 \\
\hline
\end{tabular}


Note:

Five of the 52 interviews involved interviewing two interviewees simultaneously. This was at the request of interviewees in circumstances where they either: both held senior positions within the same organisation (Respondents 42A and 42B); or had similar expertise or shared areas of specialisation in the same organisation (Respondents $25 \mathrm{~A}$ and 25B, 47A and 47B); or worked closely together in a professional capacity (Respondents 37A, 37B, 49A and 49B). 


\section{BIBLIOGRAPHY}

\section{BOOKS}

Adeney, Elizabeth The Moral Rights of Authors and Performers: An International and Comparative Analysis (Oxford University Press, New York, 2006)

Alston, Philip and Robinson, Mary (eds) Human Rights and Development: Towards Mutual Reinforcement (Oxford University Press, New York, 2005)

Ayogu, Melvin and Ross, Don (eds) Development Dilemmas: The Methods and Political Ethics of Growth Policy (Routledge, Oxfordshire and New York, 2005)

Baldacchino, Godfrey and Greenwood, Robert (ed) Competing Strategies of Socio-Economic Development for Small Islands (Island Studies Press, University of Prince Edward Island, Canada, 1998)

Bently, Lionel and Sherman, Brad Intellectual Property Law (3rd ed, Oxford University Press, New York, 2008)

Blair, Roger and Cotter, Thomas Intellectual Property: Economic and Legal Dimensions of Rights and Remedies (Cambridge University Press, New York, 2005)

Bradley, Lloyd Reggae: The Story of Jamaican Music (BBC publications, London, 2002)

Braithwaite, John Regulatory Capitalism: How it Works, Ideas for Making it Work Better (Edward Elgar, Cheltenham, 2008)

Chang, Ha-Joon Kicking Away the Ladder: Development Strategy in Historical Perspective (Anthem Press, London, 2002)

Cooper, Carolyn Sound Clash: Jamaican Dancehall Culture at Large (Palgrave Macmillan, New York, 2004)

Correa, Carlos Intellectual Property Rights, the WTO and Developing Countries: The TRIPS Agreement and Policy Options (Zed Books, London, 2000)

Correa, Carlos Trade Related Aspects of Intellectual Property Rights: A Commentary on the TRIPS Agreement (Oxford University Press, New York, 2007)

Creswell, John Research Design: Qualitative, Quantitative and Mixed Methods Approaches (2nd ed, Sage, Thousand Oaks, 2003)

Crotty, Michael The Foundations of Social Research (Allen \& Unwin, Australia, 1998) 
Crump, Andy The A to $Z$ of World Development (Wayne Ellwood ed., New Internationalist, Oxford, 1998)

Daley, Dianne Jamaica (Blanpain, Roger and Colucci, Michele (eds) Kluwer Law International: International Encyclopaedia of Laws (Intellectual Property-Supplement 47, Wolters Kluwer, Eastbourne, 2008)

D'Amato, Anthony and Long Doris Estelle International Intellectual Property Law (Kluwer Law International, London, 1997)

Dinwoodie, Graeme and Dreyfuss, Rochelle A Neofederalist Vision of TRIPS: The Resilience of the International Intellectual Property Regime (Oxford University Press, New York, 2012)

Emmerij, Louis (ed) Economic and Social Development into the XXI Century (InterAmerican Development Bank, Washington DC, 1997)

Ficsor, Mihàly Collective Management of Copyright and Related Rights (WIPO Pub, Geneva, 2002)

Foehr, Stephen Waking up in Jamaica (Sanctuary, London, 2002)

Frankel, Susy Intellectual Property in New Zealand (2nd ed, LexisNexis, Wellington 2011)

Garnett, Kevin, Davies, Gillian and Harbottle, Gwilym Copinger and Skone James on Copyright (15th ed, Sweet \& Maxwell, London, 2005)

Gervais, Daniel The TRIPS Agreement: Drafting History and Analysis (Sweet \& Maxwell, London, 1998)

Gervais, Daniel The TRIPS Agreement: Drafting History and Analysis (2nd ed, Sweet \& Maxwell, London, 2003)

Gervais, Daniel The TRIPS Agreement: Drafting History and Analysis (3rd ed, Sweet \& Maxwell, London, 2008)

Goldstein, Paul International Copyright: Principles, Law and Practice (Oxford University Press, New York, 2001)

Goldstein, Paul Copyright: Principles, Law and Practice (Little Brown, Boston, 1989) vol 1

Gooden, Lou Reggae Heritage (Olivier Printery, Kingston, 2003)

Gooden, Lou Dancehall Sound Systems: The Good, The Bad and The Ugliest (manuscript, 2011, forthcoming book)

Gosseries, Axel, Marciano, Alain and Strowel, Alain (eds) Intellectual Property and Theories of Justice (Palgrave Macmillan, Hampshire and New York, 2008) 
Goulet, Denis The Cruel Choice: A New Concept on the Theory of Development (Atheneum, New York, 1971)

Hebdige, Dick Cut N Mix: Culture, Identity and Caribbean Music (Routledge, London, 1987)

Helfer, Laurence and Austin, Graeme Human Rights and Intellectual Property: Mapping the Global Interface (Cambridge University Press, New York, 2011)

Hope, Donna Inna di Dancehall: Popular Culture and the Politics of Identity in Jamaica (University of the West Indies Press, Kingston, 2006)

Idris, Kamil Intellectual Property: A Power Tool for Economic Growth (2nd ed, World Intellectual Property Organization Publication No 888, Geneva, 2003)

Kant, Immanuel The Metaphysics of Morals (Mary Gregor ed., Cambridge University Press, Cambridge, 1996)

Kelsen, Hans Pure Theory of Law (2nd ed, Max Knight trans., University of California Press, Berkeley and Los Angeles, 1967

Locke, John Two Treatises of Government (1698) (Peter Laslett ed., Cambridge University Press, Cambridge, 1988)

Matthews, Duncan Globalising Intellectual Property Rights- The TRIPS Agreement (Routledge, London and New York, 2002)

Mavrotas, George and Shorrocks, Anthony (eds) Advancing Development: Core Themes in Global Economics (Palgrave Macmillian, New York, 2007)

May, Christopher The Global Political Economy of Intellectual Property Rights: The New Enclosures? (2nd ed, Routledge, London, 2010)

May, Christopher The World Intellectual Property Organization: Resurgence and the Development Agenda (Routledge, Abingdon (UK) 2006)

May, Christopher and Sell, Susan Intellectual Property Rights: A Critical History (Lynne Rienner Pub, Boulder (Colorado), 2005)

McNair, Arnold The Law of Treaties (2nd ed, Oxford University Press, Oxford, 1986)

Merges, Robert Justifying Intellectual Property (Harvard University Press, Cambridge, Mass., 2011)

Mertens, Donna Research Methods in Education and Psychology: Integrating Diversity with Quantitative and Qualitative Approaches (2nd ed, Sage, Thousand Oaks, 2005)

Mitchell, Andrew Legal Principles in WTO Disputes (Cambridge University Press, New York, 2008) 
Mock Yen, Alma Rewind: My Recollections of Radio and Broadcasting in Jamaica (Arawak Publications, Kingston, 2002)

O’Brien Chang, Kevin Jamaica Fi Real: Beauty, Vibes and Culture (Ian Randle Publishers, Kingston, 2010)

O'Brien Chang, Kevin and Chen, Wayne Reggae Routes: The Story of Jamaican Music (Temple University Press, Philadelphia, 1998)

Oman, Ralph Copyright - Engine of Development (UNESCO Publishing, Paris, 2000)

Oxford Advanced Learner's Dictionary (8th ed, Oxford University Press, USA, 2010)

Paine, Thomas "The Rights of Man: Being an Answer to Mr. Burke's Attack on the French Revolution" (3rd ed, I. Thomas and E.T. Andrews, Boston, 1791)

Patton, Michael How to Use Qualitative Methods in Evaluation (Sage, Newbury Park, 1987)

Pauwelyn, Joost Conflict of Norms in Public International Law: How WTO Law Relates to Other Rules of International Law (Cambridge University Press, Cambridge, 2003)

Pires de Carvalho, Nuno The TRIPS Regime of Patent Rights (2nd ed, Kluwer Law, The Hague, 2005)

Rubin, Herbert and Rubin, Irene Qualitative Interviewing: The Art of Hearing Data (Sage, Thousand Oaks, 1995)

Rhythms: Jamaica's Heritage in Music and Dance (Jamaica Information Service, Kingston)

Ricketson, Sam and Ginsburg, Jane International Copyright and Neighbouring Rights: The Berne Convention and Beyond (2nd ed, Oxford University Press, New York, 2006)

Salter, Michael and Mason, Julie Writing Law Dissertations: An Introduction and Guide to the Conduct of Legal Research (Pearson Education, England, 2007)

Sell, Susan Private Power, Public Law: The Globalization of Intellectual Property Rights (Cambridge University Press, Cambridge 2003)

Sen, Amartya Commodities and Capabilities (Elsevier Science Publishers, Oxford, 1985)

Sen, Amartya Development as Freedom (Oxford University Press, Oxford, 1999)

Sen, Amartya On Ethics and Economics (Blackwell, Oxford, 1987)

Seville, Catherine The Internationalisation of Copyright Law: Books, Buccaneers and the Black Flag in the Nineteenth Century (Cambridge University Press, New York, 2006)

Shaw, Malcolm International Law (4th ed, Cambridge University Press, Cambridge, 1997) 
Sinclair, Ian Vienna Convention on the Law of Treaties (2nd ed, Manchester University Press, Manchester, 1984)

Stanley-Niaah, Sonjah Dancehall: From Slave Ship to Ghetto (University of Ottawa Press, Ottawa, 2010

Stiglitz, Joseph and Charlton, Andrew Fair Trade for All: How Trade Can Promote Development (Oxford University Press, New York, 2005)

Stolzoff, Norman Wake the Town and Tell the People: Dancehall Culture in Jamaica (Duke University Press, Durham, 2000)

Thirlwall, Anthony Growth and Development: With Special Reference to Developing Economies (8th ed, Macmillan, London, 2006)

Todaro, Michael and Stephen Smith Economic Development (10th ed, Pearson/Addison Wesley, England, 2008)

Toynbee, Jason Bob Marley: Herald of a Postcolonial World? (Polity, Cambridge, 2007)

Toynbee, Jason Making Popular Music: Musicians, Creativity and Institutions (Arnold, London, 2000)

Trebilcock, Michael and Howse, Robert The Regulation of International Trade (3rd ed, Routledge, London, 2005)

UNCTAD/ICTSD Resource Book on TRIPS and Development (Cambridge University Press, New York, 2005)

Vaidhyanathan, Siva Copyrights and Copywrongs (New York University Press, New York and London, 2003)

von Lewinski, Silke International Copyright Law and Policy (Oxford University Press, Oxford, 2008)

Wengraf, Tom Qualitative Research Interviewing: Biographic Narratives and Semistructured Methods (Sage, Thousand Oaks, 2001)

Xiong, Ping An International Law Perspective on the Protection of Human Rights in the TRIPS Agreement - An Interpretation of the TRIPS Agreement in Relation to the Right to Health (Martinus Nijhoff Publishers, Leiden and Boston, 2012)

Yamane, Hiroko Interpreting TRIPS: Globalisation of Intellectual Property Rights and Access to Medicines (Hart Publishing, Oxford and Portland (Oregon), 2011)

Yin, Robert Case Study Research: Design and Methods (3rd ed, Sage, Thousand Oaks, 2003) Zemer, Lior The Idea of Authorship in Copyright (Ashgate, Hampshire, 2007) 


\section{JOURNAL ARTICLES AND ESSAYS IN EDITED TEXTS}

Abbott, Frederick "TRIPS and Human Rights: Preliminary Reflections" in Frederick Abbott, Christine Breining-Kaufmann and Thomas Cottier (eds) International Trade and Human Rights - Foundations and Conceptual Issues (University of Michigan Press, Ann Arbor, 2006) 145

Abbott, Maxwell “The Right to Development” (2011, Volume 4, UNDP News Brief)

Abramowicz, Michael “A Theory of Copyright's Derivative Right and Related Doctrines" (2005) 90 Minnesota L Rev 317

Alston, Philip "Ships Passing in the Night: The Current State of the Human Rights and Development Debate seen through the Lens of the Millennium Development Goals" (2005) 27 Human Rights Quarterly 755

Aoki, Keith "Distributive and Syncretic Motives in Intellectual Property Law (With Special Reference to Coercion, Agency, and Development)" (2007) 40 UC Davis L Rev 717

Arewa, Olufunmilayo "Copyright on Catfish Row: Musical Borrowing, Porgy and Bess and Unfair Use” (2006) 37 Rutgers LJ 277

Arewa, Olufunmilayo "Freedom to Copy: Copyright, Creation and Context" (2007) 41 UC Davis L Rev 477

Arewa, Olufunmilayo "From JC Bach to Hip Hop: Musical Borrowing, Copyright and Cultural Context" (2006) 84 NC L Rev 547

Austin, Graeme "Four Questions about the Australian Approach to Fair Dealing Defenses to Copyright Infringement” (2010) 57 J Copyright Soc'y USA 611

Baker, Maureen "La(w)- A Note to Follow So: Have We Forgotten the Federal Rules of Evidence in Music Plagiarism Cases?" (1991-1992) 65 Southern California L Rev 1583

Baldwin, John and Davis, Gwynn "Empirical Research in Law" in Peter Cane and Mark Tushnet (eds) The Oxford Handbook of Legal Studies (Oxford University Press, New York, 2003) 880

Bannerman, Sara "The WIPO Development Agenda Forum and Its Prospects for Taking into Account Different Levels of Development" in Jeremy de Beer (ed) Implementing the WIPO Development Agenda (Wilfrid Laurier University Press, Ottawa, 2009) 24

Barnes, David "Congestible Intellectual Property and Impure Public Goods" (2011) 9 NW J Tech \& Intell Prop 533

Barnes, David “The Incentives/Access Tradeoff” (2010) 9 NW J Tech \& Intell Prop 96

Barron, Anne "Copyright Infringement, 'Free-riding' and the Lifeworld" in Lionel Bently, Jennifer Davis and Jane Ginsburg (eds) Copyright and Piracy: An Interdisciplinary Critique (Cambridge University Press, New York, 2010) 93 
Beebe, Barton "An Empirical Study of the US Copyright Fair Use Opinions 1978-2005" (2008) 156 U Pa L Rev 549

Benabou, Valérie-Laure and Dusollier, Séverine "Draw me a Public Domain" in Paul Torremans (ed) Copyright Law: A Handbook of Contemporary Research (Edward Elgar, Cheltenham, 2007) 161

Berryman, Cathryn "Toward More Universal Protection of Intangible Cultural Property" (1993-1994) 1 J Intell Prop L 293

Besen, Stanley, Kirby, Sheila and Salop, Steven "An Economic Analysis of Copyright Collectives" (1992) 78 Virginia L Rev 383

Bhagwati, Jagdish "Afterword: A Question of Linkage - Symposium: The Boundaries of the WTO” (2002) 96 AJIL 126

Biadgleng, Ermias Tekeste "The Development-balance of the TRIPS Agreement and Enforcement of Intellectual Property Rights" in Justin Malbon and Charles Lawson (eds) Interpreting and Implementing the TRIPS Agreement: Is it Fair? (Edward Elgar, Cheltenham, UK and Northampton, Mass., 2008) 97

Blouin, Chantal, Chopra, Mickey and van der Hoeven, Ralph "Trade and Social Determinants of Health" (2009) The Lancet 502

Boldrin, Michele and Levine, David "The Economics of Ideas and Intellectual Property" (2005) 102 Proceedings of the National Academy of Sciences 1252

Borges Barbosa, Denis, Chon, Margaret and Moncayo von Hase, Andres "Slouching Towards Development in International Intellectual Property" (2007) 2007 Michigan State L Rev 71

Bortloff, Nils "Collective Management of Rights in Musical, Literary and Dramatic Works in Europe" (1997) 6 German American LJ 67

Boyle, James "The Second Enclosure Movement and the Construction of the Public Domain" (2003) 66 Law \& Contemp Probs 33

Bradshaw, A "Sense and Sensibility: Debates and Developments in Socio-legal Research Methods" in Philip Thomas (ed) Socio-legal Studies (Dartmouth Publishing, Aldershot, 1997) 99

Brannon, Pamela "Reforming Copyright to Foster Innovation: Providing Access to Orphaned Works" (2006-2007) 14 J Intell Prop L 145

Broussard, Whitney "The Promise and Peril of Collective Licensing" (2009) 17 J Intell Prop L 21

Brown, Jeffrey “Comments: 'They Don't Make Music The Way They Used To': The Legal Implications of 'Sampling' in Contemporary Music" (1992) 1992 Wis L Rev 1941 
Calandrillo, Steve "An Economic Analysis of Intellectual Property Rights: Justifications and Problems of Exclusive Rights, Incentives to Generate Information, and the Alternative of a Government-run Reward System” (1998) 9 Fordham Intell Prop Media \& Ent LJ 301

Campbell, Howard "Chris Blackwell and the Internationalisation of Reggae" (2010) 33 Jamaica Journal 36

Castanaro, Valeria "'It's the Same Old Song': The Failure of the Originality Requirement in Musical Copyright” (2008) 18 Fordham Intell Prop Media \& Ent L J 1271

Chamberlain, Joshua "So Special, So Special, So Special: The Evolution of the Jamaican 'Dubplate"” (2010) 33 Jamaica Journal 20

Chang, Ha-Joon "Intellectual Property Rights and Economic Development: Historical Lessons and Emerging Issues" (2001) 2 Journal of Human Development 287

Chon, Margaret "Copyright and Capability for Education: An Approach from 'Below"' in Tzen Wong and Graham Dutfield (eds) Intellectual Property and Human Development: Current Trends and Future Scenarios (Cambridge University Press, New York, 2011) at ch 6

Chon, Margaret "Intellectual Property and the Development Divide" (2006) 27 Cardozo L Rev 2821

Chon, Margaret "Substantive Equality in International Intellectual Property Norm Setting and Interpretation" in Daniel Gervais (ed) Intellectual Property, Trade and Development: Strategies to Optimize Development in a TRIPS-Plus Era (Oxford University Press, New York, 2007) 475

Cohen, Julie "Creativity and Culture in Copyright Theory" (2007) 40 UC Davis L Rev 1151

Coombe, Rosemary "Fear, Hope, and Longing for the Future of Authorship and a Revitalized Public Domain in Global Regimes of Intellectual Property" (2003) 52 DePaul L Rev 1171

Corbett, Susan "Creative Commons Licences, the Copyright Regime and the Online Community: Is there a Fatal Disconnect?” (2011) 74 Modern L Rev 503

Corbett, Susan "Going Grey: the Copyright Debate” [2004] NZ LJ 386-387, 390

Corbridge, Stuart "Development, Post-development and the Global Political-economy" in Paul Cloke, Philip Crang and Mark Goodwin (eds) Introducing Human Geographies (Hodder Arnold, London, 1999) 67

Correa, Carlos "Can the TRIPS Agreement foster Technology Transfers to Developing Countries?" in Keith Maskus and Jerome Reichman (eds) International Public Goods and Transfer of Technology Under a Globalised Intellectual Property Regime (Cambridge University Press, Cambridge, 2005) 227

Correa, Carlos "Pro-Competitive Measures under the TRIPS Agreement to Promote Technology Diffusion in Developing Countries" (2001) 4 Journal of World Intellectual Property 481 
Correa Pereira, Karina "Collective Management of Copyright in Latin America" in Daniel Gervais (ed) Collective Management of Copyrights and Related Rights (Kluwer, Netherlands, 2006) 421

Corthésy, Natalie "Copyright Ownership of Employee Works in Jamaica" (2009) 34 West Indian L J 181

Cotter, Thomas "Fair Use and Copyright Overenforcement" (2008) 93 Iowa L Rev 1271

Cottier, Thomas "From Progressive Liberalization to Progressive Regulation in WTO Law" (2006) 9 J Int'1 Econ L 779

Cullet, Philippe "Patents and Medicines: The Relationship between TRIPS and the Human Right to Health" (2003) 79 International Affairs 139

Cvetkovski, Trajce “The Great Rock n' Roll Firesale: The Politics of Popular Music Production and Consumption" (paper published in Vol 6(1) Dialogue E-Journal, University of Queensland, 2008)

D'Agostino, Giuseppina "Healing Fair Dealing? A Comparative Copyright Analysis of Canada's Fair Dealing to UK Fair Dealing and US Fair Use" (2008) 53 McGill LJ 309

Daley, Dianne and Foga, Nicole "Jamaica: Progress Despite Challenges" in Managing IP magazine (IP Focus, Americas, 4th ed, 2008) 43

Daley, Dianne and Foga, Nicole "Jamaica- Significant IP progress...on the horizon" in IP Value 2006: Building and Enforcing Intellectual Property Value (Global White Page, 2006) 150

Daley, Dianne and Foga, Nicole "Jamaica: Tapping Into the Value of Intellectual Property" in IP Value: Building and Enforcing Intellectual Property Value 2009 (Global White Page, 2009) 91

Di Giovanni, Adrian "Introduction to the Human Rights and Development Panel" (presented to the Canadian Council on International Law 40th Annual Conference, Ottawa, 5 November 2011)

Davies, Margaret "Towards the Common Law? The Limits of Law and the Problem of Translation" (1993) 2 Asia Pac L Rev 65

de Beer, Jeremy "Defining WIPO's Development Agenda" in Jeremy de Beer (ed) Implementing the WIPO Development Agenda (Wilfrid Laurier University Press, Ottawa, 2009) 1

Deere, Carolyn "Reforming Governance to Advance the WIPO Development Agenda" in Jeremy de Beer (ed) Implementing the WIPO Development Agenda (Wilfrid Laurier University Press, Ottawa, 2009) 43

Denzin, Norman and Lincoln, Yvonna "The Discipline and Practice of Qualitative Research" in Norman Denzin and Yvonna Lincoln (eds) Handbook of Qualitative Research (3rd ed, Sage, Thousand Oaks, 2005) 
Dietz, Adolf "Legal Regulation of Collective Management of Copyright (Collecting Societies Law) in Western and Eastern Europe" (2002) 49 J Copyright Soc'y USA 897

Dinwoodie, Graeme "Remarks: 'One Size Fits All' Consolidation and Difference in Intellectual Property Law" in Annette Kur and Vytautas Mizaras (eds) The Structure of Intellectual Property Law: Can One Size Fit All? (Edward Elgar, Cheltenham, UK and Northampton, Mass., 2011) 3

Dinwoodie, Graeme "The Development and Incorporation of International Norms in the Formation of Copyright Law" (2001) 62 Ohio State LJ 733

Dinwoodie, Graeme and Dreyfuss, Rochelle "TRIPS and the Dynamics of International Property Lawmaking” (2004) 36 Case W Res J Int'l L 95

Dougherty, Meghan "Voluntary Collective Licensing: The Solution to the Music Industry's File Sharing Crisis?” (2006) 13 J Intell Prop L 405

Drahos, Peter "Introduction" in Peter Drahos and Ruth Mayne (eds) Global Intellectual Property Rights: Knowledge, Access and Development (Palgrave Macmillan, Hampshire and New York, 2002)

Dreyfuss, Rochelle and Lowenfeld, Andreas "Two Achievements of the Uruguay Round: Putting TRIPS and Dispute Settlement Together” (1997) 37 Virginia J Int'1 L 275

Duncanson, Ian "Writing and Praxis: Law, History and the Postcolonial" (2003) 7 Law Text Culture 9

Dutfield, Graham "Knowledge Diplomacy and the New Intellectual Property Fundamentalism" in Justin Malbon and Charles Lawson (eds) Interpreting and Implementing the TRIPS Agreement: Is it Fair? (Edward Elgar, Cheltenham, UK and Northampton, Mass., 2008) 31

Ehlermann, Claus-Dieter and Ehring, Lothar "The Authoritative Interpretation Under Article IX(2) of the Agreement Establishing the World Trade Organization: Current Law, Practice and Possible Improvements" (2005) 8 Journal of Int'1 Econ L 803

Elliott, Jennifer "Development and Social Welfare/Human Rights" in Vandana Desai and Robert Potter (eds) The Companion to Development Studies (2nd ed, Hodder Education, London, 2008) 40

Fink, Carsten and Primo Braga, Carlos "How Stronger Protection of Intellectual Property Rights Affects International Trade Flows" in Carsten Fink and Keith Maskus (eds) Intellectual Property and Development: Lessons from Recent Economic Research (World Bank and Oxford University Press, New York, 2005) 19

Fischman Afori, Orit "Copyright Infringement Without Copying - Reflections on the Thebérge case" (2007-2008) 39 Ottawa L Rev 23

Fisher, William "Theories of Intellectual Property" in Stephen Munzer (ed) New Essays in the Legal and Political Theory of Property (Cambridge University Press, Cambridge, 2001) 168 
Forsythe, Dennis "West Indian Culture through the Prism of Rastafarianism" (1980) 26 Caribbean Quarterly 62

Frankel, Susy “The WTO's Application of 'the Customary Rules of Interpretation of Public International Law' to Intellectual Property” (2005) 46 Va J Int'l L 365

Frischmann, Brett and Lemley, Mark “Spillovers" (2007) 107 Columbia Law Review 257

Gathii, James "The Legal Status of the Doha Declaration on TRIPS and Public Health Under the Vienna Convention on the Law of Treaties" (2002) 15 Harvard Journal of Law \&Technology 291

Gervais, Daniel "A Uniquely Canadian Institution: The Copyright Board of Canada" in Ysolde Gendreau (ed) An Emerging Intellectual Property Paradigm: Perspectives from Canada (Edward Elgar, Cheltenham, UK, 2008) 197

Gervais, Daniel "Feist Goes Global: A Comparative Analysis of the Notion of Originality in Copyright Law” (2002) 49 J. Copyright Soc’y U.S.A. 949

Gervais, Daniel "Introduction" in Daniel Gervais (ed) Collective Management of Copyrights and Related Rights (Kluwer, Netherlands, 2006) at xix

Gervais, Daniel "Intellectual Property, Trade \& Development: The State of Play" (2005) 74 Fordham L Rev 505

Gervais, Daniel "Making Copyright Whole: A Principled Approach to Copyright Exceptions and Limitations" (2008) 5 U Ottawa L \& Tech J 1

Gervais, Daniel "(Re)implementing the Agreement on Trade-Related Aspects of Intellectual Property Rights to Foster Innovation" (2009) 12 The Journal of World IP 348

Gervais, Daniel "The Landscape of Collective Management Schemes" (2011) 34 Columbia Journal of Law \& the Arts 423

Gervais, Daniel "TRIPS and Development" in Daniel Gervais (ed) Intellectual Property, Trade and Development: Strategies to Optimize Economic Development in a TRIPS-Plus Era (Oxford University Press, New York, 2007) 4

Ginsburg, Jane "A Tale of Two Copyrights: Literary Property in Revolutionary France and America” (1989-1990) 64 Tul L Rev 991

Ginsburg, Jane "A Tale of Two Copyrights: Literary Property in Revolutionary France and America" in Brad Sherman and Alain Strowel (eds) Of Authors and Origins: Essays on Copyright Law (Clarendon Press, Oxford, 1994) 131

Ginsburg, Jane "'Une Chose Publique'? The Author's Domain and the Public Domain in Early British, French and US Copyright Law" in Paul Torremans (ed) Copyright Law: A Handbook of Contemporary Research (Edward Elgar, Cheltenham, 2007) 133

Goffe, Marcus "Protecting the Traditions of the Maroons and Rastafari: An Analysis of the Adequacy of the Intellectual Property Laws of Jamaica and Proposals for Reform" (2009) 6 SCRIPTed 575 
Gold, E. Richard and Morin, Jean-Frederic "From Agenda to Implementation: Working Outside the WIPO Box" in Jeremy de Beer (ed) Implementing the WIPO Development Agenda (Wilfrid Laurier University Press, Ottawa, 2009)

Gonzalez, Carmen "Markets, Monocultures, and Malnutrition: Agricultural Trade Policy through an Environmental Justice Lens” (2006) 14 Michigan St J Int'l L 345

Gopakumar KM "Product Patents and Access to Medicines in India: A Critical Review of the Implementation of TRIPS Patent Regime" (2010) 3 L \& Dev Rev 325

Gordon, Wendy "A Property Right in Self-Expression: Equality and Individualism in the Natural Law of Intellectual Property” (1993) 102 Yale LJ 1533

Gordon, Wendy "Intellectual Property" in Peter Can and Mark Tushnet (eds) The Oxford Handbook of Legal Studies (Oxford University Press, New York, 2003) 617

Greenberg, Brad "More Than Just a Formality: Instant Authorship and Copyright's Opt-Out Future in the Digital Age" (2012) 59 UCLA L Rev 1028

Gruszczynski, Lukasz "Customary Rules of Interpretation in the Practice of WTO Dispute Settlement Bodies" in Fauchald, Ole and Nollkaemper, Andre (eds) The Practice of International and National Courts and (De)Fragmentation of International Law (Hart Publishing, Oxford and Portland (Oregon), 2012) 35

Guibault, Lucie and van Gompel, Stef "Collective Management in the European Union" in Daniel Gervais (ed) Collective Management of Copyrights and Related Rights (Kluwer, Netherlands, 2006) 117

Gutowski, Robert "The Marriage of Intellectual Property and International Trade in the TRIPS Agreement: Strange Bedfellows or a Match made in Heaven?" (1999) 47 Buff L Rev 713

Handke, Christian and Towse, Ruth "Economics of Copyright Collecting Societies" (2007) 38 International Review of Intellectual Property and Competition Law 937

Hariani, Krishna and Hariani, Anirudh "Analyzing 'Originality' in Copyright Law: Transcending Jurisdictional Disparity” (2011) 51 IDEA 491

Harper, Emily "Music Mashups: Testing the Limits of Copyright Law as Remix Culture Takes Society By Storm” (2010) 39 Hofstra L Rev 405

Heald, Paul "Bestselling Musical Compositions (1913-32) and their Use in Cinema (19682007)" (2009) 6 Review of Economic Research on Copyright Issues 31

Heald, Paul "Misreading a Canonical Work: An Analysis of Mansfield's 1994 Study" (2003) 10 J Intell Prop L 309

Helfer, Laurence "Collective Management of Copyright and Human Rights: An Uneasy Alliance" in Daniel Gervais (ed) Collective Management of Copyrights and Related Rights (Kluwer, Netherlands, 2006) 85 
Helfer, Laurence "Regime Shifting: The TRIPS Agreement and the New Dynamics of International Intellectual Property Law-Making” (2004) 29 Yale J Int'1 L 1

Helfer, Laurence "World Music on a US Stage: An Analysis of the section 110(5) WTO Dispute" in Hugh Hansen (ed) International Intellectual Property Law \& Policy (vol 6, Juris Publishing, Huntington, 2001) [48-1]

Hettne, Björn "Current Trends and Future Options in Development Studies" in Vandana Desai and Robert B. Potter (eds) The Companion to Development Studies (2nd ed, Hodder Education, London, 2008) 8

Hope, Donna "Dancehall: Origins, History, Future" in Groundings (St. Michael's Theological College, Kingston, July 2011) at 7

Howard, Dennis "Copyright and the Music Business in Jamaica- Protection for Whom?" (2009) IX Revista Brasileira do Caribe 503

Howard, Dennis "Punching for Recognition: The Juke Box as a Key Instrument in the Development of Popular Jamaican Music" (2007) 53 Caribbean Quarterly 32

Howse, Robert "From Politics to Technocracy - And Back Again: The Fate of the Multilateral Trading Regime” (2002) 96 Am J Int'1 L 94

Hughes, Justin “Philosophy of Intellectual Property” (1988) 77 Georgetown LJ 287

Hutton, Clinton "Forging Identity and Community through Aestheticism and Entertainment: The Sound System and the Rise of the DJ" (2007) 53 Caribbean Quarterly 16

Hutton, Clinton "The Creative Ethos of the African Diaspora: Performance Aesthetics and the Fight for Freedom and Identity" (2007) 53 Caribbean Quarterly 127

Hutton, Clinton "The Social and Aesthetic Roots and Identity of Ska: Interview with Garth White" (2007) 53 Caribbean Quarterly 81

Jaszi Peter "On the Author Effect: Contemporary Copyright and Collective Creativity" (1992) 10 Cardozo Arts \& Ent LJ 293

Jordana, Jacint and Levi-Faur, David "The Politics of Regulation in the Age of Governance" in Jacint Jordana and David Levi-Faur (eds) The Politics of Regulation: Institutions and Regulatory Reforms for the Age of Governance (Edward Elgar, Cheltenham, 2005) 1

Judge, Elizabeth and Gervais, Daniel "Of Silos and Constellations: Comparing Notions of Originality in Copyright Law” (2009) 27 Cardozo Arts \& Entertainment 375

Kamperman Sanders, Anselm "Intellectual Property Treaties and Development" in Daniel Gervais (ed) Intellectual Property, Trade and Development: Strategies to Optimize Development in a TRIPS-Plus Era (Oxford University Press, New York, 2007) 157

Karnell, Gunnar and von Lewinski, Silke "Collective Administration of Copyrights and Neighbouring Rights" in Gerhard Schricker (ed) International Encyclopedia of Comparative Law (Martinus Nijhoff Publishers, Lancaster, 2006) vol xiv: Copyright and Industrial Property at ch 6 
Kennedy, David "The 'Rule of Law,' Political Choices, and Development Common Sense" in David Trubek and Alvaro Santos (eds) The New Law and Economic Development: A Critical Appraisal (Cambridge University Press, New York, 2006) 95

Keyes, J Michael "Musical Musings: The Case for Rethinking Music Copyright Protection" (2004) 10 Mich Telecomm \& Tech L Rev 407

Kingston, William "An Agenda for Radical Intellectual Property Reform" in Keith Maskus and Jerome Reichman (eds) International Public Goods and Transfer of Technology Under a Globalized Intellectual Property Regime (Cambridge University Press, Cambridge, 2005) 653

Klabbers, Jan "International Legal Histories: The Declining Importance of Travaux Préparatoires in Treaty Interpretation?” (2003) 50 Netherlands Int'l L Rev 267

Koskinen-Olsson, Tarja "Collective Management in the Nordic Countries" in Daniel Gervais (ed) Collective Management of Copyrights and Related Rights (Kluwer, Netherlands, 2006) 257

Kravis, Randy "Does a Song by any Other Name still Sound as Sweet?: Digital Sampling and Its Copyright Implications" (1993-1994) 43 Am U L Rev 231

Kretschmer, Martin "The Failure of Property Rules in Collective Administration: Rethinking Copyright Societies as Regulatory Instruments" [2002] EIPR 126

Landes, William and Posner, Richard "An Economic Analysis of Copyright Law" (1989) 18 Journal of Legal Studies 325

Legall, Sharon “Justifying Intellectual Property Rights” (2002) 12 Caribbean L Rev 15

Lessig, Lawrence "Free(ing) Culture for Remix" (2004) 2004 Utah L Rev 961

Lewin, Olive "Traditional Music in Jamaica" (1983) 29 Caribbean Quarterly 32

Li, Lihong "Localizing WIPO's Legislative Assistance: Lessons from China's Experience with the TRIPS Agreement" in Jeremy de Beer (ed) Implementing the WIPO Development Agenda (Wilfrid Laurier University Press, Ottawa, 2009)

Lipszyc, Delia and Villalba, Carlos "Preserving and Accessing Our Cultural Heritage: Argentina's Experience through the Domaine Public Payant" in Estelle Derclaye (ed) Copyright and Cultural Heritage: Preservation and Access to Works in a Digital World (Edward Elgar, Cheltenham, 2010) 179

Litman, Jessica "Real Copyright Reform” (2010) 96 Iowa L Rev 1

Long, Andrew "Mashed Up Videos and Broken Down Copyright: Changing Copyright to Promote the First Amendment Values of Transformative Video" (2007) 60 Oklahoma L Rev 317

Loren, Lydia "Redefining the Market Failure Approach to Fair Use in an Era of Copyright Permission Systems" (1997) 5 J Intell Prop L 1 
Loren, Lydia "Understanding the Complexity of Music Copyrights in the United States" in Peter Yu (ed) Intellectual Property and Information Wealth: Issues and Practices in the Digital Age-Volume One (Praeger, Connecticut, 2007) vol 1 at 161

Mackenzie, Noella and Knipe, Sally "Research Dilemmas: Paradigms, Methods and Methodology" (2006) 16 Issues in Educational Research 193

Madison, Michael "Fair Use and Social Practices" in Peter Yu (ed) Intellectual Property and Information Wealth: Issues and Practices in the Digital Age - Volume One (Praeger, Connecticut, 2007) 177

Malbon, Justin "TRIPS-Plus Treaty Terms: Dealing with Coercion" in Justin Malbon and Charles Lawson (eds) Interpreting and Implementing the TRIPS Agreement: Is it Fair? (Edward Elgar, Cheltenham, UK and Northampton, Mass., 2008) 159

Manley, Michael "Overcoming Insularity in Jamaica" in Foreign Affairs (Council on Foreign Relations Inc., October 1970) <www.foreignaffairs.com>

Mansfield, Edwin "Intellectual Property Protection, Foreign Direct Investment, and Technology Transfer" (Int'l Fin Corp Discussion Paper No 19, 1994)

Manuel, Peter and Marshall, Wayne "The Riddim Method: Aesthetics, Practice, and Ownership in Jamaican Dancehall” (2006) 25 Popular Music 447

Maskus, Keith "Intellectual Property Rights and Economic Development" (2000) 32 Case W Res J Int'1 L 471

Maskus, Keith "The Role of Intellectual Property Rights in Encouraging Foreign Direct Investment and Technology Transfer" (1998) 9 Duke J Comp \& Intl L 109

Maskus, Keith "The Role of Intellectual Property Rights in Encouraging Foreign Direct Investment and Technology Transfer" in Carsten Fink and Keith Maskus (eds) Intellectual Property and Development: Lessons from Recent Economic Research (World Bank and Oxford University Press, New York, 2005) 41

McGrady, Benn “Fragmentation of International Law or 'Systemic Integration' of Treaty Regimes: EC - Biotech Products and the Proper Interpretation of Article 31(3)(c) of the Vienna Convention on the Law of Treaties" (2008) 42 Journal of World Trade 589

McInerney-Lankford, Siobhan "Human Rights and Development: A Comment on Challenges and Opportunities from a Legal Perspective" (2009) 1 Journal of Human Rights Practice 51

McLachlan, Campbell "The Principle of Systemic Integration and Article 31(3)(c) of the Vienna Convention” (2005) 54 Int'l \& Comp LQ 279

McLay, Geoff "Being Fair to Users: The Welcome Arrival of a New, More Liberal Approach to Fair Dealing" (1999) 2 NZ Intell Prop J 135

Meltzer, Joshua "Comment: Interpreting the WTO Agreements - A Commentary on Professor Pauwelyn's Approach” (2004) 25 Michigan J of Int'l L 917 
Mgbeoji, Ikechi "TRIPS and TRIPS-Plus Impacts in Africa" in Daniel Gervais (ed) Intellectual Property, Trade and Development: Strategies to Optimize Economic Development in a TRIPS-Plus Era (Oxford University Press, New York, 2007) 259

Miller, Jody and Glassner, Barry "The 'Inside' and the 'Outside': Finding Realities in Interviews" in David Silverman (ed) Qualitative Research: Theory, Method and Practice (2nd ed, Sage, Thousand Oaks, 2004) 125

Mouchet, Carlos "Problems of the 'Domaine Public Payant"' (1983-1984) 8 Columbia Journal of Art and the Law 137

Neely, Daniel "Calling All Singers, Musicians and Speechmakers: Mento Aesthetics and Jamaica’s Early Recording Industry” (2007) 53 Caribbean Quarterly 1

Netanel, Neil "Introduction: The WIPO Development Agenda and Its Development Policy Context" in Neil Netanel (ed) The Development Agenda: Global Intellectual Property and Developing Countries (Oxford University Press, New York, 2009)

Netanel, Neil "The Next Round: The Impact of the WIPO Copyright Treaty on TRIPS Dispute Settlement" (1997) 37 Va J Int'l L 441

Nettleford, Rex “The Arts and Post Colonial Certitude” (2007) 53 Caribbean Quarterly 1

Newman, Christopher "Transformation in Property and Copyright" (2011) 56 Villanova L Rev 251

Ochoa, Tyler "Copyright Duration: Theories and Practice" in Peter Yu (ed) Intellectual Property and Information Wealth: Issues and Practices in the Digital Age - Volume One (Praeger, Connecticut, 2007) 133

Oguamanam, Chidi "Agro-Biodiversity and Food Security: Biotechnology and Traditional Agricultural Practices at the Periphery of International Intellectual Property Regime Complex" (2007) Michigan State Law Review 215

Okediji, Ruth "Back to Bilateralism? Pendulum Swings in International Intellectual Property Protection" (2003-2004) 1 UOLTJ 125

Okediji, Ruth "Public Welfare and the Role of the WTO: Reconsidering the TRIPS Agreement” (2003) 17 Emory Int'1 L Rev 819

Okediji, Ruth "The International Relations of Intellectual Property: Narratives of Developing Country Participation in the Global Intellectual Property System" (2003) 7 Sing J Int'l \& Comp L 315.

Okpaluba, Johnson “"Free-riding on the Riddim?' Open source, Copyright law and Reggae music in Jamaica" in Lionel Bently, Jennifer Davis and Jane Ginsburg (eds) Copyright and Piracy: An Interdisciplinary Critique (Cambridge University Press, New York, 2010) 374

Oliver, Jo "Copyright in the WTO: The Panel Decision on the Three-Step Test" (2002) 25 Colum J L \& Arts 119

Ostergard Jr, Robert "Economic Growth and Intellectual Property Rights Protection: A 
Reassessment of the Conventional Wisdom" in Daniel Gervais (ed) Intellectual Property, Trade and Development: Strategies to Optimize Economic Development in a TRIPS-Plus Era (Oxford University Press, New York, 2007) 115

Outterson, Kevin "Should Access to Medicines and TRIPS Flexibilities Be Limited to Specific Diseases?” (2008)34 Am J Law \& Medicine 279

Parchomovsky, Gideon and Goldman, Kevin "Fair Use Harbors" (2007) 93 Va L Rev 1483

Patterson, Ray “Folsom v Marsh and Its Legacy” (1998) 5 J Intell Prop L 431

Pauwelyn, Joost “Reply to Joshua Meltzer” (2004) 25 Michigan J of Int'1 L 924

Pauwelyn, Joost "The Role of Public International Law in the WTO: How Far Can We Go?" (2001) 95 Am J Int'1 L 535

Piaskowski, Nathalie "Collective Management in France" in Daniel Gervais (ed) Collective Management of Copyrights and Related Rights (Kluwer, Netherlands, 2006) 153

Pope, Alexander "Note: A Second Look at First Sale: An International Look at U.S. Copyright Exhaustion" (2011) 19 J Intell Prop L 201

Pote, Michael "Mashed-Up in Between: The Delicate Balance of Artists' Interests Lost Amidst the War on Copyright" (2010) 88 NC L Rev 639

Power, Dominic and Hallencreutz, Daniel "Profiting from Creativity? The Music Industry in Stockholm, Sweden and Kingston, Jamaica" (2002) 34 Environment and Planning A 1833

Prior, Lindsay "Doing Things with Documents" in David Silverman (ed) Qualitative Research: Theory, Method and Practice (2nd ed, Sage, Thousand Oaks, 2004)

Radin, Margaret "Property and Personhood” (1982) 34 Stanford L Rev 957

Rajagopal, Balakrishnan "Counter-hegemonic International Law: rethinking human rights and development as a Third World strategy" (2006) 27 Third World Quarterly 767

Reichman, Jerome "Universal Minimum Standards of Intellectual Property Protection under the TRIPS Component of the WTO Agreement" (1995) 29 The International Lawyer 345

Reinbothe, Jorg "Collective Rights Management in Germany" in Daniel Gervais (ed) Collective Management of Copyrights and Related Rights (Kluwer, Netherlands, 2006) 193

Ricolfi, Marco "Individual and Collective Management of Copyright in a Digital Environment" in Paul Torremans (ed) Copyright Law: A Handbook of Contemporary Research (Edward Elgar, Cheltenham, 2007) 283

Ris, Martin "Treaty Interpretation and ICJ Recourse to Travaux Préparatoires: Towards a Proposed Amendment of Articles 31 and 32 of the Vienna Convention on the Law of Treaties" (1991) 14 Boston College Int'l \& Comp L Rev 111 
Robeyns, Ingrid "Capability Approach, a Theoretical Survey" (2005) 6 Journal of Human Development 93

Roffe, Pedro "Comment: Technology Transfer on the International Agenda" in Keith Maskus and Jerome Reichman (eds) International Public Goods and Transfer of Technology Under a Globalized Intellectual Property Regime (Cambridge University Press, Cambridge, 2005) 257

Ruse-Khan, Henning "The Concept of Sustainable Development in International IP LawNew Approaches from EU Economic Partnership Agreements?" in Annette Kur and Vytautas Mizaras (eds) The Structure of Intellectual Property Law: Can One Size Fit All? (Edward Elgar, Cheltenham and Northampton, Mass., 2011) 308

Ryan, Michael "Knowledge-Economy Elites, the International Law of Intellectual Property and Trade, and Economic Development" (2002) 10 Cardozo J Int'l \& Comp L 271

Samuelson, Pamela “The US Digital Agenda at WIPO” (1997) 37 Va J Int'l L 369

Samuelson, Pamela "Unbundling Fair Use" (2009) 77 Fordham L Rev 2537

Samuelson, Paul "The Pure Theory of Public Expenditure" (1954) 36 The Review of Economics and Statistics 387

Sanjek, David “'Don't Have to DJ No More': Sampling and the 'Autonomous' Creator" (1992) 10 Cardozo Arts \& Ent J 607

Sapsford, David "Smith, Ricardo and the World Marketplace, 1776 - 2007: Back to the Future?" in Vandana Desai and Robert B. Potter (eds) The Companion to Development Studies (2nd ed, Hodder Education, London, 2008) 75

Scotchmer, Suzanne "The Political Economy of Intellectual Property Treaties" (2004) 20 Journal of Law, Economics and Organizations 415

Semaj, Leachim "Rastafari: From Religion to Social Theory" (1980) 26 Caribbean Quarterly 22

Sen, Amartya "Capability and Well-being" in Martha Nussbaum and Amartya Sen (eds) The Quality of Life (Clarendon Press, Oxford, 1993) 30

Sen, Amartya "Human Rights and Capabilities" (2005) 6 Journal of Human Development 151

Shanker, Daya "The Vienna Convention on the Law of Treaties, the Dispute Settlement System of the WTO and the Doha Declaration on the TRIPs Agreement" (2002) 36 Journal of World Trade 721

Sherwood, Robert "Global Prospects for the Role of Intellectual Property in Technology Transfer" (2002) 42 IDEA 27 
Sherwood, Robert, Scartezini, Vanda and Siemsen, Peter Dirk "Promotion of Inventiveness in Developing Countries through a More Advanced Patent Administration" (1999) 39 IDEA 473

Simon, David "Neoliberalism, Structural Adjustment and Poverty Reduction Strategies" in Vandana Desai and Robert B. Potter (eds) The Companion to Development Studies (2nd ed, Hodder Education, London, 2008) 86

Sims, Alexandra "Arrangements and Originality in Copyright Law" (2007) 4 New Zealand Intellectual Property Journal 286

Sims, Alexandra "Abundant Pest or Endangered Species? The Future of Fair Dealing in Copyright Law” (2008) 14 New Zealand Business Law Quarterly 231

Smith, Richard, Correa, Carlos and Oh, Cecilia "Trade, TRIPS, and Pharmaceuticals" (2009) 373 The Lancet 684

Stake, Robert "Qualitative Case Studies" in Norman Denzin and Yvonna Lincoln (eds) Handbook of Qualitative Research (3rd ed, Sage, Thousand Oaks, 2005)

Stavenhagen, Rodolfo "Cultural Rights: A Social Science Perspective" in Halina Niec (ed) Cultural Rights and Wrongs (UNESCO Publishing, Paris, 1998) 1

Stiglitz, Joseph "Knowledge as a Global Public Good" in Inge Kaul, Isabelle Grunberg and Marc Stern (eds) Global Public Goods: International Cooperation in the $21^{\text {st }}$ Century (Oxford University Press, New York, 1999) 311

Straub, Peter "Farmers in the IP Wrench - How Patents on Gene-Modified Crops Violate the Right to Food in Developing Countries" (2006) 29 Hastings Int'l and Comparative L Rev 187

Sun, Haochen "Overcoming the Achilles Heel of Copyright Law" (2007) 5 NW J Tech \& Intell Prop 265

Sunder, Madhavi "Intellectual Property and Development as Freedom" in Neil Netanel (ed) The Development Agenda: Global Intellectual Property and Developing Countries (Oxford University Press, New York, 2009) 453

Sunder, Madhavi “IP3” (2006) 59 Stan L Rev 257

Suthersanen, Uma "Collectivism of Copyright: The Future of Rights Management in the European Union" in Eric Barendt and Alison Firth (eds) The Yearbook of Copyright and Media Law (Oxford University Press, Oxford, 2000) 15

Suthersanen, Uma "The Role and Structure of the United Kingdom Copyright Tribunal" in Ysolde Gendreau (ed) Institutions administratives du droit d'auteur/Copyright Administrative Institutions (Yvon Blais, Montreal, 2002) 481 
Tafari, I Jabulani "The Rastafari- Successors of Marcus Garvey" (1980) 26 Caribbean Quarterly 1

Thirlwall, Anthony "Development and Economic Growth" in Vandana Desai and Robert Potter (eds) The Companion to Development Studies (2nd ed, Hodder Education, London, 2008) 37

Towse, Ruth "The Singer or the Song? Developments in Performers' Rights from the Perspective of a Cultural Economist (2007) 3 Review of Law and Economics 745

Toynbee, Jason "Reggae Open Source: How the Absence of Copyright Enabled the Emergence of Popular Music in Jamaica" in Lionel Bently, Jennifer Davis and Jane Ginsburg (eds) Copyright and Piracy: An Interdisciplinary Critique (Cambridge University Press, New York, 2010) 357

van Gompel, Stef "Formalities in the digital era: An Obstacle or Opportunity?" in Lionel Bently, Uma Suthersanen and Paul Torremans (eds) Global Copyright: Three Hundred Years Since the Statute of Anne, from 1709 to Cyberspace (Edward Elgar, Cheltenham, 2010) 395

van Gompel, Stef "Les formalités sont mortes, vive les formalités! Copyright Formalities and the Reasons for their Decline in Nineteenth Century Europe" in Ronan Deazley, Martin Kretschmer and Lionel Bently (eds) Privilege and Property: Essays on the History of Copyright (Open Book Publishers, Cambridge, 2010) 157

VerSteeg, Russ “Rethinking Originality” (1993) 34 Wm \& Mary L Rev 801

von Lewinski, Silke "Copyright in Central and Eastern Europe: An Intellectual Property Metamorphosis" (1997) 8 Fordham Intell Prop Media \& Ent LJ 39

von Lewinski, Silke "Mandatory Collective Administration of Exclusive Rights- A Case Study on Its Compatibility with International and EC Copyright Law" (e-Copyright Bulletin, UNESCO, January - March 2004)

Vrana, Robert "The Remix Artist's Catch-22: A Proposal for Compulsory Licensing for Transformative, Sampling-Based Music" (2011) 68 Wash and Lee L Rev 811

Wallis, Roger, Baden-Fuller, Charles, Kretschmer, Martin and Klimis, George Michael "Contested Collective Administration of Intellectual Property Rights in Music: The Challenge to the Principles of Reciprocity and Solidarity" (1999) 14 European Journal of Communication 5

White, Garth "The Evolution of Jamaican Music Part I: Proto-Ska to Ska" (1998) 47 Social and Economic Studies 5

Witmer, Robert “Kingston's Popular Music Culture: Neo-colonialism to Nationalism” (1989) 22 Jamaica Journal 11 
Wong, Tzen "Intellectual Property through the Lens of Human Development" in Tzen Wong and Graham Dutfield (eds) Intellectual Property and Human Development: Current Trends and Future Scenarios (Cambridge University Press, New York, 2011) 1

Wong, Tzen and Fernandini, Claudia "Traditional Cultural Expressions: Preservation and Innovation" in Tzen Wong and Graham Dutfield (eds) Intellectual Property and Human Development: Current Trends and Future Scenarios (Cambridge University Press, New York, 2011)

Yelpaala, Kojo, "Quo Vadis WTO? The Threat of TRIPS and the Biodiversity Convention to Human Health and Food Security" (2012) 30 Boston U Int'l L J 55

Yi-chong, $\mathrm{Xu}$ "Last chance? Multilateralism, TRIPS and Developing countries" in Justin Malbon and Charles Lawson (eds) Interpreting and Implementing the TRIPS Agreement- Is it Fair? (Edward Elgar, Cheltenham, 2008)

Yu, Peter “A Tale of Two Development Agendas” (2009) 35 Ohio N.U. L Rev 465

$\mathrm{Yu}$, Peter "Intellectual Property, Economic Development, and the China Puzzle" in Daniel Gervais (ed) Intellectual Property, Trade and Development: Strategies to Optimize Economic Development in a TRIPS-Plus Era (Oxford University Press, New York, 2007) 173

Yu, Peter “Teaching International Intellectual Property Law” (2008) 52 St. Louis U LJ 923

Yu, Peter "The Global Intellectual Property Order and Its Undetermined Future" (2009) 1(1) WIPO Journal 1

Yu, Peter "The Objectives and Principles of the TRIPS Agreement" (2009) 46 Houston L Rev 979

Yu, Peter “TRIPS and Its Discontents” (2006) 10 Marquette IP L Rev 369

Zemer, Lior "On the Value of Copyright Theory” (2006) 1 IPQ 55

Zhang, Naigen "Dispute Settlement under the TRIPS Agreement from the Perspective of Treaty Interpretation” (2003) 17 Temple Int'l \& Comp LJ 199

III UNPUBLISHED REPORTS, RESEARCH PAPERS, SEMINAR PAPERS, PRESENTATIONS AND DISSERTATIONS

Abbott, Frederick "Parallel Importation: Economic and Social Welfare Dimensions" (Swiss Agency for Development and Cooperation Report, June 2007)

Asian Development Bank Institute "Information and Communication Technology (ICT) Strategies for Developing Countries" (Report, 28 February 2001) <www.adbi.org> 
Besen, Stanley and Kirby, Sheila "Compensating Creators of Intellectual Property: Collectives that Collect" (RAND Corporation Report, 1989)

Bourne, Compton and Allgrove, SM "Prospects for Exports of Entertainment Services From the Caribbean: The Case of Music" (World Bank Report, 1995 (revised 1996))

Brown, Hilary "National Strategy \& Action Plan to further develop the Jamaican Music Industry" (UNESCO Report, 2004)

Chon, Margaret "A Rough Guide to Global Intellectual Property Pluralism" (Seattle University School of Law, Legal Studies Paper 09:01, 2009)

Clarke, David "The Capability Approach: Its Development, Critiques and Recent Advances" (2006) (Global Poverty Research Group Working Paper Series, Paper 32, 2006) <www.gprg.org>

Commission on Intellectual Property Rights "Integrating Intellectual Property Rights and Development Policy" (London, 2002)

Commission on Intellectual Property Rights, Innovation and Public Health "Public Health, Innovation and Intellectual Property Rights" (Report, World Health Organization, Switzerland, 2006)

Correa, Carlos "Integrating Public Health Concerns into Patent Legislation in Developing Countries" (Report, South Centre, Geneva, 2000) <www.southcentre.org >

Daley, Dianne "Commission on Intellectual Property Rights Country Case Study for Study 9: Institutional Issues for Developing Countries in IP Policy-Making, Administration and Enforcement Jamaica, Trinidad \& Tobago, St. Lucia" (Commission on Intellectual Property Rights Report, 2002)

Daley, Dianne Presentation to the Commission on Intellectual Property Rights' Conference: "How Intellectual Property Rights Could Work Better for Developing Countries and Poor People - Session 4: Copyright and Developing Countries" Transcript (The Royal Society, London, 21-22 February 2002)

Davis, Andrea "Brand Jamaica as the Home of Reggae" in UNCTAD/UNDP "The Creative Economy Report 2010” (United Nations, 2010) 59

Davis, Andrea "Brand Jamaica: Creative Industries as an Economic Strategy" (presentation to the Secretaries of Culture and Development to the State of São Paulo/ United Nations Development Programme's International Forum on Creative Economy, Sao Paulo, Brazil, 5 December 2007)

Davis, Andrea "Entertainment Sector Policy Proposal - Discussion Paper" (Report prepared for the Ministry of Tourism and Sport, 2001)

Davis, Andrea "Strategic Plan for Jamaican Music in the $21^{\text {st }}$ Century, 1999-2004" (JAMPRO Report, December 1998) 
Demas, Allison and Henry, Ralph "Entertainment Services with Special Reference to Music, Mas and the Film and Video Segments" (CARICOM Trade Project/Caribbean Regional Negotiating Machinery Report, 2001)

des Landes, Stephen "Rethinking Musical Works in Copyright Law" (Bachelors of Commerce Dissertation, Victoria University of Wellington, 2012)

Dinwoodie, Graeme and Dreyfuss, Rochelle "Designing a Global Intellectual Property System Responsive to Change: The WTO, WIPO and Beyond" (University of Oxford Legal Research Paper Series Paper No. 50, 2009)

Drahos, Peter "An Alternative Framework for the Global Regulation of Intellectual Property Rights" (Centre for Governance of Knowledge and Development Working Paper No. 1, Australian National University, October 2005)

Drahos, Peter Presentation to Commission on Intellectual Property Rights' Conference: "How Intellectual Property Rights Could Work Better for Developing Countries and Poor People - Session 4: Copyright and Developing Countries" Transcript (The Royal Society, London, 21-22 February 2002)

Dunn, Hopeton "Link ICTS, Telecoms and Culture for Regional Growth" (paper presented at the Caribbean Regional Negotiating Machinery consultative forum, Trinidad and Tobago, 7 October 2007)

Emerging Market Economics Limited "Strategic Plan for the Promotion of Professional Service Exports in Jamaica" (Jamaica Trade and Invest and the Commonwealth Secretariat Report, 2008)

European Commission “A European Initiative in Electronic Commerce” (EC, 15 April 1997, Document Reference COM(97)157)

Falvey, Rod, Foster, Neil and Greenaway David "Intellectual Property Rights and Economic Growth” (Internationalisation of Economic Policy Research Paper No 2004/12, 2004)

Foga, Nicole "Intellectual Property and Electronic Commerce- the Caribbean Experience" (Paper presented to the WIPO International Conference on Intellectual Property, the Internet, Electronic Commerce and Traditional Knowledge, Sofia, Bulgaria, 29-31 May 2001)

Foga, Nicole and Newman, Delreo "Liberalization of the Telecommunications Industry in CARICOM: Case Study Jamaica and Dominica" unpublished paper <www.fogadaley.com>

Frankel, Susy "The Legitimacy and Purpose of Intellectual Property Chapters in FTAs" (Victoria University of Wellington Legal Research Paper No 1/2011, 2011)

Gasper, Des "Human Rights, Human Needs, Human Development, Human Security: Relationships between Four International 'Human' Discourses" (Garnet Working Paper No 20/07, 2007) 
Gervais, Daniel "Application of an Extended Collective Licensing Regime in Canada: Principles and Issues Related to Implementation" (study prepared for the Department of Canadian Heritage, June 2003)

Gilardi, Fabrizio, Jordana, Jacint and Levi-Faur David "Regulation in the Age of Globalization: The Diffusion of Regulatory Agencies Across Europe and Latin America" (IBEI Working Paper 2006/1, 2006)

Ginsburg, Jane "The Copyright Future: Authors, Owners, Orphans, Users and Repeat Infringers" (presentation to New Zealand Centre of International Economic Law Symposium, Wellington, 30 October 2009)

Ginsburg, Jane "Toward Supranational Copyright Law? The WTO Panel Decision and the 'Three-Step Test' for Copyright Exceptions" (The Center for Law and Economic Studies, Columbia Law School Working Paper No. 181, 2001)

Goffe, Marcus "Exploring Ras Tafari Culture" (WIPO Magazine, April 2011) <www.wipo.int/wipo_magazine/en/2011/02/article_0008.html>

Goulet, Denis “A New Discipline: Development Ethics" (The Kellogg Institute Working Paper No 231, 1996)

<www.kellogg.nd.edu/publications/workingpapers/WPS/231.pdf>

Gowers, Andrew "Gowers Review of Intellectual Property" (Report prepared for Her Majesty's Treasury, 2006)

Green, Cordel “The Regulators' Dilemma: Payback Trade-offs - a Developing Countries Perspective" (paper presented at the $34^{\text {th }}$ International Institute of Communication Conference, 30 September 2003)

Gurry, Francis "The Future of Copyright" (speech to the Blue Sky Conference: Future Directions in Copyright Law, Queensland University of Technology, Sydney, 25 February 2011)

Gurry, Francis "Intellectual Property, Innovation and Creativity: Current International Developments" (Public Lecture at Victoria University of Wellington, Wellington, 4 April, 2012)

Heald, Paul "Do Bad Things Happen When Works Fall into the Public Domain?" (Public Lecture, New Zealand Centre of International Economic Law, Wellington, 21 March 2012)

Inniss, Abiola "Caribbean IP: Ensuring Unending Local Protection of Traditional Knowledge” (2010) Intellectual Property Watch: Inside Views <www.ip-watch.org>

Inniss, Abiola "Fair Usage in Caribbean Intellectual Property" (2011) Intellectual Property Watch: Inside Views <www.ip-watch.org>

Intellectual Property Office "The Government Response to the Hargreaves Review of Intellectual Property and Growth" (London, 2011) 
International Federation of the Phonographic Industry "IFPI Digital Music Report 2011: Music at the Touch of a Button" (2011)

Jamaican Justice System Reform Task Force "Final Report" (June 2007) <www.cba.org/jamaicanjustice>

James, Vanus “The Caribbean Music Industry Database (CMID), 2000” (UNCTAD/WIPO Report, 2001)

James, Vanus "The Economic Contribution of Copyright-based Industries to the Jamaican Economy” (WIPO Report, 2007)

KEA European Affairs "Collective Management of Rights in Europe: the Quest for Efficiency" (European Parliament Report, 2006)

<www.europarl.europa.eu/comparl/juri/study/rights_en.pdf>

Khan, Zorina "Intellectual Property and Economic Development: Lessons from American and European History" (British Commission on Intellectual Property Rights Report, Study Paper 1a, 2002)

Khan, Zorina "IP Rights and Economic Development: A Historical Perspective" (WIPO Magazine, June 2007) < www.wipo.int >

Klein, Allison "How Record Labels Work" (2011) How Stuff Works <entertainment.howstuffworks.com/record-label.htm>

Knopf, Howard "Canadian Copyright Collectives and the Copyright Board: A Snap Shot in 2008" (Paper presented to Law Society of Upper Canada Continuing Legal Education Program, Ottawa, 28 February 2008)

Kozul-Wright, Zeljka, Foga, Nicole and Montague, Masani "Electronic Commerce and Music Business Development in Jamaica: a Portal to the New Economy?" (Report prepared for United Nations Conference on Trade and Development's (UNCTAD) Technology for Development Series, 2002)

Kozul-Wright, Zeljka and Stanbury, Lloyd "Becoming a Globally Competitive Player: The Case of the Music Industry in Jamaica" (UNCTAD Discussion Paper No 138, 1998)

Kumar, Mohan "Intellectual Property in the World Trade Organization: Turning it into Developing Countries' Real Property" (United Nations Conference on Trade and Development Report, 2010)

Kur, Annette and Ruse-Khan, Henning "Enough is Enough - the Notion of Binding Ceilings in International Intellectual Property Protection" (Max Planck Institute for Intellectual Property, Competition \& Tax Law Research Paper Series No. 09-01, 2008)

Lall, Sanjaya "Indicators of the Relative Importance of Intellectual Property Rights to Developing Countries" (UNCTAD-ICTSD Project on IPRs and Sustainable Development, Issue Paper No. 3, 2003)

Maskus, Keith "Intellectual Property Rights and Foreign Direct Investment" (Centre for International Economic Studies Policy Discussion Paper No 0022, 2000) 
Matthews, Duncan "Challenges to Enforcement - An International Perspective" (World Intellectual Property Day Public Lecture, University of the West Indies, Mona, Kingston, 26 April 2011)

Matthews, Duncan "The Fight Against Counterfeiting and Piracy in the Bilateral Trade Agreements of the EU" (Briefing Paper for the European Parliament Committee on International Trade, Brussels, 2008)

Menell, Peter and Scotchmer, Suzanne "Intellectual Property" (Public Law Research Paper No. 741724, University of California at Berkeley, 2005)

McMillan, John "Trench Town Rock: The Creation of Jamaica's Music Industry" (unpublished paper, Graduate School of Business, Stanford University, June 2005)

Mullings, Evon "Copyright Infringement as a Major Economic Loss to Rights-Owners and the Broader Cultural Industry: Can this Problem be Fixed?" (paper presented to the Broadcasting Commission's Payola and Anti-Piracy Seminar, Kingston, 22 March 2011)

Nurse, Keith "The Caribbean Music Industry: Building Competitiveness and Enhancing Export Capabilities in an Emerging Sector" (Caribbean Export Development Agency Report, 2003)

Nurse, Keith "The Creative Sector in CARICOM: The Economic and Trade Policy Dimensions" (CARICOM Secretariat Regional Symposium on Services Report, 2009)

Nurse, Keith "The Cultural Industries in CARICOM: Trade and Development Challenges" (Caribbean Regional Negotiating Machinery Report, 2006 (revised 2007))

Organisation for Economic Co-operation and Development (OECD) "Measuring Electronic Commerce" (OCED, Paris, 1997, Document Reference: OCDE/GD(97)185)

Parchomovsky, Gideon and Siegelman, Peter "Towards an Integrated Theory of Intellectual Property" (University of Connecticut School of Law Working Paper No. 35, 2002)

Park, Walter and Lippoldt, Douglas "International Licensing and the Strengthening of Intellectual Property Rights in Developing Countries During the 1990s" (OECD Economic Studies No 40, 2005/1, 2005)

Parks, Craig "A Report on the Copyright Collectives Operating in Canada" (Report prepared for Canadian Heritage- Copyright Policy Branch, 2006)

Pereira, Beverley "A Regional Approach to the Management of Copyright in the Caribbean Community" (PhD thesis, Queen Mary, University of London, 2009)

Piron, Laure-Helene and O'Neil, Tammie "Integrating Human Rights into Development" (Paper prepared for the OECD DAC Network on Governance, 2005)

Portnoff, Linda and Nielsén, Tobias "The Music industry in Numbers - Statistics for 2010 Executive Report" (Report prepared for the Swedish Agency for Economic and Regional Growth and Musiksverige, 2012) 
Rodrik, Dani “The Global Governance of Trade As If Development Really Mattered” (UNDP Background Paper, 2001)

Ruse-Khan, Henning "The (Non)Use of Treaty Object and Purpose in Intellectual Property Disputes in the WTO" (Max Planck Institute for Intellectual Property and Competition Law Research Paper No 11-15, 2011)

Schonwetter, Tobias "Economics of IP" (paper presented to the WIPO Summer School, South Africa, December 2011)

Schroeder, Jeanne "Unnatural Rights: Hegel and Intellectual Property" (Benjamin N Cardozo School of Law Working Paper No. 8, 2004)

Sprigman, Christopher "Reform(aliz)ing Copyright" (Unpublished paper, 25 March 2004) <www.cyberlaw.stanford.edu>

Stanbury, Lloyd "Mapping the Creative Industries - The Experience of Jamaica" (paper presented to WIPO-CARICOM Meeting of Experts on the Creative Industries and Intellectual Property, Georgetown, Guyana, 8-9 February 2006)

Story, Alan "Study on Intellectual Property Rights, the Internet, and Copyright" (Commission on Intellectual Property Rights Report, 2001)

Sykes, Bryan "Moral Rights: A Critical View" (LLM Dissertation, University of Wales, College of Cardiff, 1995)

Tansey, Geoff "Food Security, Biotechnology and Intellectual Property: Unpacking Some Issues Around TRIPS" (Quaker United Nations Office Discussion Paper, July 2002) <www.quno.org>

United Nations Conference on Trade and Development (UNCTAD)/United Nations Development Programme (UNDP) “The Creative Economy Report 2010" (United Nations, 2010)

UNCTAD "Building Confidence, Electronic Commerce and Development" (United Nations, 2000, Document Reference: UNCTAD/SDTE/Misc.11)

UNCTAD "Jamaica: The Science, Technology and Innovation Policy Review" (United Nations, New York and Geneva, 1999)

UNDP "Human Development Report 2000: Human Rights and Human Development" (Oxford University Press, New York, 2000) <www.hdr.undp.org>

UNDP "Human Development Report 2001: Making New Technologies Work for Human Development" (Oxford University Press, New York, 2001)

UNDP “Human Development Report 1997” (Oxford University Press, New York, 1997)

Van Pelt, Carter "Toward a Conventional Copyright System: The Jamaican Experience with Rights Management and a New Law" (Master of Arts dissertation, Columbia University, 2006) 
Vivas-Eugui, David "Regional and Bilateral Agreements in A TRIPS-plus World: The Free Trade Area of the Americas (FTAA)" (Quaker United Nations Office Report, 2003)

Wallace, Elaine "Telecommunications Convergence: The Implications for the Role of Traditional Media to Serve the Public Interest in the Caribbean" (paper delivered at World Press Freedom Day-Caribbean Observance, St. Lucia, 1-3 May 2007)

Wallis, Roger "Best Practice Cases in the Music Industry and their Relevance for the Government Policies in Developing Countries" (WIPO/UNCTAD Report, 2001)

Webley, Joan "Emancipating Ourselves from Mental Slavery: A Socio-legal Exploration of Existing Copyright Law Issues in Jamaica" (LLB (Hons) Dissertation, Victoria University, Australia, 2007)

Webley, Joan "First World Copyright Law in Third World Jamaica: Is there a Need for a New Approach?" (Article prepared for the International Association of Entertainment Lawyers, 27 November 2009)

Witter, Michael "Music and the Jamaican Economy" (UNCTAD/WIPO Report, 2004)

World Intellectual Property Organization "Intellectual Property on the Internet: A Survey of Issues" (WIPO, Geneva, December 2002)

WIPO Committee on Development and Intellectual Property, Fifth Session "Patent Related Flexibilities in the Multilateral Legal Framework and their Legislative Implementation at the National and Regional Levels" (WIPO Secretariat, Geneva, April 2010)

\section{JAMAICAN LEGISLATION, PARLIAMENTARY MATERIAL, REGULATIONS AND POLICY DOCUMENTS}

\section{A Constitution}

Jamaica (Constitution) Order in Council, 1962

\section{B Legislation}

Broadcasting and Radio Re-Diffusion Act 1949

Broadcasting and Radio Re-Diffusion (Amendment) Act 1986

Copyright Act No. 46, December 1911 
Copyright Act No. 12, July 1913

Copyright Act No. 17, July 1977 (never brought into force)

Copyright Act No. 4, September 1993

Copyright (Amendment) Act No. 29, 1999

Customs Act 1941

Electronic Transactions Act 2007

Entertainment Industry (Encouragement) Bill draft, 2005

Hawkers and Pedlars Act 1867

Jamaica Intellectual Property Office Act 2001

Jamaica Promotions Corporations Act 1990

Kingston \& St. Andrew Corporation Act 1931

Legal Deposit Act 2002

Motion Picture Industry (Encouragement) Act 1948

Proceeds of Crime Act 2007

The Banking Act 1992

The Fair Competition Act 1993

The Financial Institutions Act 1992

The Securities Act 1993

Towns and Communities Act 1843

\section{Regulations and Procedural Rules}

Civil Procedure Rules 2002 
Copyright Appointed Day Notice 1993

Copyright Appointed Day Notice 1999

Copyright (Customs) Regulations 1995

Copyright (Designation of National Cultural Events) Order 2003

Copyright (Educational Establishments Order) 1993

Copyright (Librarians \& Archivists) (Copying of Copyright Material) Regulations 1993

Copyright (Recording for Archives) (Designated Bodies) Order 1993

Copyright (Specified Countries) Order 1994

Copyright (Specified Countries) (No. 2) Order 1994

Television and Sound Broadcasting Regulations 1996

\section{Parliamentary Material}

Hansard, House of Representatives (26-27 January 1993)

Ministry Paper No. 49 of 1988

Ministry Paper No 5 of 1993

\section{E Policy Documents}

Government of Jamaica National Industrial Policy (1996)

Jamaica Trade and Invest (JTI) Jamaica's National Export Strategy (2009)

Ministry of Education, Youth and Culture The National Industrial Policy of Jamaica: Towards Jamaica the Cultural Superstate (2003)

Planning Institute of Jamaica Vision 2030 Jamaica: National Development Plan (2009)

Planning Institute of Jamaica "Vision 2030 Jamaica- National Development Plan: Culture, Creative Industries, and Values Sector Plan 2009-2030" (Culture, Creative Industries and Values Task Force Report, Kingston, July 2009) 


\section{DOMESTIC LEGISLATION OF OTHER COUNTRIES}

Copyright Act 1911 (Imperial Statute)(UK)

Copyright Act 1956 (UK)

Copyright Act 197617 USC $§ 107$ (United States of America)

Copyright Act (RSC 1985, c C-42) (Canada)

Copyright, Designs and Patents Act (CDPA) of 1988 (UK)

Law on the Administration of Copyright and Neighboring Rights of 9 September 1965 (Germany)

Law No. 22/1987 of November 11, 1987 on Intellectual Property (Spain)

Statute of Anne - Copyright Act 1709 (in force 1710) (UK)

\section{CASES}

\section{A Cases from Various Jurisdictions}

Aalmuhammed v Lee 202 F. 3d 1227 at $1232\left(9^{\text {th }}\right.$ Cir. 2000) (US)

American Geophysical Union v Texaco Inc 60 F. 3d 913 (2d Cir. 1994) (US)

Cala Homes (South) Limited v Alfred McAlpine [1995] FSR 818 (UK)

Campbell v Acuff-Rose Music Inc 510 US 569 (1994) (US)

Canadian Association of Broadcasters v Society of Composers, Authors and Music Publishers of Canada (SOCAN) [2006] FCA 337 (Canada)

CCH Canadian Ltd v Law Society of Upper Canada [2004] 1 SCR 339 (Canada)

Cescinsky v George Routledge [1916] 2 KB 325 (UK)

Express Newspapers Plc v News (UK) Ltd [1990] FSR 359 (UK) 
Evans $v$ E Hulton \& Co Ltd [1923-1928] MCC 51 (UK)

Folsom v Marsh 9 F Cas 342 (CCD Mass, 1841) (US)

Fothergill v Monarch Airlines [1981] AC 251 (UK)

Francis Day \& Hunter v Bron [1963] 2 All ER 16 (UK)

Fylde Microsystems Ltd v Key Radio Systems Ltd [1998] EWHC Patents 340 (UK)

Harper \& Row Publishers v Nation Enterprises 471 US 539 (1985) (US)

Princeton University Press v Michigan Document Services Inc 99 F 3d 1381 (6th Circuit 1996) (US)

Pro Sieben Media AGv Carlton UK Television Ltd \& Twenty Twenty Television Ltd [1999] 1 WLR 605 (UK)

Sawkins v Hyperion Records [2005] EWCA Civ 565 (UK)

Society of Composers, Authors and Music Publishers of Canada v Bell Canada 2012 SCC 36 (Canada)

Sony Corporation of America v Universal City Studios Inc 464 US 417 (1984) (US)

Time Inc v Bernard Geis Associates 293 F Supp 130 (SDNY 1968) (US)

Ladbroke (Football) Ltd v William Hill (Football) Ltd [1964] 1 WLR 273

Newspaper Licensing Agency Ltd v Marks \& Spencer plc [2002] RPC 4 (UK)

Paymaster (Jamaica) Limited v Grace Kennedy Remittance Services Limited and Paul Lowe (Claim No 2000/ CLP 82, 30 April 2010, Supreme Court of Jamaica)

Ray v Classic FM Plc [1998] EWHC Patents 333 (UK)

Stewart v Abend 495 US 207 (1990) (US)

Tate $v$ Thomas [1921] 1 Ch 503 (UK)

Tisi v Patrick 97 F. Supp. 2d 539 (SDNY 2000) (United States)

University of London Press Ltd v University Tutorial Press Ltd [1916] 2 Ch 601 (UK)

Walter v Lane [1900] AC 539 (UK)

Wham-O MFG Co v Lincoln Industries [1984] 1 NZLR 641 (New Zealand)

\section{B WTO Cases}

Canada - Patent Protection of Pharmaceutical Products WTO DOC WT/DS114/R (2000) (Panel Report) 
Canada - Term of Patent Protection WTO DOC WT/DS170/AB/R (2000) (Appellate Body Report)

China - Measures Affecting the Protection and Enforcement of Intellectual Property Rights WTO DOC DS362/R (2009) (Panel Report)

China - Measures Affecting Trading Rights and Distribution Services for Certain Publications and Audiovisual Entertainment Products WTO DOC WT/DS363/R (2009) (Panel Report)

EEC - Member States' Import Regime for Bananas WTO DOC DS32/R (1993) (Panel Report)

EEC - Member States' Import Regime for Bananas WTO DOC DS38/R (1994) (Panel Report)

European Communities - Measures Affecting the Approval and Marketing of Biotech Products WTO DOCS WT/DS291/R, WT/DS292/R, WT/DS293/R (2006) (Panel Report)

European Communities - Customs Classification of Certain Computer Equipment WTO DOCS WT/DS62/AB/R, WT/DS67/AB/R, WT/DS68/AB/R (1998) (Appellate Body Report)

European Communities - Customs Classification of Frozen Boneless Chicken Cuts WTO DOCS WT/DS269/AB/R and WT/DS286/AB/R (2005) (Appellate Body Report)

European Communities - Measures Concerning Meat and Meat Products (Hormones) WT/DS26/AB/R and WT/DS48/AB/R (1998) (Appellate Body Report)

European Communities - Protection of Trademarks and Geographical Indications for Agricultural Products and Foodstuffs WTO DOC WT/DS174/R (2005) (Panel Report)

European Communities - Regime for the Importation, Sale and Distribution of Bananas WTO DOC WT/DS27/AB/R (1997) (Appellate Body Report)

India - Patent Protection for Pharmaceutical and Agricultural Chemical Products WTO DOC WT/DS50/AB/R (1997) (Appellate Body Report)

Japan - Taxes on Alcoholic Beverages WTO DOC WT/DS8/AB/R (1996) (Appellate Body Report)

United States - Import Prohibition of Certain Shrimp and Shrimp Products WTO DOC WT/DS58/AB/R (1998) (Appellate Body Report)

United States - Measures Affecting the Cross-Border Supply of Gambling and Betting Services WTO DOC WT/DS285/AB/R (2005) (Report of the Appellate Body)

United States - Section 110(5) of the U.S. Copyright Act WTO DOC WT/DS160/R (2000) (Panel Report)

United States - Section 301-310 of the Trade Act of 1974 WTO DOC WT/DS152/R (1999) (Panel Report) 
United States - Standards for Reformulated and Conventional Gasoline WTO DOC WT/DS2/AB/R (1996) (Appellate Body Report)

\section{INTERNATIONAL INSTRUMENTS, AGREEMENTS, TREATIES AND}

\section{DECLARATIONS}

Agreement between the United Nations and the World Intellectual Property Organization (entered into effect 17 December 1974)

Agreement between the World Intellectual Property Organization and the World Trade Organization (22 December 1995)

Agreement Concerning the Protection and Enforcement of Intellectual Property Rights between the Government of the United States and the Government of Jamaica (signed on 17 March 1994)

Agreement on Trade-Related Aspects of Intellectual Property Rights, Annex 1C to the Agreement establishing the World Trade Organisation (WTO Agreement) (15 April 1994)

Beijing Treaty on Audiovisual Performances 2012 (adopted 24 June 2012)

Berne Convention for the Protection of Literary and Artistic Works (9 September 1886 as revised at Paris 1971)

Committee on Economic, Social and Cultural Rights "General Comment No. 17" (UN Doc. E./C.12/GC/17 (17 January 2006)

Convention Establishing the World Intellectual Property Organization (signed at Stockholm on 14 July 1967 and as amended on 28 September 1979)

Convention for the Protection of Producers of Phonograms Against Unauthorized Duplication of Their Phonograms 1971 (done at Geneva, 29 October 1971)

Convention Relating to the Distribution of Programme-Carrying Signals Transmitted by Satellite (done at Brussels, 21 May 1974)

Economic Partnership Agreement between the European Community (EC), its Members States and CARIFORUM initialled 16 December 2007

General Agreement on Trade in Services 1994

General Agreement on Tariffs and Trade 1994

International Covenant on Civil and Political Rights (19 December 1966)

International Covenant on Economic, Social and Cultural Rights (19 December 1966) 
International Convention for the Protection of Performers, Producers of Phonograms and Broadcasting Organizations 1961 (done at Rome, 26 September 1961)

Marrakesh Agreement Establishing the World Trade Organization (15 April 1994)

Paris Convention for the Protection of Industrial Property 1967 (at Stockholm, 14 July 1967)

Revised Treaty of Chaguaramas Establishing the Caribbean Community Including the CARICOM Single Market and Economy (signed on 5 July 2001) <www.caricom.org/jsp/community/revised_treaty-text.pdf>

Sub-Commission on the Promotion and Protection of Human Rights "Resolution 2000/7" UN Doc. E/CN.4/Sub.2/RES/2000/7 (17 August 2000)

Treaty between the United States of America and Jamaica concerning the Reciprocal Encouragement and Protection of Investment (signed at Washington on 4 February 1994; in force 7 March 1997)

Treaty of Chaguaramas Establishing the Caribbean Community (came into effect 1 August 1973) <www.caricom.org/jsp/community/original_treaty>

Understanding on Rules and Procedures Governing the Settlement of Disputes, Annex 2 of the WTO Agreement (15 April 1994)

United Nations Declaration on the Right to Development, G.A. Res. 41/128, Annex, U.N., GAOR 41st Sess., No. 53, U.N. Doc. A/4/53 (4 December 1986).

United Nations General Assembly "Universal Declaration of Human Rights" Resolution 217A (III) (10 December 1948)

United Nations Millennium Declaration and Development Goals, G.A. Res. 55/2, U.N. Doc. A/RES/55/2 (18 September 2000)

United Nations "Report of the World Commission on Environment and Development: Our Common Future" UN Doc A/42/427 (4 August 1987)

Vienna Convention on the Law of Treaties (23 May 1969, entered into force on 27 January 1980)

WIPO Copyright Treaty (adopted in Geneva, 20 December 1996)

WIPO Development Agenda (WIPO Doc A/43/16 Annex A) (adopted October 2007)

WIPO Performances and Phonograms Treaty (adopted in Geneva, 20 December 1996)

WIPO "Proposal by Argentina and Brazil for the Establishment of a Development Agenda for WIPO” Doc. WO/GA/31/11 (27 August 2004)

World Trade Organization "Ministerial Declaration" WT/MIN(01)/DEC/1 (adopted at Doha on 14 November 2001) 
World Trade Organization "Declaration on the TRIPS Agreement and Public Health" WT/MIN(01)/DEC/2 (adopted at Doha on 14 November 2001)

\section{NEWSPAPER ARTICLES AND MEDIA RELEASES}

Brown, Kadian "JIPO Paves Way for Growth by Protecting Intellectual Property Rights" (Jamaica Information Service Release, 4 May 2009)

Dawes, Mark "Music industry applauds tabling of Copyright Bill" Daily Gleaner (Jamaica, 12 November 1992)

Golding, Steve "Listen Up, Music Users” The Gleaner (Jamaica, 2 December 2001)

"Heather Robinson lashes critics of Copyright Act" The Gleaner (Jamaica, 22 February 1993)

Jackson, Stephen "JACAP looks to protecting works on Internet" The Daily Observer (Jamaica, 10 April 2009)

Jackson, Steven "Culture Exports Trump Financial Services" The Sunday Gleaner (Jamaica, 23 October 2011)

Jackson, Steven "Entertainment Loans Jump \$1B but Industry Sceptical” The Daily Observer (Jamaica, 14 August 2009)

Jackson, Steven "Jamaica Music Society to invest in costly software" The Observer (Jamaica, 3 January 2010)

Jackson, Steven "Music Earnings Hit Sweet Note” The Gleaner (Jamaica, 5 April 2012)

Jackson, Steven "No Recording Copyright for Alton Ellis' Muriel” The Daily Observer (Jamaica, 17 October 2008) at 15

“Jamaican Artistes Sing The Blues” The Gleaner (Jamaica, 20 December 2010)

“Jamaica Poverty Rate Jumps” Jamaica Gleaner (Jamaica, 13 October 2010)

Maximizing Profits through Intellectual Property Protection" (Ministry of Industry, Investment and Commerce Media Release, 23 March 2009)

"Music Could Expand Economy" (Jamaica Intellectual Property Office Media Release, 2009)

“Senate passes Copyright Act” The Daily Gleaner (Jamaica, 21 February 1993)

"UTECH opens Office of Intellectual Property" (University of Technology Press Release, 12 May 2009)

Walters, Basil "French Lawyer Wins Royalty Payments Case for 180 J'can Artistes" The Observer (Jamaica, 29 July 2005) at 21 
Wilmot, Natalie “Copyright or Copywrong?" The Sunday Gleaner (Jamaica, 28 November 1999)

IX ONLINE MATERIAL, WEBSITES AND MISCELLANEOUS MATERIALS

Broadcasting Commission of Jamaica <www.broadcastingcommission.org>

Broadcast Music Incorporated (BMI) “A Guide to Music Publishing Terminology" (1990)

UK Intellectual Property Office "Review of the Copyright Tribunal" (2007) at 5-6 <www.ipo.gov.uk/ctribunalreview.pdf>

Central Intelligence Agency <www.cia.gov>

International Development Ethics Association "What is Development Ethics?" <www.development-ethics.org/what_is>

International Expert Group on Biotechnology Innovation and Intellectual Property "Towards a New Era of Intellectual Property: from Confrontation to Negotiation" (2008) <www.theinnovationpartnership.org>

International Federation of the Phonographic Industries (IFPI) December 2001 <www.ifpi.org>

IFPI "Music Piracy, Serious, Violent and Organised Crime" (2004) <www.ifpi.org>

International Intellectual Property Alliance "US Trade Tools" <www.iipa.com/cbera_cbtpa.html>

Jamaica Association of Composers, Authors and Publishers "JACAP's Response to a news article printed in the Daily Gleaner on Monday, December 20, 2010" (2011) <www.jacapjamaica.com>

Jamaica Information Service <www.jis.gov.jm>

Jamaica Intellectual Property Office <www.jipo.gov.jm>

Jamaica Promotions Corporation "History of JAMPRO" <www.jamaicatradeandinvest.org>

Ministry of Justice <www.moj.gov.jm>

Office of the United States Trade Representative "Caribbean Basin Initiative" $<$ www.ustr.gov/trade-topics/trade-development/preference-programs/caribbean-basininitiative-cbi>

Planning Institute of Jamaica <www.pioj.gov.jm>

Property Rights Alliance “International Property Rights Index (IPRI) Report 2012” (2012) <www.internationalpropertyrightsindex.org> 
Serious Organised Crime Agency (SOCA) "UK Threat Assessment" (2009) <www.soca.gov.uk/threats>

Sfeir-Younis, Alfredo "Human Rights Must Be a Consideration for Economic Development Organizations" (2006) Policy Innovations <www.policyinnovations.org>

Statistical Institute of Jamaica (STATIN) <www.statinja.com>

UNCTAD "World Investment Report, 2008"

<http://vi.unctad.org/video/russiawir08/player.html>

University of Technology <www.utech.edu.jm>

World Bank “Comprehensive Development Framework" <www.worldbank.org/cdf > 